\title{
Field Evaluation of a Modular Press-Brake-Formed Steel Tub Girder in an Application that Includes Skew and Superelevation
}

Adam D. Roh

West Virginia University, adroh@mix.wvu.edu

Follow this and additional works at: https://researchrepository.wvu.edu/etd

Part of the Civil Engineering Commons, Construction Engineering and Management Commons, Structural Engineering Commons, and the Transportation Engineering Commons

\section{Recommended Citation}

Roh, Adam D., "Field Evaluation of a Modular Press-Brake-Formed Steel Tub Girder in an Application that Includes Skew and Superelevation" (2020). Graduate Theses, Dissertations, and Problem Reports. 7537. https://researchrepository.wvu.edu/etd/7537

This Thesis is protected by copyright and/or related rights. It has been brought to you by the The Research Repository @ WVU with permission from the rights-holder(s). You are free to use this Thesis in any way that is permitted by the copyright and related rights legislation that applies to your use. For other uses you must obtain permission from the rights-holder(s) directly, unless additional rights are indicated by a Creative Commons license in the record and/ or on the work itself. This Thesis has been accepted for inclusion in WVU Graduate Theses, Dissertations, and Problem Reports collection by an authorized administrator of The Research Repository @ WVU. For more information, please contact researchrepository@mail.wvu.edu. 


\title{
Field Evaluation of a Modular Press-Brake-Formed Steel TUB GIRDER IN AN APPLICATION THAT INCLUDES SKEW AND SUPERELEVATION
}

\author{
Adam D. Roh \\ Thesis submitted to the \\ Benjamin M. Statler College of Engineering and Mineral Resources \\ at \\ West Virginia University \\ on partial fulfillment of the requirements \\ for the degree of \\ Master of Science \\ in \\ Civil and Environmental Engineering
}

Karl E. Barth, Ph.D., Chair

Gregory K. Michaelson, Ph.D.

Huang-Liang Roger Chen, Ph.D.

Department of Civil and Environmental Engineering

Morgantown, West Virginia

2020

Keywords: steel bridge, press-brake-formed tub girders, live load distribution factors

Copyright 2020 Adam D. Roh 


\title{
AbSTRACT \\ Field Evaluation of a Modular Press-Brake-Formed Steel TUB GIRDER IN AN APPLICATION THAT INCLUDES SKEW AND SUPERELEVATION
}

\begin{abstract}
Adam D. Roh
The Short Span Steel Bridge Alliance (SSSBA) is a group of bridge and culvert industry leaders (including steel manufacturers, fabricators, service centers, coaters, researchers, and representatives of related associations and government organizations) who have joined together to provide educational information on the design and construction of short span steel bridges in installations up to $140^{\prime}-0$ " in length. A technical working group from within the SSSBA developed the notion for the modular shallow press-brake-formed steel tub girder as a solution for the short span steel bridge market.

After extensive testing at West Virginia University and multiple successful field demonstrations, members of the SSSBA collaborated with the West Virginia Division of Highways to arrange implementation of this system. The Fourteen Mile Bridge located in Lincoln County, West Virginia, was chosen as a prime candidate to demonstrate the system due to the significant superelevation and skew present. Upon completion of the Fourteen Mile Bridge, researchers from Marshall University and West Virginia University traveled to the bridge site to perform a live load field test.

This study presents the results and evaluation from experimental and analytical testing of the Fourteen Mile Bridge. Additionally, the research methods for both the experimental and analytical testing are outlined. Live load distribution factors were computed from the experimental data and analytical data, and these were compared to those computed following the AASHTO LRFD specifications. The results of this comparison reflect that the AASHTO LRFD specifications are conservative in the analysis of press-brake-formed tub girders. This report also includes an initial qualitative examination of bracing configurations for non-composite pressbrake-formed tub girders. The results provide the basis for extending the work towards a closer investigation to determine the best practices of bracing.
\end{abstract}




\section{ACKNOWLEDGEMENTS}

First, I would like to thank Dr. Barth, Dr. Michaelson, and Dr. Chen for serving on this graduate committee. I would like to thank Dr. Barth for all of the guidance he has provided to me as advisor during the pursuit of this master's degree. I have learned a great deal over the many classes I have taken under Dr. Barth; I am appreciative of the welcoming atmosphere during the Cannelville Road Bridge test that encouraged me to pursue graduate studies. I would also like to thank Dr. Michaelson for all of the assistant and expertise that has been provided in the realm of finite element modeling. I want to thank Dr. Chen for all of the education experiences that he has provided throughout my time at West Virginia University.

Next, I would like to express my gratitude to Robby Tennant. Robby was a great help through all of my undergraduate structural engineering classes and has continued to offer great assistance in graduate school. His jokes may not win over everyone, but he has a great sense of humor and can cheer someone up, no matter how down they may feel. Robby, you've been a great friend and mentor these past months and I couldn't imagine a better officemate to have. Further thanks go to the efforts of both Robby and his wife Danielle for all the constructive feedback that was provided for this thesis.

I would also like to thank all of my friends and family for all of the love and support that they have provided over the past year. A special shout out goes to my mother for all the assistance with edits and revisions. 


\section{TABLE OF CONTENTS}

\section{Abstract II}

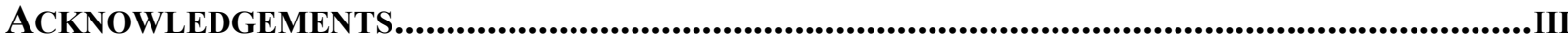

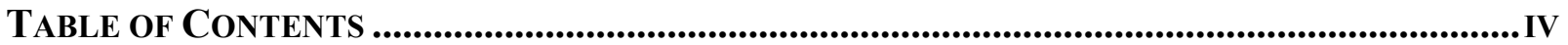

LIST OF TABLES....................................................................................................................................... VIII

LIST OF FIGURES................................................................................................................................. IX

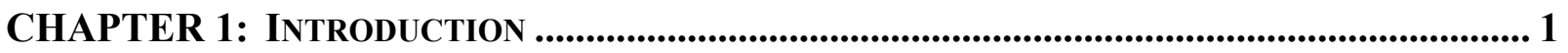

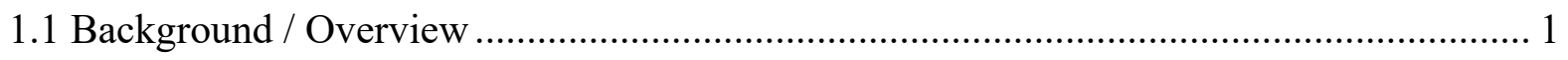

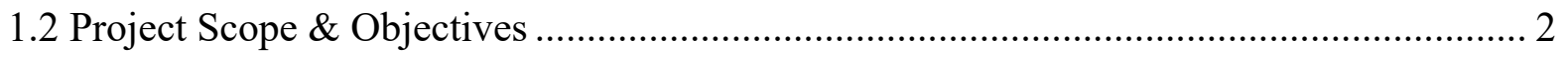

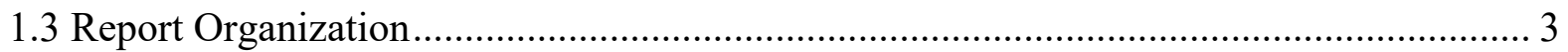

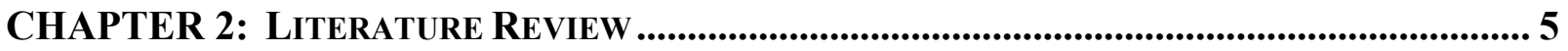

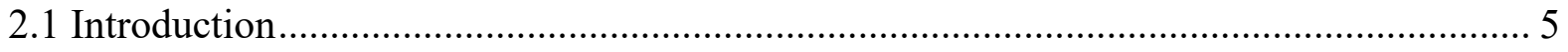

2.2 Previous Applications of Cold-Bent Steel Girders ................................................... 5

2.2.1 Prefabricated Press-Formed Steel T-Box Girder Bridge System (Taly \& Gangarao,

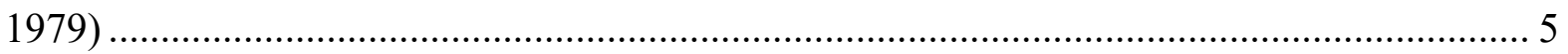

2.2.2 Composite Girders with Cold Formed Steel U-sections (Nakamura, 2002) .............. 6

2.2.3 Folded Plate Girders (Developed at the University of Nebraska) ........................... 8

2.2.4 Texas Department of Transportation Rapid Economical Bridge Replacement........... 9

2.3 Previous Research at WVU on Press-Brake-Formed Steel Tub Girders ....................... 10

2.3.1 Development and Feasibility Assessment of Shallow Press-Brake-Formed Steel Tub Girders for Short-Span Bridge Applications (Michaelson 2014) ....................................... 10

2.3.2 Experimental Evaluation of Non-Composite Shallow Press-Brake-Formed Steel Tub

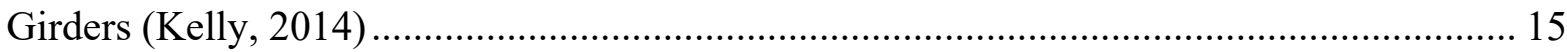

2.3.3 Evaluation of Modular Press-Brake-Formed Tub Girders with UHPC Joints (Kozhokin, 2016) 
2.3.4 Field Performance Assessment of Press-Brake-Formed Steel Tub Girder

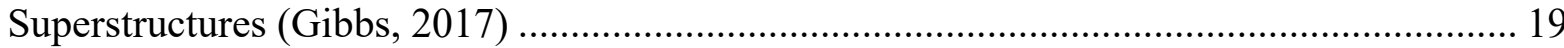

2.3.5 Fatigue Performance of Uncoated and Galvanized Composite Press-Brake-Formed

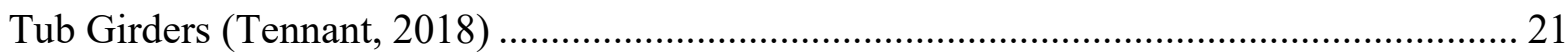

2.3.6 Field Performance and Rating Evaluation of a Modular Press-Brake-Formed Steel Tub Girder with a Steel Sandwich Plate Deck (Underwood, 2019) ....................................... 24

2.4 Current AASHTO Specifications for Tub Girder Design and Application....................... 26

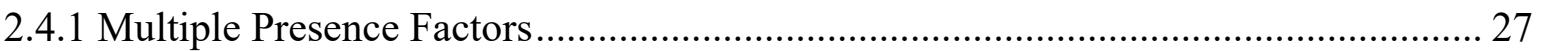

2.4.2 Beam-Slab Bridges - Live Load Distribution Factors............................................... 27

2.4.3 Box-Section Flexural Members ....................................................................... 29

CHAPTER 3: Design ANd ConstruCtion Of THE FouRteen MiLe BRIDGE ..................... 53

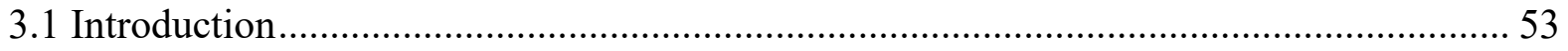

3.2 Summary of Design and Construction .......................................................................... 53

3.2.1 Fabrication of Modular Components ....................................................................... 54

3.2.2 Installation of Modular Components ..................................................................... 59

3.2.3 Accelerated Bridge Construction Strategies .............................................................. 63

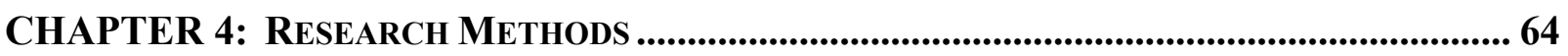

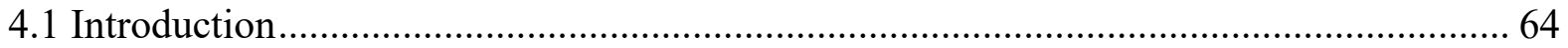

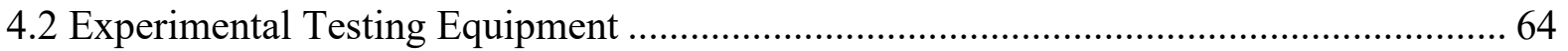

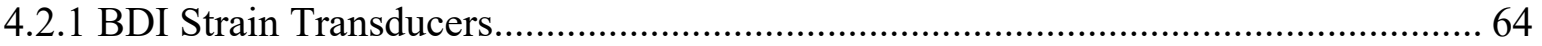

4.2.2 STS-WiFi Data Acquisition System ....................................................................... 65

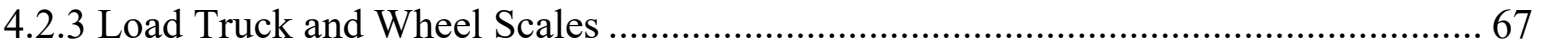

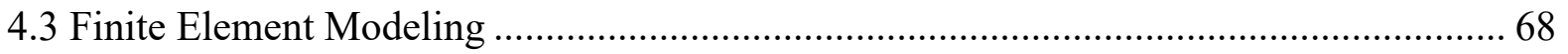

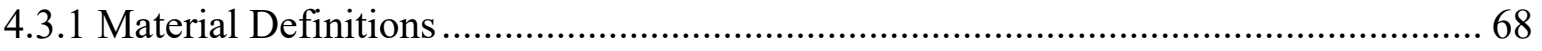

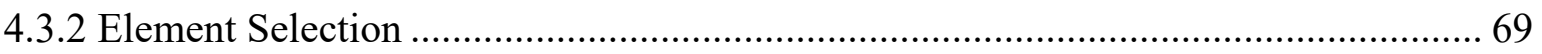




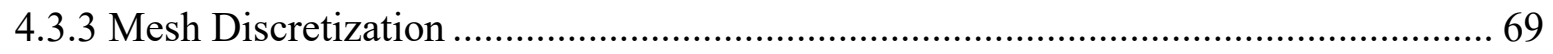

4.3.4 Boundary Conditions and Multiple Point Constraints .................................................. 71

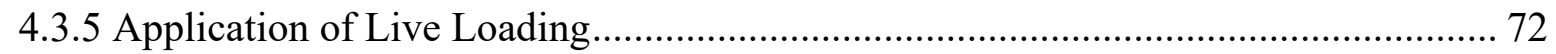

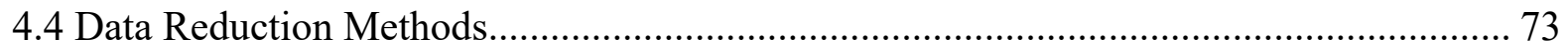

4.4.1 Computation of Quarter Span Bending Stresses......................................................... 73

4.4.2 Computation of Live Load Distribution Factors.......................................................... 75

CHAPTER 5: FIELD TESTING OF THE FOURTEEN MILE BRIDGE ............................................. 78

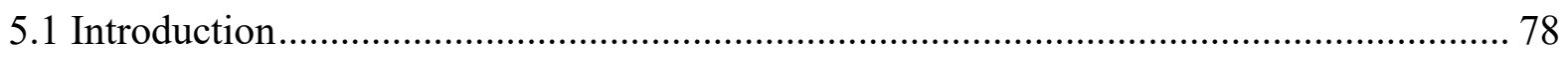

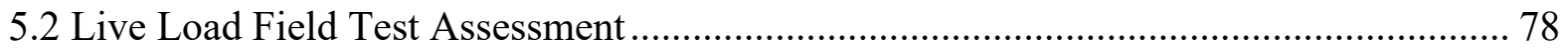

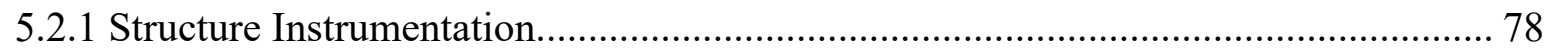

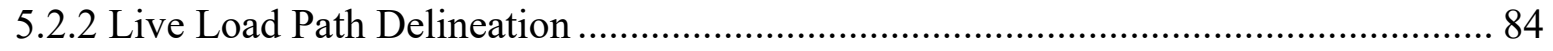

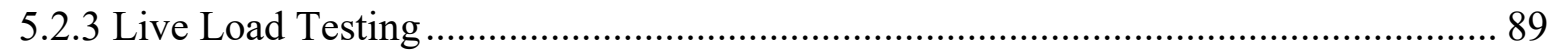

CHAPTER 6: RESULTS AND ANALYSIS …….................................................................... 91

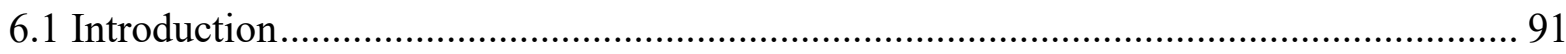

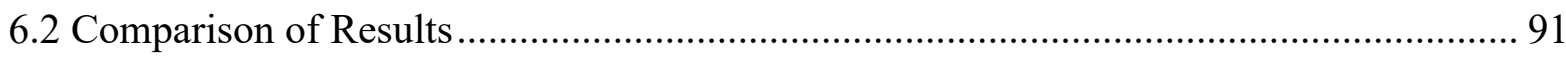

6.2.1 Live Load Field Test Results ..................................................................................... 91

6.2.2 Comparison of Analytical and Experimental Results ............................................. 93

6.3 Comparison of Live Load Distribution Factors with AASHTO LRFD Specifications.... 96

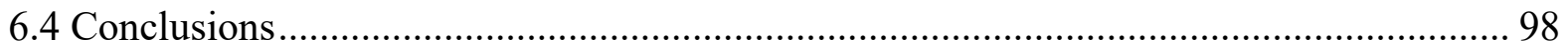

CHAPTER 7: Qualitative AsSessment of BraCing EFfectiveness and TORSIONAL RESPONSE FOR NON-COMPOSITE TUB GIRDERS ............................................................................ 99

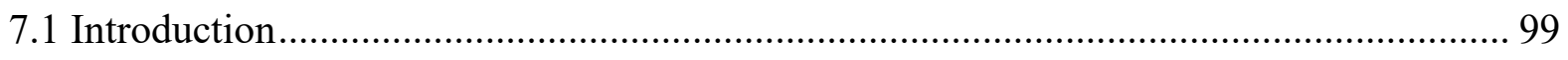

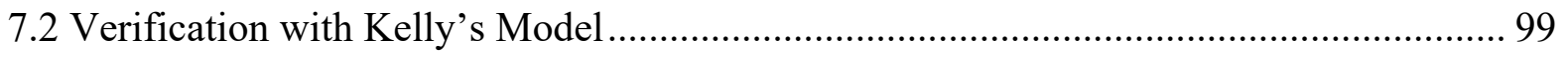

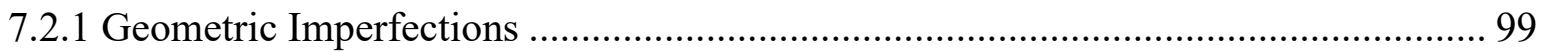

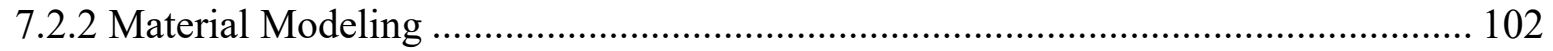




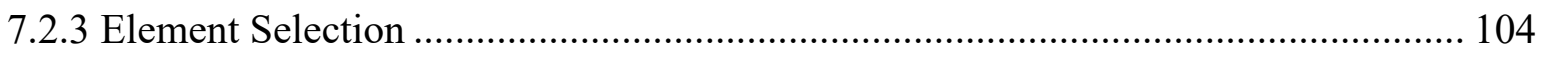

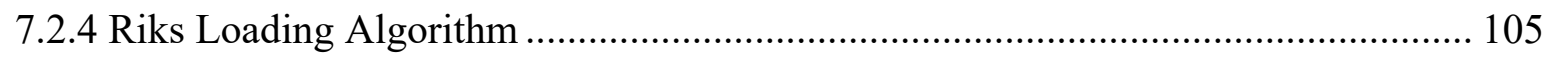

7.2.5 Comparison with Kelly's Model............................................................................... 106

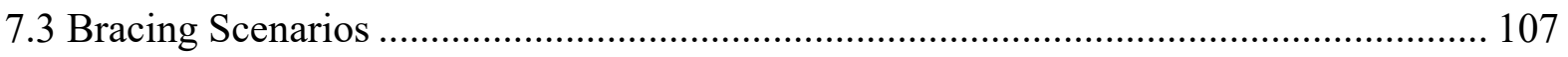

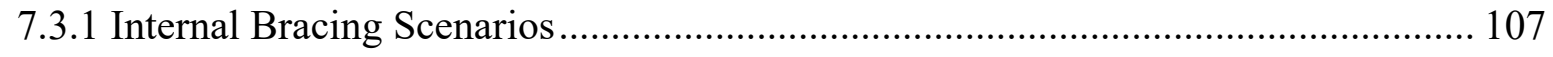

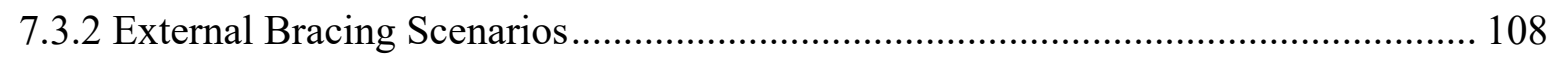

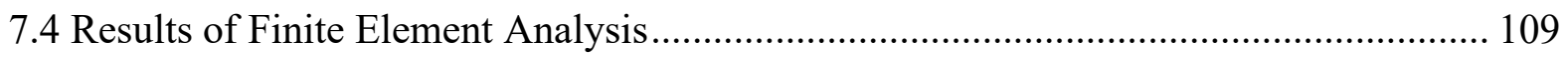

7.4.1 Comparison of Internal Bracing Scenarios ........................................................... 109

7.4.2 Comparison of External Bracing Scenarios ............................................................ 111

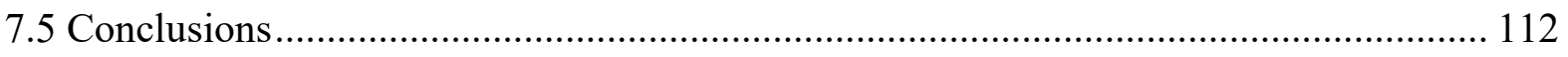

CHAPTER 8: CONCLUSIONS AND RECOMMENDATIONS ......................................................... 113

8.1 Project Summary and Conclusions ........................................................................... 113

8.2 Recommendations for Continued Work ………………………................................ 113

\section{REFERENCES 115}

APPENDIX A: RESULTS FOR ALL TRUCK RUNS............................................................................ 119

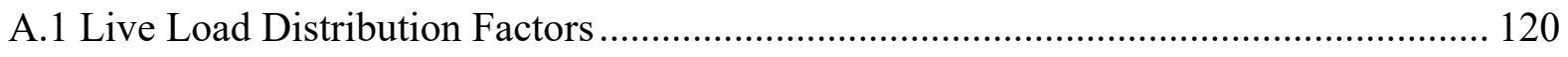

A.1.1 Live Load Field Test Results ………………………………………………..... 120

A.1.2 Finite Element Analysis Results .......................................................................... 124

A.1.3 Results Comparison: Live Load Field Test vs. Finite Element Analysis .................. 125

A.1.4 Results Comparison: Live Load Field Test, Finite Element Analysis, AASHTO

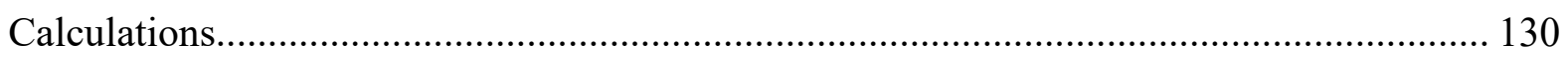

APPendix B: Finite Element Modeling Program ............................................................... 135

APPendix C: FouRteen Mile BRIdge Design Plans.............................................................. 160 


\section{LIST OF TABLES}

Table 2.1: Summary of Distribution Factors (Kozhokin, 2016) ............................................ 19

Table 2.2: Multiple Presence Factors (AASHTO, 2017) ........................................................ 27

Table 2.3: Chapter 2 Equation Legend (AASHTO, 2017) ................................................... 50

Table 4.1: Typical Aspect Ratio for Girder Elements....................................................... 71

Table 4.2: Strain Values, Quarter Span Bending Stress................................................... 74

Table 4.3: Strain Values, Single Lane Loaded LLDF Sample Calculation.............................. 76

Table 4.4: Strain Values, Two Lanes Loaded LLDF Sample Calculation................................. 76

Table 6.1: Measured Strain from Truck Run 1, Experimental ............................................. 92

Table 6.2: Computed Live Load Distribution Factors from Truck Run 1, Experimental............ 93

Table 6.3: Comparison of Field and FEA Live Load Distribution Factors, One Lane Loaded... 94 Table 6.4: Comparison of Field and FEA Live Load Distribution Factors, Two Lanes Loaded. 94

Table 6.5: Comparison of Field, FEA and AASHTO Live Load Distribution Factors, One Lane

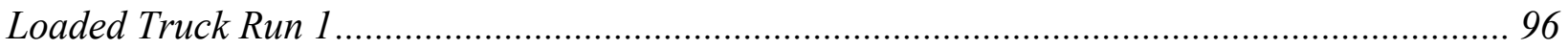

Table 6.6: Comparison of Field, FEA, and AASHTO Live Load Distribution Factors, Two Lanes

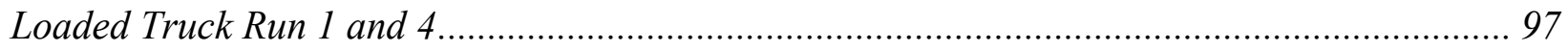

Table 7.1: Expressions for Computing Steel Stress-Strain Behavior (Galindez, 2009) ............ 103 


\section{LIST OF FIGURES}

Figure 2.1: T-Box Girder System, Typical Girder Section with 5" Pre-cast, Prestressed Concrete

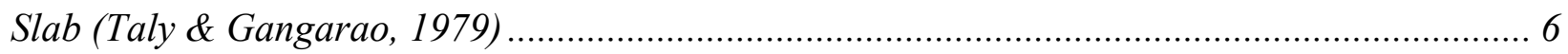

Figure 2.2: Nakamura's Proposed Bridge System (Nakamura, 2002).................................... 7

Figure 2.3: Folded Plate Girder and Composite Deck Cross Section (Burner, 2010) ................ 8

Figure 2.4: Cross Section of Box Girder from Bridge FM 3267 (Chandar et al., 2010)............. 9

Figure 2.5: Design Comparison of 84” Wide Standard Mill Plate (Michaelson, 2014)............. 11

Figure 2.6: Typical Section, Composite Test Specimen (Michaelson, 2014) ........................... 12

Figure 2.7: Typical Ductile Failure of Composite Girder Section (Michaelson, 2014) ............. 13

Figure 2.8: Typical Lateral Failure of Non-Composite Girder Section (Michaelson, 2014) ...... 13

Figure 2.9: Comparison of Analytical and Experimental Results (Michaelson, 2014).............. 14

Figure 2.10: Initial Twist of Specimen \#2 (Kelly, 2014) ..................................................... 16

Figure 2.11: Deflection at Quarter Points (Kelly, 2014) .................................................. 17

Figure 2.12: Exposed Aggregate Finish of Shear Key Detail after Wire-Brushing (Kozhokin, 2016) 18

Figure 2.13: New Amish Sawmill Bridge (Gibbs, 2017) .......................................................... 20

Figure 2.14: FEA v. Experimental v. AASHTO LLDFs (Gibbs, 2017) .................................. 21

Figure 2.15: Uncoated Steel Girder Under Fatigue Loading (Tennant, 2018) ........................ 22

Figure 2.16: Galvanized Steel Girder (Tennant, 2018).......................................................... 23

Figure 2.17: Cannelville Road Bridge Modular Unit (Underwood, 2019).............................. 24

Figure 2.18: Field v. FEA v. AASHTO LLDFs (Underwood, 2019) ...................................... 26

Figure 2.19: Center-to-Center Flange Distance (AASHTO, 2017)....................................... 28

Figure 3.1: Aerial View of Bridge Under Construction ............................................................. 54

Figure 3.2: Galvanized Tub Girder, Prior to Formwork Construction ................................... 55

Figure 3.3: Tub Girder with Completed Internal Formwork .............................................. 56

Figure 3.4: Isometric View of Reusable External Formwork.............................................. 57

Figure 3.5: Close View of Rebar Placement at Semi-Integral Abutment End........................... 57

Figure 3.6: Placement of Fresh Concrete ...................................................................... 58

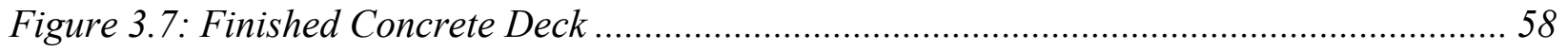

Figure 3.8: Test Fit of Two Precast Modules at Fabrication Yard ........................................... 59 


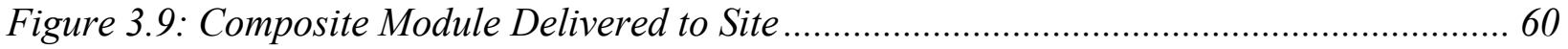

Figure 3.10: Placement of First Composite Module On-Site ................................................. 60

Figure 3.11: Verification of Fit of Adjacent Modules on Site ................................................. 61

Figure 3.12: Pouring of UHPC Along Longitudinal Joint ...................................................... 62

Figure 3.13: Diamond Grinder Used to Finish Deck On-Site............................................... 62

Figure 4.1: BDI Strain Transducer, Typical Application to Girder ........................................ 65

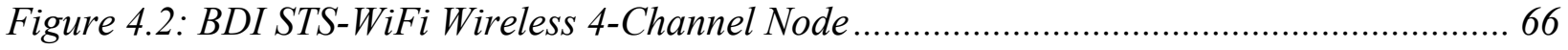

Figure 4.3: BDI STS-WiFi Mobile Base Station...................................................................... 66

Figure 4.4: Tandem Axle Dump Truck used for Live Load Test .......................................... 67

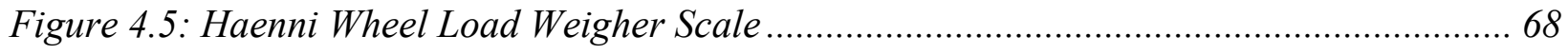

Figure 4.6: Typical Mesh Discretization for Each Tub Girder ........................................... 70

Figure 4.7: Nodal Distribution of Point Loads (Michaelson, 2010) ...................................... 72

Figure 5.1: Gage Locations on Girders, Looking Upstation.................................................. 79

Figure 5.2: Aerial Lift Supplied by Contractor .................................................................... 79

Figure 5.3: Centerline of Gages at Quarter Span, Looking Upstream .................................. 80

Figure 5.4: Typical Bottom Flange Gage Mounting Points, Looking Upstream ...................... 81

Figure 5.5: Typical Web Gage Mounting Points, Looking Downstream ................................ 81

Figure 5.6: Typical Tab Mounting to Steel Surface ................................................................. 82

Figure 5.7: Typical View of Gages Installed on Bottom Flange, Looking Downstream............. 83

Figure 5.8: Overview of Instrumentation, Looking Backstation .......................................... 83

Figure 5.9: Nail placement in Foam Joint with Construction String Line Wrapped Taut.......... 85

Figure 5.10: Parallel Longitudinal Delineations on Deck with Construction String Line .......... 85

Figure 5.11: Transverse Mark Completed with Blue Crayon ................................................. 86

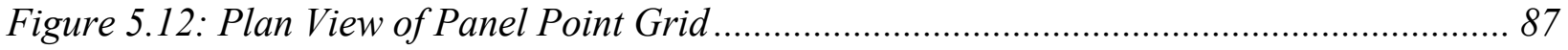

Figure 5.13: Live Load Truck Placement, Looking Upstation ............................................. 88

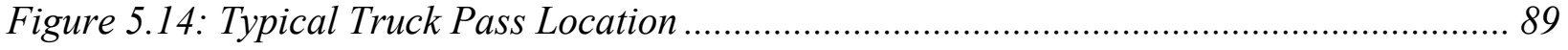

Figure 5.15: Truck Dimensions and Field Weight Measurements ....................................... 90

Figure 6.1: Deflected Shape of Finite Element Model, Truck Run 1, Panel Point 5 ................. 94

Figure 6.2: Comparison Between Analytical and Experimental Live Load Distribution Factors for Single and Two Lane Loaded Conditions ..................................................................... 95 
Figure 6.3: Comparison of Field, FEA and AASHTO Live Load Distribution Factors, One Lane Loaded Truck Run 1. 97

Figure 6.4: Comparison of Field, FEA, and AASHTO Live Load Distribution Factors, Two Lanes

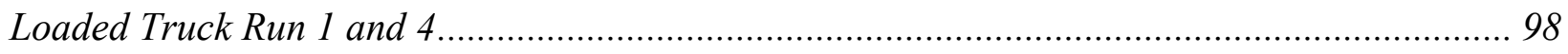

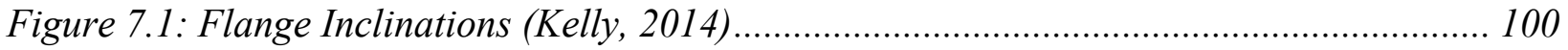

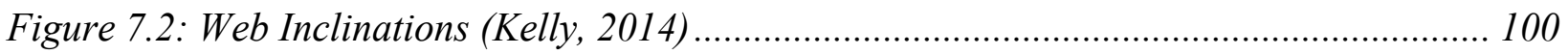

Figure 7.3: Tub Girder Modeled with Flange Tilt ........................................................... 101

Figure 7.4: Tub Girder Modeled with Girder Twist ............................................................... 101

Figure 7.5: Tub Girder Modeled with Web Out of Flatness............................................... 102

Figure 7.6: Multi-linear Stress-Strain Curve .................................................................. 103

Figure 7.7: Vertical Deflection at Midspan for Unbraced Girder and Kelly (2014) ............... 106

Figure 7.8: Internal Bracing Scenarios .................................................................. 107

Figure 7.9: External Bracing Scenarios .................................................................. 108

Figure 7.10: Lateral Displacement Comparison for Internal Bracing Scenarios.................... 110

Figure 7.11: Lateral Displacement Comparison for Internal Bracing Scenarios.................... 110

Figure 7.12: Lateral Displacement Comparison for External Bracing Scenarios................... 111

Figure 7.13: Vertical Displacement Comparison for External Bracing Scenarios.................. 112 


\section{CHAPTER 1: INTRODUCTION}

\subsection{BACKGROUND / OVERVIEW}

The Short Span Steel Bridge Alliance (SSSBA) is a group of bridge and culvert industry leaders (including steel manufacturers, fabricators, service centers, coaters, researchers, and representatives of related associations and government organizations) who have joined together to provide educational information on the design and construction of short span steel bridges in installations up to 140 '-0" in length. The idea of the modular press-brake-formed steel tub girder was developed by a technical working group within the SSSBA. Initial research and testing began in the fall of 2011. After extensive laboratory demonstrations, the first implementation was installed in Buchanan County, Iowa in 2016. Following successful performance, a second bridge was installed in Muskingum County, Ohio the following year. The third bridge to employ this technology and the first to use a precast reinforced concrete deck in conjunction with the pressbrake-formed tub girders is West Virginia State Project No. S322-37-3.29 00 along State Route 37 near Ranger, West Virginia (referred to hereafter as the Fourteen Mile Bridge). The Fourteen Mile Bridge is also unique due to both a skew and significant superelevation present. After completion of the Fourteen Mile Bridge, researchers from Marshall University (MU) and West Virginia University (WVU) traveled to the bridge site to perform a live load field test.

Strain data was recorded during the live load field test and the experimental results were compared to results from a finite element model developed to validate field data. American Association of State Highway and Transportation Officials (AASHTO) Load and Resistance Factor Design (LRFD) Bridge Design Specifications (hereafter referred to as AASHTO LRFD specifications) were applied and live load distribution factors (LLDFs) were computed for 
experimental data, analytical data, and AASHTO LRFD specifications. The results from this research verify the field performance of press-brake-formed tub girders is adequate and confirm the AASHTO LRFD specifications may be safely used in the design of press-brake-formed tub girder bridges.

This report also includes efforts to examine the effectiveness of bracing configurations of the non-composite press-brake-formed tub girder. When combined with a cast-in-place reinforced concrete deck, the non-composite section must resist the full construction load of the fresh concrete. It is imperative that geometric imperfections be consider in order to account for second order amplification effects. A finite element model was developed, using a previous lab test as a benchmark, and different bracing scenarios were assessed. The results provide the basis for extending the work towards a closer investigation to determine the best practices of bracing.

\subsection{Project Scope \& OBJectives}

The scope of this report was to evaluate the field performance of a modular press-brakeformed steel tub girder bridge topped with a precast reinforced concrete deck in Lincoln County, West Virginia. This study also served to determine what effect skew and superelevation may have on the distribution of live load to each girder. A live load field test was performed, a finite element model was developed to verify the recorded data, and the results were used to compute LLDFs. When compared to the AASHTO LRFD specifications, it was determined the field performance exceeded the predicted performance of modular press-brake-formed tub girders topped with a precast reinforced concrete deck. This report also includes an initial qualitative investigation into 
the torsional response of the non-composite press-brake-formed tub girder under construction loading. The following objectives were assessed:

- A discussion of previous work relating to the implementation and design of pressbrake-formed tub girders

- A brief review of the sections of the current AASHTO LRFD specifications relevant to the design of press-brake-formed steel tub girders and LLDFs

- An overview of the design and construction of the Fourteen Mile Bridge, in addition to the accelerate bridge construction methods that were employed

- An explanation of the research methodology and the field test performed on the Fourteen Mile Bridge with a description of the procedures used for the field testing and the finite element analysis that was completed

- A summary of the results and conclusions after comparing the experimental data, analytical data, and values determined following the AASHTO LRFD specifications

- A brief qualitative evaluation of the non-composite behavior of steel press-brakeformed tub girders with different interior and exterior bracing configurations under construction loading

\subsection{REPORT ORGANIZATION}

The organization of this thesis is as follows:

- Chapter 2:

- This chapter discusses previous work on cold-bent steel tub girders at WVU and elsewhere. Additionally, current AASHTO LRFD specifications for steel box girders are reviewed. 
- Chapter 3:

- This chapter documents the design and construction of the composite pressbrake-formed tub girder modules along with the installation of the Fourteen Mile Bridge in Lincoln County, West Virginia.

- Chapter 4:

- This chapter details the research methods utilized in the evaluation of the Fourteen Mile Bridge and discussion of equipment used during the physical load testing.

- Chapter 5:

- This chapter describes the structure instrumentation and testing procedures for the live load field test performed on the Fourteen Mile Bridge.

\section{- Chapter 6:}

- This chapter discusses a qualitative analysis performed to assess the noncomposite behavior of press-brake-formed tub girders when varying bracing systems are employed.

- Chapter 7:

- This chapter compares the results of the field test to the finite element analysis. This includes a comparison of the LLDFs determined by the field data, analytical model, and AASHTO LRFD specifications.

- Chapter 8:

- This chapter summarizes the findings of this study and provides recommendations for future work in this field of research. 


\section{CHAPTER 2: LITERATURE REVIEW}

\subsection{INTRODUCTION}

This chapter begins with an overview of previous work on cold-bent steel tub girders for utilization in bridge applications. Additionally, a summary of research performed by WVU in the area of design and evaluation of press-brake-formed steel tub girders will be discussed. This chapter concludes with a review of articles relevant to the design of tub girder bridges from the current 2017 AASHTO LRFD specifications.

\subsection{Previous Applications of Cold-Bent Steel Girders}

Cold-bent steel has been used in a variety of ways in bridge girders for several decades. Recent initiatives have encouraged further innovation and research to standardize a system of coldbent girders for use in short span bridge applications. This section reviews previous research on the use of cold-bent steel girders in bridge applications.

\subsubsection{Prefabricated Press-Formed Steel T-Box Girder Bridge System (Taly \& Gangarao, 1979)}

Taly and Gangarao (1979) performed early development of cold formed steel box girder systems. Two alternatives were proposed in the research: 1) An all steel deck and box girder assembly, and 2) A steel box girder topped with a pre-cast, prestressed, concrete deck. The girders were comprised of grade A36 steel plate bent into a trapezoidal shape. Shear studs were welded to the plates embedded in the pre-cast concrete planks, and plates were welded to the top flanges of the box girder. This enabled composite action between the steel box and the concrete deck. Load transfer between adjacent girders was achieved through shear keys and weld ties (Figure 2.1) and filled with a nonshrink grout. 


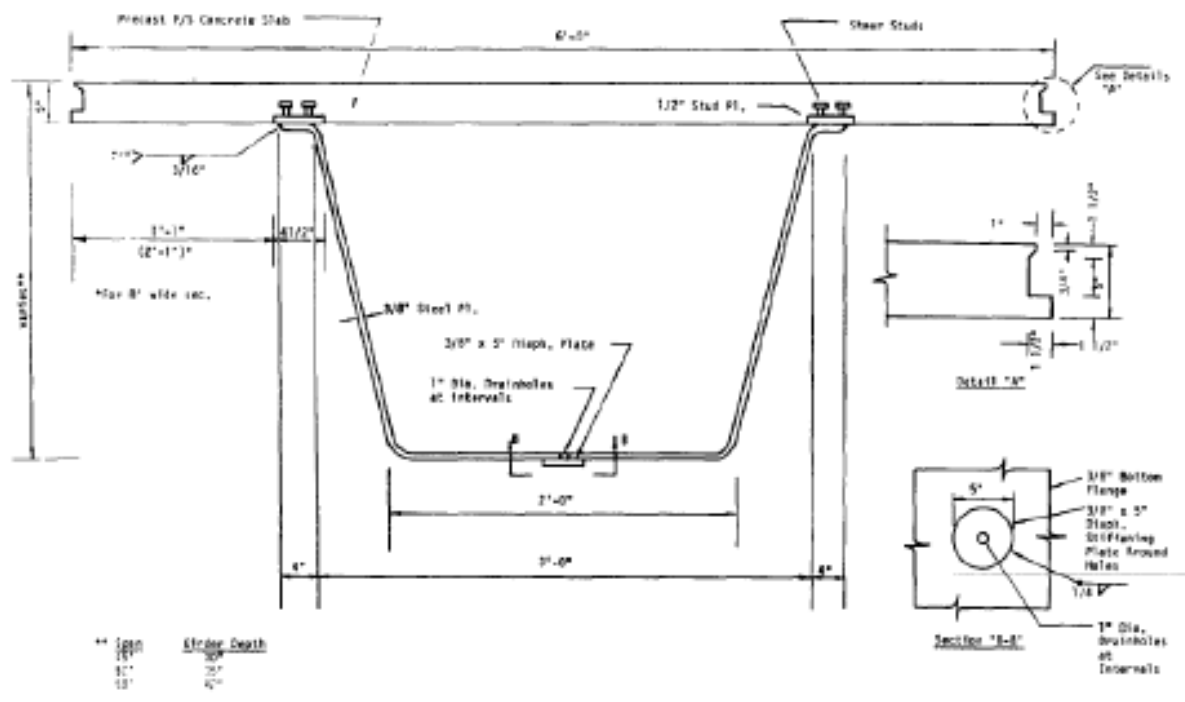

\section{Figure 2.1: T-Box Girder System, Typical Girder Section with 5” Pre-cast, Prestressed Concrete Slab (Taly \& Gangarao, 1979)}

The box girders can be designed at a variety of depths to meet different span requirements, and the small size of each unit makes transportation to the site easier. Most of the fabrication for each unit can be completed in an offsite shop, greatly reducing the necessary time for construction on site. The low weight of the units requires less crane capacity and improves handling and erection characteristics.

\subsubsection{Composite Girders with Cold Formed Steel U-sections (Nakamura, 2002)}

Nakamura (2002) investigated the use of cold formed U-shape girders in continuous spans. The girders were cold formed from a single steel sheet, and a reinforced concrete slab was used for a deck (Figure 2.2). In the middle of the span where the positive bending moment was greatest, 
shear studs were welded to the top flange of the girder to allow composite action with the deck. Concern arose over the supports where the bridge was in negative bending, and the reinforced concrete deck was placed into tension. To prevent buckling, the U-section acted as a mold and was filled with reinforced concrete with prestressing bars. This increased dead load affected weight at the supports but did not affect the bending moment as the load was concentrated near the ends.

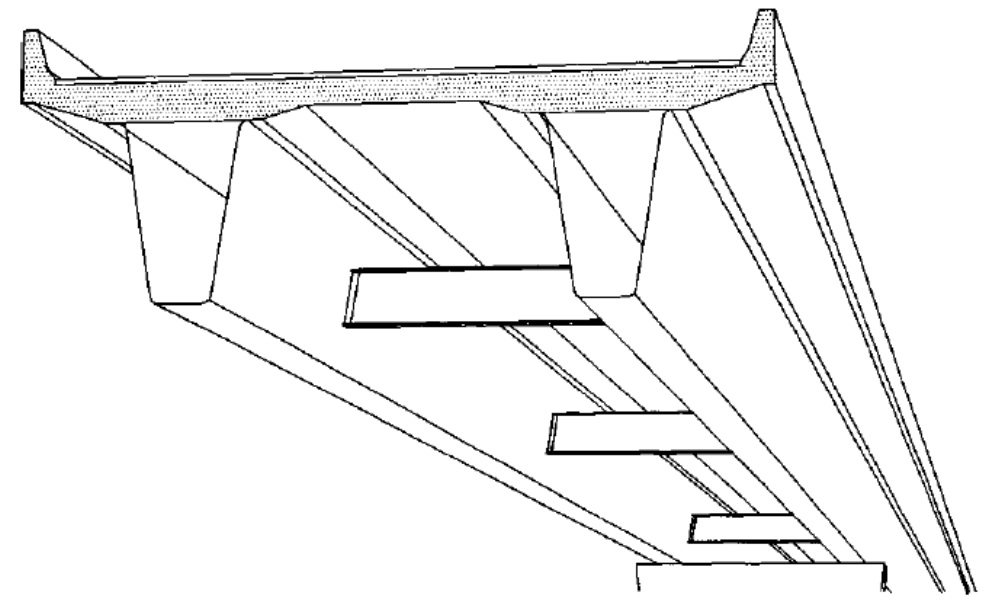

Figure 2.2: Nakamura's Proposed Bridge System (Nakamura, 2002)

Testing of the bending characteristics of this type of beam was performed on several specimens. The girder model performed similarly to typical composite beams on the positive bending sections, and the girder behaved as a prestressed beam near the supports in the regions of positive bending. It was also determined that the system was economical. Though a variety of materials were used to make each module, including structural steel, reinforced concrete, and prestressed concrete, savings from reduced fabrication improved the feasibility of the system. 


\subsubsection{Folded Plate Girders (Developed at the University of Nebraska)}

Research performed at the University of Nebraska-Lincoln investigated rebar detailing between adjacent modules and non-composite behavior during construction of a trapezoidal, coldbent plate box girder that was open at the bottom. Figure 2.3 presents an example cross section of the girder and a composite deck. The fabrication process to make each girder used readily available equipment and produced a consistent product in a limited amount of time. The inclusion of an open bottom improved the ease of inspection inside of the girder. Glaser (2010) determined the deformation under construction load was stable and the use of horizontal tie plates connected to each bottom flange serve to maintain the shape of the girder. Burner (2010) investigated the detailing of the reinforcement in the closure pour region and found that in addition to being resistant to fatigue, the hooked bar was more cost effective than the headed bar.

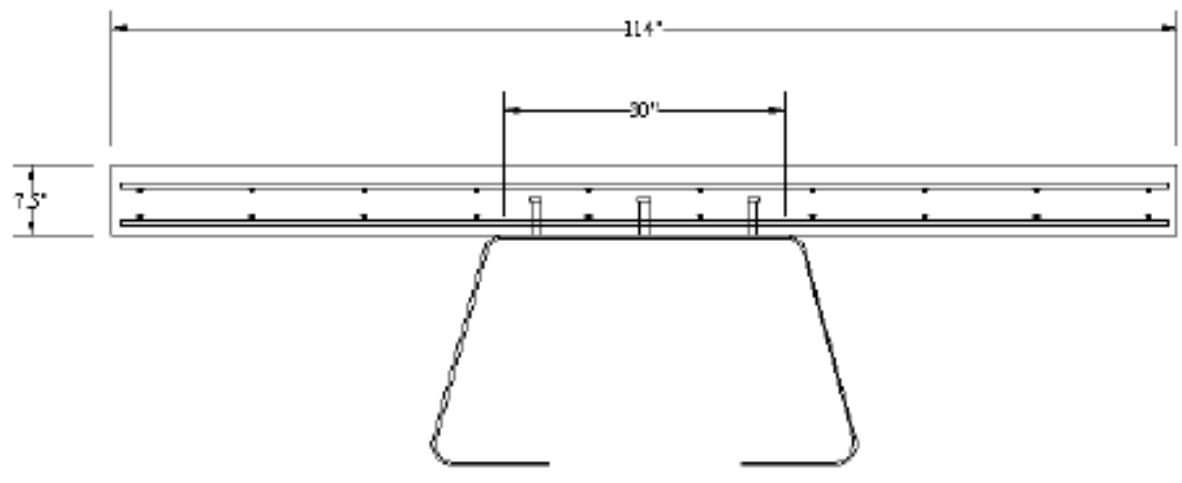

Figure 2.3: Folded Plate Girder and Composite Deck Cross Section (Burner, 2010) 


\subsubsection{Texas Department of Transportation Rapid Economical Bridge Replacement}

The Texas Department of Transportation developed a standardized bridge system employing box girders as part of a large-scale corridor improvement of Interstate 35. FM 3267 was one of the bridges determined to be replaced (Chandar et al., 2010). To enable bridge replacements of large spans without creating height restrictions, shallow box girders were chosen due to the member's structural efficiency. Because of the lightweight nature of box girders, no bent caps were required for the pier columns, which helped maintain the original elevation of the bridge. The box girders were used in conjunction with a cast-in-place reinforced concrete deck. The design for each girder was standardized to reduced design and fabrications costs. As shown in Figure 2.4, the box girders were made up of several sizes of plate that were welded together to form a modular unit.

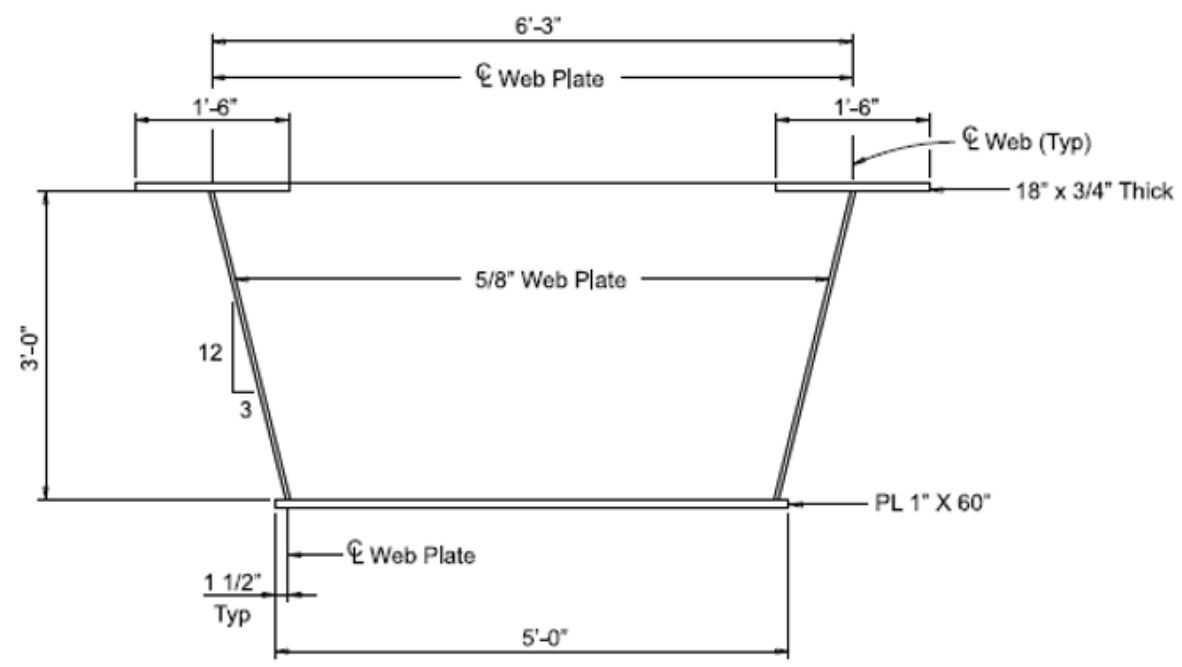

Figure 2.4: Cross Section of Box Girder from Bridge FM 3267 (Chandar et al., 2010) 


\subsection{Previous Research at WVU on Press-Brake-Formed Steel Tub Girders}

Research on press-brake-formed tub girders at WVU began in 2011 after researchers collaborated with the Short Span Steel Bridge Alliance (SSSBA) to develop the modular cold formed box girder. This section describes the previous research performed at WVU concerning press-brake-formed tub girders.

\subsubsection{Development and Feasibility Assessment of Shallow Press-Brake-Formed Steel Tub Girders for Short-Span Bridge Applications (Michaelson 2014)}

Initial research at WVU on press-brake-formed tub girders was performed by Michaelson (2014) and the focus was to expand and refine the development of the modular notion from the SSSBA. The original concept included a cold-formed tub girder made composite with a precast deck. Each modular unit could be transported by truck to the bridge site to allow for accelerated bridge construction (ABC). In order to keep the system economical, an emphasis would be placed on utilizing plate sizes commonly available from mills.

To first grasp an understanding of the behavior of the shallow press-brake-formed tub girder, section properties were determined, and an iterative routine was developed in Microsoft Excel and MATLAB. Several variables, such as web slope, bend radii, and top flange width, were kept constant across all the configurations to better compare the effect of varying plate width and thickness. Initial designs considered six standard plate widths (60”, 72”, 84”, 96", 108”, 120”) and three standard thicknesses (7/16", 1/2", 5/8"). Yield moments were calculated for each plate width and plotted as a function of depth of the unit to determine the optimal cross section for each configuration (Figure 2.5). 


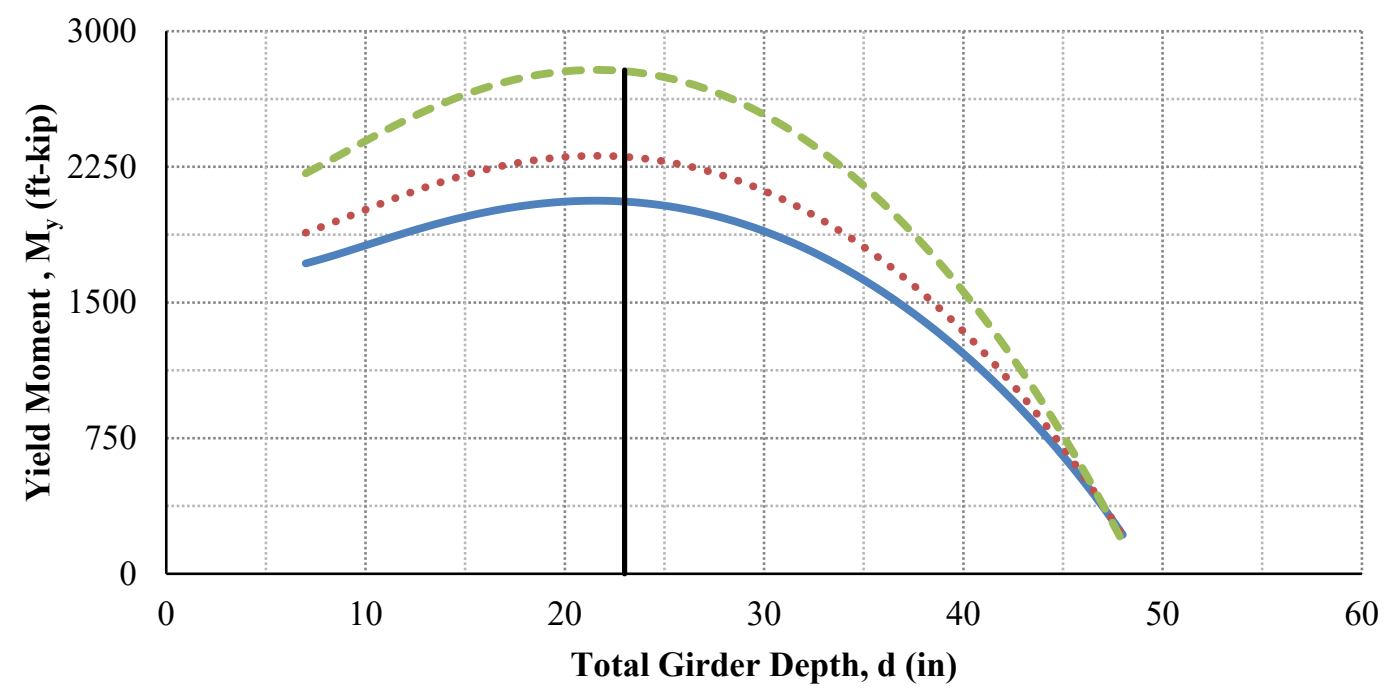

$\longrightarrow t=7 / 16$ in $\cdots \cdot t=1 / 2$ in $\quad-\infty t=5 / 8$ in

Figure 2.5: Design Comparison of 84” Wide Standard Mill Plate (Michaelson, 2014)

Once a methodology was selected for determining the geometry of the cross-section, experimental flexural testing was performed to assess composite and non-composite behavior. Four specimens were fabricated, each from 84 " x $7 / 16$ " x 480 " plate. To test the girders to failure, a deck thickness less than the AASHTO minimum 8" was employed. Experiments one and two both used HPS-50 steel with a composite cast-in-place deck (Figure 2.6) while experiments three and four used HPS-50W weathering steel and HPS-50 steel that was hot-dip galvanized as a surface treatment, respectively. 


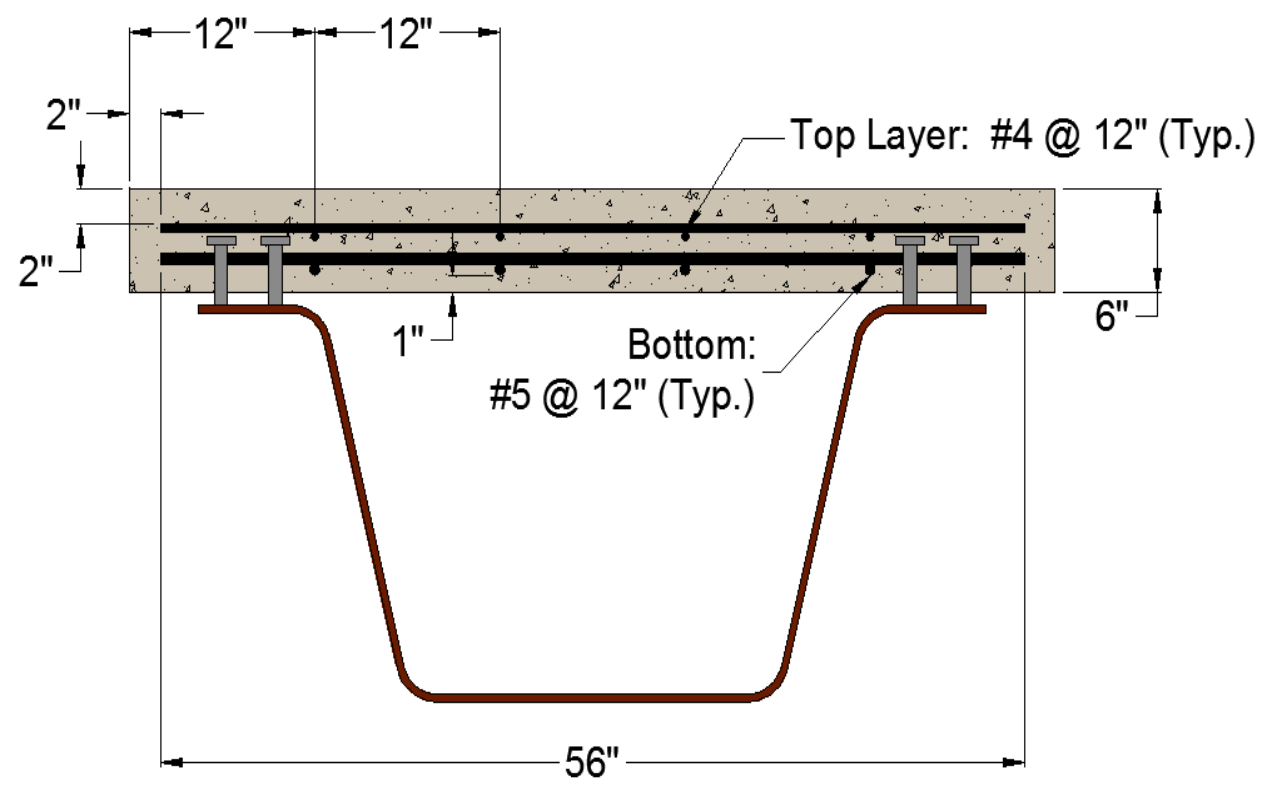

Figure 2.6: Typical Section, Composite Test Specimen (Michaelson, 2014)

Load was applied at the midspan of each specimen with a servo-hydraulic actuator and spreader beam and the displacement was increased in 0.05 " increments until the specimen had reached failure. The composite specimens failed in ductility at approximately 304 kips (Figure 2.7). The non-composite specimens failed due to excessive lateral deflection and twist at relatively low-level loads as seen in Figure 2.8. This is not a significant issue, because the intent of the system is to be topped with a precast deck. 


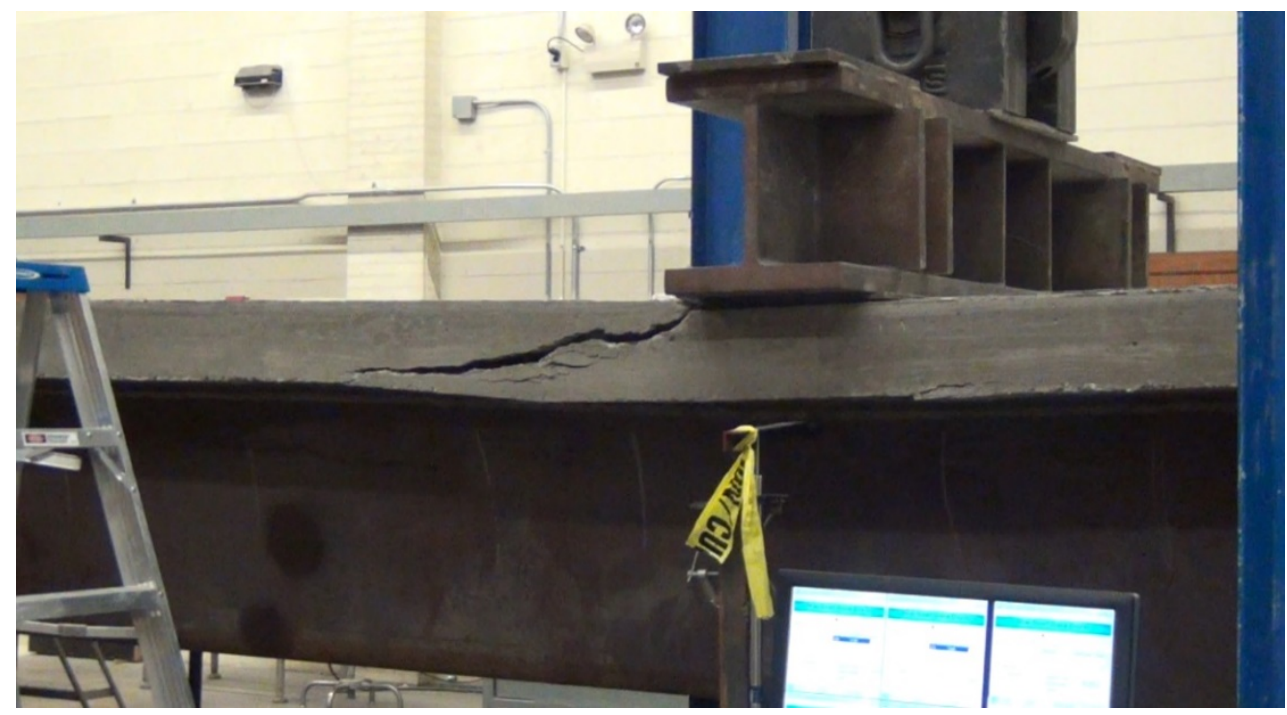

Figure 2.7: Typical Ductile Failure of Composite Girder Section (Michaelson, 2014)

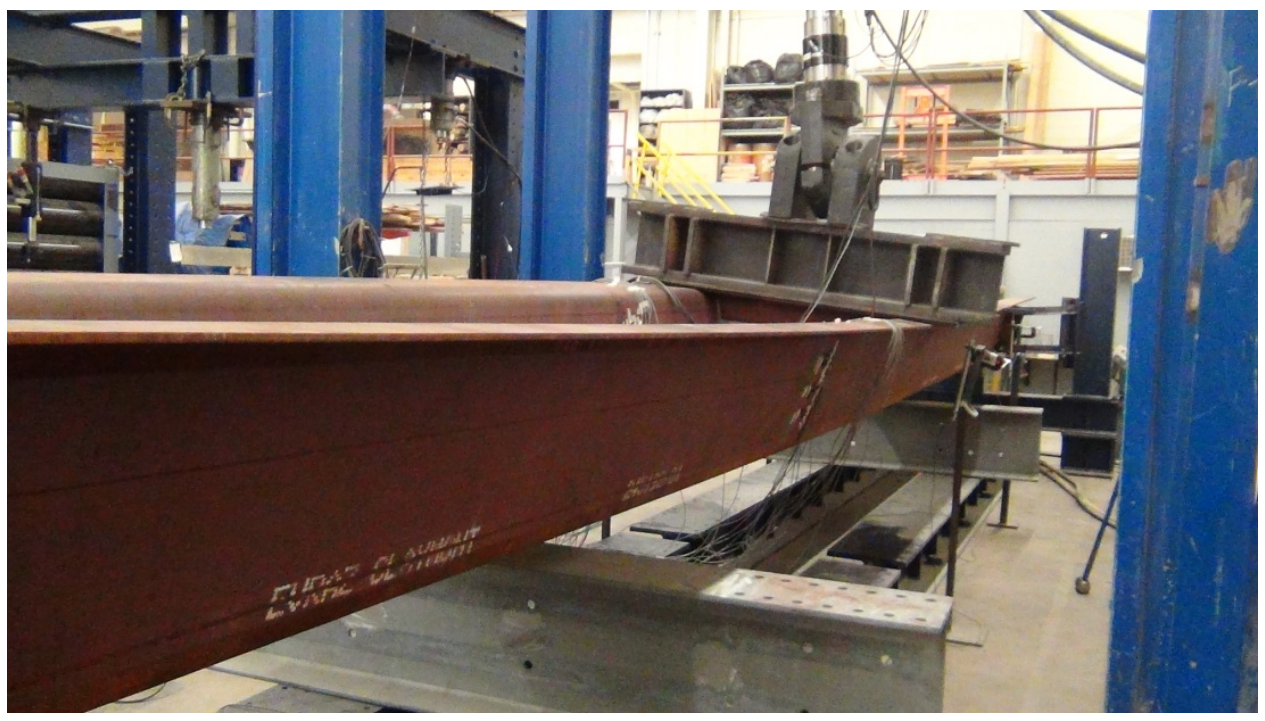

Figure 2.8: Typical Lateral Failure of Non-Composite Girder Section (Michaelson, 2014)

To verify the experimental testing, finite element models were developed and were benchmarked against previous laboratory results. To fully capture the non-composite behavior, the model was adapted to consider second order effects due to geometric imperfections and residual 
stresses. A strain-compatibility approach was also developed to assess each girder's capacity. The model was simulated for each performed experiment and little discrepancy was found between the experimental and analytical data as seen in Figure 2.9.

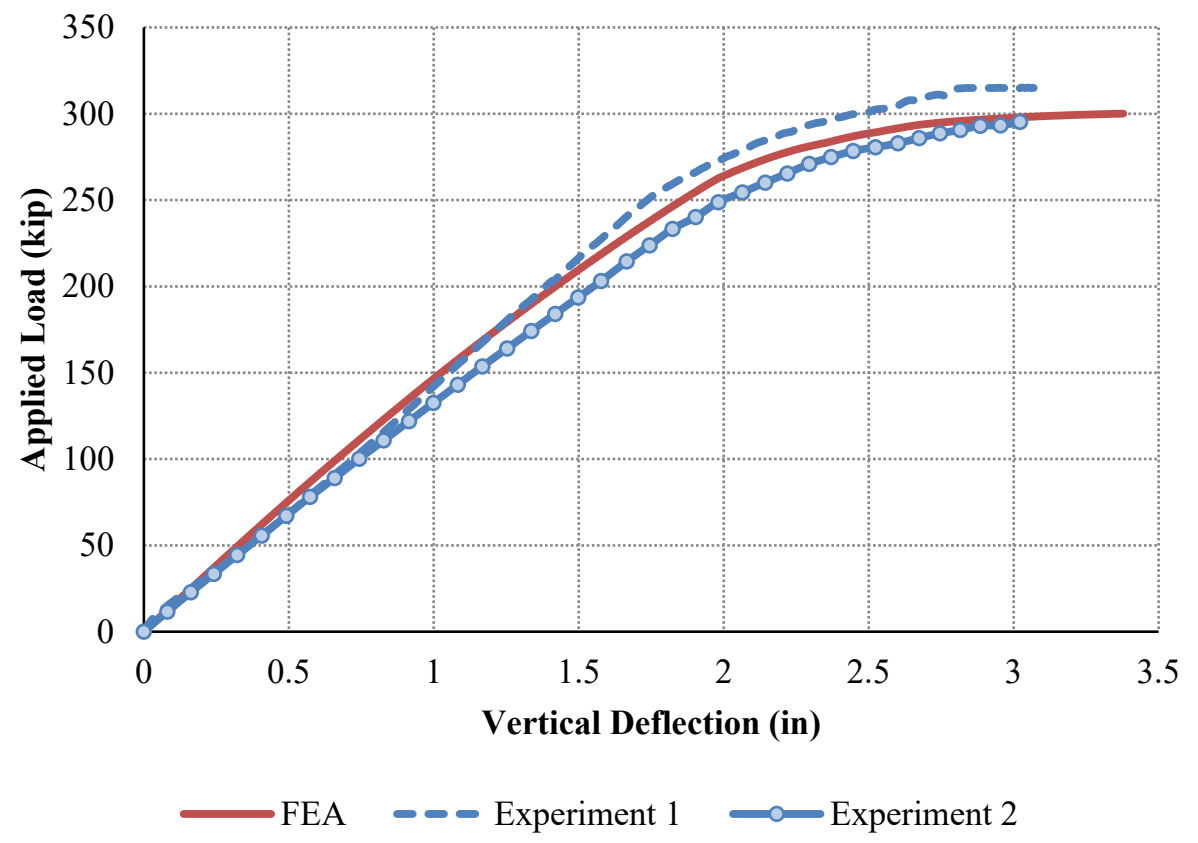

Figure 2.9: Comparison of Analytical and Experimental Results (Michaelson, 2014)

After the experimental results were verified against the analytical model, behavioral studies were performed to determine the applicability of the AASHTO LRFD specifications. Each girder configuration met the requirements to be considered as a box girder, and several of the configurations were determined to be compact. Comparisons were made to the analytical and experimental data, and it was determined the AASHTO LRFD specifications were conservative for calculating the nominal capacity of the section, and an equation that better fit data for nominal capacity was proposed. 
A feasibility assessment was performed to determine if the proposed system could be economically competitive. In order to simplify the data set of possible configurations, plate widths that fell outside the current industry standards were removed as options. The maximum span for each plate size was calculated and configurations not produced at that length were removed from the data set. Four standardized plate sizes were selected from this reduced plate matrix to be used in spans up to $80^{\prime}-0^{\prime \prime}$ in length; however, the system was most competitive in spans up to 60'-0" in length. It should be noted that in the design of the system, a LLDF was assumed to be 1.0, so further work is necessary to accurately determine live load distribution.

\subsubsection{Experimental Evaluation of Non-Composite Shallow Press-Brake-Formed Steel Tub Girders}

(Kelly, 2014)

In collaboration with the work that Michaelson had performed, Kelly (2014) furthered research efforts of stability and torsional behavioral of non-composite press-brake-formed tub girders to determine the feasibility of a cast-in-place deck. The non-composite state is critical to understand as the girder must be able to withstand the full construction load, including wet concrete. To assess this condition, destructive flexural testing was performed, and a finite element model was developed.

Two specimens were tested in the laboratory using a servo-hydraulic actuator. The first specimen was fabricated from 84" x 7/16" HPS-50W weathering steel plate with a WT section bolted to the top flanges at midspan. Load was transferred to the WT by a spreader beam and elastomeric pad. Elastic failure occurred at the critical load of 94 kips with a measured 2.25 " of vertical deflection. The second specimen was fabricated from 84" x 7/16" HPS-50 plate but was hot-dip galvanized as a method of corrosion resistance. Unlike the first specimen, a noticeable 
initial twist due to fabrication was present and varied along the span of the girder as seen in Figure 2.10. Under flexural testing, the galvanized girder experienced lateral torsional buckling at a load of 33 kips and 0.73 " of deflection.

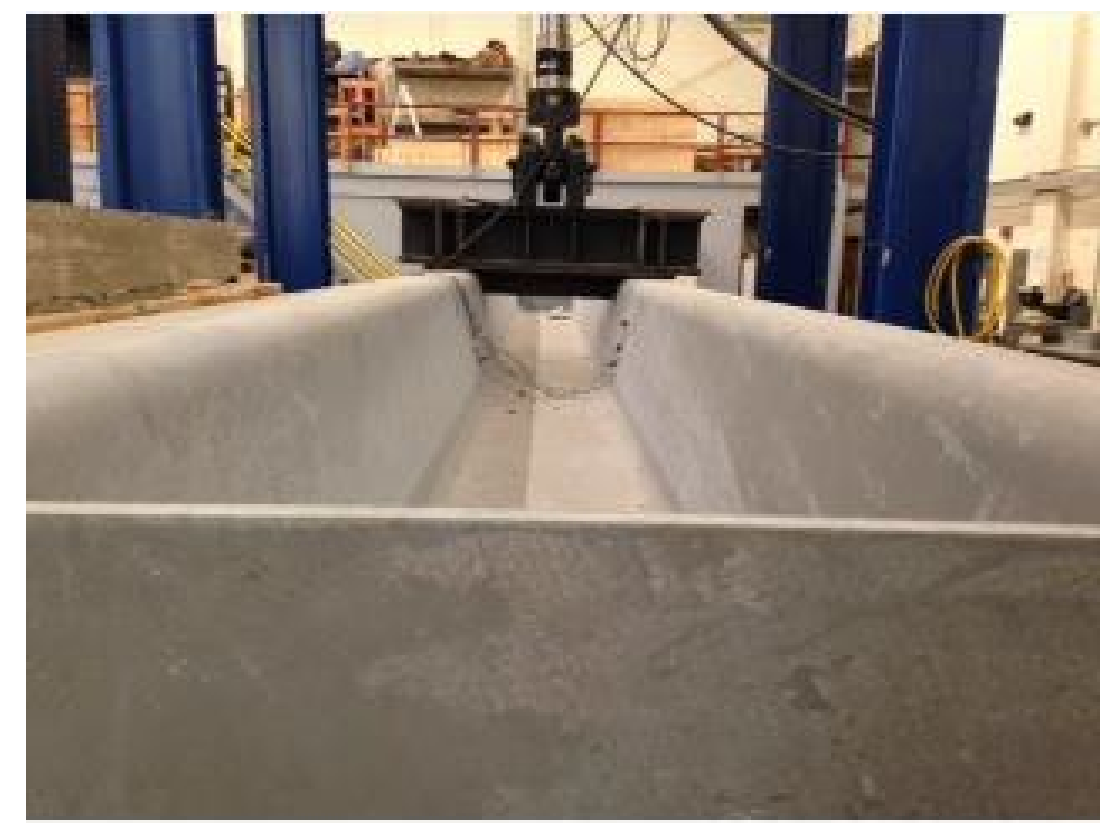

Figure 2.10: Initial Twist of Specimen \#2 (Kelly, 2014)

A finite element model was developed to replicate the laboratory testing, and the results were compared to the measured experimental values as seen in Figure 2.11. The weathering steel specimen behaved nearly identical to the finite element model under the loading, while the galvanized specimen behaved similarly, until it reached the critical load of much less than the predicted value. This premature failure was largely attributed to second order effects due to the original deformity. To improve torsional stability under construction loads, it was recommended stay-in-place formwork be installed to each girder prior to erection. 


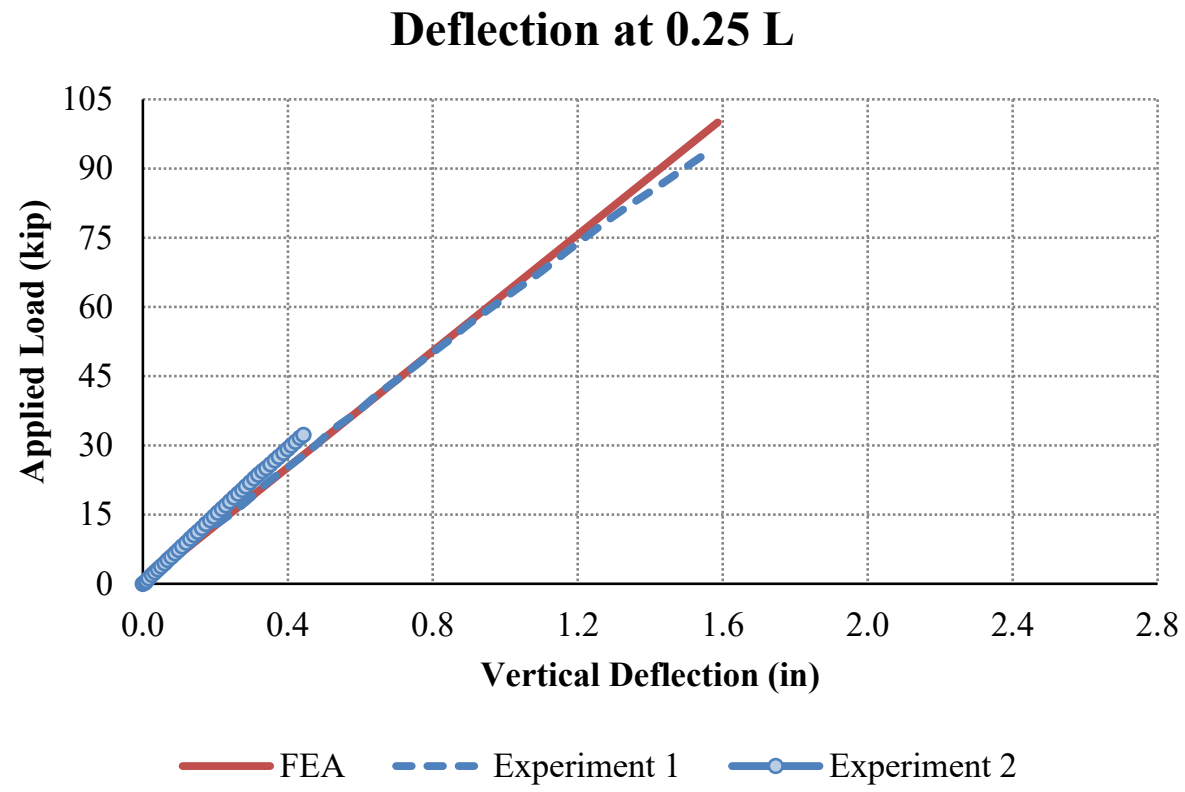

Figure 2.11: Deflection at Quarter Points (Kelly, 2014)

\subsubsection{Evaluation of Modular Press-Brake-Formed Tub Girders with UHPC Joints (Kozhokin,} 2016)

Research was extended by Kozhokin (2016) to evaluate the applicability of the pressbrake-formed tub girder as a modular bridge component and the performance of joints between such modules. Following research from the Federal Highway Administration, ultra-highperformance concrete (UHPC) was chosen to be used for the closure pour between adjacent modules to develop durable connections. UHPC is a steel fiber reinforced Portland cement-based product with advantageous fresh and hardened properties. To ensure proper bonding between the concrete deck and the UHPC joint, an exposed aggregate finish would be required. Techniques were assessed on sample slabs. The best results were produced by the application of a retarder to the shear key formwork and removal the concrete paste using a wire brush (Figure 2.12). 


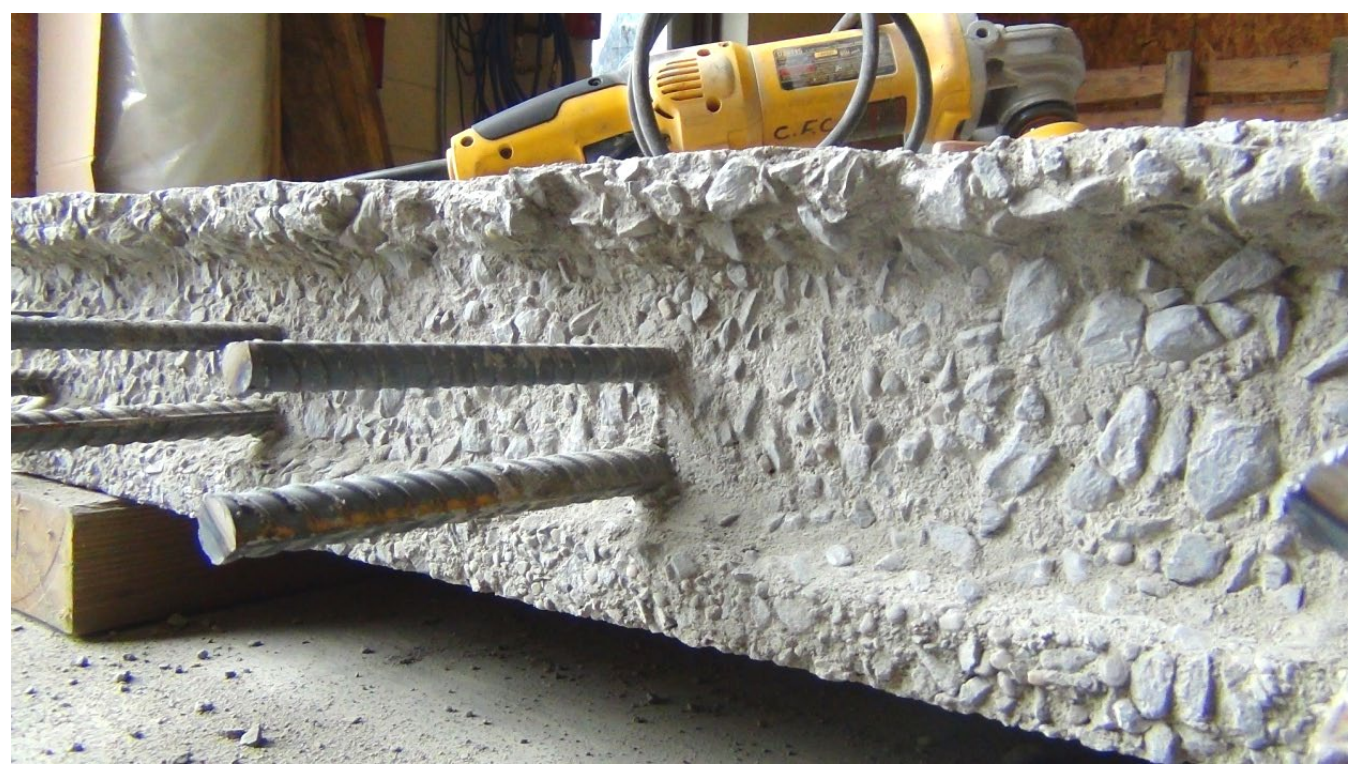

Figure 2.12: Exposed Aggregate Finish of Shear Key Detail after Wire-Brushing (Kozhokin, 2016)

After the appropriate approach was determined to produce the desired shear key detail, two full-scale modules were constructed to physically test the UHPC joint. Once the joint had cured, testing was performed by a servo-hydraulic actuator placed at midspan of one specimen along the girder's centerline. A steel plate replicating the contact area of a truck tire was attached to the actuator, and an elastomeric pad was placed between the deck and the steel plate. Loading was accomplished by the application of a Fatigue I moment due to a cyclic load of 67.43 kips over 2.8 million cycles and a Service II moment due to a static load of 90.78 kips applied at 10 predetermined cycle intervals. After approximately 1.6 million cycles, the concrete deck failed from punching shear failure. The actuator was moved to the adjacent, undamaged girder to continue testing. Subsequent testing found that the UHPC joint satisfactorily transferred stress from the directly loaded girder to the indirectly loaded girder. Distribution factors were calculated, and a summary of the values are presented in Table 2.1 . 
Table 2.1: Summary of Distribution Factors (Kozhokin, 2016)

\begin{tabular}{|r|c|c|}
\hline \multicolumn{3}{|c|}{ Average Distribution Factor } \\
\hline Cycle Count & Directly Loaded Girder & Indirectly Loaded Girder \\
0 & 0.691 & 0.309 \\
\hline 100,000 & 0.631 & 0.369 \\
\hline 250,000 & 0.676 & 0.324 \\
\hline 500,000 & 0.678 & 0.322 \\
\hline $1,000,000$ & 0.690 & 0.310 \\
\hline $1,500,000$ & 0.717 & 0.283 \\
$2,000,000$ & 0.707 & 0.293 \\
\hline $2,100,000$ & 0.708 & 0.292 \\
\hline $2,200,000$ & 0.707 & 0.293 \\
\hline $2,300,000$ & 0.706 & 0.294 \\
\hline $2,500,000$ & 0.711 & 0.289 \\
\hline $2,700,000$ & 0.712 & 0.288 \\
\hline $2,800,000$ & 0.743 & 0.257 \\
\hline
\end{tabular}

\subsubsection{Field Performance Assessment of Press-Brake-Formed Steel Tub Girder Superstructures} (Gibbs, 2017)

The first bridge to utilize the press-brake-formed tub girder concept developed by the SSSBA was installed in Buchanan County, Iowa in 2015. The bridge superstructure consisted of four tub girders constructed from 96 " x 1/2" hot-dip galvanized plate. Unlike the original concept, this implementation employed the erection of non-composite girders topped with an $81 / 2$ " castin-place deck and diaphragms between each girder to support the construction load. To further reduce the amount of time related to construction, Geosynthetic Reinforced Soil abutments were used. An overall view of the completed bridge is seen in Figure 2.13. 


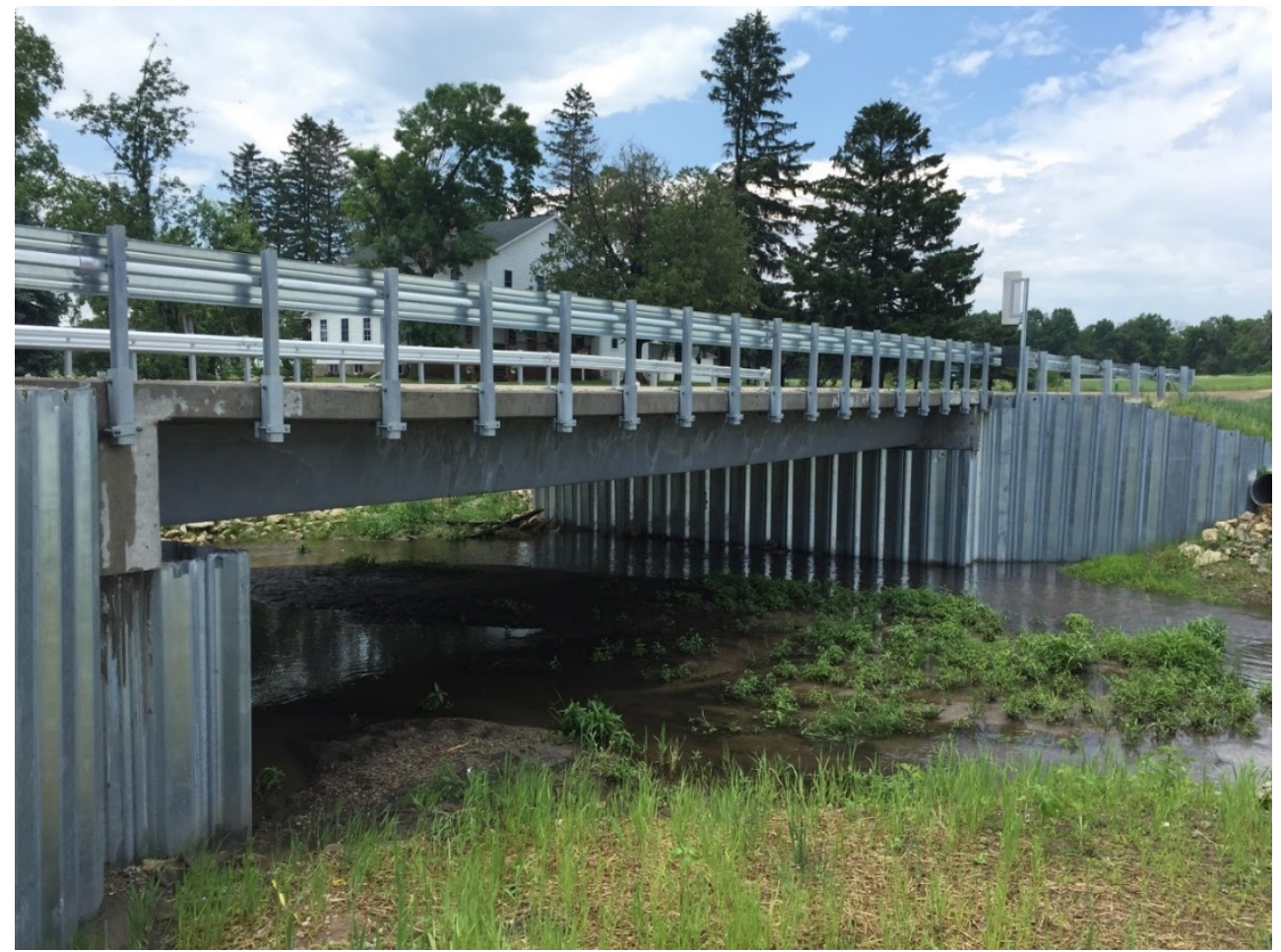

Figure 2.13: New Amish Sawmill Bridge (Gibbs, 2017)

Gibbs (2017), along with other researchers from WVU and MU, performed live load testing on site to further develop analytical models and verify AASHTO LRFD specifications could safely be used to design press-brake-formed tub girders. Upon arrival at the site, the girders were instrumented with Bridge Diagnostics, Inc. equipment to measure the strain in each of the girder's bottom flanges. A tandem-axle truck was positioned across the structure at various panel points, and the strain readings at each location were recorded. This strain data was used to calculate bottom flange bending stresses and LLDFs for single lane loaded and multiple lanes loaded conditions. A finite element model was developed, and LLDFs were calculated per AASHTO LRFD specifications; the LLDFs from all three methods were compared as seen in Figure 2.14. It should be noted, that the stresses determined in the bottom flange by the finite element model were greater 
than those of the field testing. This was attributed to a difference in the boundary conditions as the bridge was constructed with integral abutments, while the finite element model assumed simply supported boundary conditions. However, the LLDF's were similar to the experimental values. The experimental and finite element analysis (FEA) values were both significantly lower than those from AASHTO. Therefore, the AASHTO LRFD specifications were determined to be conservative in design applications for press-brake-formed tub girders.

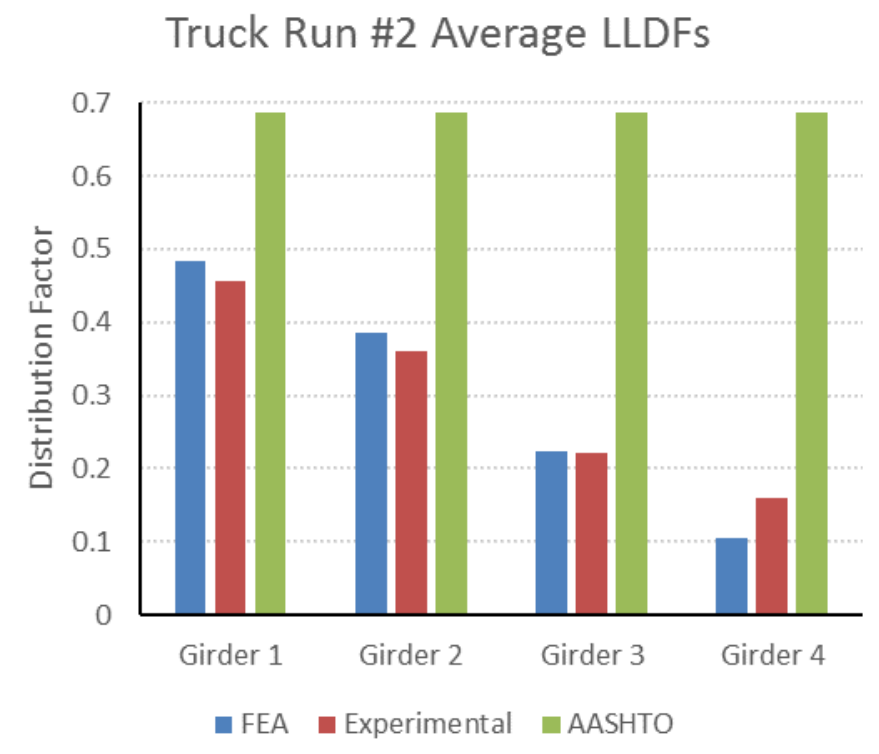

Figure 2.14: FEA v. Experimental v. AASHTO LLDFs (Gibbs, 2017)

\subsubsection{Fatigue Performance of Uncoated and Galvanized Composite Press-Brake-Formed Tub} Girders (Tennant, 2018)

Galvanic surface treatments are an effective means to provide corrosion resistance to steel members, but industry concern had arisen with the fatigue performance over the reheating of coldformed members. Tennant (2018) examined the performance of two specimens with varying 
surface treatments; both girders were produced using ASTM A709 steel, but one was left uncoated (Figure 2.15), and the other was coated with a galvanic surface treatment (Figure 2.16). The composite system was fatigue loaded simulating a 75-year life in a rural environment. At a predetermined number of load cycles, a Service II load was applied to the system to observe the performance of the specimen. A combination of linear variable displacement transducers and strain gages were used to measure deflections that could be compared for each service loading interval.

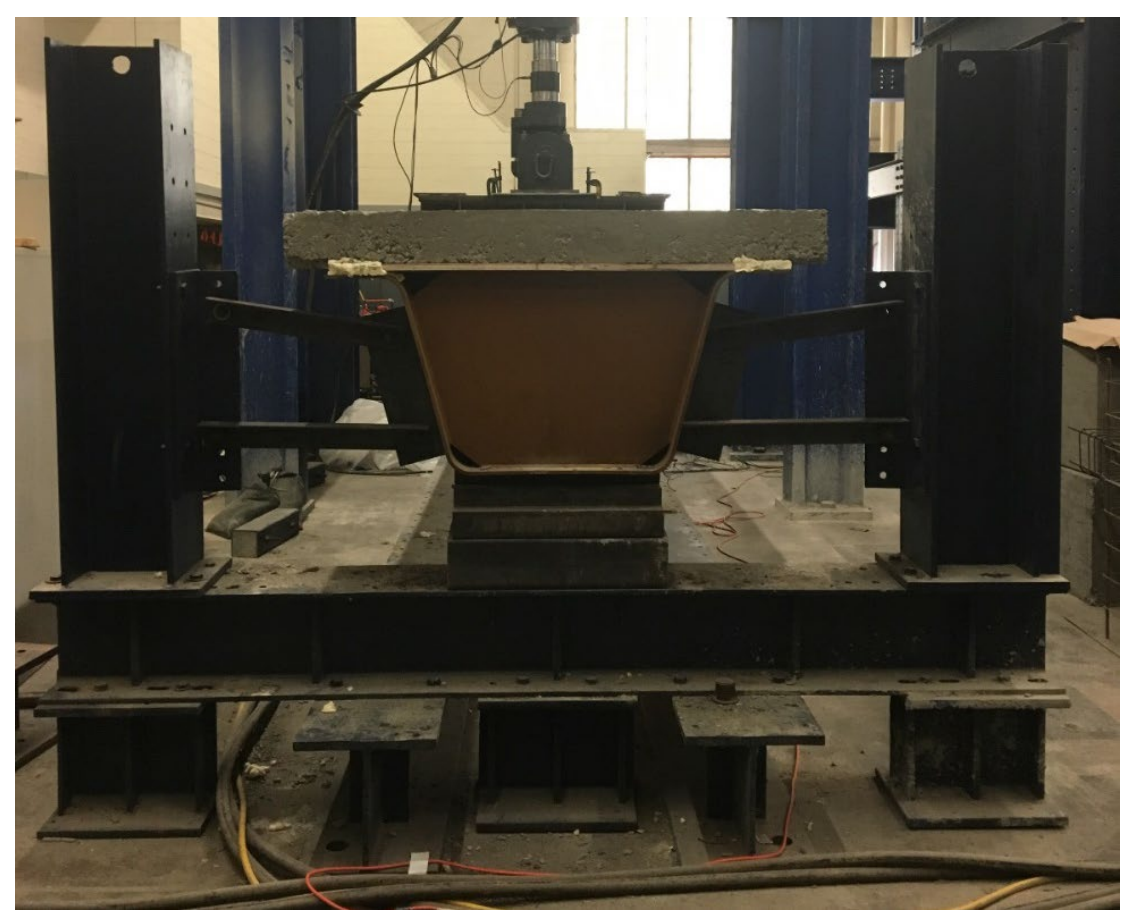

Figure 2.15: Uncoated Steel Girder Under Fatigue Loading (Tennant, 2018) 


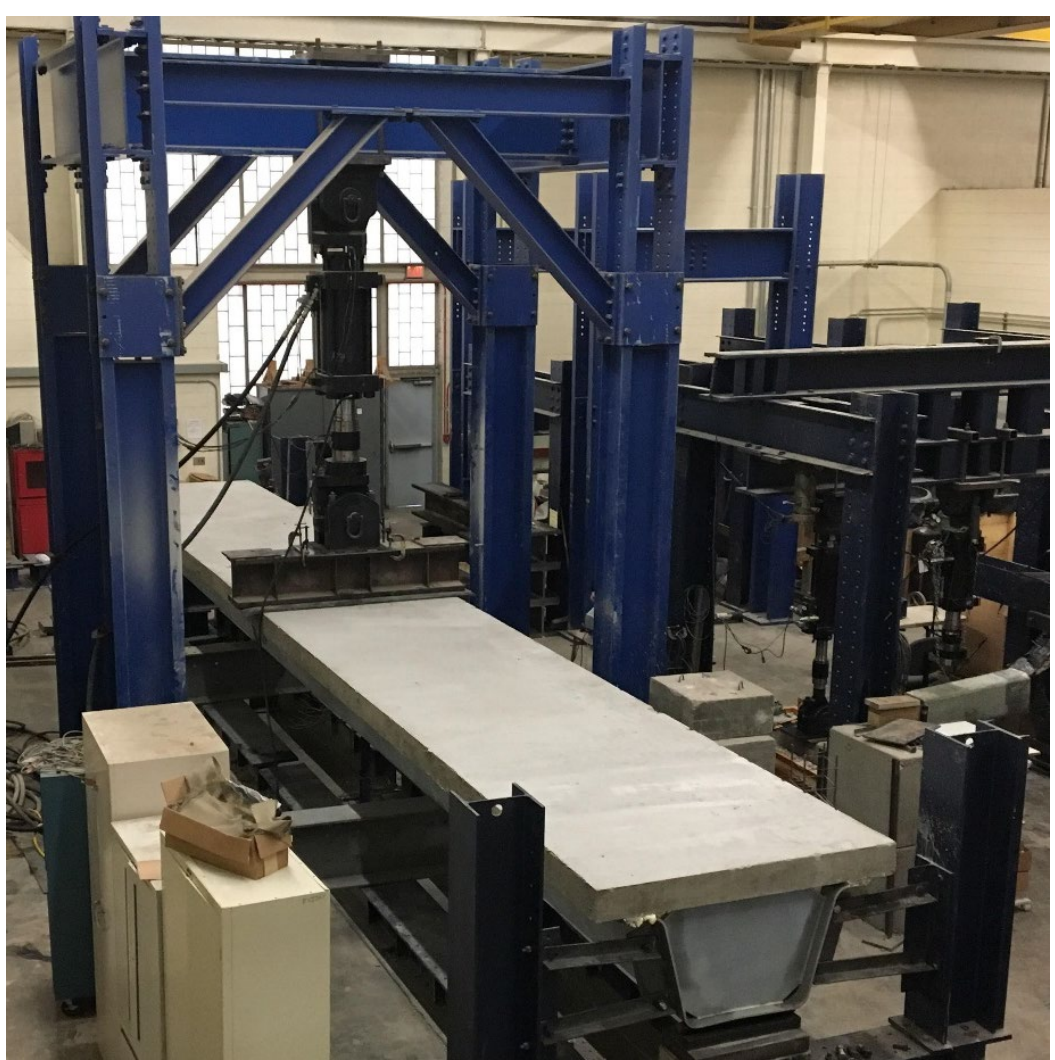

Figure 2.16: Galvanized Steel Girder (Tennant, 2018)

A 6" thick concrete deck was cast-in-place for each girder to become composite. Compressive testing of cylinder samples taken from casting reflected the deck on the galvanized girder had significantly lower compressive strength than the deck on the uncoated girder. To confirm precision, theoretical applied loads were compared to loads calculated from the measured strain data, and the differences were small. The project concluded that the heat of galvanization had no adverse effect on the fatigue performance of a press-brake-formed tub girder. 


\subsubsection{Field Performance and Rating Evaluation of a Modular Press-Brake-Formed Steel Tub}

Girder with a Steel Sandwich Plate Deck (Underwood, 2019)

The Cannelville Road Bridge in Muskingum County, Ohio was the second bridge utilizing press-brake-formed tub girders. The bridge was composed of two modular units each made up of two press-brake-formed tub girders attached to a sandwich plate steel (SPS®) deck with bolts. SPS ${ }^{\circledR}$ decks are a thin, lightweight option that is particularly useful in areas with limited hydraulic openings. The tub girders were fabricated from $5 / 8$ " thick plate and were braced at various locations internally and externally. The entire unit was hot-dip galvanized to provide corrosion resistance. Figure 2.17 shows one of the modular units on site. Erection of most of the superstructure was placed in approximately 20 minutes, and the entire project used only 26 of the allotted 30 days from demolition of the old bridge to carrying traffic on the new bridge.

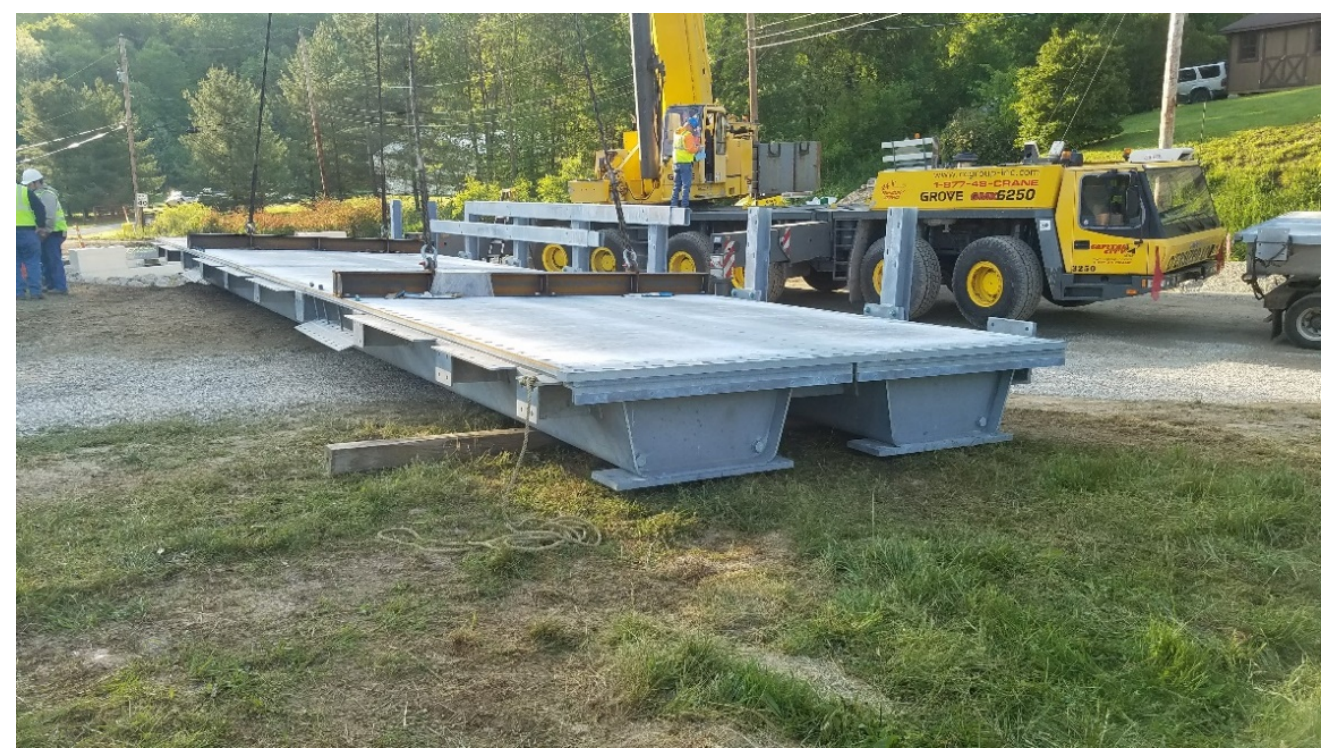

Figure 2.17: Cannelville Road Bridge Modular Unit (Underwood, 2019) 
Underwood (2019) worked with researchers at WVU and MU to perform live load testing of the bridge to assess the applicability of AASHTO LRFD specifications to press-brake-formed tub girders topped with a SPS ${ }^{\circledR}$ deck. The structure was instrumented with Bridge Diagnostics, Inc. equipment and a tandem axle load truck was placed at predetermined grid points. The strain in the bottom flanges of each girder was recorded in addition to the weight of each wheel on the load truck.

A finite element model was produced to make comparisons to the data collected in the field. LLDFs were calculated for the finite element model and the experimental data and the results were compared to LLDFs calculated per the AASHTO LRFD specifications as seen in Figure 2.18. Inventory and operating load ratings for interior and exterior girders were also computed from both field data and the analytical model. Live load ratings were compared to AASHTO serviceability and strength requirements. As in other tests, the data reflected that the AASHTO LRFD specifications tend to be conservative and underpredict the performance of the press-brake-formed tub girder system; therefore, the provisions used safely model press-brake-formed tub girders. 


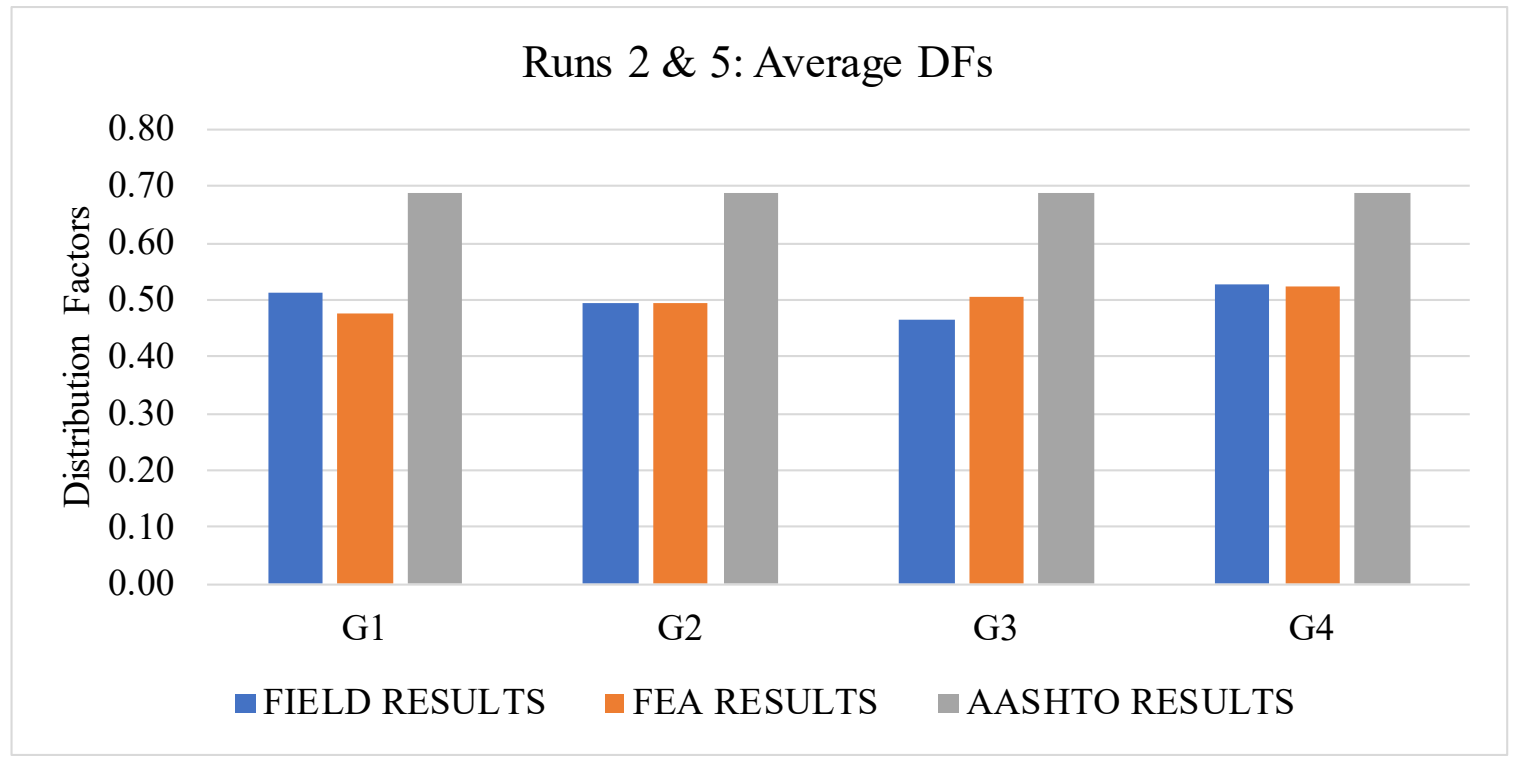

Figure 2.18: Field v. FEA v. AASHTO LLDFs (Underwood, 2019)

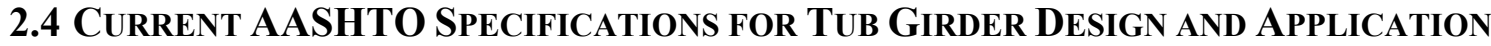

AASHTO is the governing body regulated the practice of roadway design. AASHTO's presence extends into the design and analysis of bridge structures with the LRFD Bridge Design Specifications, a code manual that is updated every three years based on improvements in behavioral understandings and to improve safety of the traveling public. Design under the LRFD philosophy accounts for varying levels of loadings that may be applied to structures and the varying capacity that members may have based on sound statistical evidence. The current AASHTO LRFD Bridge Design Specifications (hereafter referred to as AASHTO LRFD specifications), is the $8^{\text {th }}$ edition which was published in September 2017. This section summarizes the relevant portions of the code related to the design of the Fourteen Mile Bridge. 


\subsubsection{Multiple Presence Factors}

Multiple presence factors are empirical values used to investigate the extreme live load force effect by considering the probability of simultaneous lane occupation by the HL-93 design live load. Each design lane is defined to be $12^{\prime}-0$ " in width or lesser if the traffic lanes are less than 12'-0". When calculating distribution factors per Articles 4.6.2.2 and 4.6.2.3, the appropriate multiple presence factor has already been included in the expressions and need not be taken into consideration. The values are based on an average daily truck traffic of 5,000 trucks in a single direction. Table 2.2 presents the multiple presence factors from the AASHTO LRFD specifications for each scenario of the number of lanes loaded. Multiple presence factors shall not be considered for the fatigue limit state where only a single design truck is applied.

Table 2.2: Multiple Presence Factors (AASHTO, 2017)

\begin{tabular}{|c|c|}
\hline Number of Loaded Lanes & $\begin{array}{c}\text { Multiple Presence } \\
\text { Factors, } m\end{array}$ \\
\hline \hline 1 & 1.20 \\
\hline 2 & 1.00 \\
\hline 3 & 0.85 \\
\hline$>3$ & 0.65 \\
\hline
\end{tabular}

\subsubsection{Beam-Slab Bridges - Live Load Distribution Factors}

Provisions for calculated LLDFs in Article 4.6.2.2 require the cross-sections of bridges containing multiple boxes meet geometric criteria in Article 6.11.2.3. These specifications require when parallel box sections are used, the spacing of the center of adjacent top flanges shall be at least 80 percent of the interior spacing of the center of top flanges and not greater than 120 percent 
of the spacing the center of top flanges. These distances are represented by $w$ and $a$, respectively, in Figure 2.19. In addition, the inclination of web plate to the plane normal to the bottom flange shall be limited to 1 to 4 . The provisions of Article 4.6.2.2 are only applicable in situations where the bearing lines are not skewed; in cases of skew at the supports, a more refined structural analysis must occur. Cantilevered overhang of the concrete deck including the curb and parapet is limited to either 60 percent of the interior spacing of the center of top flanges, $w$, or 6'-0'.

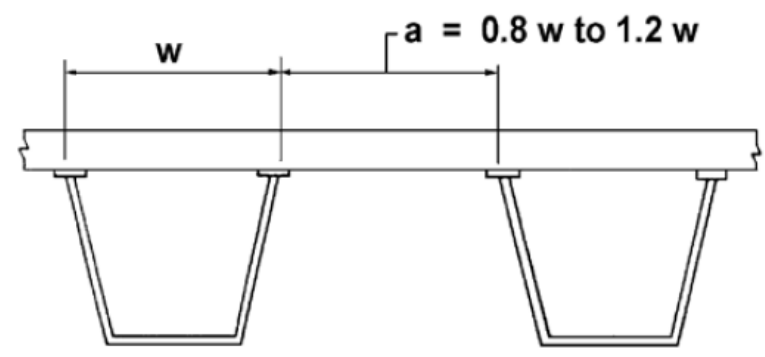

Figure 2.19: Center-to-Center Flange Distance (AASHTO, 2017)

If the cross-section of a bridge constructed from multiple boxes meets these criteria, Article 4.6.2.2 may be used to calculate the LLDFs. Article 4.6.2.2 refers to use of Table 4.6.2.2.2b-1 for multiple steel box girders with a concrete deck; the appropriate cross section is matched to the list provided in Table 4.6.2.2.1-1. For bridges constructed of multiple steel box girders topped with a concrete deck, only one equation for determining the LLDFs, regardless of the number of lanes loaded. The applicable expression is listed as Equation 2-1 and is valid for moment and shear in interior beams. Table 4.6.2.2.2d-1 specifies that Equation 2-1 may also be used for calculation of LLDFs in exterior beams. Multiple presence factors are already incorporated into the expression for the calculation of distribution factors by approximate means. 


$$
\begin{gathered}
L L D F_{I N T}=0.05+0.85\left(\frac{N_{L}}{N_{b}}\right)+\frac{0.425}{N_{L}} \\
\text { Where: } 0.5 \leq \frac{N_{L}}{N_{b}} \leq 1.5 \\
\mathrm{~N}_{\mathrm{L}}=\text { number of design lanes } \\
\mathrm{N}_{\mathrm{b}}=\text { number of girders }
\end{gathered}
$$

\subsubsection{Box-Section Flexural Members}

This section details the relevant limit states and capacity requirements that must be checked in the design of box-section flexural members.

\subsubsection{Cross Section Proportion Limits}

Webs may be either vertical or inclined; the inclination of the web plates to the plane perpendicular to the bottom flange shall be limited to 1 to 4 . In addition, the criteria of Equation 2-2 and Equation 2-3 must be met regarding web proportions.

For webs without longitudinal stiffeners:

$$
\frac{D}{t_{w}} \leq 150
$$


For webs with longitudinal stiffeners:

$$
\begin{aligned}
\frac{D}{t_{w}} \leq & 300 \\
\text { Where: } \mathrm{D} & =\text { web depth (in) } \\
\mathrm{t}_{\mathrm{w}} & =\text { web thickness (in) }
\end{aligned}
$$$$
\text { Equation 2-2 }
$$

Top flanges of tub sections shall meet the criteria specified in Equation 2-4, Equation 2-5, and Equation 2-6, regardless if the flange section is subjected to compression or tension.

$$
\begin{aligned}
& \frac{b_{f}}{2 t_{f}} \leq 12.0 \\
& b_{f} \leq D / 6 \\
& t_{f} \geq 1.1 t_{w} \\
& \text { Where: } \mathrm{b}_{\mathrm{f}}=\text { flange width (in) } \\
& \qquad \mathrm{t}_{\mathrm{f}}=\text { flange thickness (in) } \\
& \qquad \mathrm{D}=\text { web depth measure along inclination (in) } \\
& \mathrm{t}_{\mathrm{w}}=\text { web thickness (in) }
\end{aligned}
$$

\subsubsection{Constructability}

To ensure the geometry of the box section is maintained during construction, the section must be checked in various states to verify adequate capacity. Through investigation, it may be determined additional internal and/or external cross-frames may be temporarily required during construction or as a permanent fixture to support possible eccentric loads. Load factors for 
construction loads are taken from Article 3.4.2. Article 6.11.3 specifies the provisions of Article 6.10.3 are to be applied unless otherwise stated.

For sections in flexure, Articles 6.10.3.2.1 through 6.10.3.2.3 shall be applied to only the top flanges of tub sections. Equations 2-8, 2-10, and 2-11 shall be checked as applicable. The unbraced length is defined as the distance between interior cross-frames or diaphragms. Equation 2-9 shall not be checked in cases of either compact or noncompact webs and when $f_{1}=0$. If the section contains a slender web, Equation 2-7 shall not be checked. The provisions also specify that non-composite sections with slender webs, flanges in compression shall also satisfy Equation 2-9.

For discretely braced flanges in compression:

$$
\begin{array}{lr}
f_{b u}+f_{l} \leq \phi_{f} R_{h} F_{y c} & \text { Equation 2-7 } \\
f_{b u}+\frac{1}{3} f_{l} \leq \phi_{f} F_{n c} & \text { Equation 2-8 } \\
f_{b u} \leq \phi_{f} F_{c r w} & \text { Equation 2-9 }
\end{array}
$$

Where: $\phi_{\mathrm{f}}=$ resistance factor for flexure specified in Article 6.5.4.2

$$
\begin{aligned}
& f_{b u}=\text { flange stress calculated without consideration of flange lateral bending } \\
& \text { determined as specified in Article } 6.10 .1 .6(\mathrm{ksi}) \\
& \mathrm{f}_{\mathrm{l}}=\text { flange lateral bending stress determined as specified in Article } 6.10 .1 .6 \\
& (\mathrm{ksi}) \\
& \mathrm{F}_{\mathrm{crw}}=\text { nominal bend-buckling resistance for webs specified in Article } \\
& 6.10 .1 .6(\mathrm{ksi})
\end{aligned}
$$


$\mathrm{F}_{\mathrm{nc}}=$ nominal flexural resistance of the flange as specified in Article 6.10.8.2 (ksi), with the web load-shedding factor, $\mathrm{R}_{\mathrm{b}}$, taken as 1.0 for constructability

$\mathrm{R}_{\mathrm{h}}=$ hybrid factor as specified in Article 6.10.1.10.1, $\mathrm{R}_{\mathrm{h}}=1.0$ when fbu does not exceed the specified yield strength of the web

$\mathrm{F}_{\mathrm{yc}}=$ specified minimum yield strength of compression flange (ksi)

For discretely braced flanges in tension:

$$
f_{b u}+f_{l} \leq \phi_{f} R_{h} F_{y t}
$$

Where: $F_{y t}=$ specified minimum yield strength of tension flange (ksi)

For continuously braced flanges in compression or tension:

$$
f_{b u} \leq \phi_{f} R_{h} F_{y f}
$$

Where: $F_{y f}=$ specified minimum yield strength of flange $(\mathrm{ksi})$

For critical stages of construction, non-composite box flanges in compression must meet the criteria specified in Equation 2-12 and Equation 2-13.

$$
\begin{aligned}
& f_{b u} \leq \phi_{f} F_{n c} \\
& f_{b u} \leq \phi_{f} F_{c r w}
\end{aligned}
$$


For critical stages of construction, non-composite box flanges in tension and continuously braced box flanges in either compression or tension must meet the criteria specified in Equation $2-14$.

$$
\begin{array}{cc}
f_{b u} \leq \phi_{f} R_{h} F_{y f} \Delta & \text { Equation 2-14 } \\
\text { Where: } \Delta=\sqrt{1-3\left(\frac{f_{v}}{F_{y f}}\right)^{2}} & \text { Equation 2-15 } \\
f_{v}=\frac{T}{2 A_{o} t_{f}} & \text { Equation 2-16 } \\
f_{\mathrm{v}}= & \text { St. Venant torsional shear stress in the flange due to the factored loads } \\
& \text { at the section under consideration (ksi) } \\
\mathrm{T}= & \text { internal torque due to the factored loads (kip-in) }
\end{array}
$$


For inclined webs:

$$
V_{u i}=\frac{V_{u}}{\cos (\theta)}
$$

Where: $V_{u i}=$ vertical shear due to factored loads along one inclined web (kip)

$$
\theta=\text { angle of inclination of the web plate to vertical (degrees) }
$$

\subsubsection{Service Limit State}

Service limit states are employed to control deflection under typical live loads. Limited deflection not only provides user comfort, but it ensures adequate performance of bearings, joints, and other critical features of the bridge structure. Box sections must meet the provisions of Article 6.10.4, except in Equation 2-20, fi shall be taken as zero, and Equation 2-21 shall not apply.

Elastic deformation limits are specified in Article 2.5.2.6, and when applying the relevant criteria, the vehicular live load taken from Article 3.6.1.3.2 shall include the dynamic load allowance, IM per Table 3.4.1-1. The provisions specify all design lanes should be loaded, and all components can be assumed to deflect uniformly. In cases where a bridge is skewed, a right cross section may be employed. The following deflection limit is to be considered for steel bridges:

Vehicular load, general Span $/ 800$

Permanent deformations are governed by Article 6.10.4.2, and Service II load combinations per Table 3.4.1-1 shall apply. The criteria specified by Equations 2-19, 2-20, and 221 shall be met for flanges in flexure.

Flexure:

Top steel flange, composite sections 


$$
f_{f} \leq 0.95 R_{h} F_{y f}
$$

Bottom steel flange, composite sections

$$
f_{f}+\frac{f_{l}}{2} \leq 0.95 R_{h} F_{y f}
$$

Both steel flanges, non-composite sections

$$
f_{f}+\frac{f_{l}}{2} \leq 0.80 R_{h} F_{y f}
$$

Where: $\mathrm{ff}_{\mathrm{f}}=$ flange stress at the section under consideration due to the Service II loads calculated without consideration of flange lateral bending (ksi)

$\mathrm{f}_{\mathrm{l}}=$ flange lateral bending stress at the section under consideration due to the Service II loads determined as specific in Article 6.10.1.6 (ksi)

$$
\mathrm{R}_{\mathrm{h}}=\text { hybrid factor as specified in Article 6.10.1.10.1 }
$$

In addition to flange stress criteria, limits also apply to the web of the composite section. Except for sections in positive flexure in which the web satisfies Article 6.11.2.1.2, all sections shall satisfy Equation 2-22.

$$
f_{c} \leq F_{c r w}
$$

Where: $f_{c}=$ compression flanges stress at section under consideration due to Service

II loads calculated without consideration of flange lateral bending (ksi)

$$
\mathrm{F}_{\mathrm{crw}}=\text { nominal bend-buckling resistance for webs with or without }
$$
longitudinal stiffeners, as applicable, determined as specified in Article 6.10.1.9 (ksi) 


\subsubsection{Fatigue and Fracture Limit State}

Fatigue limits shall be considered to ensure cracks in steel members due to cyclic loading are limited and do not propagate. Article 6.10 .5 specifies the general provisions that must be met, while Article 6.11.10 specifies criteria for shear connectors. In cases where the cross section of a bridge with multiple straight box girders does not meet the requirements of Article 6.11.2.3, longitudinal warping stress and transverse bending stress due to distortion shall be considered. Connection details shall be investigated per the specifications in Article 6.6.1 with the appropriate load combination for fatigue from Table 3.4.1-1.

Fatigue is separated into two categories, load-induced and distortion-induced. Loadinduced fatigue is a result of the live load stresses present in members. In scenarios where a concrete deck is cast, the long-term composite section shall be used when resisting dead loads, and the short-term composite section shall be used when resisting live loads. The provisions are only applicable to details with a net tensile stress; residual stresses are to be neglected in fatigue considerations.

For load-induced fatigue considerations, each detail shall satisfy:

$$
\gamma(\Delta f) \leq(\Delta F)_{n}
$$

Where: $\gamma=$ load factor as specified in Table 3.4.1-1 for the fatigue load combination

$$
\begin{aligned}
(\Delta \mathrm{f})= & \text { force effect, live load stress range due to the passage of the fatigue } \\
& \text { load as specified in Article 3.6.1.4 (ksi) } \\
(\Delta \mathrm{F})_{\mathrm{n}}= & \text { nominal fatigue resistance as specified in Article 6.6.1.2.5 (ksi) }
\end{aligned}
$$


For the Fatigue I load combination (infinite life), nominal fatigue resistance is computed as shown in Equation 2-24:

$$
(\Delta F)_{n}=(\Delta F)_{T H}
$$

Equation 2-24

For the Fatigue II load combination (finite life), nominal fatigue resistance is computed as shown in Equation 2-25:

$$
\begin{aligned}
& (\Delta F)_{n}=\left(\frac{A}{N}\right)^{\frac{1}{3}} \\
& \text { Where: } N=(365)(75) n(A D T T)_{S L} \\
& \mathrm{~A}=\text { constant taken from table 6.6.1.2.5-1 }\left(\mathrm{ksi}^{3}\right) \\
& \mathrm{n}=\text { number of stress range cycles per truck passage taken from Table 6.6.1.2.5-2 } \\
& (\mathrm{ADTT})_{\mathrm{SL}}=\text { single-lane ADTT as specified in Article 3.6.1.4 } \\
& (\Delta \mathrm{F})_{\mathrm{TH}}=\text { constant-amplitude fatigue threshold taken from Table 6.6.1.2.5-3 }(\mathrm{ksi})
\end{aligned}
$$


components subject to net tensile stress under Strength I load combination shall require the performance of Charpy V-notch testing.

\subsubsection{Strength Limit State}

The strength limit state is employed to ensure the structure has adequate capacity to resist the shears and moments generated during loading. Article 6.11 .6 specifies the provisions that must be met. Applicable load combinations are taken from Table 3.4.1-1.

\subsection{General Flexure Requirements}

In box sections with holes in the tension flange at the section under consideration, the tension flange shall satisfy provisions of Article 6.10.1.8 and Equation 2-27.

$$
f_{t} \leq 0.84\left(\frac{A_{n}}{A_{g}}\right) F_{u} \leq F_{y t}
$$

Where: $A_{n}=$ net area of the tension flange determined as specified in Article 6.8.3 $\left(\mathrm{in}^{2}\right)$

$\mathrm{A}_{\mathrm{g}}=$ gross area of the tension flange $\left(\mathrm{in}^{2}\right)$

$\mathrm{f}_{\mathrm{t}}=$ stress on the gross area of the tension flange due to the factored loads calculated without consideration of flange lateral bending (ksi)

$\mathrm{F}_{\mathrm{u}}=$ specified minimum tensile strength of the tension flange determines as specified in Table 6.4.1-1 (ksi) 
Sections in straight bridges in positive flexure must meet the following criteria to be considered compact:

- The specified minimum yield strengths of flanges and web do not exceed $70.0 \mathrm{ksi}$

- The web satisfies the requirement of Article 6.11.2.1.2

- The section under consideration is part of a bridge that satisfies Article 6.11.2.3

- The box flange is fully effective as specified in Article 6.11.1.1

- The section satisfies the requirements of Article 6.11.7.1

- The section satisfies the web slenderness limit of Equation 2-28:

$$
\frac{2 D_{c p}}{t_{w}} \leq 3.76 \sqrt{\frac{E}{F_{y c}}}
$$

Where: $\mathrm{D}_{\mathrm{cp}}=$ depth of the web in compression at the plastic moment determined as specified in Article D6.3.2 (in)

$$
\mathrm{E}=\text { modulus of elasticity of steel (ksi) }
$$

If the section does not meet these criteria, it will be considered noncompact and must satisfy the requirements of Article 6.11.7.2. Both compact and noncompact sections must satisfy ductile requirements of Article 6.10.7-3 and Equation 2-29:

$$
D_{p} \leq 0.42 D_{t}
$$

Where: $D_{p}=$ distance from the top of the concrete deck to the neutral axis of the composite section (in)

$$
\mathrm{D}_{\mathrm{t}}=\text { total depth of the composite section (in) }
$$




\subsection{Flexural Capacity of Composite Sections, Positive Flexure}

For compact composite sections, Equation 2-30 shall be satisfied at the strength limit state. Lateral bending need not be considered in the compression flanges of the tub sections because the flanges are continuously supported by the concrete deck.

$$
M_{u} \leq \phi_{f} M_{n}
$$

Where: $\phi_{\mathrm{f}}=$ resistance factor for flexure as specified in Article 6.5.4.2

$$
\begin{aligned}
\mathrm{M}_{\mathrm{n}}= & \text { nominal flexural resistance of the section determined as specified in } \\
& \text { Article 6.11.7.1.2 (kip-in) } \\
\mathrm{M}_{\mathrm{u}}= & \text { bending moment about the major axis of the cross-section due to the } \\
& \text { factored loads at the section under consideration (kip-in) }
\end{aligned}
$$

Nominal flexural resistance of a section shall be calculated using the applicable equation:

\section{Equation 2-31 or Equation 2-32.}

$$
\begin{aligned}
& \text { If } D_{p} \leq 0.1 D_{t}: \\
& \qquad M_{n}=M_{p}
\end{aligned}
$$

Equation 2-31

Otherwise:

$$
M_{n}=M_{p}\left(1.07-0.7 \frac{D_{p}}{D_{t}}\right)
$$

Where: $D_{p}=$ distance from the top of the concrete deck to the neutral axis of the composite section at the plastic moment (in)

$$
\mathrm{D}_{\mathrm{t}}=\text { total depth of the composite section (in) }
$$




$$
\mathrm{M}_{\mathrm{p}}=\text { plastic moment of the composite section as specified in Article D6.1 }
$$

It should be noted that Michaelson (2014) modelled several scenarios for the press-brakeformed tub girder and found that Equation 2-32 from AASHTO did not accurately depict the nominal flexural resistance of the girders and was significantly conservative. The study recommended a similar expression with constants that better predicted capacity presented as Equation 2-33:

$$
M_{n}= \begin{cases}M_{p} & D_{p} \leq 0.1 D_{t} \\ M_{p}\left(1.0229-0.229 \frac{D_{p}}{D_{t}}\right) & 0.1 D_{t}<D_{p} \leq 0.42 D_{t}\end{cases}
$$

In cases where a continuous span is employed, the nominal flexural resistance of the section shall satisfy Equation 2-34.

$$
M_{n} \leq 1.3 R_{h} M_{y}
$$

Where: $\mathrm{M}_{\mathrm{n}}=$ nominal flexural resistance calculated per Equation 2-31 and Equation 2-32 as applicable(kip-in)

$$
\begin{aligned}
& \mathrm{M}_{\mathrm{y}}=\text { yield moment as determined by Article D6.2 (kip-in) } \\
& \mathrm{R}_{\mathrm{h}}=\text { hybrid factor as determined by Article 6.10.1.10.1 }
\end{aligned}
$$

For noncompact composite sections, Equation 2-35 shall be satisfied for compression flanges at the strength limit state.

$$
f_{b u} \leq \phi_{f} F_{n c}
$$

Where: $\phi_{\mathrm{f}}=$ resistance factor for flexure as specified in Article 6.5.4.2 
$f_{b u}=$ longitudinal flange stress at the section under consideration calculated without consideration of flange lateral bending or longitudinal warping as applicable (ksi)

$F_{n c}=$ nominal flexural resistance of the compression flange determined as specified in Article 6.11.7.2.2 and Equation 2-36 (kip-in)

$F_{n c}=R_{b} R_{h} F_{y c}$ Equation 2-36

Where: $\mathrm{Rb}_{\mathrm{b}}=$ web load-shedding factor determined as specified in Article $6.10 .1 \cdot 10.2$

$\mathrm{R}_{\mathrm{h}}=$ hybrid factor determined as specified in Article 6.10.1.10.1

Equation 2-37 shall be satisfied for compression flanges at the strength limit state.

$$
f_{b u} \leq \phi_{f} F_{n t}
$$

Where: $F_{n t}=$ nominal flexural resistance of the tension flange determined as specified in Article 6.11.7.2.2 (kip-in)

$$
F_{n t}=R_{h} F_{y t} \Delta
$$

$$
\text { Where: } \begin{gathered}
\Delta=\sqrt{1-3\left(\frac{f_{v}}{F_{y f}}\right)^{2}} \\
f_{v}=\frac{T}{2 A_{o} t_{f}}
\end{gathered}
$$

The maximum longitudinal compressive stress in the concrete deck at the strength limit state, determined as specified in Article 6.10.1.1.1d, shall not exceed 0.6 $f^{\prime} c$. 


\subsection{Flexural Capacity of Non-composite Sections}

Compression flanges of box sections not made composite must satisfy Equation 2-41 at the strength limit state.

$$
f_{b u} \leq \phi_{f} F_{n c}
$$

Where: $\phi_{\mathrm{f}}=$ resistance factor for flexure as specified in Article 6.5.4.2

$$
\begin{aligned}
f_{b u}= & \text { longitudinal flange stress due to the factored loads at the section under } \\
& \text { consideration calculated without consideration of longitudinal } \\
& \text { warping }(\mathrm{ksi}) \\
\mathrm{F}_{\mathrm{nc}}= & \text { nominal flexural resistance of the flange as specified in Article } \\
& 6.11 .8 .2(\mathrm{ksi})
\end{aligned}
$$

Nominal flexural resistance is computed by the following equations when flange longitudinal stiffeners are not used:

$$
F_{n c}=F_{c b} \sqrt{1-\left(\frac{f_{v}}{\phi_{v} F_{c v}}\right)^{2}}
$$

Where: $F_{c b}=$ nominal axial compression buckling resistance of the flange under compression alone, calculated per Equation 2-43 through Equation 2-45 as applicable (ksi)

If $\lambda_{f} \leq \lambda_{p}$ then:

$$
F_{c b}=R_{b} R_{h} F_{y c} \Delta
$$

If $\lambda_{p}<\lambda_{f} \leq \lambda_{r}$ then: 


$$
F_{c b}=R_{b} R_{h} F_{y c}\left[\Delta-\left(\Delta-\frac{\Delta-0.3}{R_{h}}\right)\left(\frac{\lambda_{f}-\lambda_{p}}{\lambda_{r}-\lambda_{p}}\right)\right]
$$

If $\lambda_{f}>\lambda_{r}$ then:

$$
F_{c b}=\frac{0.9 E R_{b} k}{\lambda_{f}^{2}}
$$

Where: $\mathrm{F}_{\mathrm{cv}}=$ nominal shear buckling resistance of the flange under shear alone and is determined by Equation 2-46 through Equation 2-48 as applicable

If $\lambda_{f} \leq 1.12 \sqrt{\frac{E k_{s}}{F_{y c}}}$, then:

$$
F_{c v}=0.58 F_{y c}
$$

If $1.12 \sqrt{\frac{E k_{s}}{F_{y c}}}<\lambda_{f} \leq 1.40 \sqrt{\frac{E k_{s}}{F_{y c}}}$, then:

$$
F_{c v}=\frac{0.65 \sqrt{F_{y c} E k_{s}}}{\lambda_{f}}
$$

If $\lambda_{f}>1.40 \sqrt{\frac{E k_{s}}{F_{y c}}}$, then:

$$
F_{c v}=\frac{0.9 E k_{s}}{\lambda_{f}^{2}}
$$

Where: $\lambda_{\mathrm{f}}=$ slenderness ratio of compression flange per Equation 2-49

$$
\begin{aligned}
& \lambda_{f}=\frac{b_{f c}}{t_{f c}} \\
& \lambda_{p}=0.57 \sqrt{\frac{E k}{F_{y c} \Delta}}
\end{aligned}
$$

Equation 2-50 


$$
\begin{aligned}
& \lambda_{r}=0.95 \sqrt{\frac{E k}{F_{y r}}} \\
& \Delta=\sqrt{1-3\left(\frac{f_{v}}{F_{y t}}\right)^{2}}
\end{aligned}
$$

Equation 2-52

Where: $f_{v}=$ St. Venant torsional shear stress $n$ the flange due to the factored loads at the section under consideration per Equation 2-53 (ksi)

$$
f_{v}=\frac{T}{2 A_{o} t_{f}}
$$

Where: $\mathrm{F}_{\mathrm{yr}}=$ smaller of the compression-flange stress at the onset of nominal yielding, with consideration of residual stress effects, or the specified yield strength of the web determined per Equation 2-54 (ksi)

$$
f_{v}=(\Delta-0.3) F_{y c}
$$

Where: $\mathrm{k}=$ plate-buckling coefficient for uniform normal stress $=4.0$

$\mathrm{ks}_{\mathrm{s}}=$ plate-buckling coefficient for shear stress $=5.34$

$\phi_{\mathrm{f}}=$ resistance factor for flexure specified in Article 6.5.4.2

$\phi_{\mathrm{v}}=$ resistance factor for shear specified in Article 6.5.4.2

$\mathrm{b}_{\mathrm{fc}}=$ compression-flange width between webs (in)

$\mathrm{A}_{\mathrm{o}}=$ enclosed area within the box section $\left(\mathrm{in}^{2}\right)$

$\mathrm{R}_{\mathrm{b}}=$ web load-shedding factor determined as specified in Article 6.10.1.10.2

$\mathrm{R}_{\mathrm{h}}=$ hybrid factor determined as specified in Article 6.10.1.10.1 


$$
\mathrm{T}=\text { internal torque due to the factored loads (kip-in) }
$$

The nominal flexural resistance of a longitudinally stiffened compression flange shall be calculated in the same manner as the compression flange when flange longitudinal stiffeners are not used with the following substitutions:

- w shall be substituted for $b_{\mathrm{fc}}$

- the plate-buckling coefficient for uniform normal stress, $\mathrm{k}$, shall be taken as:

$$
\begin{gathered}
\circ \text { If } \mathrm{n}=1 \text {, then: } \\
k=\left(\frac{8 I_{s}}{w t^{3}{ }_{f c}}\right)^{\frac{1}{3}}
\end{gathered}
$$

$$
\text { - If } \mathrm{n}=2 \text {, then: }
$$

$$
\begin{gathered}
k=\left(\frac{0.894 I_{s}}{w t^{3} f c}\right)^{\frac{1}{3}} \\
1.0 \leq k \leq 4.0
\end{gathered}
$$

- the plate-buckling coefficient for shear stress, $\mathrm{k}_{\mathrm{s}}$, shall be taken per Equation 2-57:

$$
k_{s}=\frac{5.34+2.84\left(\frac{I_{S}}{w t_{f c}^{3}}\right)^{\frac{1}{3}}}{(n+1)^{2}} \leq 5.34
$$

Where: $I_{s}=$ moment of inertia of a single longitudinal flange stiffener about an axis parallel to the flange and taken at the base of the stiffener $\left(\mathrm{in}^{4}\right)$ $\mathrm{n}=$ number of equally spaced longitudinal flange stiffeners 
$\mathrm{w}=$ larger of the width of the flange between longitudinal flange stiffeners or the distance from a web to the nearest longitudinal flange stiffener (in)

Compression-flange longitudinal stiffeners shall satisfy the requirements specified in Article 6.11.11.2. Nominal flexural resistance of tension flanges of tub sections shall be determined in Equation 2-58.

$$
F_{n t}=R_{h} F_{y t}
$$

Equation 2-58

Where: $\mathrm{R}_{\mathrm{h}}=$ hybrid factor determined as specified in Article 6.10.1.10.1

\subsection{Shear Capacity}

Shear resistance shall be defined by the provisions of Article 6.10 .9 for single webs. In cases where the web is inclined, D in Article 6.10.9 shall be taken as the depth of the web plate measured along the inclination. Straight and curved web panels shall satisfy Equation 2-59 at the strength limit state.

$$
V_{u} \leq \phi_{v} V_{n}
$$

Where: $\phi_{\mathrm{v}}=$ resistance factor for shear as specified in Article 6.5.4.2

$$
\begin{gathered}
\mathrm{V}_{\mathrm{u}}=\text { factored shear in the web at the section under consideration (kip) } \\
\mathrm{V}_{\mathrm{n}}=\text { nominal shear resistance determined as specified in Article 6.10.9.2 } \\
\text { and 6.10.9.3 for unstiffened and stiffened webs, respectively (kip) }
\end{gathered}
$$

Nominal shear resistance is computed by the following equations when webs are unstiffened: 


$$
\begin{aligned}
& V_{n}=V_{c r}=C V_{p} \\
& V_{p}=0.58 F_{y w} D t_{w}
\end{aligned}
$$

Where: $\mathrm{C}=$ ratio of the shear-buckling resistance to the shear yield strength determined by Equations 2-65, 2-66, and 2-67 with, $\mathrm{k}=5.0$

$$
\begin{aligned}
& V_{c r}=\text { shear-yielding or shear-buckling resistance (kip) } \\
& V_{n}=\text { nominal shear resistance (kip) } \\
& V_{p}=\text { plastic shear force (kip) }
\end{aligned}
$$

The nominal shear resistance of stiffened interior web panels is determined by Equations 2-63 and 2-64. The section proportions must satisfy Equation 2-61 and must meet the provisions of Article 6.10.9.1.

$$
\begin{aligned}
& \frac{2 D t_{w}}{\left(b_{f c} t_{f c}+b_{f t} t_{f t}\right)} \leq 2.5 \\
& V_{n}=V_{p}\left[C+\frac{0.87(1-C)}{\sqrt{1+\left(\frac{d_{o}}{D}\right)^{2}}}\right] \\
& V_{p}=0.58 F_{y w} D t_{w}
\end{aligned}
$$

Where: $d_{0}=$ transverse stiffener spacing (in)

$$
\begin{aligned}
& V_{n}=\text { nominal shear resistance of the web panel (kip) } \\
& V_{p}=\text { plastic shear force (kip) } \\
& C=\text { ratio of the shear-buckling resistance to the shear yield strength }
\end{aligned}
$$


The ratio, $\mathrm{C}$, shall be determined as specified by Equations 2-65 through 2-67:

$$
\begin{aligned}
& \text { If } \frac{D}{t_{w}} \leq 1.12 \sqrt{\frac{E k}{F_{y w}}} \text {, then: } \\
& C=1.0 \\
& \text { If } 1.12 \sqrt{\frac{E k}{F_{y w}}}<\frac{D}{t_{w}} \leq 1.40 \sqrt{\frac{E k}{F_{y w}}}, \text { then: } \\
& C=\frac{1.12}{\frac{D}{t_{w}}} \sqrt{\frac{E k}{F_{y w}}} \\
& \text { If } \frac{D}{t_{w}}>1.40 \sqrt{\frac{E k}{F_{y w}}}, \text { then: } \\
& C=\frac{1.57}{\left(\frac{D}{t_{w}}\right)}\left(\frac{E k}{F_{y w}}\right)
\end{aligned}
$$

Where: $\mathrm{k}=$ shear-buckling coefficient

$$
k=5+\frac{5}{\left(\frac{d_{o}}{D}\right)^{2}}
$$

If the section proportions do not satisfy Equation 2-62, Equation 2-69 shall be used to determine the nominal shear resistance.

$$
V_{n}=V_{p}\left[C+\frac{0.87(1-C)}{\left(\sqrt{1+\left(\frac{d_{o}}{D}\right)^{2}}+\frac{d_{o}}{D}\right)}\right]
$$

The nominal shear resistance of stiffened end panels shall be determined as specified in Equations 2-70 and 2-71. 


$$
\begin{aligned}
& V_{n}=V_{c r}=C V_{p} \\
& V_{p}=0.58 F_{y w} D t_{w}
\end{aligned}
$$

Where: $\mathrm{C}=$ ratio of the shear buckling resistance to the shear yield strength determined by Equations 2-62 through 2-64 as applicable.

$$
\begin{aligned}
& \mathrm{V}_{\mathrm{cr}}=\text { shear-yielding or shear-buckling resistance (kip) } \\
& \mathrm{V}_{\mathrm{p}}=\text { plastic shear force (kip) }
\end{aligned}
$$

Transverse stiffener spacing for stiffened end panels, with or without longitudinal stiffeners, shall not exceed 1.5 times the section depth.

\subsubsection{AASHTO Equation References}

Table 2.3 includes a summary of the equations referenced and included in this chapter from the ASHTO LRFD Specifications with the appropriate AASHTO equation references.

Table 2.3: Chapter 2 Equation Legend (AASHTO, 2017)

Chapter 2 Equations

\begin{tabular}{|c|c|}
\multicolumn{1}{c|}{ Chapter 2 Equations } & AASHTO 8 ${ }^{\text {th }}$ Edition \\
\hline \hline Equation 2-1 & Table 4.6.2.2.2b-1 \\
\hline Equation 2-2 & Equation 6.11.2.1.2-1 \\
\hline Equation 2-3 & Equation 6.11.2.1.3-1 \\
\hline Equation 2-4 & Equation 6.11.2.2-1 \\
\hline Equation 2-5 & Equation 6.11.2.2-2 \\
\hline Equation 2-6 & Equation 6.11.2.2-3 \\
\hline Equation 2-7 & Equation 6.10.3.2.1-1 \\
\hline Equation 2-8 & Equation 6.10.3.2.1-2 \\
\hline Equation 2-9 & Equation 6.10.3.2.1-3 \\
\hline Equation 2-10 & Equation 6.10.3.2.2-1 \\
\hline Equation 2-11 & Equation 6.10.3.2.3-1 \\
\hline Equation 2-12 & Equation 6.11.3.2-1 \\
\hline
\end{tabular}


Table 2.3 (cont): Chapter 2 Equation Legend (AASHTO, 2017)

\begin{tabular}{|c|c|}
\hline Chapter 2 Equations & AASHTO $8^{\text {th }}$ Edition \\
\hline Equation 2-13 & Equation $6.11 .3 .2-2$ \\
\hline Equation 2-14 & Equation 6.11.3.2-3 \\
\hline Equation 2-15 & Equation 6.11.3.2-4 \\
\hline Equation 2-16 & Equation 6.11.3.2-5 \\
\hline Equation 2-17 & Equation $6.10 .3 .3-1$ \\
\hline Equation 2-18 & Equation 6.11.9-1 \\
\hline Equation 2-19 & Equation $6.10 .4 .2 .2-1$ \\
\hline Equation 2-20 & Equation 6.10.4.2.2-2 \\
\hline Equation 2-21 & Equation 6.10.4.2.2-3 \\
\hline Equation 2-22 & Equation 6.10.4.2.2-4 \\
\hline Equation 2-23 & Equation 6.6.1.2.2-1 \\
\hline Equation 2-24 & Equation 6.6.1.2.5-1 \\
\hline Equation 2-25 & Equation 6.6.1.2.5-2 \\
\hline Equation 2-26 & Equation 6.6.1.2.5-3 \\
\hline Equation 2-27 & Equation $6.10 .1 .8-1$ \\
\hline Equation 2-28 & Equation 6.11.6.2.2-1 \\
\hline Equation 2-29 & Equation 6.10.7.3-1 \\
\hline Equation 2-30 & Equation 6.11.7.1.1-1 \\
\hline Equation 2-31 & Equation 6.10.7.1.2-1 \\
\hline Equation 2-32 & Equation $6.10 .7 \cdot 1.2-2$ \\
\hline Equation 2-34 & Equation 6.10.7.1.2-3 \\
\hline Equation 2-35 & Equation 6.11.7.2.1-1 \\
\hline Equation 2-36 & Equation 6.11.7.2.2-1 \\
\hline Equation 2-37 & Equation 6.11.7.2.1-2 \\
\hline Equation 2-38 & Equation 6.11.7.2.2-5 \\
\hline Equation 2-39 & Equation 6.11.7.2.2-6 \\
\hline Equation 2-40 & Equation 6.11.7.2.2-7 \\
\hline Equation 2-41 & Equation 6.11.8.1.1-1 \\
\hline Equation 2-42 & Equation 6.11.8.2.2-1 \\
\hline
\end{tabular}


Table 2.3 (cont.): Chapter 2 Equation Legend (AASHTO 2017)

Chapter 2 Equations

AASHTO $8^{\text {th }}$ Edition

\begin{tabular}{|c|c|}
\hline Equation $2-43$ & Equation 6.11.8.2.2-2 \\
\hline Equation 2-44 & Equation 6.11.8.2.2-3 \\
\hline Equation $2-45$ & Equation 6.11.8.2.2-4 \\
\hline Equation 2-46 & Equation 6.11.8.2.2-5 \\
\hline Equation 2-47 & Equation 6.11.8.2.2-6 \\
\hline Equation $2-48$ & Equation 6.11.8.2.2-7 \\
\hline Equation 2-49 & Equation 6.11.8.2.2-8 \\
\hline Equation $2-50$ & Equation 6.11.8.2.2-9 \\
\hline Equation 2-51 & Equation 6.11.8.2.2-10 \\
\hline Equation 2-52 & Equation 6.11.8.2.2-11 \\
\hline Equation 2-53 & Equation 6.11.8.2.2-12 \\
\hline Equation 2-54 & Equation 6.11.8.2.2-13 \\
\hline Equation 2-55 & Equation 6.11.8.2.3-1 \\
\hline Equation 2-56 & Equation 6.11.8.2.3-2 \\
\hline Equation 2-57 & Equation 6.11.8.2.3-3 \\
\hline Equation 2-58 & Equation 6.10.8.3-1 \\
\hline Equation 2-59 & Equation 6.10.9.1-1 \\
\hline Equation 2-60 & Equation 6.10.9.2-1 \\
\hline Equation 2-61 & Equation 6.10.9.2-2 \\
\hline Equation 2-62 & Equation 6.10.9.3.2-1 \\
\hline Equation 2-63 & Equation 6.10.9.3.2-2 \\
\hline Equation 2-64 & Equation 6.10.9.3.2-3 \\
\hline Equation 2-65 & Equation 6.10.9.3.2-4 \\
\hline Equation 2-66 & Equation 6.10.9.3.2-5 \\
\hline Equation 2-67 & Equation 6.10.9.3.2-6 \\
\hline Equation 2-68 & Equation 6.10.9.3.2-7 \\
\hline Equation 2-69 & Equation 6.10.9.3.2-8 \\
\hline Equation 2-70 & Equation 6.10.9.3.3-1 \\
\hline Equation 2-71 & Equation 6.10.9.3.3-2 \\
\hline
\end{tabular}




\section{CHAPTER 3: Design AND CONSTRUCTION OF THE FOURTEen MILE}

\section{BRIDGE}

\subsection{INTRODUCTION}

This chapter details the design and construction of the Fourteen Mile Bridge in Lincoln County, West Virginia. This was the first installation of a bridge in West Virginia utilizing pressbrake-formed tub girders. This bridge site has unique characteristics, such as significant skew and superelevation. The full bridge plans are located in Appendix C of this Thesis.

\subsection{SUMMARY OF DESIGN AND CONSTRUCTION}

The Fourteen Mile Bridge is a 58'-0" long, single span press-brake-formed tub girder bridge near the community of Ranger, West Virginia. The Bridge carries traffic across Fourteenmile Creek on State Route Number 37. The bridge has a skew angle of $10^{\circ}$ and a superelevation of $8 \%$. Construction was started in the spring of 2019 and completed on November

6, 2019 by Orders Construction Company. An aerial image of the bridge under construction is shown in Figure 3.1. 


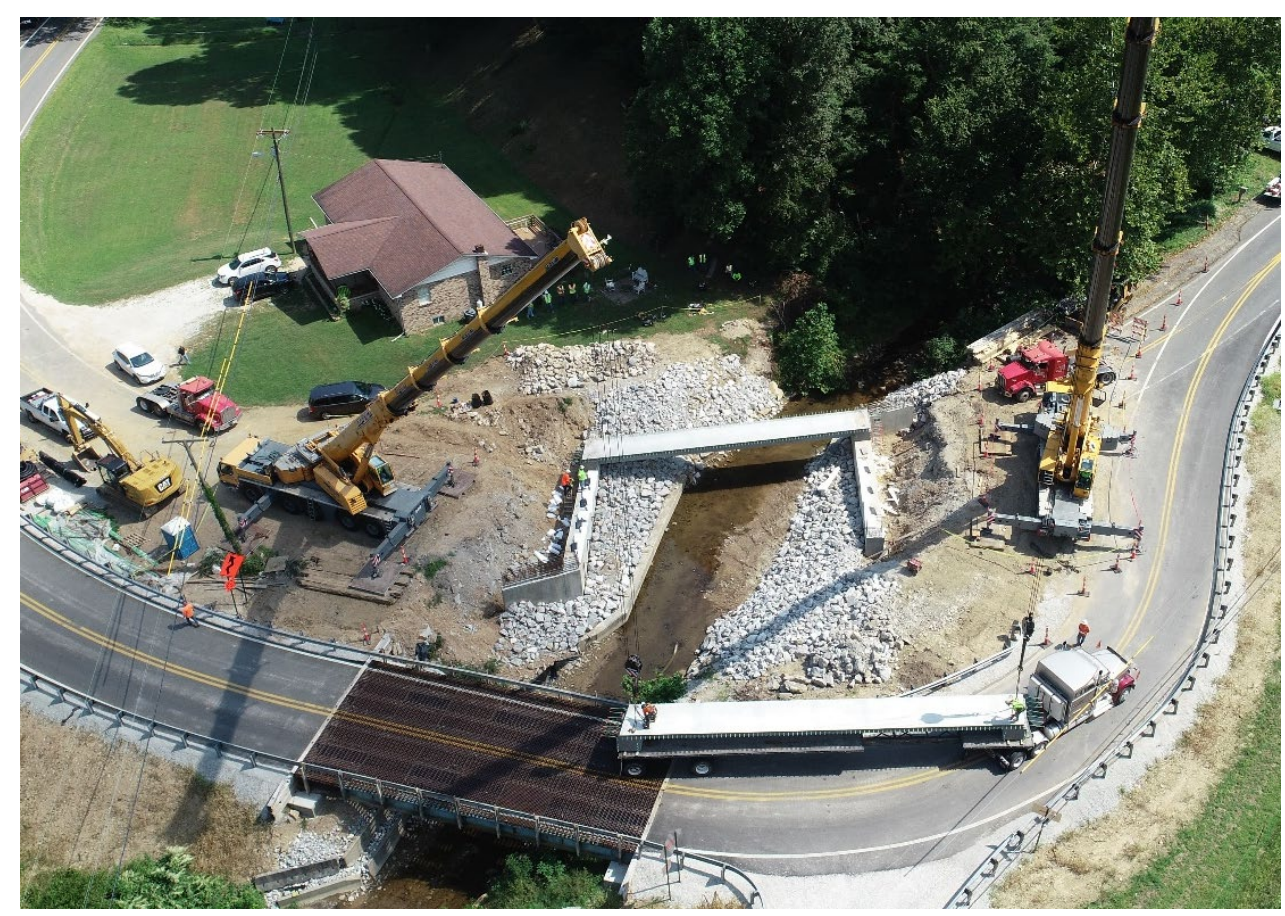

Figure 3.1: Aerial View of Bridge Under Construction

\subsubsection{Fabrication of Modular Components}

The press-brake-formed tub girders used in construction of the bridge were assembled in five fully composite modular components each brought to the site by truck and lifted into place by crane. This offsite manufacture enabled each step of the fabrication to be closely monitored and for progress to continue before the field would typically allow certain steps to be undertaken.

The five press-brake-formed tub girders used began as 96 " wide by $1 / 2$ " thick plate of AASHTO M270 steel shaped using a large capacity press-brake. Once formed, additional details such as shear studs, end bearing diaphragms, and mounting angles for the internal formwork were welded onto the steel tub. The entire assembly was hot-dipped galvanized for corrosion resistance. A photo of the galvanized press-brake-formed tub girder is seen in Figure 3.2. 


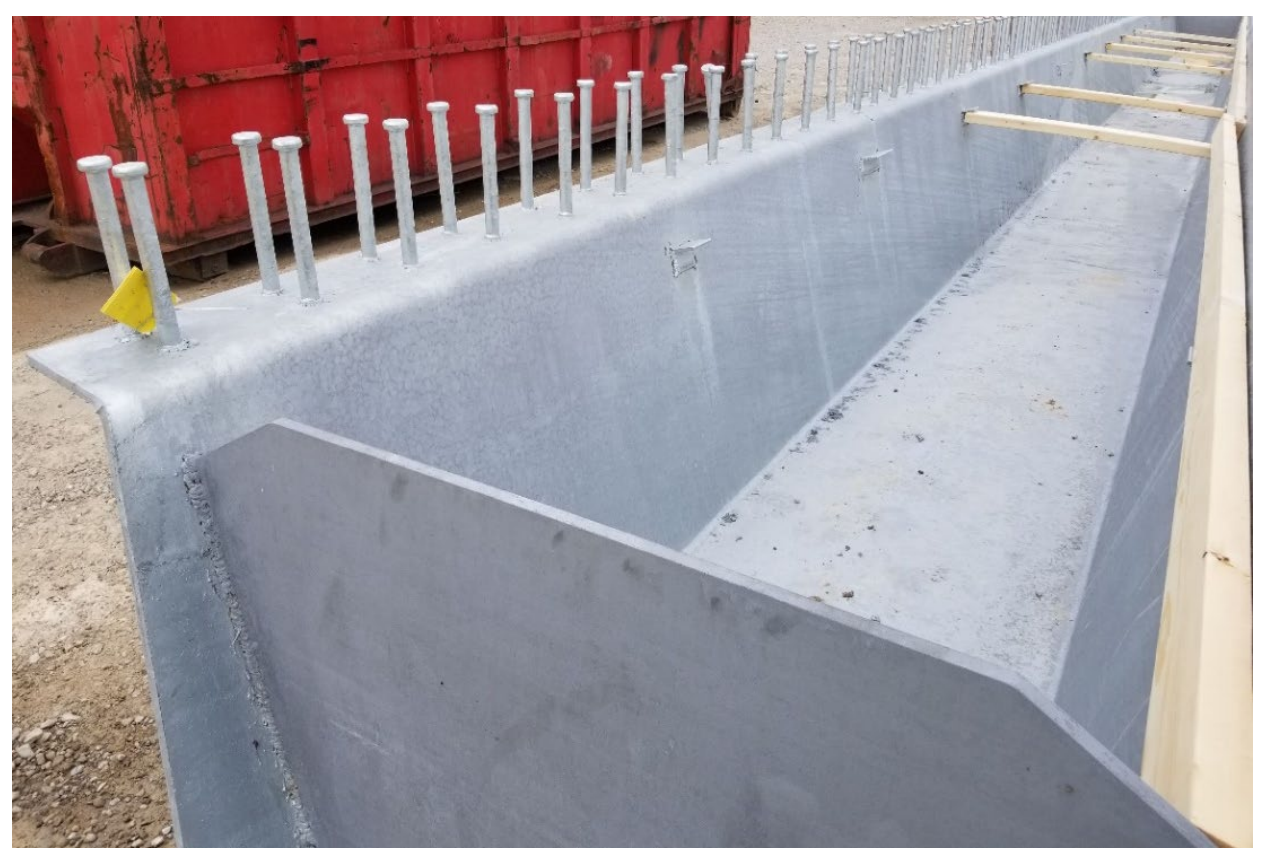

Figure 3.2: Galvanized Tub Girder, Prior to Formwork Construction

Once the press-brake-formed tub girders were galvanized, the modules were shipped to Carr Concrete in Waverly, West Virginia where the formwork could be assembled and a concrete deck could be cast. The prescaster used wooden studs and plywood to create the internal sacrificial formwork. Figure 3.3 shows a press-brake-formed tub girder module with the internal formwork. 


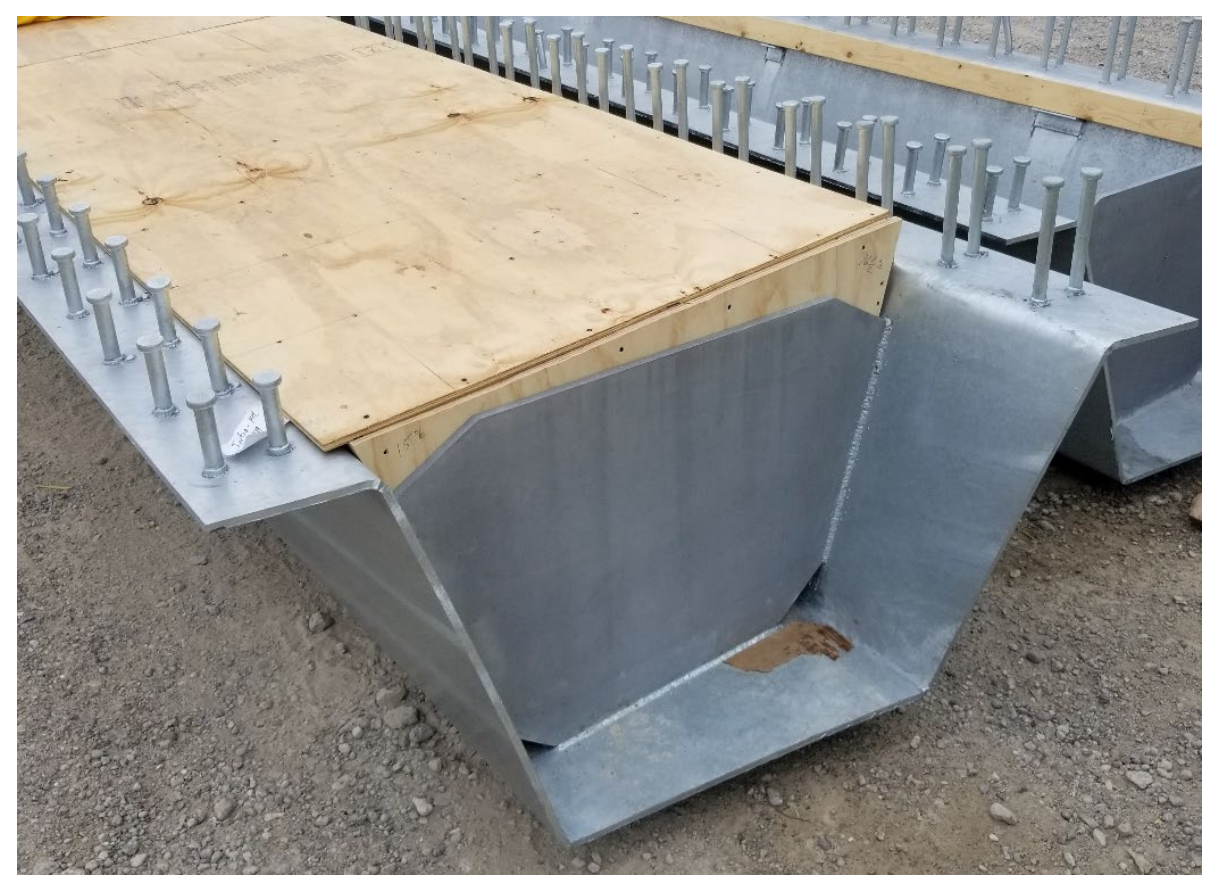

Figure 3.3: Tub Girder with Completed Internal Formwork

While internal formwork was being fabricated, reusable external formwork was being constructed. The external formwork used a combination of steel formwork panels, wooden studs, and plywood. Upon completion of the external formwork, each press-brake-formed tub girder was placed into the forms (Figure 3.4) and the mats of rebar were added (Figure 3.5). A retardant was placed on the edges of the shear key detail on the external formwork where the UHPC joints would be. This retardant allowed the concrete paste at the edge to be removed by a pressure washer, leaving exposed aggregate to which the UHPC could properly bond. 


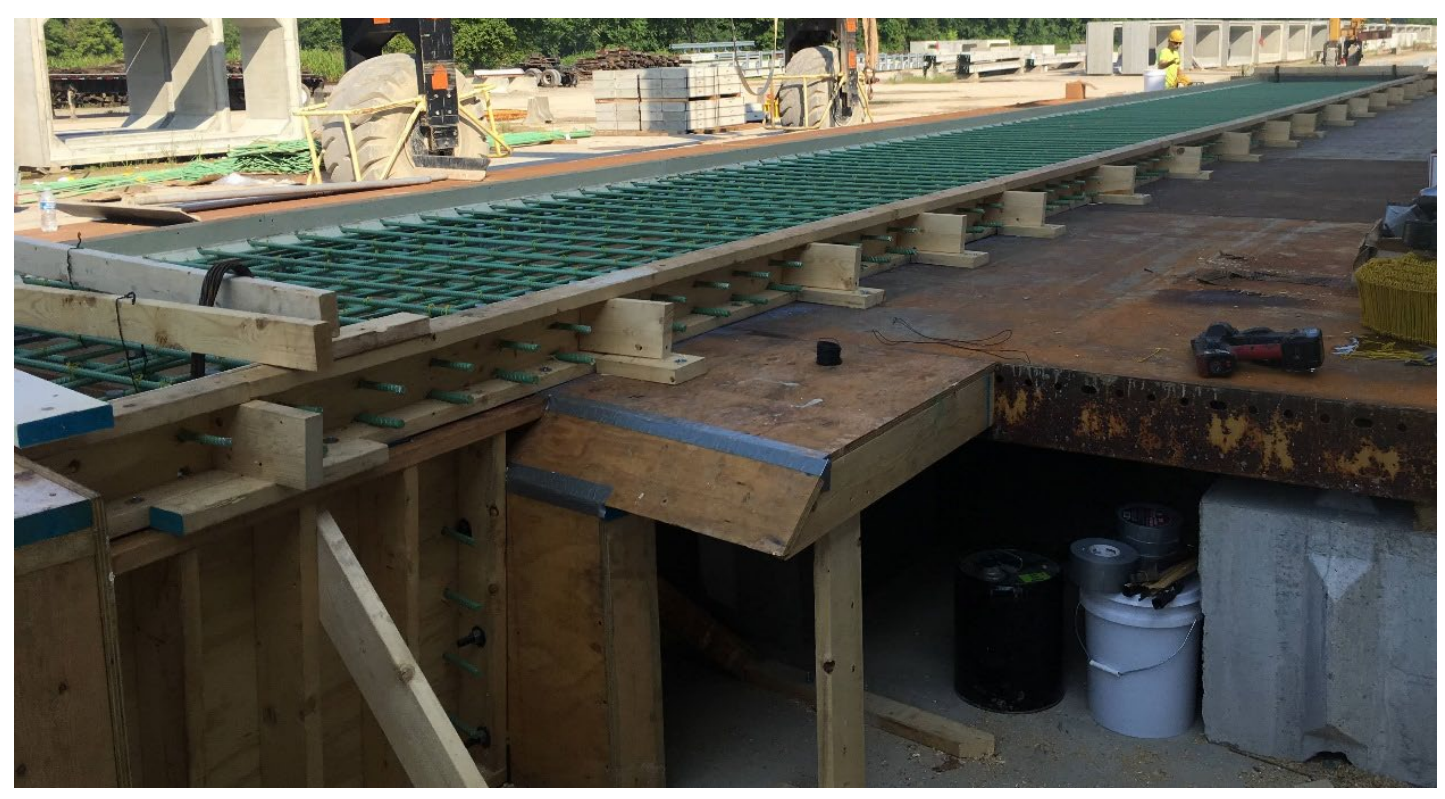

Figure 3.4: Isometric View of Reusable External Formwork

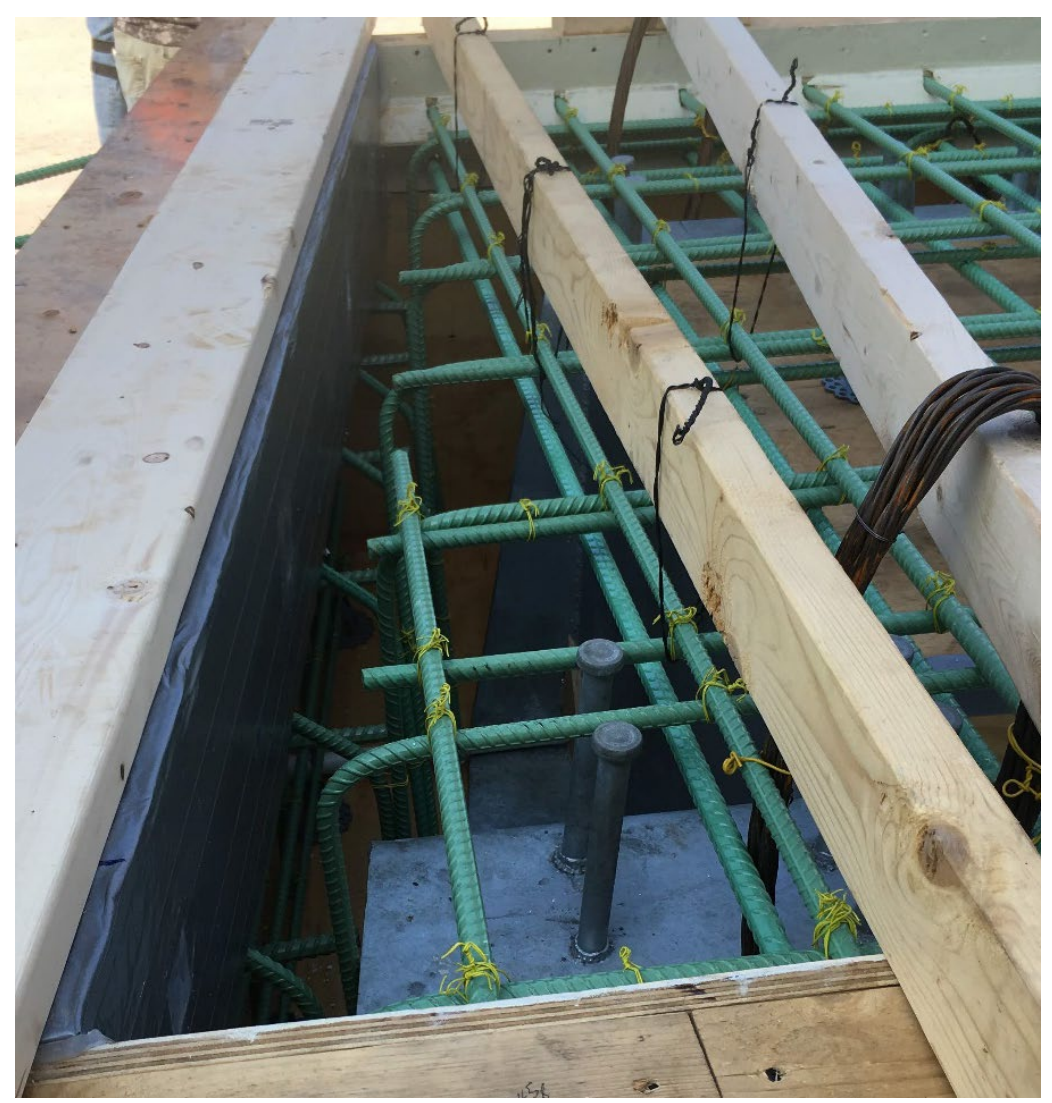

Figure 3.5: Close View of Rebar Placement at Semi-Integral Abutment End 
Following the setting of the rebar, placement of the concrete began. The crew used two concrete buckets, so any downtime from waiting for more material was minimized, and the deck could be cast continuously. Once pouring was completed, the deck was finished, and a plastic sheet covering was applied, so the deck could cure. Figure 3.6 and Figure 3.7 show the placement of the concrete and finishing of the deck, respectively.

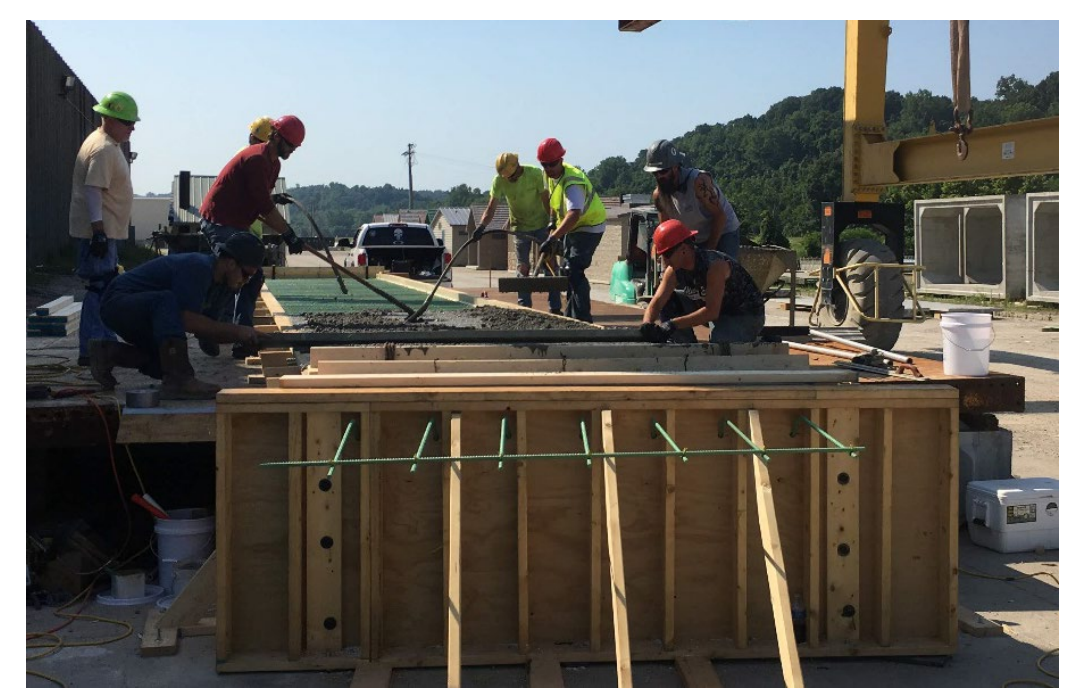

Figure 3.6: Placement of Fresh Concrete

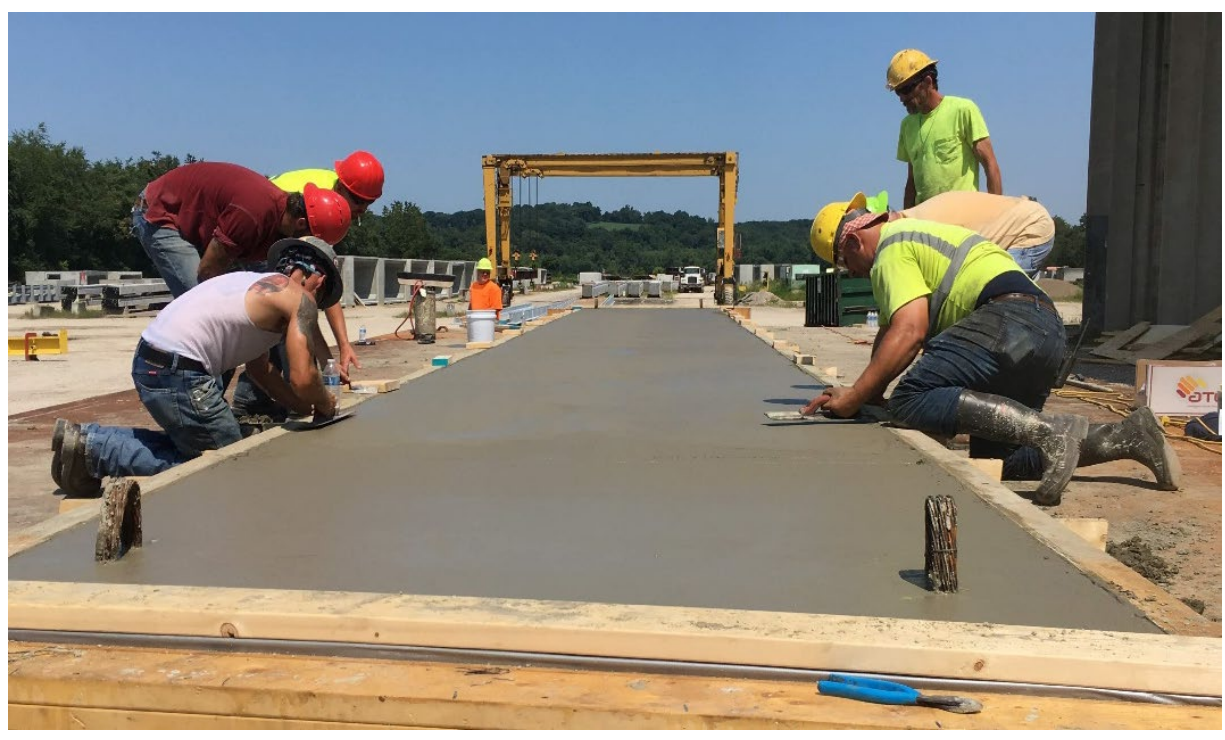

Figure 3.7: Finished Concrete Deck 
After the concrete had set, the external formwork was removed, and the next press-brakeformed tub girder was placed into the formwork. After the first two modules had been cast, a test fit was performed to ensure compatibility of the composite modules in the field. Figure 3.8 shows the test fit in the fabrication yard.

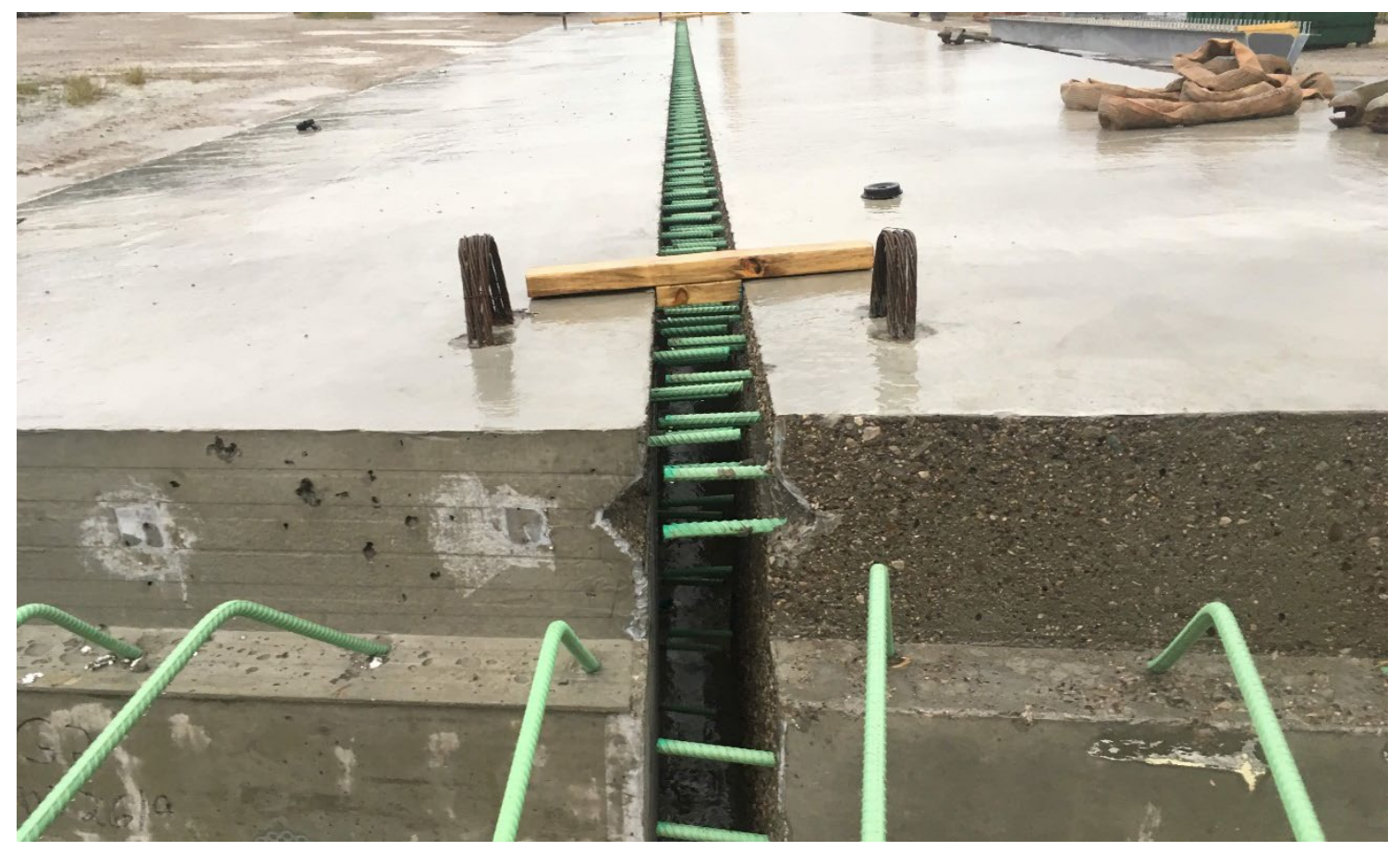

Figure 3.8: Test Fit of Two Precast Modules at Fabrication Yard

\subsubsection{Installation of Modular Components}

Once all five composite modules had been completed, they were transported by truck to the bridge site and lifted into place by crane. The UHPC closure pours were then performed, and the deck was diamond ground for the appropriate finish. In order to reduce traffic congestion during placement and the amount of time necessary to rent the cranes, each successive truck was 
staged. This allowed the next modular unit to be delivered and set in minimal time. A typical composite module loaded on a staged truck is shown in Figure 3.9.

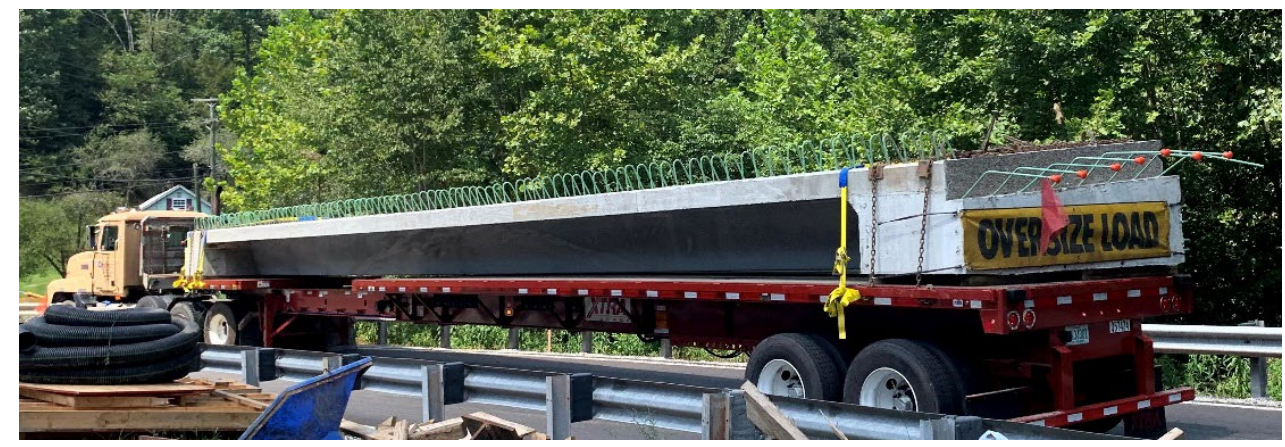

Figure 3.9: Composite Module Delivered to Site

Two cranes operated in tandem to lift each composite module from the trailer to the abutment seats. Workers on the ground verified measurements for the first composite module since this placement defined further composite module positions. Figure 3.10 shows the placement of the first composite module and Figure 3.11 shows the placement of the second composite module and the appropriate fit of the two.

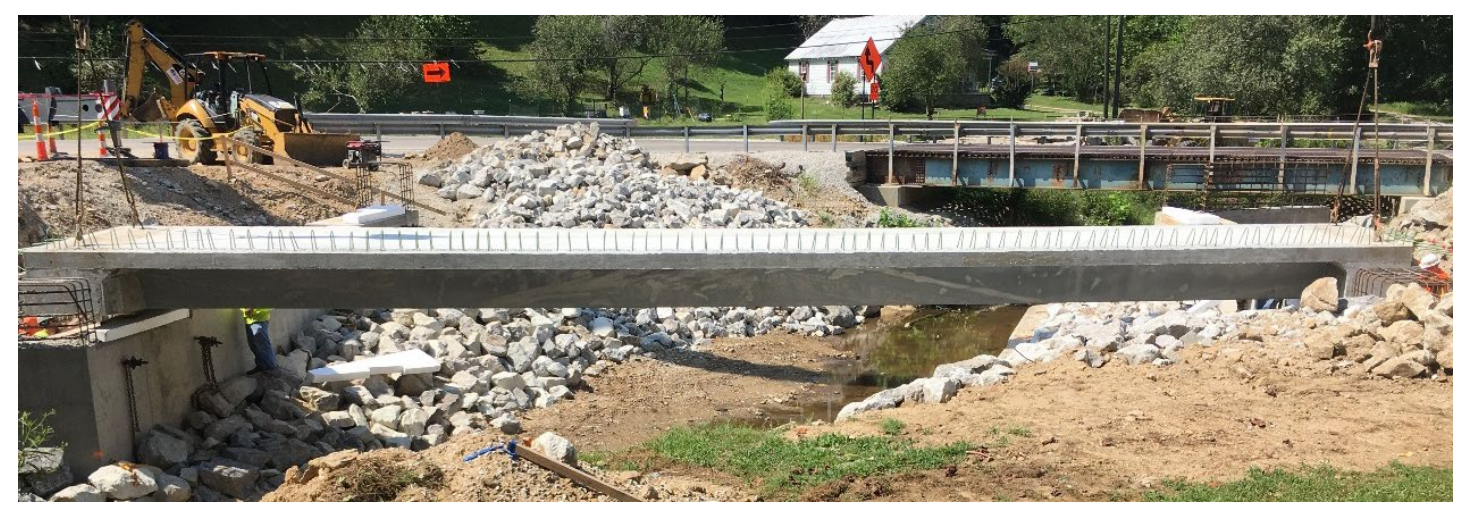

Figure 3.10: Placement of First Composite Module On-Site 


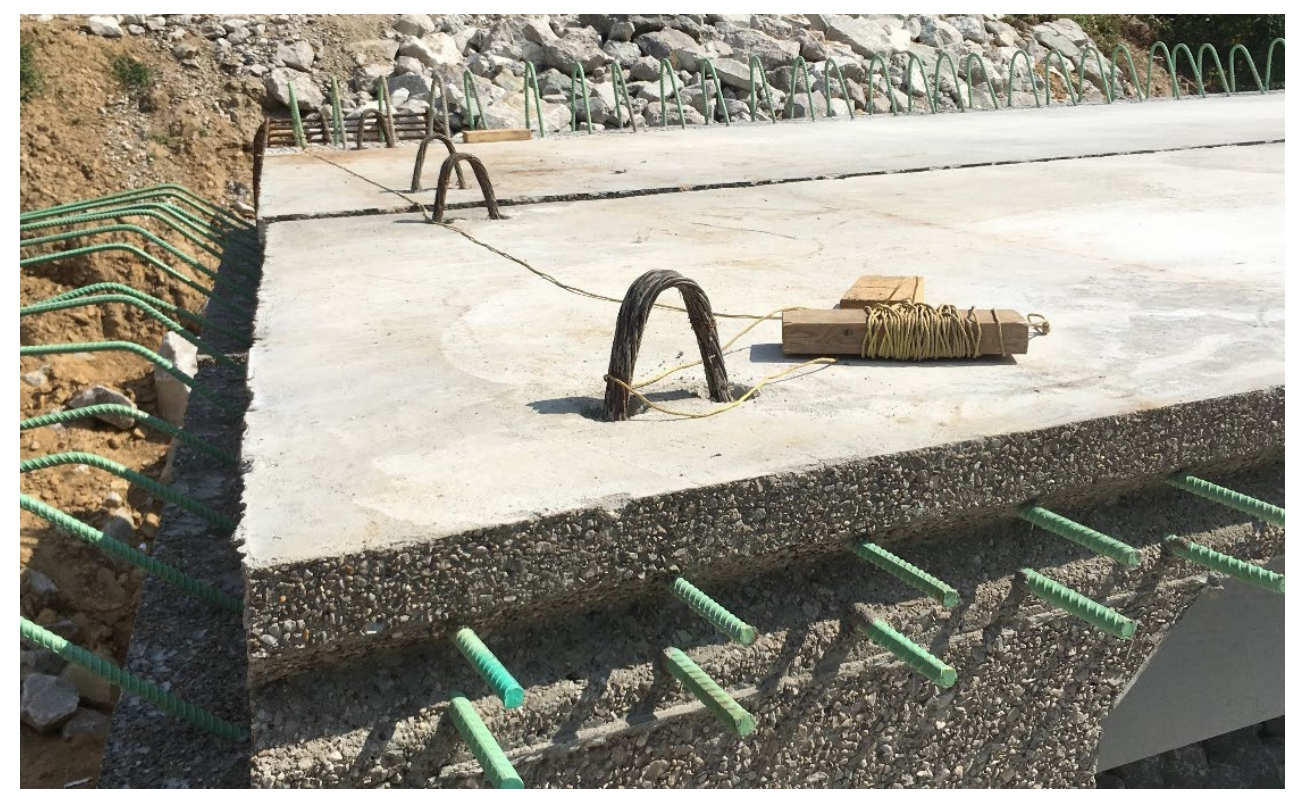

Figure 3.11: Verification of Fit of Adjacent Modules on Site

After all composite modules were placed, formwork was erected around the joints for the UHPC closure pours. The UHPC was mixed onsite with a pan mixer, then concrete buggies moved the concrete from the mixer to the bridge to place along the joints. The pouring of the UHPC is shown in Figure 3.12. 


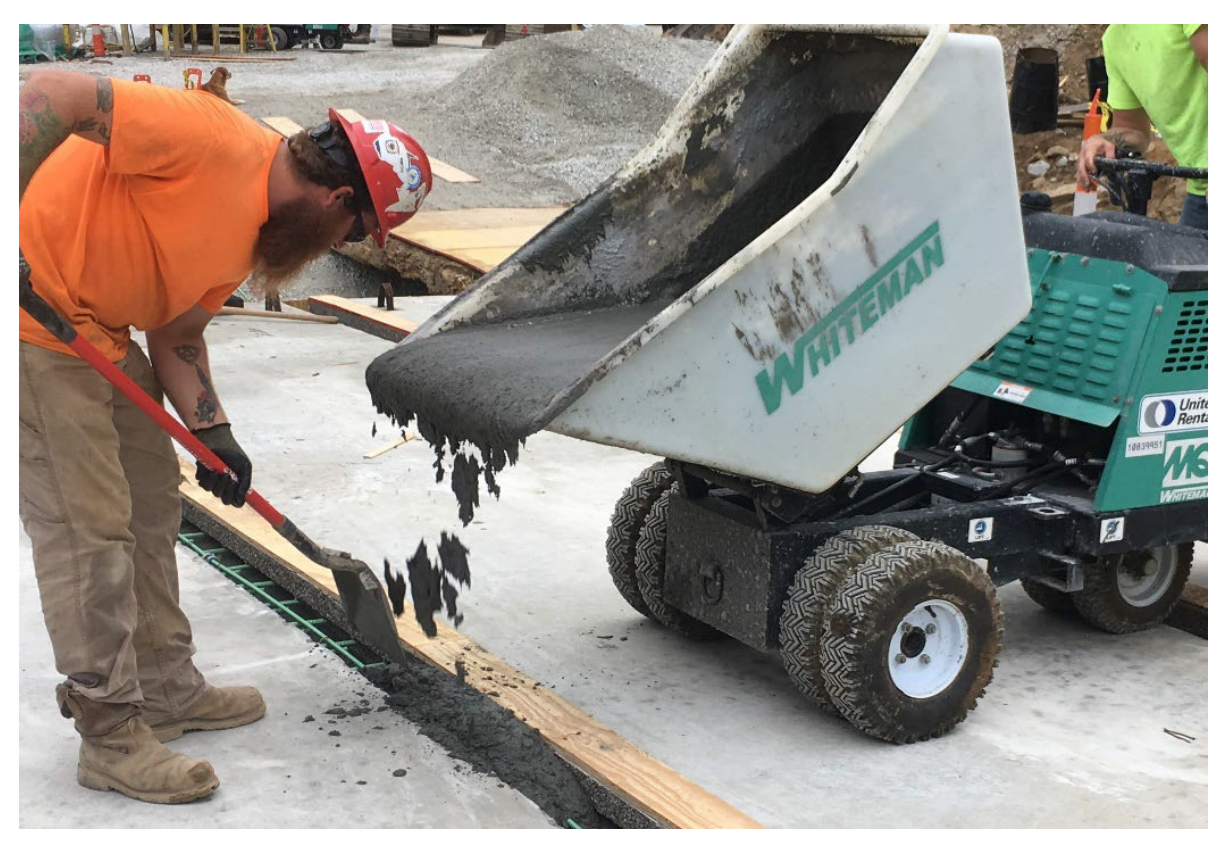

Figure 3.12: Pouring of UHPC Along Longitudinal Joint

After the UHPC set, the forms were removed, and a diamond grinder was used to adjust the deck profile as desired (Figure 3.13). This enabled a smooth transition from the cast-in-place concrete approach slab to the precast concrete deck modules.

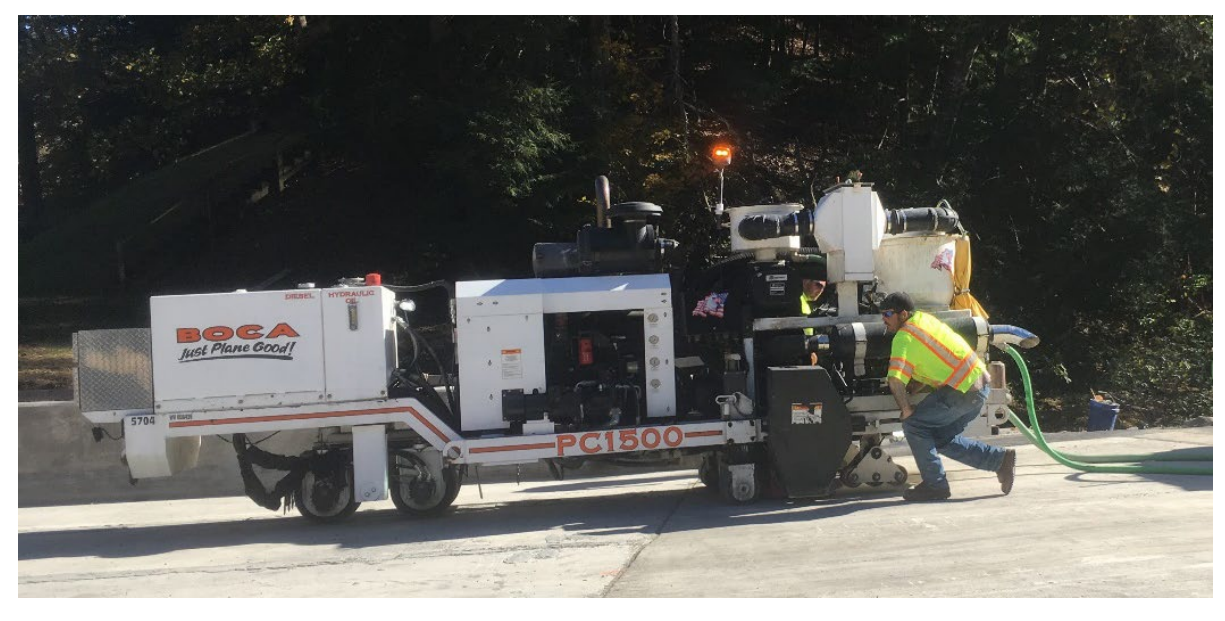

Figure 3.13: Diamond Grinder Used to Finish Deck On-Site 


\subsubsection{Accelerated Bridge Construction Strategies}

Several accelerated bridge construction $(\mathrm{ABC})$ strategies were employed in this bridge replacement project to minimize project duration and improve the work product of the finished structure. Instead of a traditional cast-in-place deck for the bridge superstructure, the Fourteen Mile Bridge used five composite modules manufactured individually off site. By having the deck precast in a controlled shop environment, the contractor was able to closely monitor the timing of the application of the fresh concrete. The minimal difference between the pouring of each bucket of concrete ensured that no cold joints formed in the deck structure. The controlled shop environment was also beneficial for the curing process to allow the concrete to gain maximum strength. Once the composite modules were complete, they were transported by truck to the bridge site and the modules were placed directly from the trucks to the abutments. The removal of a staging yard for construction reduced the amount of time spent to perform material handling and the necessary footprint of the construction site. The choice of UHPC was advantageous for the closure pours due to the high compressive strength and the short amount of time required to develop full strength of UHPC. 


\section{CHAPTER 4: RESEARCH METHODS}

\subsection{INTRODUCTION}

This chapter serves to provide an overview of the research methodology employed during the field evaluation of the Fourteen Mile Bridge. This includes descriptions of the field-testing equipment and finite element modeling, along with the data reduction approaches.

\subsection{EXPERIMENTAL TESTING EQUIPMENT}

This section details the pieces of field equipment used to assess the performance of the Fourteen Mile Bridge during the live load field test. Instrumentation and software were developed by Bridge Diagnostics, Inc. (BDI).

\subsubsection{BDI Strain Transducers}

BDI strain transducers (Figure 4.1) were chosen for use as the data sensor to measure strain during the live load field test. These gages are an appropriate choice for outdoor field tests because the gages are reusable and resistant to adverse weather conditions. Each gage is fully sealed to the elements, has been rated IP67 for dust and moisture resistance, and has an operating temperature range of $-58^{\circ} \mathrm{F}$ to $+185^{\circ} \mathrm{F}$. Inside of each gage is a full Wheatstone bridge with four active $350 \Omega$ foil gages. The applicable range for strain measurements of the gage is $\pm 2000 \mu \varepsilon$. Each gage is individually calibrated to meet National Institute of Standards and Technology specifications and has a variation in readings of less than $\pm 1 \%$. The BDI strain transducers attach to the surface of the steel member being investigating with reusable tabs that included a 1/4"-20 threaded mounting shaft. For this live load field test, Loctite HY 4070 Structural Repair Hybrid Adhesive was used 
to affix the transducers to the girder. More details on structure instrumentation are available in section 5.2.1.

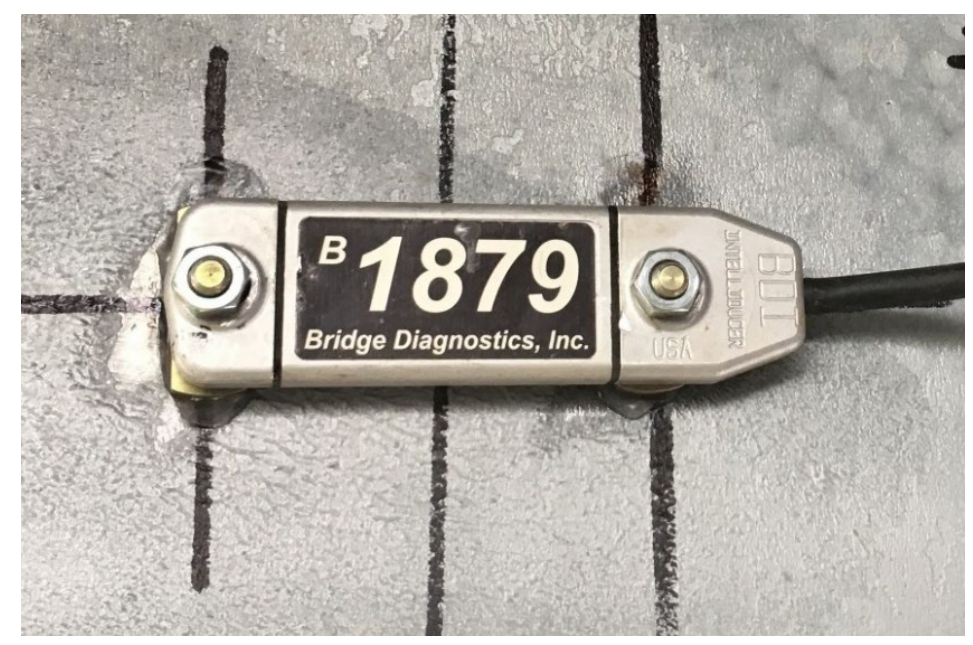

Figure 4.1: BDI Strain Transducer, Typical Application to Girder

\subsubsection{STS-WiFi Data Acquisition System}

In order to record the data measured with the strain transducers, BDI created the STS-WiFi Data Acquisition System. This system consists of nodes collecting data from various sensors and a base station serving as the interface between the nodes and the computer software. The STSWiFi Data Acquisition System is especially useful for field testing where access to a power source is difficult or running cables between devices is limited. Sensors, such as a strain transducer, plug into one of the four connectors of the wireless four-channel node (Figure 4.2). These nodes transmit the data readings over a local wireless broadcast to the mobile base station as seen in Figure 4.3. Power is supplied to the wireless nodes and base station by rechargeable NiMH batteries. In cases where a source of continuous AC power is available, the wireless nodes may also be powered by a DC power adapter. 


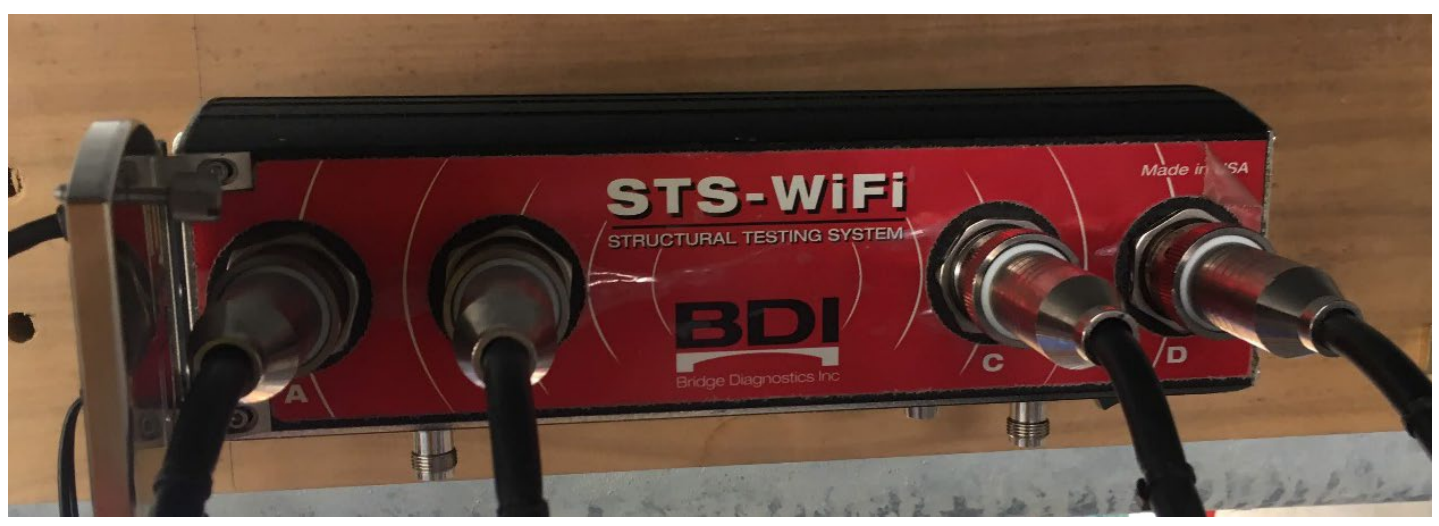

Figure 4.2: BDI STS-WiFi Wireless 4-Channel Node

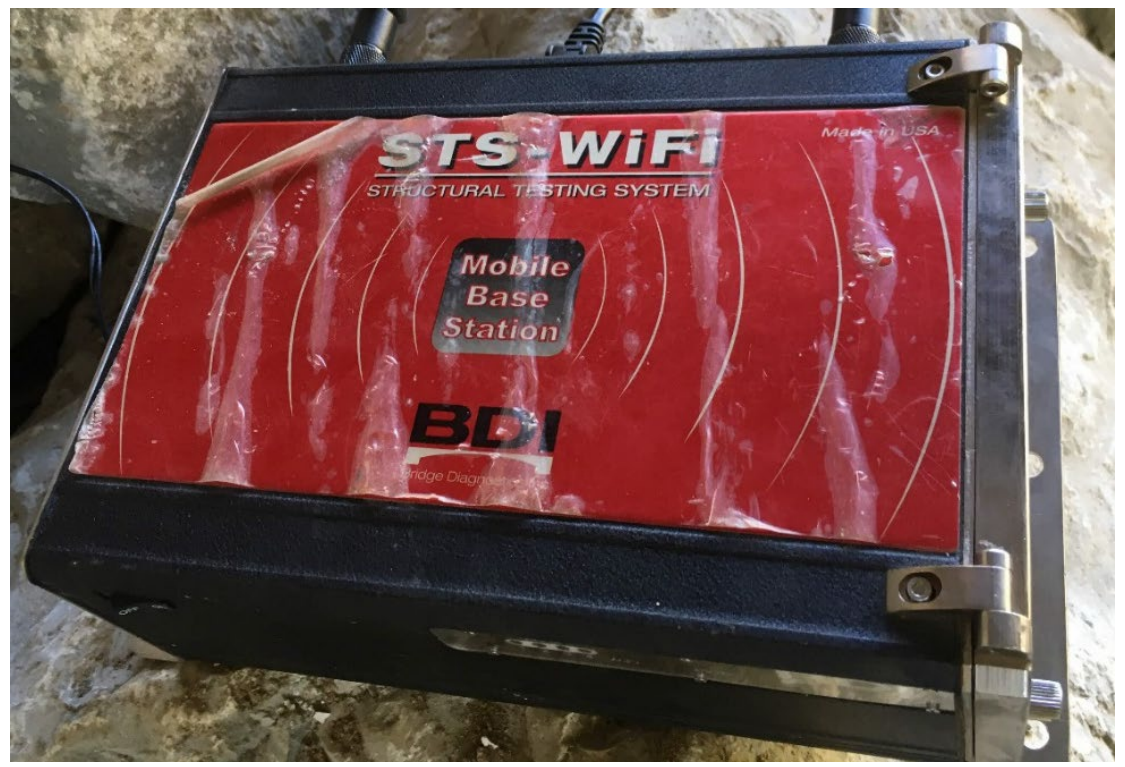

Figure 4.3: BDI STS-WiFi Mobile Base Station

Even though the units are designed with the capability to wirelessly transmit data for use in applications with limited access, there is the option to use wired ethernet connections between each node and the base station. Like the strain transducers, BDI designed the base stations and wireless nodes to be able to resist dust and water. A weather seal and locking mechanism is provided on the access door to both the base station and wireless node. BDI also provided mounting locations on the wireless nodes and base station; these mounts were combined with high 
strength magnets to affix the testing equipment to the outside of the girders in a sturdy and temporary fashion. To improve data reduction efforts, each piece of equipment in the BDI Data Acquisition System is equipped with a BDI "Intelliducer" chip. This chip allows the equipment to identify itself inside of the software package. The ease of installation and durable nature of the BDI system makes its use in field testing an appropriate choice.

\subsubsection{Load Truck and Wheel Scales}

The live load was produced by a loaded tandem axle dump truck provided by Lusher Trucking of Prichard, West Virginia (Figure 4.4.) The total weight of the truck was measured prior to arrival on site. The weight of each wheel was measured on site using Haenni Wheel Load Weigher scales as seen in Figure 4.5. The wheel scales were provided by the Public Service Commission of West Virginia Transportation Enforcement Division.

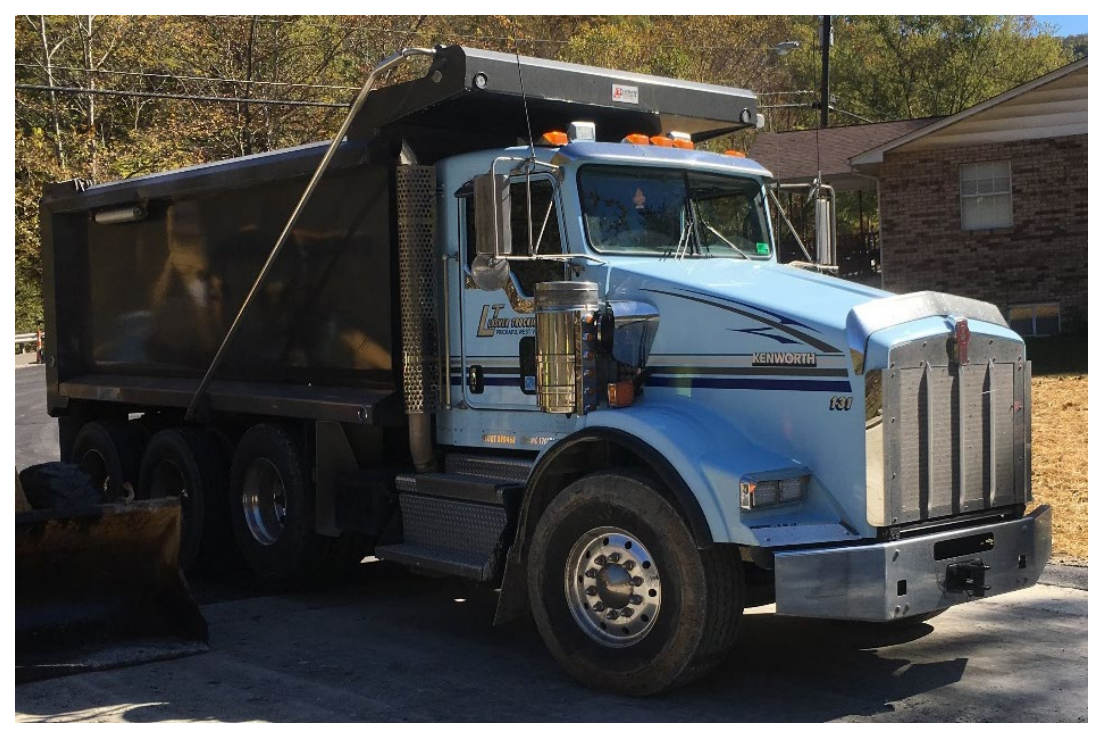

Figure 4.4: Tandem Axle Dump Truck used for Live Load Test 


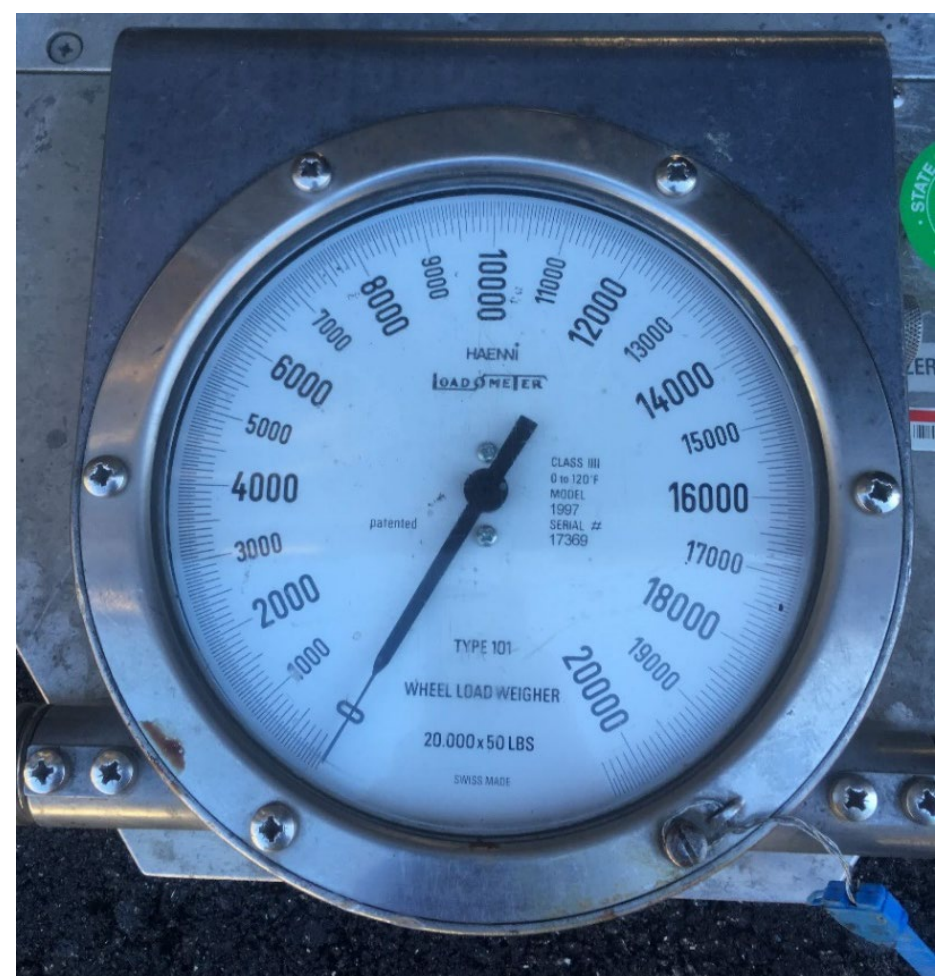

Figure 4.5: Haenni Wheel Load Weigher Scale

\subsection{Finite Element Modeling}

This section details the process followed to conduct a finite element analysis to compare analytical values to the results from the field. Abaqus/CAE 6.14-1 (Dassault Systèmes, 2014) was used to develop a finite element model of the Fourteen Mile Bridge. Load simulating a tandem axle truck was applied and an analysis was conducted. Article 4.6.3.3 of the AASHTO LRFD specifications was used as a guide for the considerations in a refined analysis approach. Data from the model was used to compare the girder strains and LLDF's calculated from the field results.

\subsubsection{Material Definitions}

The Fourteen Mile Bridge superstructure consists of AASHTO M270 Grade 50 plate for the girders and Class $\mathrm{H}$ concrete for the deck. Due to the narrow widths of the UHPC closure 
pours, Class H concrete was assumed for the entire deck. Following AASHTO 6.4.1, the structural steel had a modulus of elasticity of 29,000 ksi, a minimum yield strength of $50 \mathrm{ksi}$, and a Poisson's ratio of 0.3 . The compressive strength of the concrete, f'c, was 4,000 psi as stated in the design plans. Following AASHTO Article 5.4.2, the concrete had a modulus of elasticity of 3,640 ksi and a Poisson's ratio of 0.2. Linear elastic behavior was assumed in this analysis and all materials were assumed to be isotropic.

\subsubsection{Element Selection}

Due to the uniform geometry of the Fourteen Mile Bridge, quadrilateral shell elements were employed in the finite element model. Following the Abaqus/Standard User's Manual and work from previous analytical models of press-brake-formed tub girders (Gibbs, 2017; Underwood, 2019), S4R shell elements were chosen to be used. S4R elements are four-noded stress/displacement shell elements with reduced integration. These properties make S4R elements a suitable choice for a wide variety of uses. Comparison of analytical results to the field data indicated the element produced accurate results for finite element analysis.

\subsubsection{Mesh Discretization}

Following Article 4.6.3.3 of the AASHTO LRFD specifications, abrupt changes in the sizes or shapes of finite elements should be avoided, and the aspect ratio of finite elements and grid panels should not exceed 5.0. This controls the shapes used in the mesh and the relative sizes of elements. 
The mesh discretization of the finite element model for the Fourteen Mile Bridge adhered to the guidelines set by AASHTO to produce accurate results. Each portion of the cross section was seeded to generate a desired number of elements. The typical mesh discretization for the cross section is presented in Figure 4.6. Nodes were spaced in the longitudinal dimension of the girders at 6" increments for 116 elements along the length of each girder. Both top flanges consist of two elements each, top and bottom bends consist of three elements each, webs consist of 12 elements each, and the bottom flange consists of 10 elements.

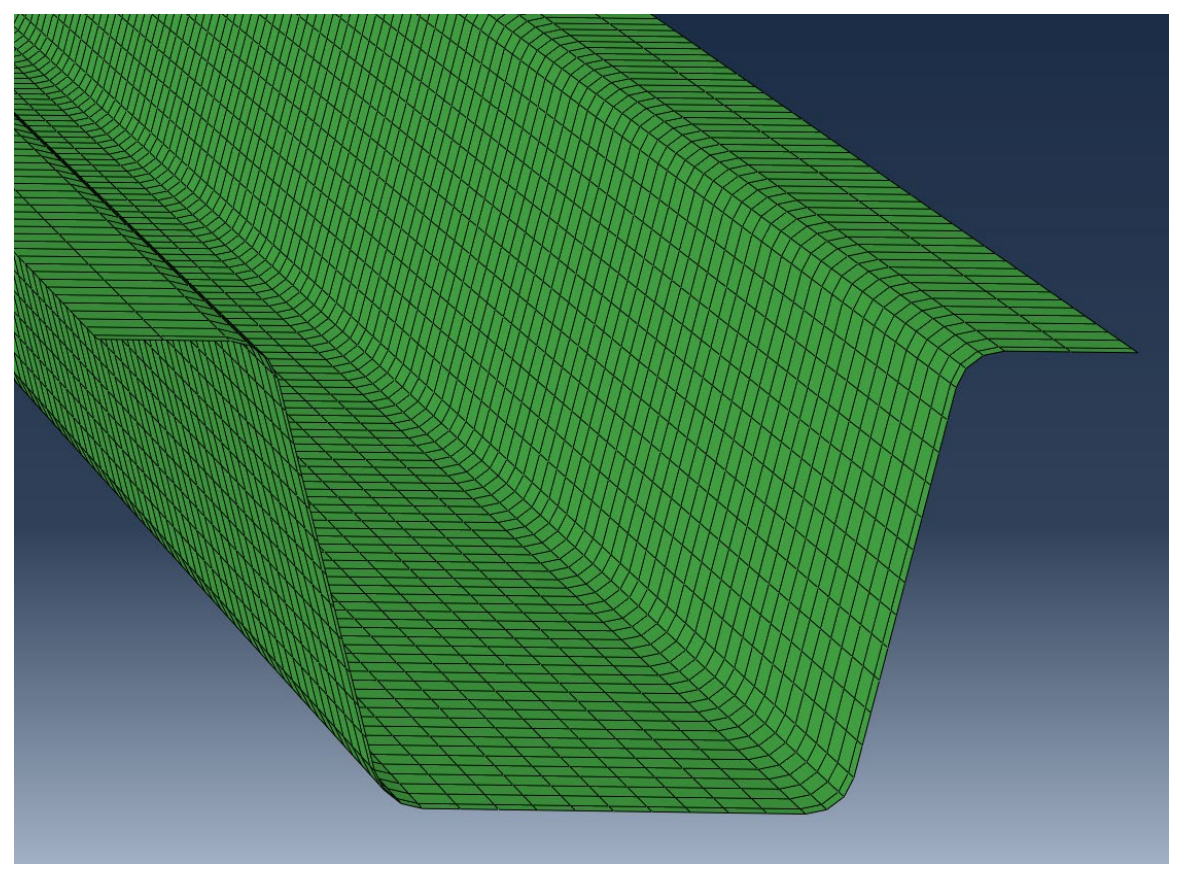

Figure 4.6: Typical Mesh Discretization for Each Tub Girder

Elements were grouped by similar geometries, and each was checked to verify the aspect ratios met the guidelines set by AASHTO. The results of this validation are presented in Table 4.1. 
Table 4.1: Typical Aspect Ratio for Girder Elements

\begin{tabular}{|c|c|c|c|c|}
\hline Geometry & Number of Elements & Depth, D (in) & Length, L (in) & Aspect Ratio (D/L) \\
\hline Top Flange & 2 & 3.00 & 3.74 & 0.80 \\
\hline Bend & 3 & 3.00 & 1.21 & 2.48 \\
\hline Web & 12 & 3.00 & 1.89 & 1.59 \\
\hline Bottom Flange & 10 & 3.00 & 2.16 & 1.39 \\
\hline
\end{tabular}

Seeding of the deck nodes in the longitudinal direction matched the 6" spacing used to seed the girder. However, for the multiple-point constraints to be collinear between deck and girder nodes, transverse spacings of nodes varied between 6.77 " for exterior overhangs, 6.41 " over each girder, and 5.77" for interior overhangs. Aspect ratios for each deck element met the AASHTO guidelines for advanced modeling techniques.

\subsubsection{Boundary Conditions and Multiple Point Constraints}

The boundary conditions of the Fourteen Mile Bridge were modeled as a "hinge-roller" simple span which limited horizontal and vertical displacement. The girders were restrained from lateral movement at the ends. All boundary conditions were applied to the nodes on the bottom flange of each girder. Multiple-Point Constraints are used to associate disconnected nodes of a finite element model to limit displacement between the two points. This feature is useful in the analysis of beam-slab bridges when the deck is composite where the deck and girders can be modeled to act together. 


\subsubsection{Application of Live Loading}

Load placement on the finite element model simulated the loading performed in the field to maximize the strain in the bottom flange of each girder. Because the point loads were applied in the middle of elements and not at distinct nodes, the load from each wheel would need to be statically distributed to each node defining the element (Figure 4.7). The proportion of the applied load taken to each node was computed by Equations 4-1 through 4-4, which follows AASHTO Article 4.6.3.3.1 as the sum for each nodal load is statically equivalent to the applied load.

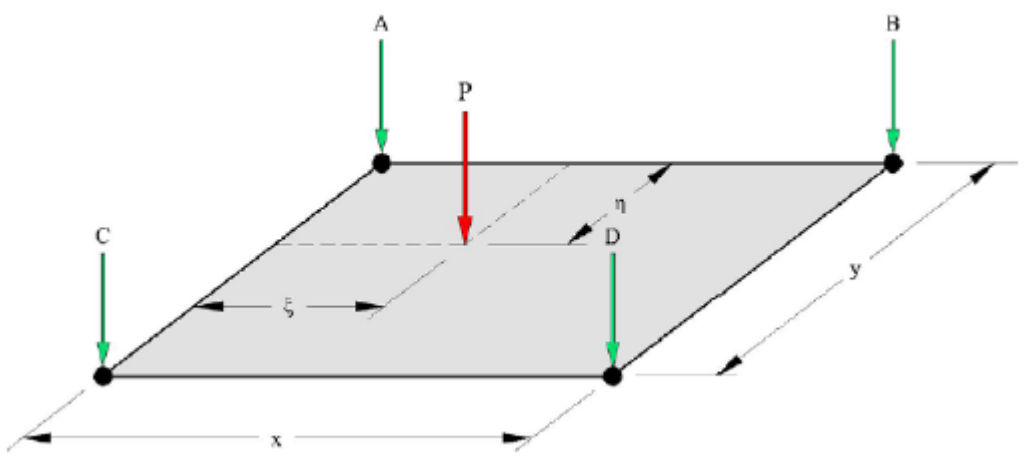

Figure 4.7: Nodal Distribution of Point Loads (Michaelson, 2010)

$$
\begin{aligned}
& A=P\left(1-\frac{\xi}{x}\right)\left(1-\frac{\eta}{y}\right) \\
& B=P\left(\frac{\xi}{x}\right)\left(1-\frac{\eta}{y}\right) \\
& C=P\left(1-\frac{\xi}{x}\right)\left(\frac{\eta}{y}\right) \\
& D=P\left(\frac{\xi}{x}\right)\left(\frac{\eta}{y}\right)
\end{aligned}
$$

Equation 4-4 


\subsection{Data Reduction Methods}

This section details the methods used to analyze the data collected in the field and from the finite element model used to calculate the LLDFs. Example calculations for the quarter span bending stress and LLDFs are also included. Structure instrumentation is further described in Section 5.2. Raw data from the field testing included the strain readings (measured in microstrain, $\mu \varepsilon$ ) and corresponding gage numbers. The five strain readings from each panel point were averaged to a single strain reading for each gage; the initial strain recorded from when the truck was located off the bridge was subtracted from the strain at each panel point. The location of each gage on the structure was determined from field notes, and the gages were grouped by girders. For simplicity, the truck passes were defined as the physical positions of the truck during live load testing and the truck runs were the positions that maximized the strains on targeted girders. More information on the distinction between truck passes and runs is provided in Section 5.2.2. The three gage measurements for each girder were averaged to obtain the strain at each panel point on each girder for each truck pass. The strains were subsequently linearly interpolated to determine the strain at each panel point for each truck run.

\subsubsection{Computation of Quarter Span Bending Stresses}

Recorded strain data was separated by girder and the readings were averaged to obtain a single strain value for each panel point measured in microstrain, $\mu \varepsilon$. These strain values were used in combination with Hooke's Law to compute the bending stress at the gage locations at quarter span. The strain values were averaged for each girder, then divided by $1 \mathrm{e} 6$ to convert to strains. The values were multiplied by Young's Modulus of steel, $E_{s}=29,000 \mathrm{ksi}$. The resultant value is the 
stress in ksi at the quarter span for each girder. An example of these calculations for the selected data shown in Table 4.2 is presented below as Equations 4-5 and 4-6.

Table 4.2: Strain Values, Quarter Span Bending Stress

\begin{tabular}{|c|c|c|c|c|}
\hline \multicolumn{5}{|c|}{ Truck Pass 4, Girder 3, Panel Point 5 } \\
\hline \multicolumn{2}{|c|}{ Panel Point } & \multicolumn{3}{|c|}{ Strain in Gages, Girder 3 $(\mu \varepsilon)$} \\
\hline $\mathrm{x}(\mathrm{ft})$ & $\mathrm{x} / \mathrm{L}$ & $\mathrm{G} 01$ & $\mathrm{G} 02$ & $\mathrm{G} 03$ \\
\hline 29 & 0.5 & 37.83 & 39.39 & 39.58 \\
\hline
\end{tabular}

Average Strain in Girder 3:

$$
\varepsilon_{\text {avg }}=\frac{\Sigma \varepsilon}{n}=\frac{37.83+39.39+39.58}{3}=38.93 \mu \varepsilon
$$

Application of Hooke's Law to Compute Bending Stress

$$
\sigma=\frac{\varepsilon_{a v g}}{1,000,000} * E_{s}=\frac{38.93}{1,000,000} * 29000=\mathbf{1 . 1 3} \mathbf{k s i}
$$

Where: $\mathrm{n}=$ number of gages

$$
\begin{aligned}
& \varepsilon_{\text {avg }}=\text { average bottom flange strain }(\mu \varepsilon) \\
& \sigma=\text { bottom flange bending stress (ksi) } \\
& \mathrm{E}_{\mathrm{s}}=\text { Young's Modulus of Steel }(\mathrm{ksi})
\end{aligned}
$$




\subsubsection{Computation of Live Load Distribution Factors}

The average girder strain for each panel point was used to calculate the LLDFs for each girder following Equation 4-7. The strain in each girder is divided by the total amount of strain in all girders. This value is multiplied by the number of applied design trucks and the multiple presence factor, which is described in Section 2.4.1. For the single lane loaded condition, the multiple presence factor is taken as 1.2 , and for the two lanes loaded condition, the multiple presence factor is taken as 1.0.

$$
L L D F_{g i}=\frac{n \varepsilon_{i}}{\sum_{i=1}^{k} \varepsilon_{i}} * m
$$

Where: $L L D F g i=$ distribution factor for a target "i'th" girder

$$
\begin{aligned}
& \varepsilon_{\mathrm{i}}=\text { bottom flange static strain for a target “ } \mathrm{i} \text { ' th" girder } \\
& \mathrm{n}=\text { number of applied design trucks } \\
& \mathrm{m}=\text { AASHTO multiple presence factor } \\
& \mathrm{k}=\text { number of girders }
\end{aligned}
$$

Sample calculations will first be shown for calculating the LLDFs for the single lane loaded condition at a Panel Point 5 for Truck Pass 4 and Girder 2. This computation for the data shown in Table 4.3 is represented by Equation 4-8. In the case of multiple lanes loaded, strain data from separate passes must be superimposed to simulate the loading of two trucks. This means the strain would be the sum of the strain on a given girder due to each relevant pass. Data presented in Table 
4.4 represents the average girder strain for each pass and the summation of girder strains for each respective girder. The two lanes loaded calculations are shown in Equation 4-9 for the summation of Panel Point 5 for Truck Pass 1 and 7 on Girder 1.

Table 4.3: Strain Values, Single Lane Loaded LLDF Sample Calculation

\begin{tabular}{|c|c|c|c|c|c|c|}
\hline \multicolumn{7}{|c|}{ Truck Pass 4, Panel Point 5 } \\
\hline \multicolumn{2}{|c|}{ Panel Point } & \multicolumn{5}{c|}{ Girder Average Strain $(\mu \varepsilon)$} \\
\hline $\mathrm{x}(\mathrm{ft})$ & $\mathrm{x} / \mathrm{L}$ & $\mathrm{G} 1$ & $\mathrm{G} 2$ & $\mathrm{G} 3$ & $\mathrm{G} 4$ & $\mathrm{G} 5$ \\
\hline 29 & 0.5 & 38.75 & 45.52 & 38.93 & 25.21 & 9.67 \\
\hline
\end{tabular}

$$
L L D F_{G 2, P P 5}=\frac{1.2 *(45.52)}{38.75+45.52+38.93+25.21+9.67} * 1=\mathbf{0 . 3 4 6}
$$

Equation 4-8

Table 4.4: Strain Values, Two Lanes Loaded LLDF Sample Calculation

\begin{tabular}{|c|c|c|c|c|c|c|}
\hline \multicolumn{7}{|c|}{ Truck Pass 1, Panel Point 5} \\
\hline \multicolumn{2}{|c|}{ Panel Point } & \multicolumn{5}{|c|}{ Girder Average Strain $(\mu \varepsilon)$} \\
\hline $\mathrm{x}(\mathrm{ft})$ & $\mathrm{x} / \mathrm{L}$ & G1 & G2 & G3 & G4 & G5 \\
\hline 29 & 0.5 & 64.28 & 59.56 & 35.36 & 17.46 & 6.42 \\
\hline \multicolumn{7}{|c|}{ Truck Pass 7, Panel Point 5} \\
\hline \multicolumn{2}{|c|}{ Panel Point } & \multicolumn{5}{|c|}{ Girder Average Strain $(\mu \varepsilon)$} \\
\hline $\mathrm{x}(\mathrm{ft})$ & $\mathrm{x} / \mathrm{L}$ & G1 & G2 & G3 & G4 & G5 \\
\hline 29 & 0.5 & 26.81 & 39.31 & 47.95 & 46.40 & 28.26 \\
\hline \multicolumn{7}{|c|}{ Truck Pass 2+7, Panel Point 5} \\
\hline \multicolumn{2}{|c|}{ Panel Point } & \multicolumn{5}{|c|}{ Girder Average Strain $(\mu \varepsilon)$} \\
\hline $\mathrm{x}(\mathrm{ft})$ & $\mathrm{x} / \mathrm{L}$ & G1 & G2 & G3 & G4 & G5 \\
\hline 29 & 0.5 & 91.09 & 98.88 & 83.31 & 63.86 & 34.68 \\
\hline
\end{tabular}




$$
L L D F_{G 1, P P 5}=\frac{1.0 *(91.09)}{91.09+98.88+83.31+63.86+34.68} * 2.0=\mathbf{0 . 4 9 0}
$$

Equation 4-9

LLDFs were calculated following AASHTO Article 4.6.2.2. The specifications within Article 4.6.2.2 are discussed earlier in Section 2.4.2 and Equation 4-10 represents the LLDF equation for steel box girders. In the AASHTO LRFD specifications, no differentiation is made for the calculation of interior girder or exterior girder LLDF's, or for the number of design lanes loaded. Note the multiple presence factor is already taken into consideration by Equation 4-10.

$$
L L D F=0.05+0.85 * \frac{N_{L}}{N_{b}}+\frac{\mathbf{0 . 4 2 5}}{N_{L}}
$$

Where: $\mathrm{N}_{\mathrm{L}}=$ number of design lanes as specified in Article 3.6.1.1.1

$$
\begin{aligned}
& \mathrm{N}_{\mathrm{b}}=\text { number of girders } \\
& 0.5 \leq \frac{N_{L}}{N_{b}} \leq 1.5
\end{aligned}
$$

In the case of the Fourteen Mile Bridge, there are five girders and two design lanes. As shown in Equation 4-11, the LLDF determined by the methods specified in the AASHTO LRFD specifications Article 4.6.2.2 is 0.603 . It should be noted this bridge does not fall within the range of applicability. The calculation of $\mathrm{N}_{\mathrm{L}} / \mathrm{N}_{\mathrm{b}}$ is $2 / 5$ or 0.4 which is below the minimum requirement the equation may be utilized for. No provisions are described by AASHTO for steel box bridges that lie outside this range.

$$
L L D F=0.05+0.85 * \frac{2}{5}+\frac{0.425}{2}=\mathbf{0 . 6 0 3}
$$




\section{CHAPTER 5: FIELD TESTING OF THE FOURTEEN MILE BRIDGE}

\subsection{INTRODUCTION}

This section details the loading and data recording process performed for the physical field testing of the Fourteen Mile Bridge in October 2019. Researchers from MU and WVU traveled to Ranger, West Virginia to perform a live load field test on the bridge. The goal of the field test was to compare measured strains due to physical loading to strains determined from analytical modeling to assess performance of the structure.

\subsection{Live LoAd Field TeSt AsSessment}

The field test of the Fourteen Mile Bridge was completed over two days. The first day was used to measure and apply instruments to the structure. The field testing and data collection was completed on the second day.

\subsubsection{Structure Instrumentation}

The BDI STS Wi-Fi Data Acquisition System was used to instrument the structure and record results. Nineteen gage locations were identified for this field test; three gages were located on the bottom of each girder (15 total) and one gage was located on each web of Girders 1 and 2. Gages were placed at quarter span to allow for easier access for preparation and removal. An overview of the gage layout is shown in Figure 5.1. 


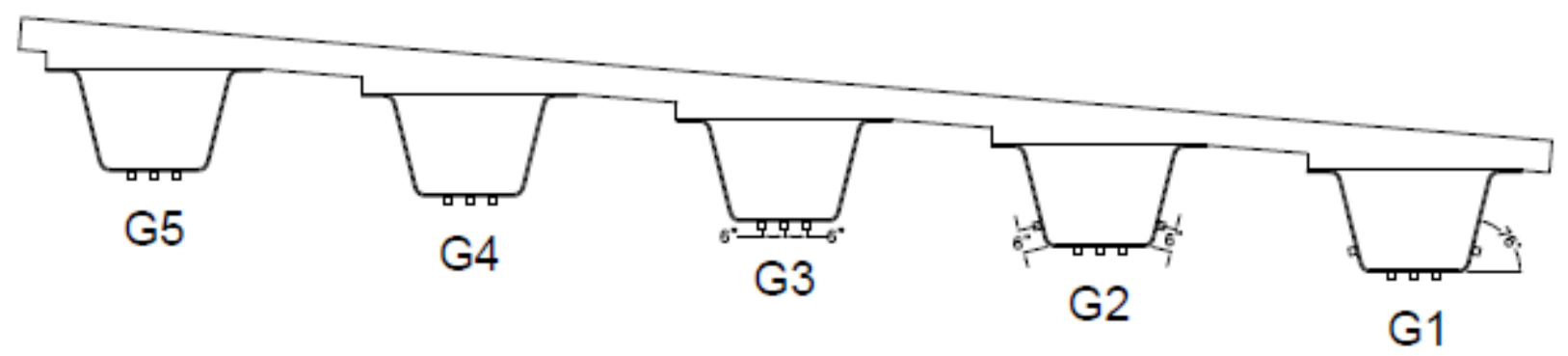

Figure 5.1: Gage Locations on Girders, Looking Upstation

To improve access to mark and prepare the girders and apply the instrumentation, an allterrain aerial lift was supplied by the contractor for use during the field testing. The aerial lift is presented in Figure 5.2.

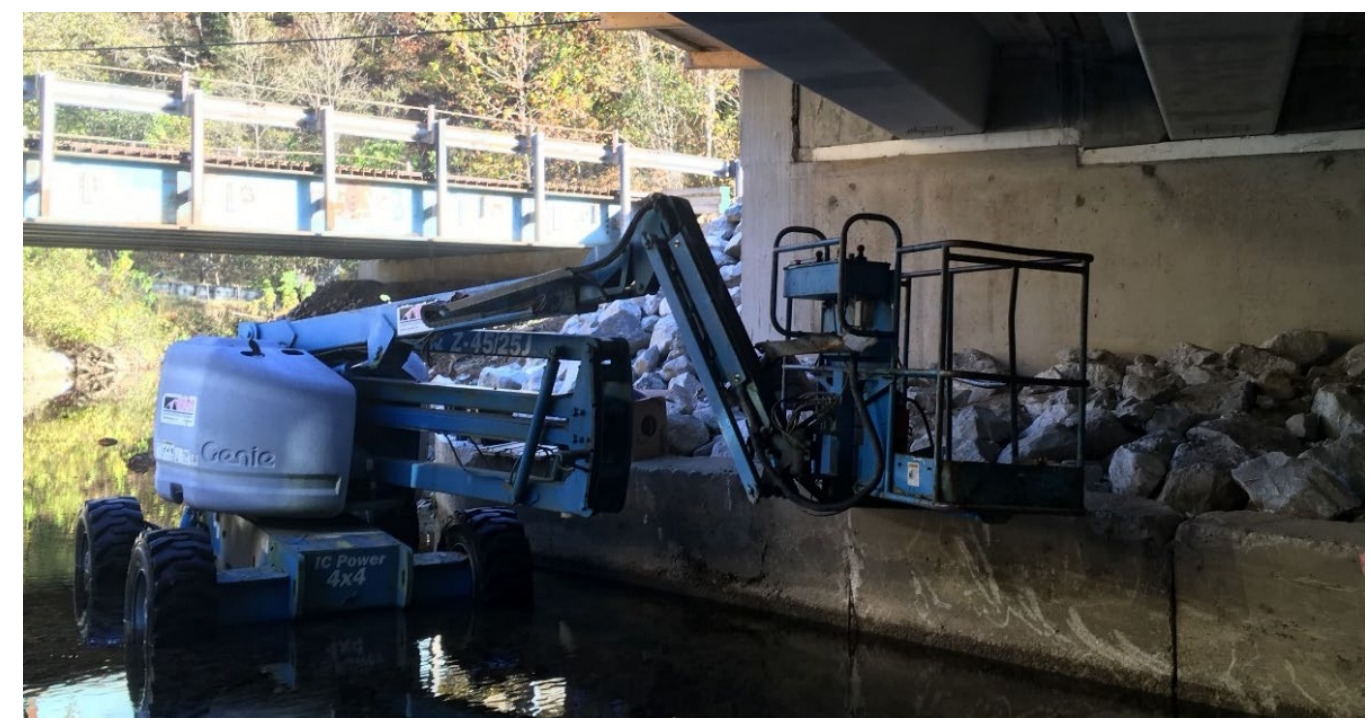

Figure 5.2: Aerial Lift Supplied by Contractor 
Quarter span locations were determined by measuring the distance from the inside face of one precast abutment to the inside face of the other. This distance was 60 ' -6 ," which was divided by four to find quarter span. The resulting distance measured from the back-station abutment to quarter span was $13^{\prime}-7^{5} / 16$." A mark was made at quarter span for the transverse middle of each girder. Quarter points were also measured the along the bends of each girder; a square was used to mark the resulting diagonal. The middle of the gages, as seen in Figure 5.3, is at an angle parallel to the skew. After this mark was made, measurements were made at 6" normal to the longitudinal direction at each side from the center and then 1.5 " from each intersection point to determine the tab locations for the gages. The resulting grid of markings is seen in Figure 5.4. Web locations were measured using an angled rule; the web gages were placed 6" from the bottom flange measured along the inclination of the web. The web gage mounting points were determined in a similar fashion as the bottom flange mounting points. Typical web gage mounting locations are seen in Figure 5.5.

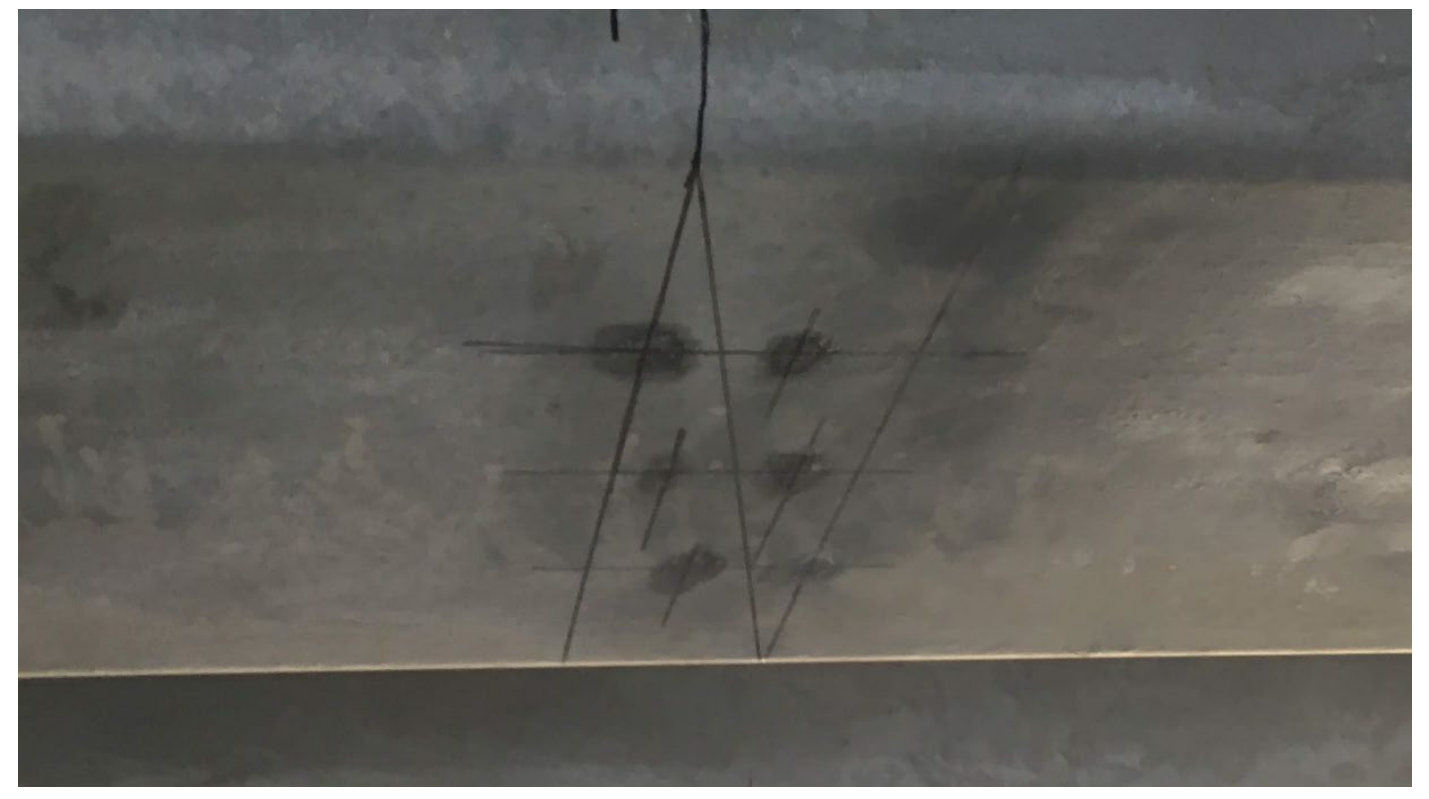

Figure 5.3: Centerline of Gages at Quarter Span, Looking Upstream 


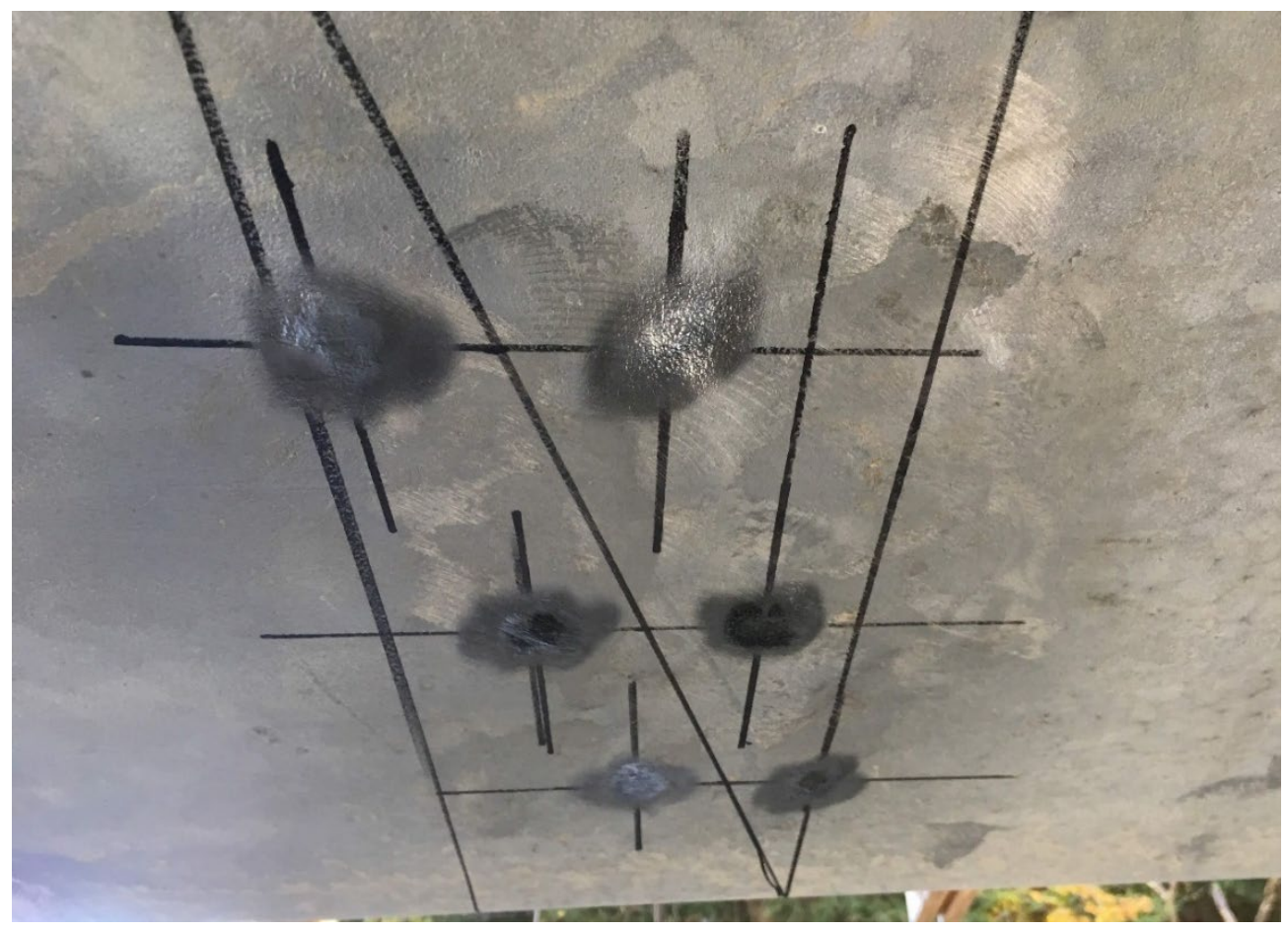

Figure 5.4: Typical Bottom Flange Gage Mounting Points, Looking Upstream

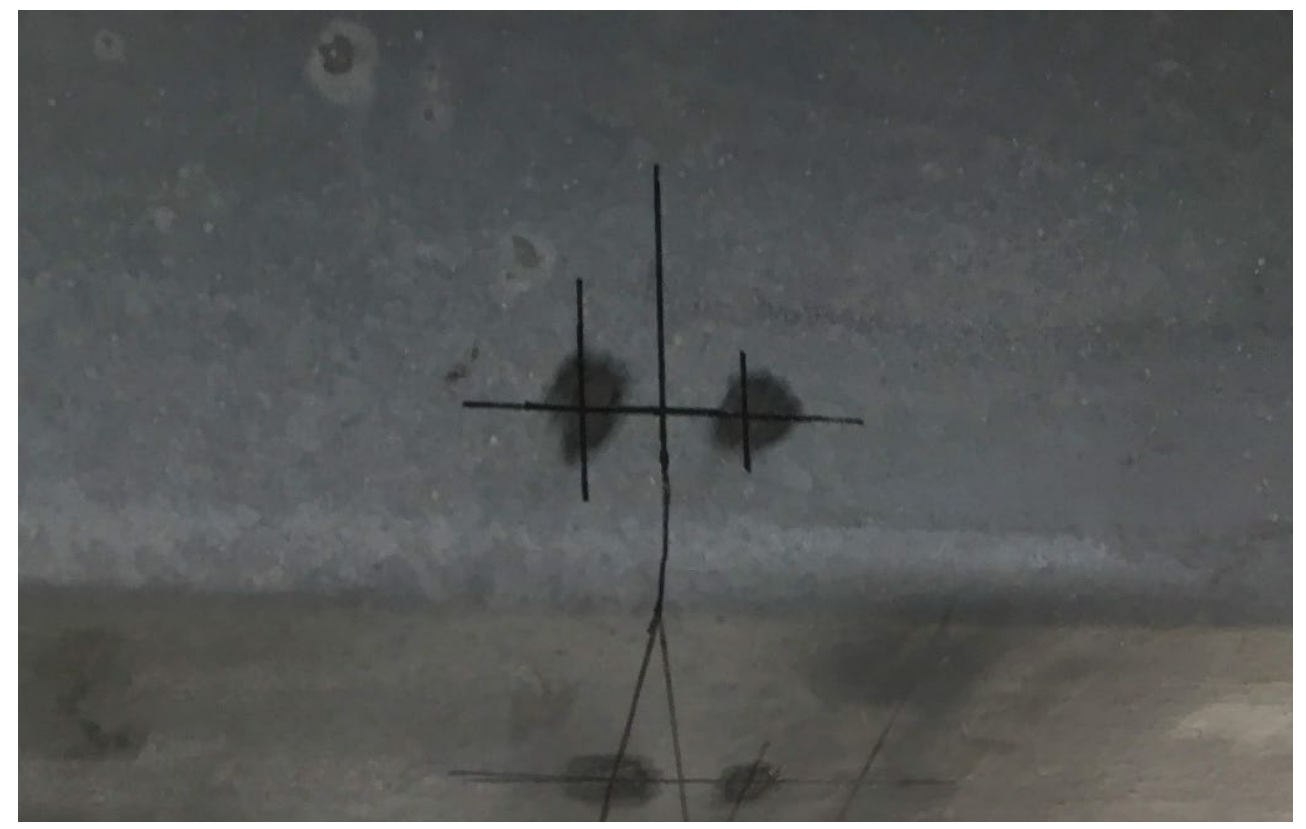

Figure 5.5: Typical Web Gage Mounting Points, Looking Downstream 
After the gage locations had been marked, a battery-powered angle grinder with a wire brush attachment was used to buff the surface of the girder to allow the adhesive to bond to the bare steel. After the surface was prepared, the marks were replaced so the gages could be installed at the correct locations. A gage blank was used in combination with the tab jig provided by BDI to ensure correct spacing of the mounting locations. A small bead of Loctite ${ }^{\circledR}$ HY 4070 Superfast Fixture Structural Repair Hybrid Adhesive was applied to the bottom of each tab and uniform pressure was used to fix the tabs against the steel surface. Approximately 90 seconds after the initial contact, the adhesive set, and pressure could be released. Figure 5.6 shows the tab mounts in place on the girder.

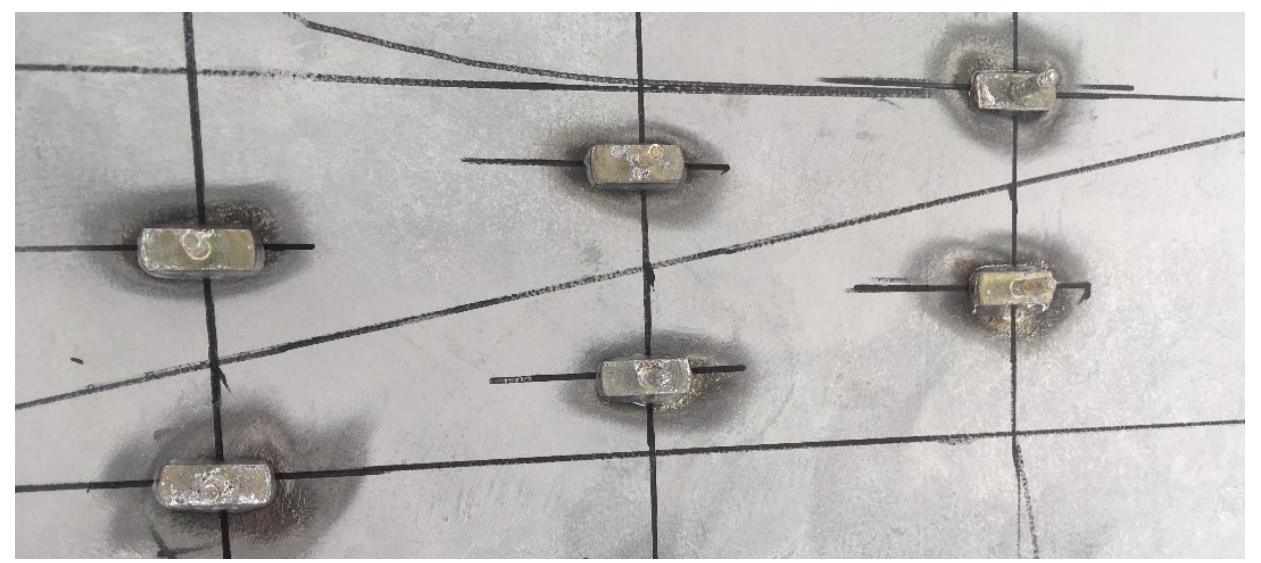

Figure 5.6: Typical Tab Mounting to Steel Surface

Approximately 20 minutes following the original application, the gage blank was removed, and the appropriate BDI strain transducer was installed based on the necessary cable length. The gages attached to the two tabs with $7 / 16$ " nuts tightened with a wrench until snug. The cables were connected to the appropriate wireless node. Nodes were attached to the surface of the steel using a magnetic mounting assembly. Figure 5.7 shows the gages installed on the girder. 


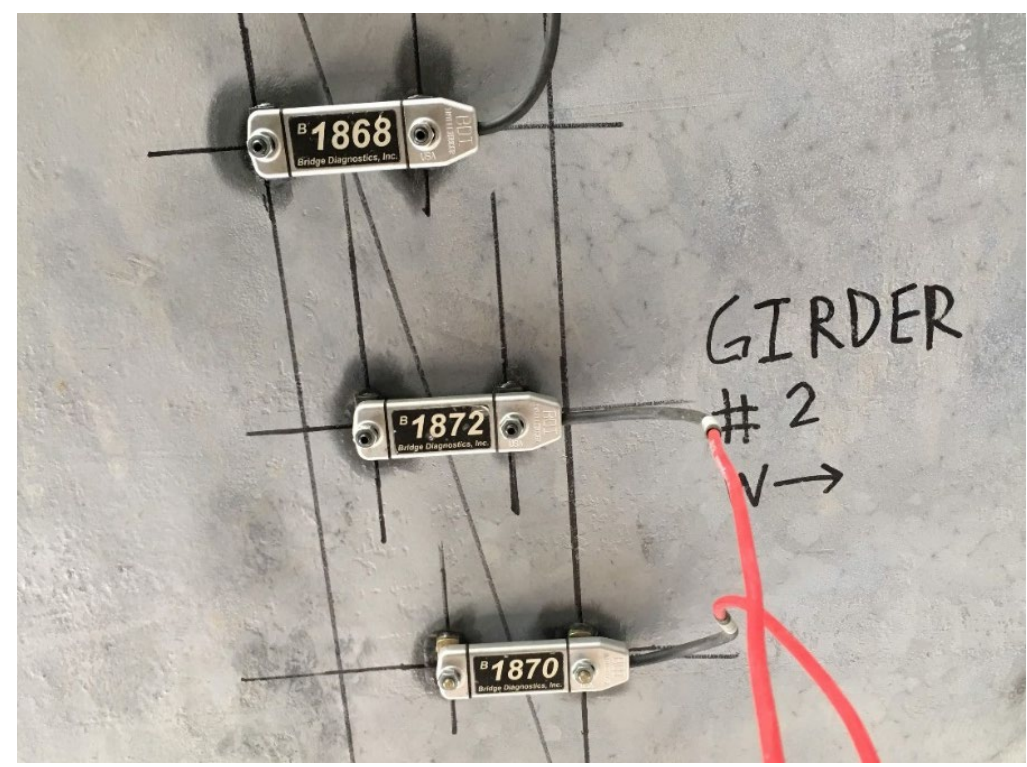

Figure 5.7: Typical View of Gages Installed on Bottom Flange, Looking Downstream

Because a portable generator was available, it was determined that using DC power adapters with the wireless nodes and base station would be an appropriate option. A wired ethernet cable connected one of the five nodes to the base station. Figure 5.8 shows an overview of the instrumentation once all connections were completed.

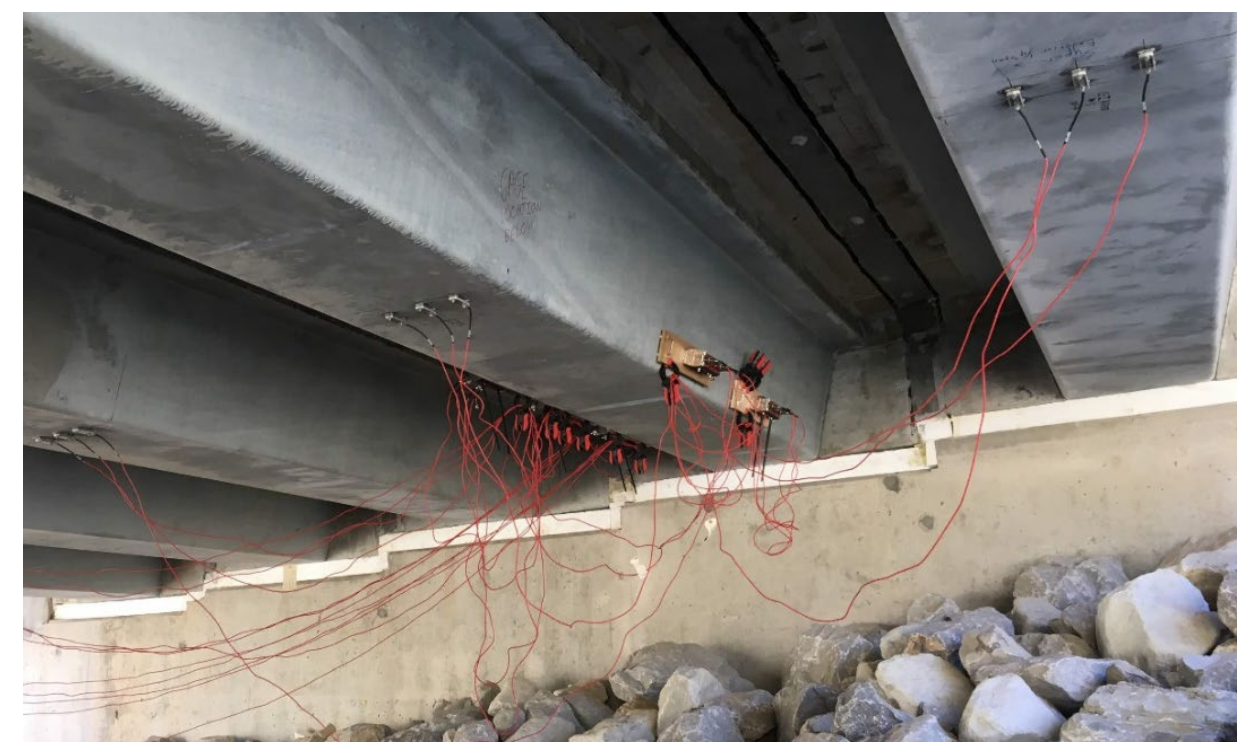

Figure 5.8: Overview of Instrumentation, Looking Backstation 


\subsubsection{Live Load Path Delineation}

The second day of the study began with troubleshooting all connections and verifying the system recorded data correctly. The live load paths were developed from the AASHTO LRFD specifications for maximizing load on individual girders. Measurements to determine the panel points started with identification of the centerline of the road survey. A straight line was marked between both survey points. Subsequent parallel lines were measured in 2'-0" measurements, resulting in the last longitudinal marking located 2'-0" from the edge of the downstream parapet. In total, 13 longitudinal markings were made. To determine transverse locations, the distance between the survey points was measured and was broken into 10 equal panel points, each $6{ }^{\prime}-5 / 8$ " in length.

Delineation of load paths was accomplished by marking the deck by string and crayon. At the 2'-0" increments from the centerline of road survey, nails were placed in the deck at the foam joints at the end of the precast modules. Yellow construction string lines were wrapped around the nails and care was taken to ensure the string was taut (Figure 5.9). Figure 5.10 shows several longitudinal markings with the construction string lines. In the transverse direction, blue crayon was used to mark the 10 panel points as seen in Figure 5.11. 


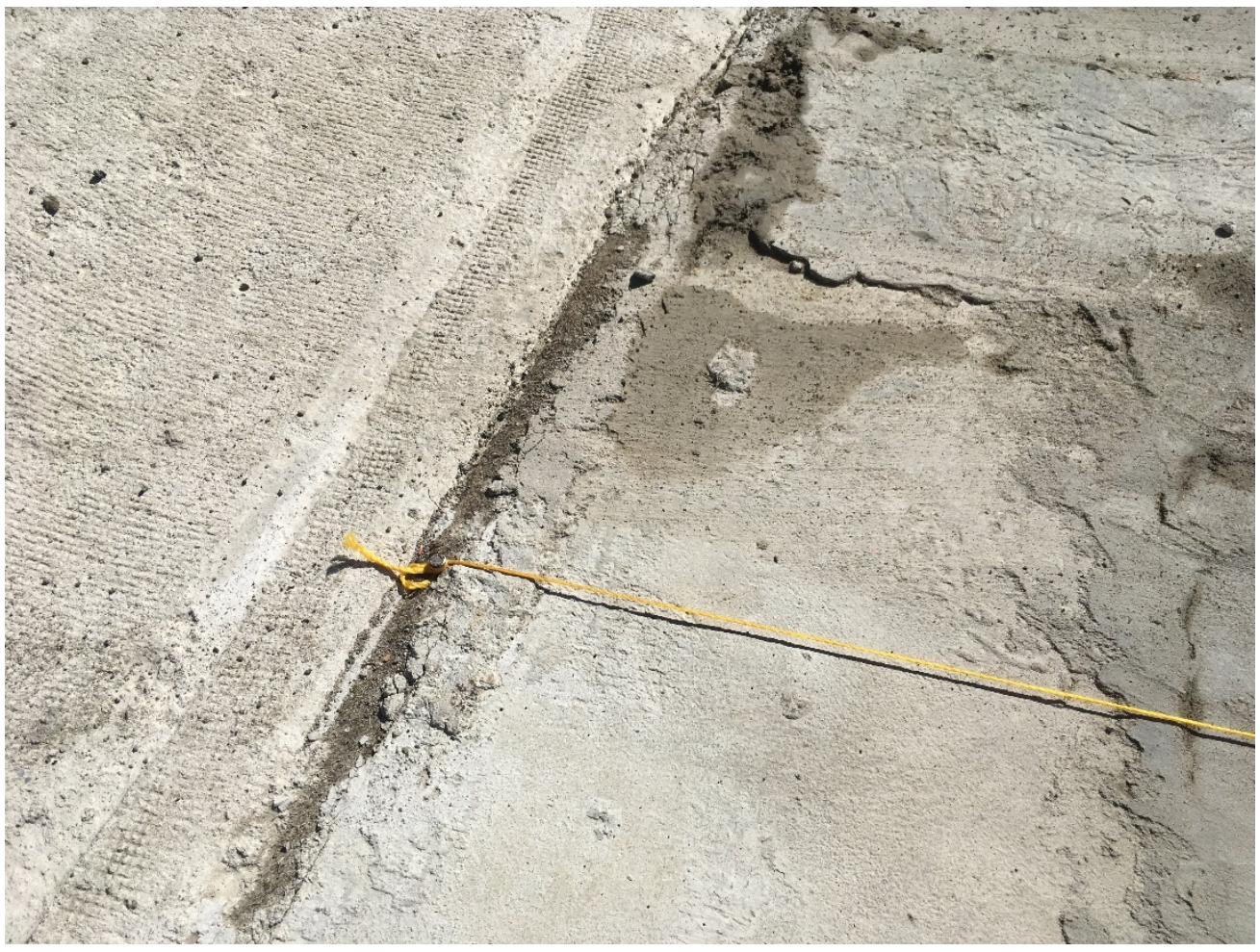

Figure 5.9: Nail placement in Foam Joint with Construction String Line Wrapped Taut

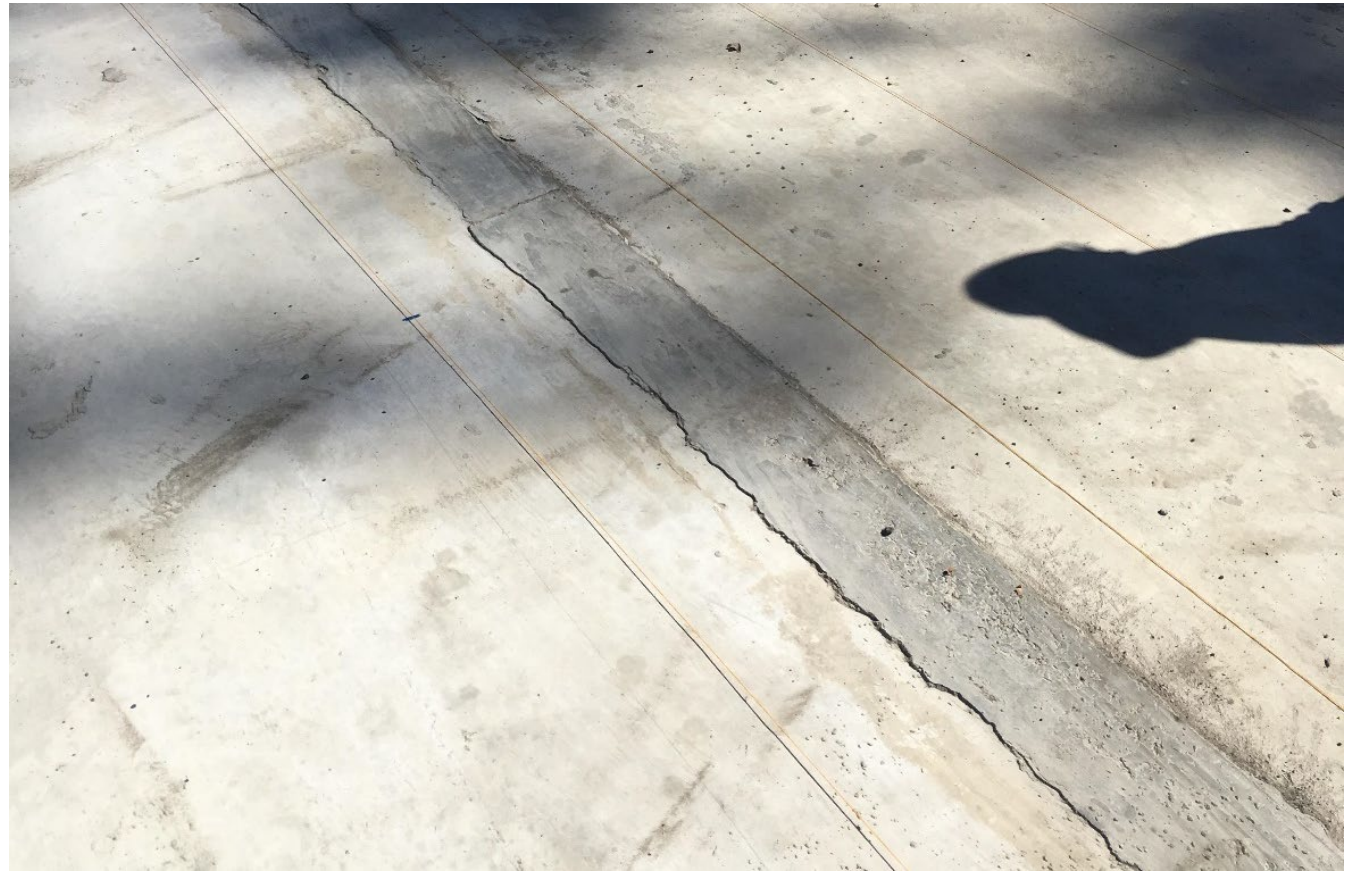

Figure 5.10: Parallel Longitudinal Delineations on Deck with Construction String Line 


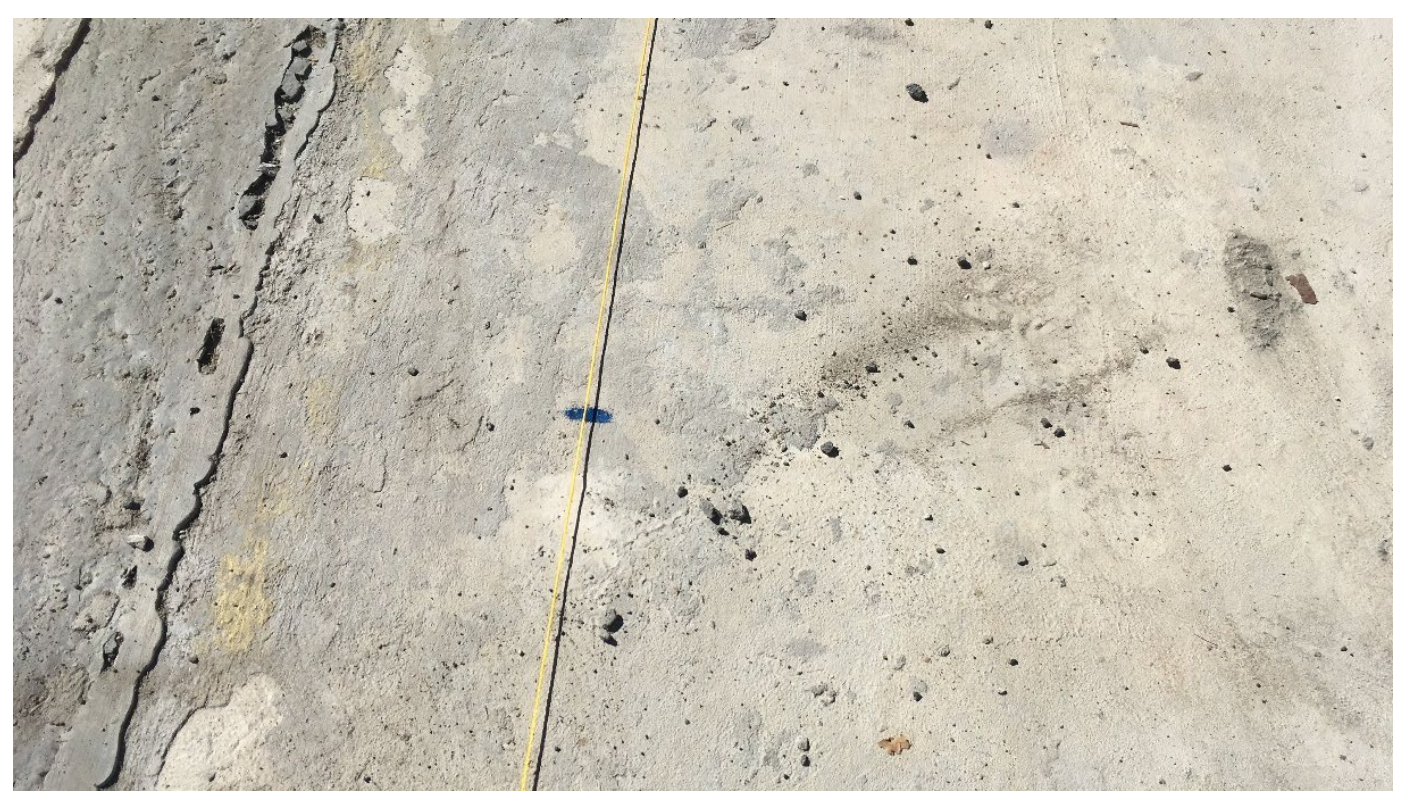

Figure 5.11: Transverse Mark Completed with Blue Crayon

Once the markings had been placed on the deck, a grid was created with the intersections representing the panel points for each placement where the truck would be located. For the purpose of this study, passes will refer to the particular transverse spacing that the truck path is following, and panel point will refer to the truck's position in the longitudinal direction. This grid is indicated by Figure 5.12. It should be noted, due to the radius of curvature of the roadway, the truck would not be able to be placed at either the upstation or backstation end of the longitudinal pass for passes 12 and 13. Subsequently, there is no data from either pass. 


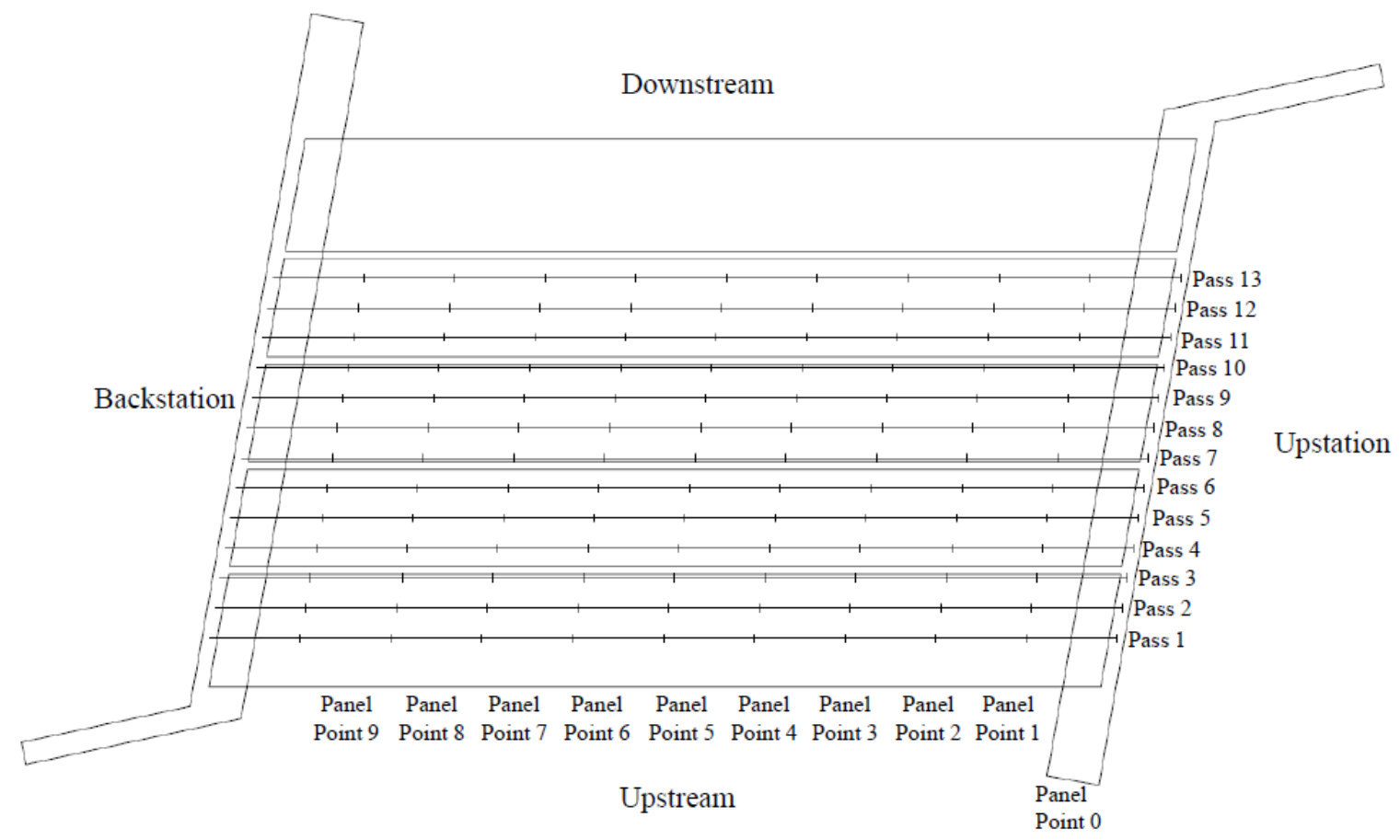

Figure 5.12: Plan View of Panel Point Grid

Referencing work from Gibbs on the Amish Sawmill Bridge (2017) and Underwood on the Cannelville Road Bridge (2019), these delineated truck passes were linearly interpolated to maximize loading on specific girders. Strain values from multiple passes could be added together for each respective girder to simulate the effects of multiple lane loaded scenarios. The following methodology was performed to determine the appropriate location of runs. All transverse distances were measured along the grade of the deck. Girder 1, an exterior girder, would have the strains maximized by having the truck run located 2'-0" from the inside edge of the downstream parapet. To simulate the two lanes loaded scenario, a second truck located 12'-0”, the spacing of a design lane, away from the first truck run, or 14'-0" from the inside edge of the downstream parapet. These two runs are shown in Figure 5.13, along with their distance to the inside edge of the 
downstream parapet as Runs 1 and 4, respectively. A similar procedure is followed for Girders 2 and 3. To maximize the strain for the single lane load in Girder 2, an interior girder, the truck run must be placed so the middle of the tire is along the centerline of Girder 1, 3'-13/16" from the inside edge of the downstream parapet, labeled as Run 2. To induce the multiple lane loaded scenario, the strains from Run 2 must be superimposed with Run 5, located 12'-0"' in the upstream direction. Runs 3 and 6 are used to maximize strain from the single and multiple lanes loaded scenarios, respectively, for girder 3 .

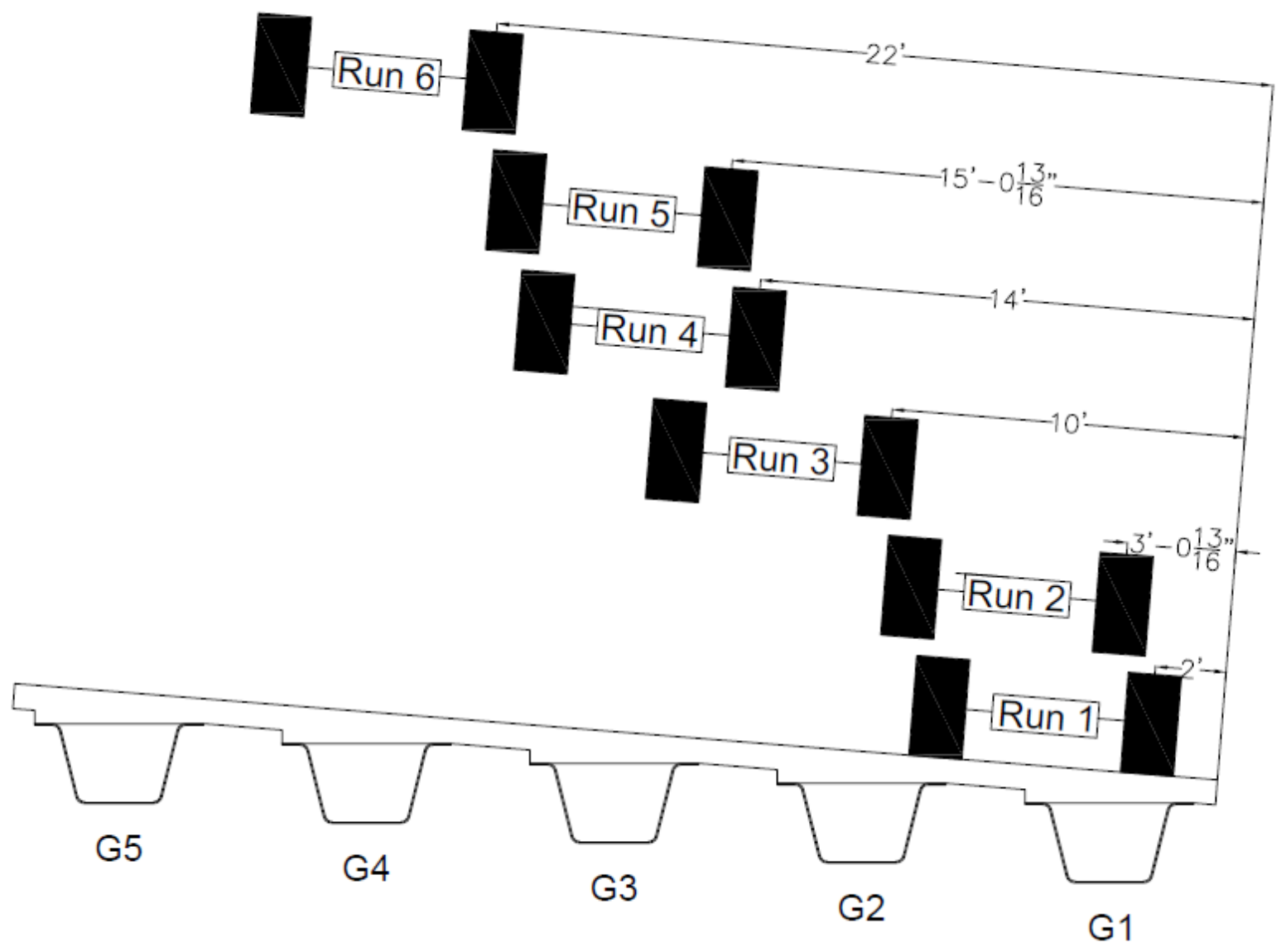

Figure 5.13: Live Load Truck Placement, Looking Upstation 


\subsubsection{Live Load Testing}

Upon arrival of the tandem axle truck to the bridge site, testing began. The truck was deemed fit for use in the live load test due to the similarity with the HS-20 design load truck from AASHTO. The initial truck pass began at the downstream edge of the deck oriented in the direction of back station. Successive passes were worked in the upstream direction. Before the truck moved onto the bridge, the right edge of the front left tire, wheel 1, was lined up with the construction string line. Once the physical testing began, $10 \mathrm{~Hz}$ was chosen as the sample rate within the BDI Software to record strain values. Five measurements were taken before the bridge was loaded to serve as a baseline. The truck would be positioned at each panel point at the intersection of the sting line and crayon mark. A typical pass location can be seen in Figure 5.14. Once the truck had stopped and the bridge had return to a static condition, five readings were taken. At the conclusion of the testing, each wheel was weighed and the geometry of the axle spacings were measured. Figure 5.15 shows the weight of each wheel along with the geometric configuration of the axles.

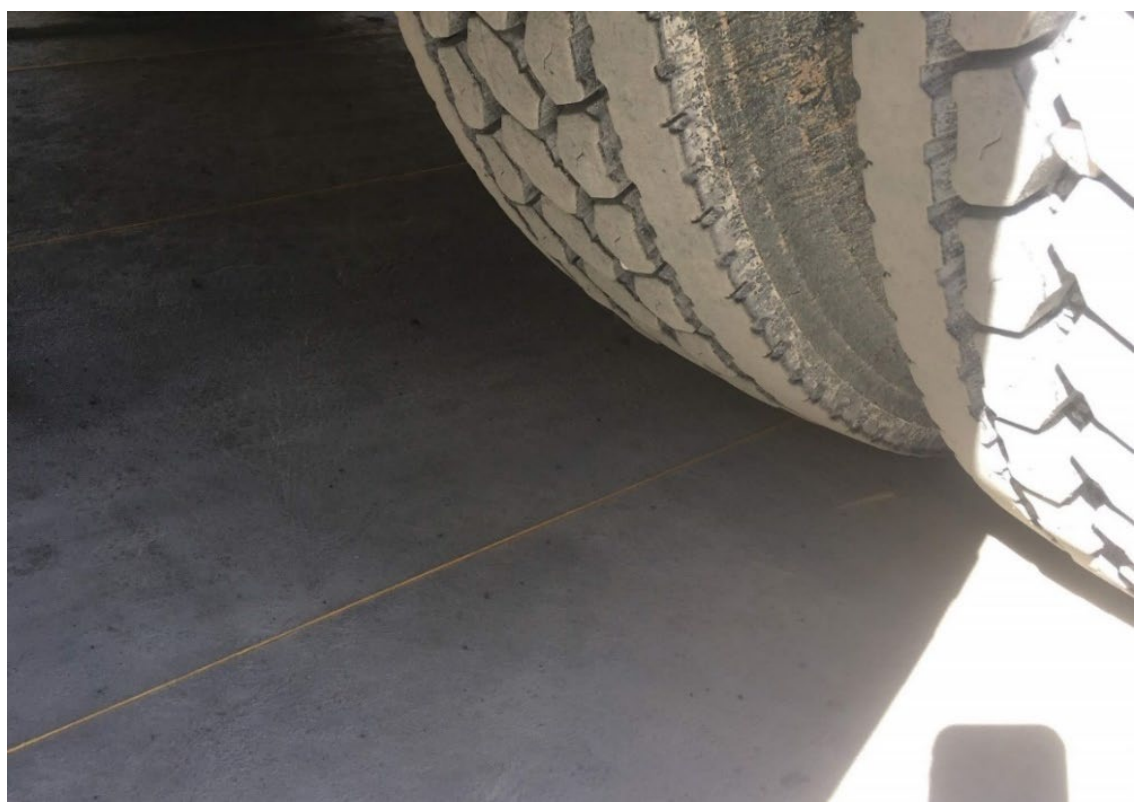

Figure 5.14: Typical Truck Pass Location 


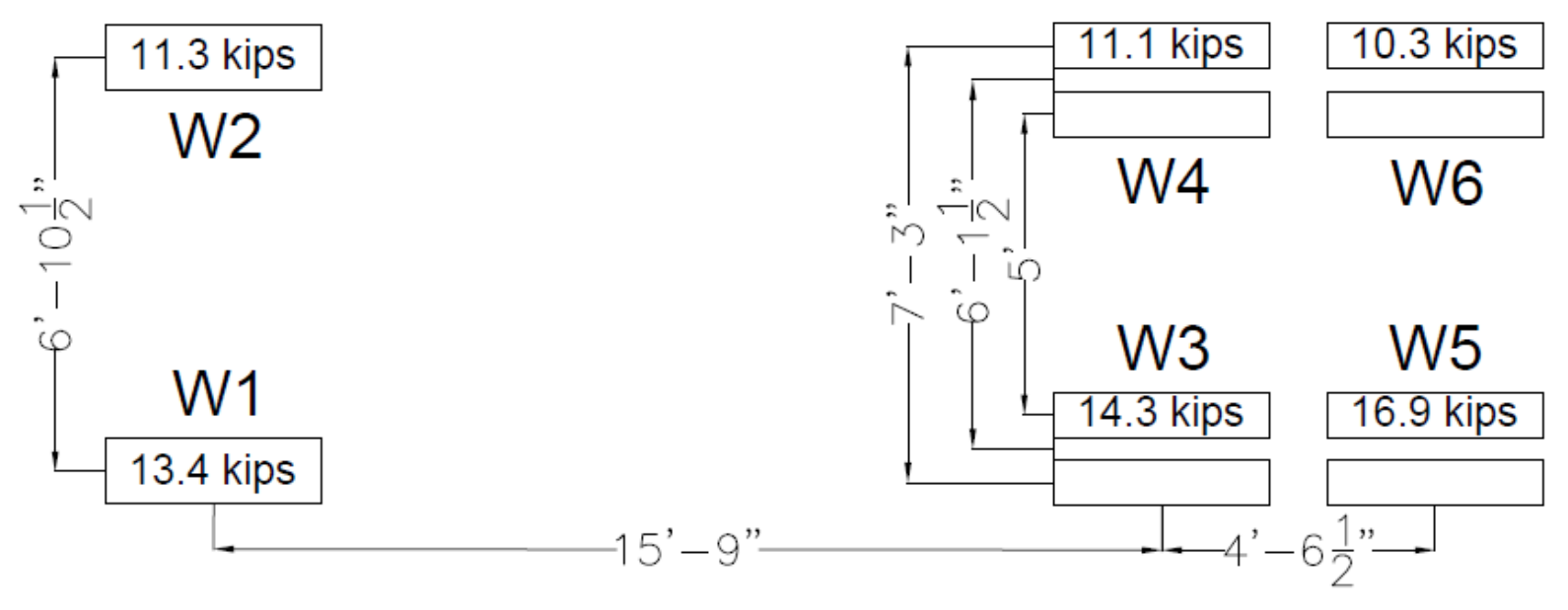

Figure 5.15: Truck Dimensions and Field Weight Measurements 


\section{CHAPTER 6: RESULTS AND ANALYSIS}

\subsection{INTRODUCTION}

This chapter summarizes the results of the Fourteen Mile Bridge live load field test and compares the values to those computed by analytical models. LLDFs will be compared from the live load field test, the finite element analysis, and the AASHTO LRFD specification (2017).

\subsection{COMPARISON OF RESUltS}

This section presents the results determined from the live load field test and the finite element model. The raw data from the live load field test is included, and the subsequent LLDFs are discussed. Truck Run 1 will be the focus of this section. The full results for all truck runs with all relevant tables and charts are shown in Appendix A.

\subsubsection{Live Load Field Test Results}

The following section discusses the results collected from the live load field test of the Fourteen Mile Bridge. Data was collected with the BDI STS Wi-Fi Data Acquisition System, and data reduction was performed following the methods outlined in Section 4.4. The three strain readings across the bottom flange of each girder were averaged respectively to account for torsion; the strain readings from the webs were not used. Girder stresses at quarter span, where the gages were located, were computed and LLDFS were determined for comparison with the finite element model and AASHTO LRFD specifications. A sample of the raw strain data from Truck Run 1 is shown in Table 6.1. 
Table 6.1: Measured Strain from Truck Run 1, Experimental

\begin{tabular}{|c|c|c|c|c|c|c|}
\hline \multicolumn{7}{|c|}{ Truck Run 1, Measured Strain (Field) } \\
\hline \multicolumn{2}{|c|}{ Panel Points } & \multicolumn{7}{c|}{ Average Bottom Flange Strain $(\mu \varepsilon)$} \\
\hline $\mathrm{x}(\mathrm{ft})$ & $\mathrm{x} / \mathrm{L}$ & $\mathrm{G} 1$ & $\mathrm{G} 2$ & $\mathrm{G} 3$ & $\mathrm{G} 4$ & $\mathrm{G} 5$ \\
\hline 0 & 0 & 0 & 0 & 0 & 0 & 0 \\
\hline 5.8 & 0.1 & 5.513 & 2.877 & 0.157 & -1.270 & -3.635 \\
\hline 11.6 & 0.2 & 17.992 & 14.074 & 9.539 & 5.401 & 0.336 \\
\hline 17.4 & 0.3 & 34.632 & 30.154 & 21.157 & 12.541 & 4.579 \\
\hline 23.2 & 0.4 & 52.685 & 49.797 & 30.625 & 16.274 & 6.498 \\
\hline 29 & 0.5 & 64.277 & 59.563 & 35.360 & 17.456 & 6.418 \\
\hline 34.8 & 0.6 & 66.936 & 64.148 & 37.530 & 16.816 & 5.658 \\
\hline 40.6 & 0.7 & 72.247 & 71.656 & 32.655 & 11.770 & 2.987 \\
\hline 46.4 & 0.8 & 70.454 & 65.424 & 25.459 & 7.196 & 0.984 \\
\hline 52.2 & 0.9 & 42.457 & 36.502 & 12.600 & 0.863 & -2.546 \\
\hline 58 & 1 & 0 & 0 & 0 & 0 & 0 \\
\hline
\end{tabular}

\section{$\underline{6.2 .1 .1} \underline{\text { Live Load Distribution Factors }}$}

The girder strains were used to calculate the LLDFs following the procedures discussed in Section 4.4.2. The multiple presence factor was applied following the AASHTO LRFD specifications. LLDFs were calculated for each panel point in the field test, but only the LLDFs at Panel Point $5\left(0.5^{*} \mathrm{~L}\right)$ was compared to the analytical model because that position would have the maximum effect of the truck on the girders. A sample of the calculated LLDFs for Truck Run 1 is presented in Table 6.2. 
Table 6.2: Computed Live Load Distribution Factors from Truck Run 1, Experimental

\begin{tabular}{|c|c|c|c|c|c|c|}
\hline \multicolumn{2}{|c|}{ Panel Points } & \multicolumn{5}{|c|}{ Distribution Factors } \\
\hline $\mathrm{x}(\mathrm{ft})$ & $\mathrm{x} / \mathrm{L}$ & G1 & $\mathrm{G} 2$ & G3 & G4 & G5 \\
\hline 0 & 0 & --- & --- & --- & --- & --- \\
\hline 5.8 & 0.1 & 1.514 & 0.790 & 0.043 & -0.349 & -0.998 \\
\hline 11.6 & 0.2 & 0.380 & 0.297 & 0.201 & 0.114 & 0.007 \\
\hline 17.4 & 0.3 & 0.336 & 0.293 & 0.205 & 0.122 & 0.044 \\
\hline 23.2 & 0.4 & 0.338 & 0.319 & 0.196 & 0.104 & 0.042 \\
\hline 29 & 0.5 & 0.351 & 0.325 & 0.193 & 0.095 & 0.035 \\
\hline 34.8 & 0.6 & 0.350 & 0.336 & 0.196 & 0.088 & 0.030 \\
\hline 40.6 & 0.7 & 0.378 & 0.375 & 0.171 & 0.062 & 0.016 \\
\hline 46.4 & 0.8 & 0.416 & 0.386 & 0.150 & 0.042 & 0.006 \\
\hline 52.2 & 0.9 & 0.472 & 0.406 & 0.140 & 0.010 & -0.028 \\
\hline 58 & 1 & --- & --- & --- & --- & --- \\
\hline \multicolumn{2}{|c|}{ Average } & 0.504 & 0.392 & 0.166 & 0.032 & -0.094 \\
\hline \multicolumn{2}{|c|}{ MPF applied (1.2*PP5) } & 0.421 & 0.390 & 0.232 & 0.114 & 0.042 \\
\hline \multicolumn{2}{|c|}{ St. Dev. } & 0.381 & 0.154 & 0.052 & 0.147 & 0.340 \\
\hline
\end{tabular}

\subsubsection{Comparison of Analytical and Experimental Results}

This section details the comparison between the results developed from the experimental data collected in the field and the analytical values determined from the finite element analysis. The deflected shape of the finite element model is shown in Figure 6.1 and additional information is provided in Section 4.3. Table 6.3 presents a comparison between the analytical and experimental LLDFs for each girder at Panel Point 5 for the single lane loaded condition of Truck Run 1. Table 6.4 presents a similar comparison for the two lanes loaded condition of Truck Runs 1 and 4. Note the appropriate AASHTO multiple presence factor is applied in each scenario. 


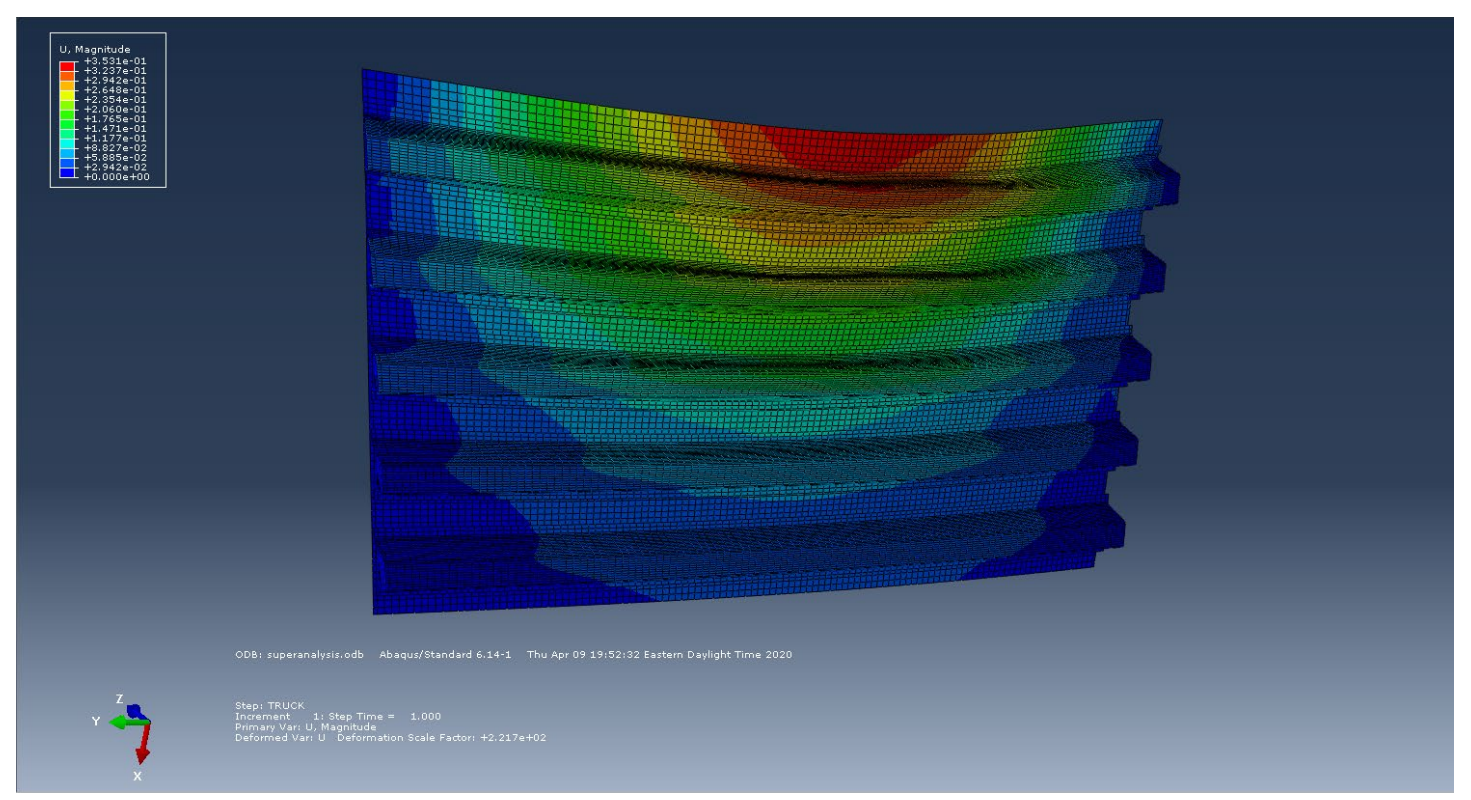

Figure 6.1: Deflected Shape of Finite Element Model, Truck Run 1, Panel Point 5

Table 6.3: Comparison of Field and FEA Live Load Distribution Factors, One Lane Loaded

\begin{tabular}{|c|c|c|c|c|c|}
\hline \multicolumn{6}{|c|}{ Truck Run 1, Distribution Factors at Panel Point 5 } \\
\hline Girder & G1 & G2 & G3 & G4 & G5 \\
\hline Field Results & 0.421 & 0.390 & 0.232 & 0.114 & 0.042 \\
\hline FEA Results & 0.440 & 0.355 & 0.217 & 0.116 & 0.072 \\
\hline
\end{tabular}

Table 6.4: Comparison of Field and FEA Live Load Distribution Factors, Two Lanes Loaded

\begin{tabular}{|c|c|c|c|c|c|}
\hline \multicolumn{5}{|c|}{ Truck Run $1 \&$ 4, Distribution Factors at Panel Point 5} \\
\hline Girder & G1 & G2 & G3 & G4 & G5 \\
\hline Field Results & 0.490 & 0.532 & 0.448 & 0.343 & 0.187 \\
\hline FEA Results & 0.502 & 0.503 & 0.440 & 0.334 & 0.221 \\
\hline
\end{tabular}


While the two methods produce similar results, some variance is still present. This may be partially due to varying boundary conditions. The Fourteen Mile Bridge utilized integral abutments as described in Section 3.2, which would yield similar results to a "fixed-fixed" end condition and a stiffer structure due to the decrease in rotation at the supports. There is not an adequate manner to model integral abutments in the finite element analysis, so simply supported ("hinge-roller") conditions were used in the analytical model. The results are both in line with each other in the sense of the amount of the given loading scenario that will get distributed to each girder. Figure 6.2 presents a Q-Q plot reflecting the comparison of each girder's distribution factors at Panel Point 5. Note the $\mathrm{R}^{2}$ value represents the correlation of the entire data set, both single and two-lane loaded scenarios.

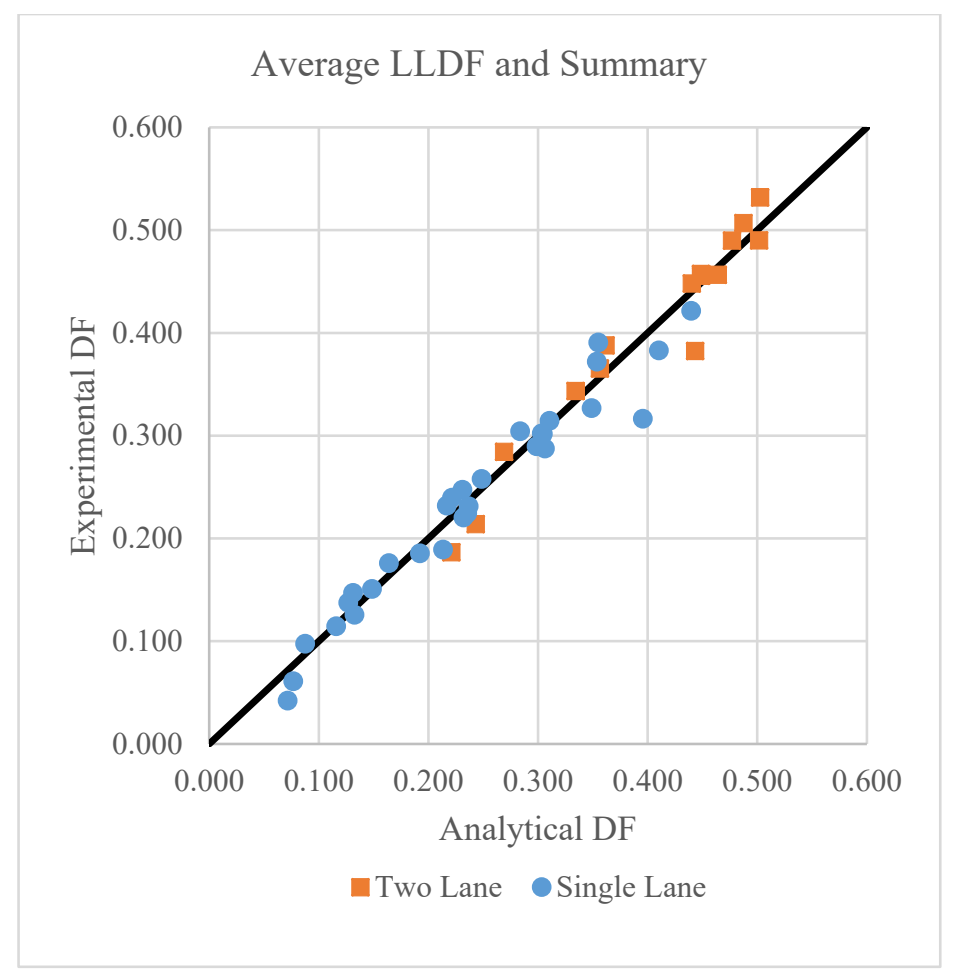

Figure 6.2: Comparison Between Analytical and Experimental Live Load Distribution Factors for Single and Two Lane Loaded Conditions 


\subsection{Comparison OF Live Load Distribution Factors with AASHTO LRFD SPECIFICATIONS}

This section will provide a comparison between LLDFs determined from the experimental data of the live load field test, the analytical data from the finite element model, and the relevant AASHTO LRFD specifications. LLDFs calculated with the expressions from the 2017 AASHTO LRFD specifications already take the multiple presence factors into consideration, so the comparison for each scenario will have the appropriate multiple presence factors applied. Calculations for the AASHTO LLDFs are presented in Section 4.4.2. Truck Run 1 will be used for comparison between the three methods for the single lane condition. Table 6.5 and Figure 6.3 provide a comparison of the three methods.

Table 6.5: Comparison of Field, FEA and AASHTO Live Load Distribution Factors,

One Lane Loaded Truck Run 1

\begin{tabular}{|c|c|c|c|c|c|}
\hline \multicolumn{7}{|c|}{ Truck Run 1, Distribution Factors at Panel Point 5 } \\
\hline Girder & G1 & G2 & G3 & G4 & G5 \\
\hline Field Results & 0.421 & 0.390 & 0.232 & 0.114 & 0.042 \\
\hline FEA Results & 0.440 & 0.355 & 0.217 & 0.116 & 0.072 \\
\hline AASHTO & 0.603 & 0.603 & 0.603 & 0.603 & 0.603 \\
\hline
\end{tabular}




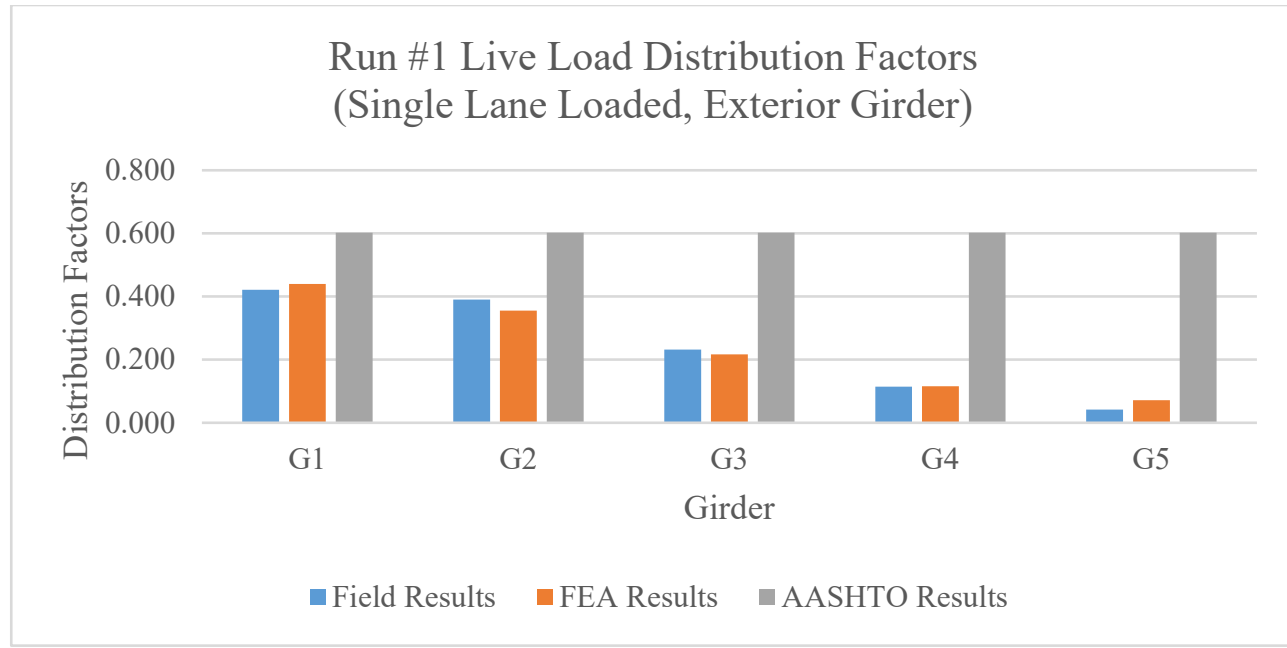

Figure 6.3: Comparison of Field, FEA and AASHTO Live Load Distribution Factors, One Lane Loaded Truck Run 1

LLDFs determined from the field results and the analytical model are similar; the AASHTO equations predict a much higher distribution factor for the single lane loaded condition. A comparison between the three methods for the two-lane loaded scenario is presented in Table 6.6 and Figure 6.4. Again, the LLDFs for both the analytical and experimental methods are close, but the AASHTO values are significantly higher. The discrepancy between AASHTO and the analytical and experimental methods is increased for girders further away from the placement of the load truck.

Table 6.6: Comparison of Field, FEA, and AASHTO Live Load Distribution Factors, Two Lanes Loaded Truck Run 1 and 4

\begin{tabular}{|c|c|c|c|c|c|}
\hline \multicolumn{6}{|c|}{ Truck Run 1 \& 4, Distribution Factors at Panel Point 5 } \\
\hline Girder & G1 & G2 & G3 & G4 & G5 \\
\hline Field Results & 0.490 & 0.532 & 0.448 & 0.343 & 0.187 \\
\hline FEA Results & 0.502 & 0.503 & 0.440 & 0.334 & 0.221 \\
\hline AASHTO & 0.603 & 0.603 & 0.603 & 0.603 & 0.603 \\
\hline
\end{tabular}




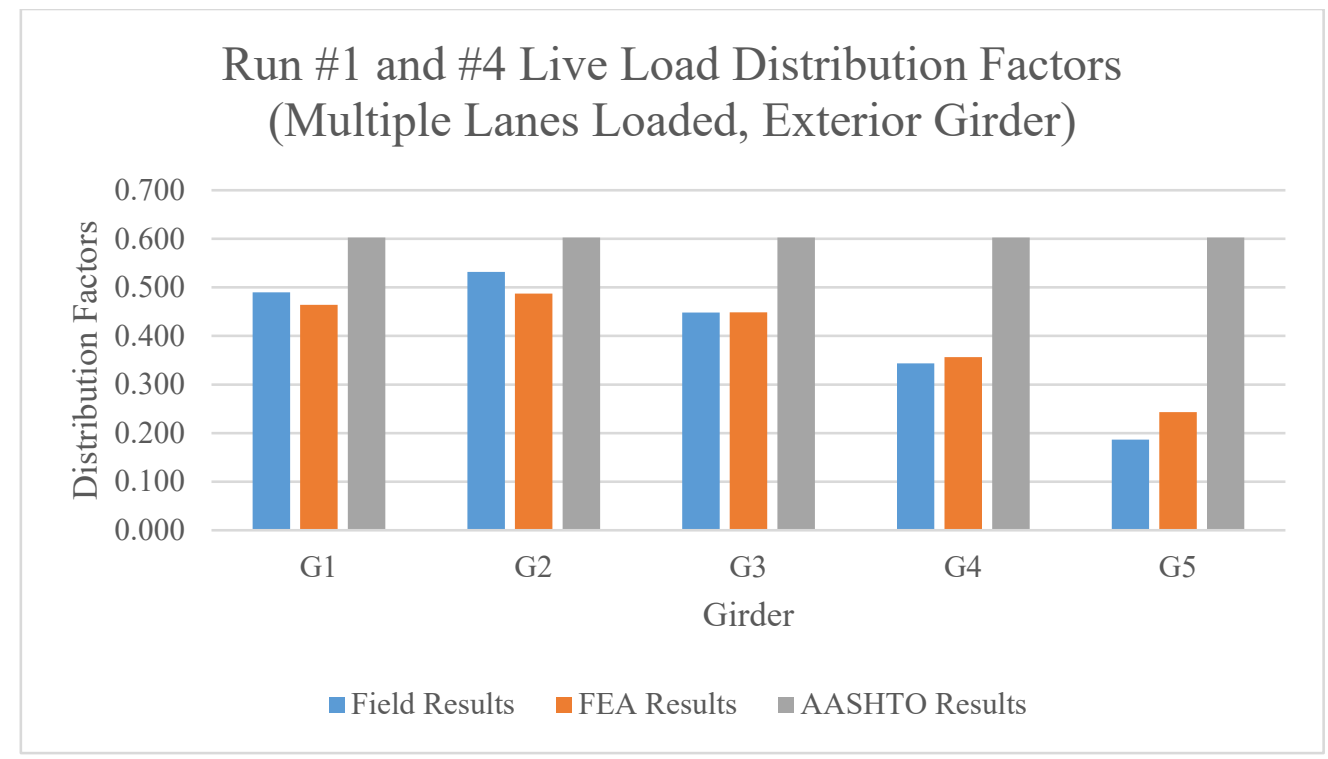

Figure 6.4: Comparison of Field, FEA, and AASHTO Live Load Distribution Factors, Two Lanes Loaded Truck Run 1 and 4

\subsection{Conclusions}

This chapter provided a summary of the results computed from the experimental data from the field test of the Fourteen Mile Bridge along with the finite element analysis performed. The data was used to calculate the LLDFs for the field data and the analytical data and the computed LLDFs were then compared to the LLDFs calculated following the AASHTO LRFD specifications to assess the applicability of AASHTO in regards to press-brake-formed tub girders. The comparison showed minor differences in LLDFs between the finite element model and the experimental results, likely due to the differing boundary conditions. In all cases, the AASHTO LLDFs underpredicted the performance of the press-brake-formed tub girder and were more conservative than the experimental and analytical values. Therefore, AASHTO LLDFs may be safely used in the application of press-brake-formed steel tub girder bridges. 


\section{CHAPTER 7: QUALitATive ASSESSMENT OF BRACING}

\section{EFFECTIVENESS AND TORSIONAL RESPONSE FOR NON-COMPOSITE TUB GIRDERS}

\subsection{INTRODUCTION}

When press-brake-formed tub girders are used in conjunction with a precast reinforced concrete deck, the top flanges are fully supported during casting. In cases where a cast-in-place reinforced concrete deck is used, significant loading is placed on the top flanges. This can lead to instability issues as the open shape of the non-composite tub girder is susceptible to torsional effects. Bracing may be added either to the interior or the exterior of the tub shape to control undesirable deflection. This chapter examines work performed by Kelly (2014) on non-composite behavior of press-brake-formed steel tub girders and evaluates different bracing scenarios from a qualitative view. Abaqus/CAE 6.14-1 (Dassault Systèmes, 2014) was utilized to create a finite element model for each scenario and a nonlinear analysis was performed. Program files from MATLAB (The Mathworks, Inc., 2020 used to write the Abaqus input files are included in Appendix B of this report.

\subsection{VERIFICATION WITH KELLY'S MODEL}

\subsubsection{Geometric Imperfections}

A significant discrepancy in the critical load that led to buckling in the experiments performed by Kelly (2014) was attributed to geometric imperfections that were induced during the fabrication process of the press-brake-formed tub girder. Flange inclinations and web inclinations 
were recorded for each specimen. Plots of the recorded flange inclination and web inclination for each specimen are presented in Figure 7.1 and 7.2.

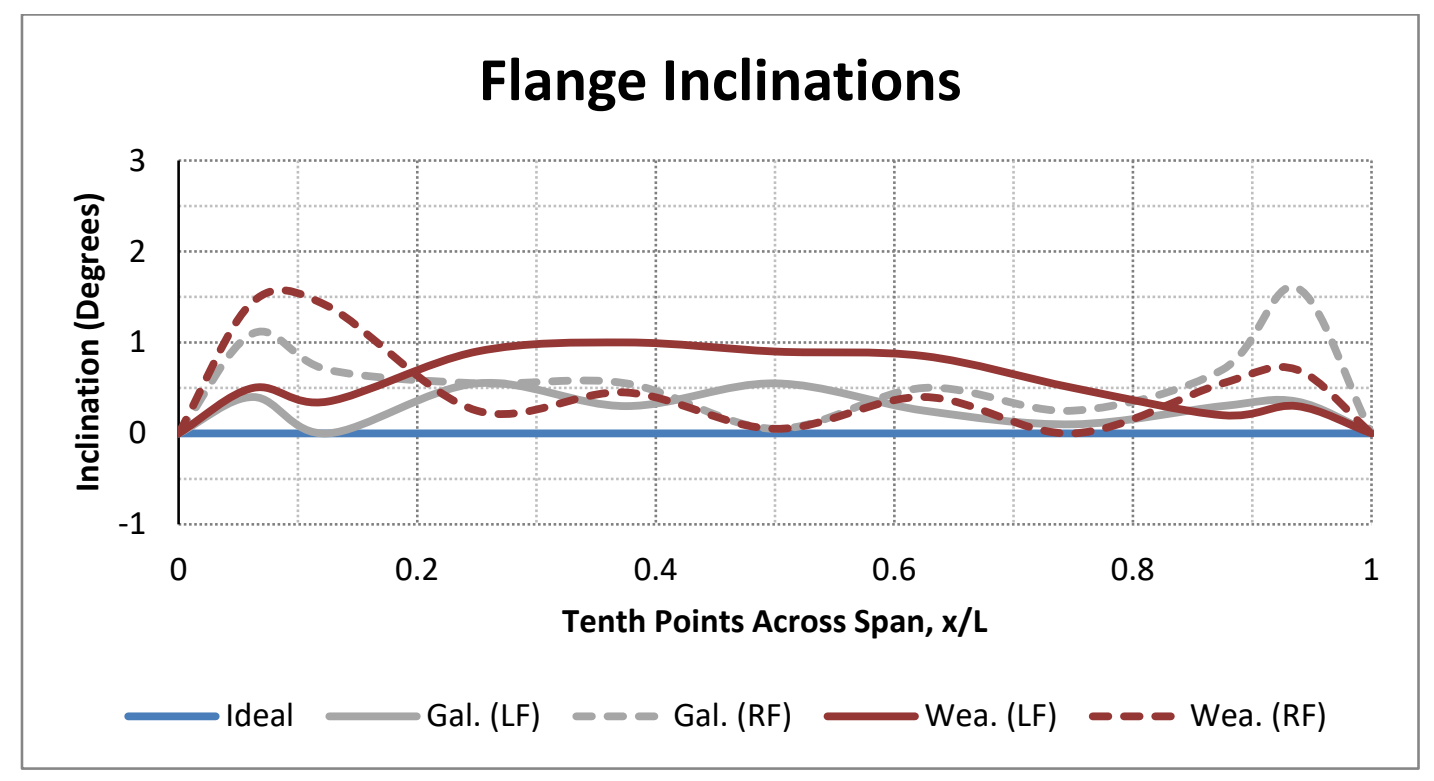

Figure 7.1: Flange Inclinations (Kelly, 2014)

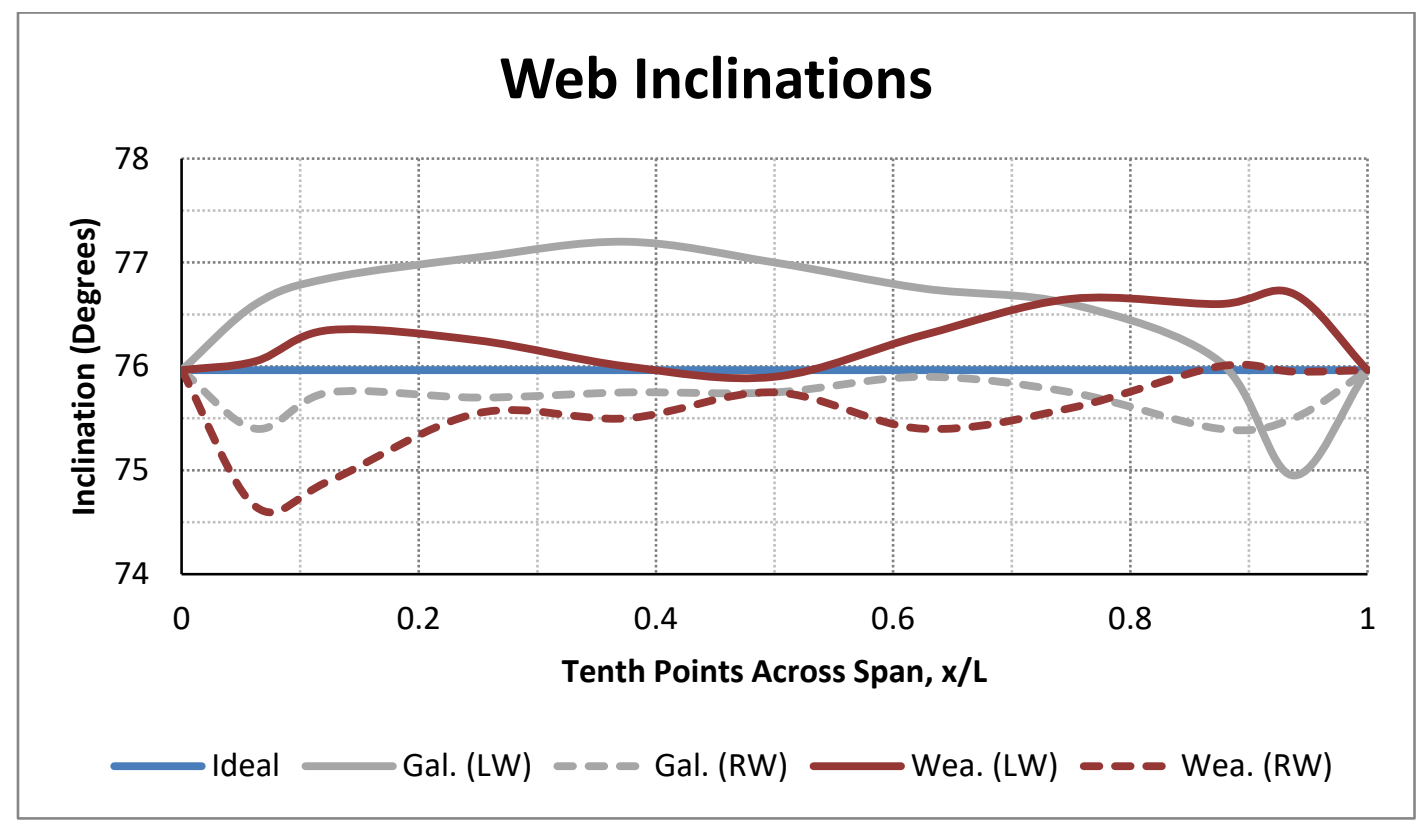

Figure 7.2: Web Inclinations (Kelly, 2014) 
The finite element model was developed to induce the imperfections onto the generated mesh based on user inputs. The geometric imperfections separated into flange tilt, girder twist, and web out of flatness. Each of the geometric imperfections was modeled to follow a sine curve with the maximum amplitude and anchor points specified by the user to control the imperfection across the mesh. Figures 7.3 through 7.5 present an exaggerated view of the effect of flange tilt, girder twist, and web out of flatness, respectively.

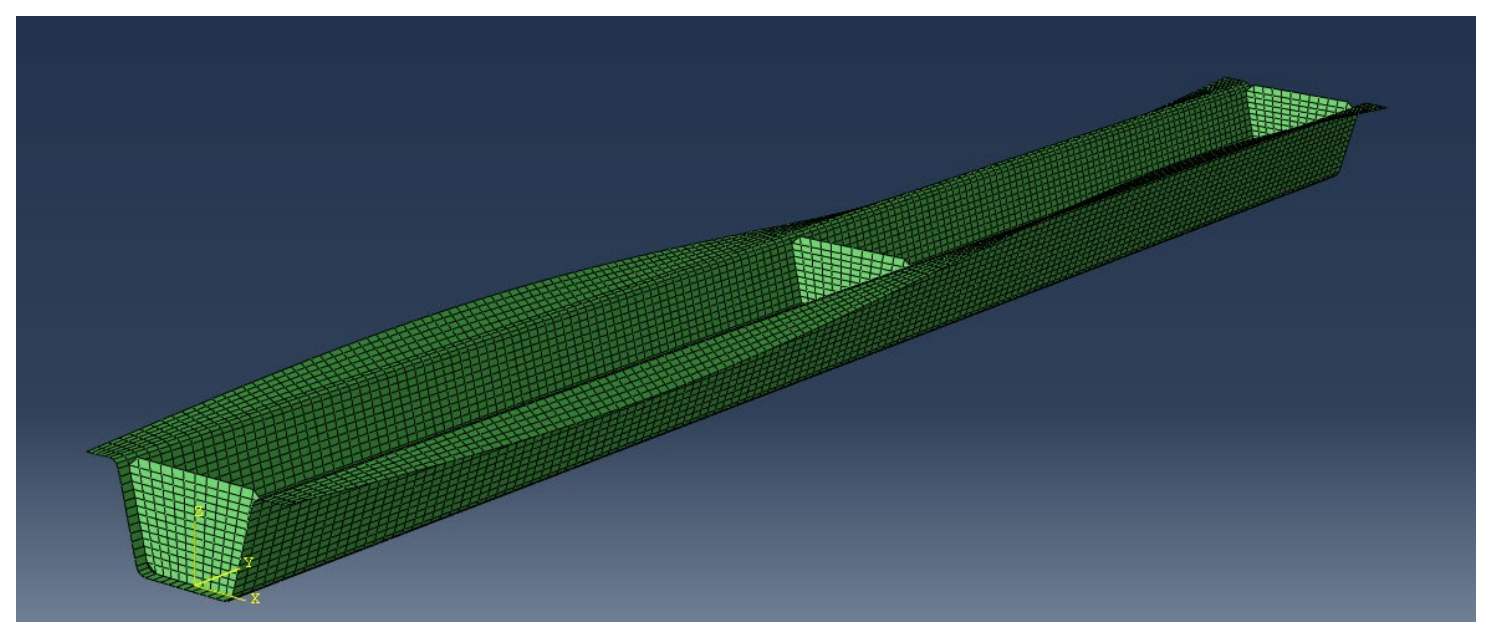

Figure 7.3: Tub Girder Modeled with Flange Tilt

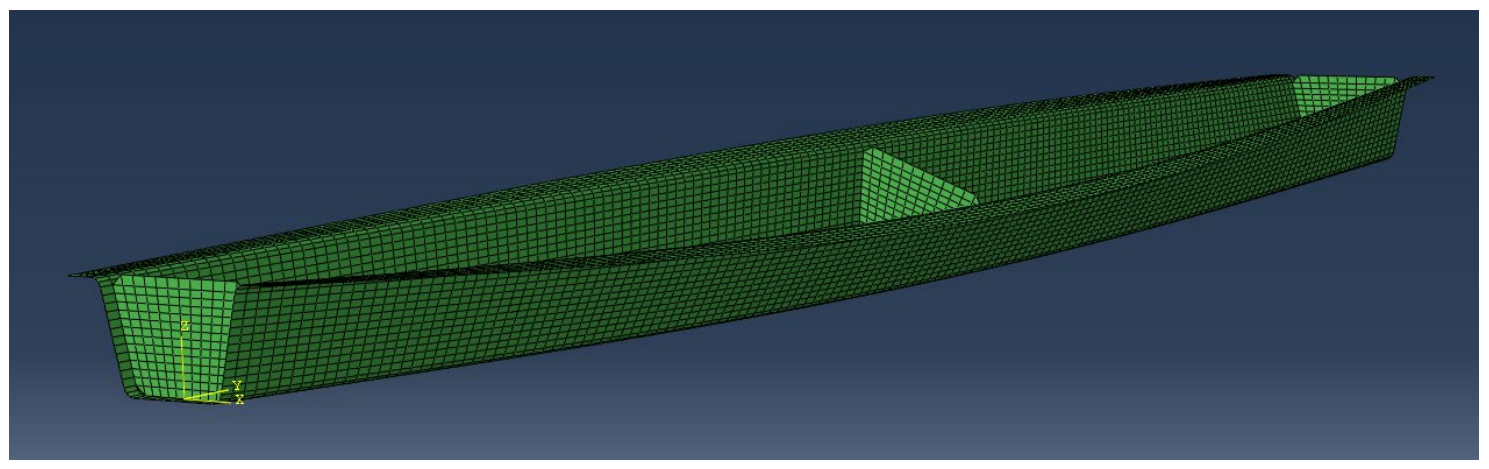

Figure 7.4: Tub Girder Modeled with Girder Twist 


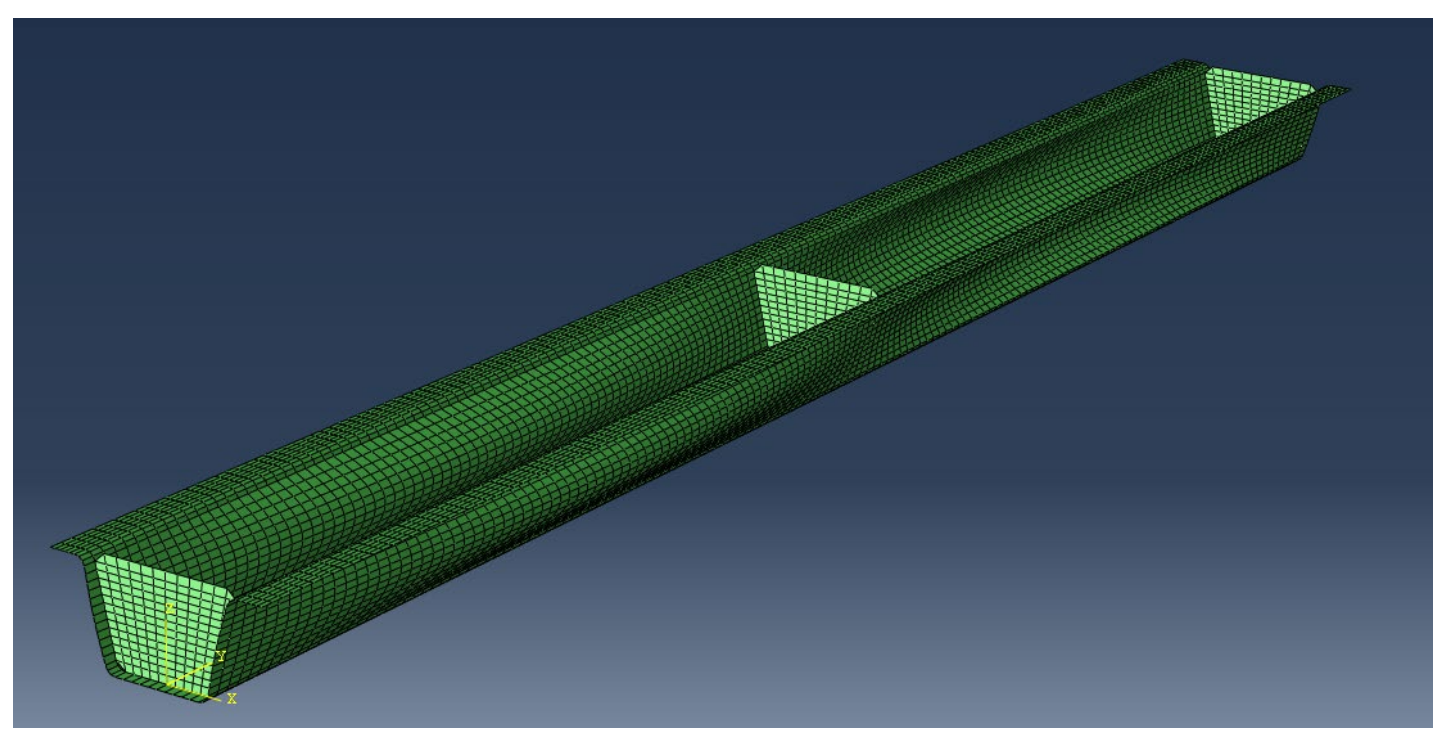

Figure 7.5: Tub Girder Modeled with Web Out of Flatness

To best fit the geometric imperfections that were recorded by Kelly (2014), only the flange tilt and girder twist were considered. Using the recorded data previously mentioned in Figures 7.1 and 7.2, the amplitude for each imperfection was determined. The peak values were input as $1^{\circ}$ of flange tilt clockwise and $1^{\circ}$ of girder twist clockwise. For both imperfections, the end supports were selected as the anchor points to best fit the model.

\subsubsection{Material Modeling}

To capture the behavior of a nonlinear analysis, steel material in the finite element model was modeled using an elastic-plastic constitutive law following work by Michaelson (2014) and Kelly (2014). A multilinear relationship (Galindez, 2009) was uses to represent the stress-strain behavior of material modeling (Figure 7.6) and (Table 7.1). The plastic material properties are a function of the true stress and strain, and these are input into the Abaqus input file. 


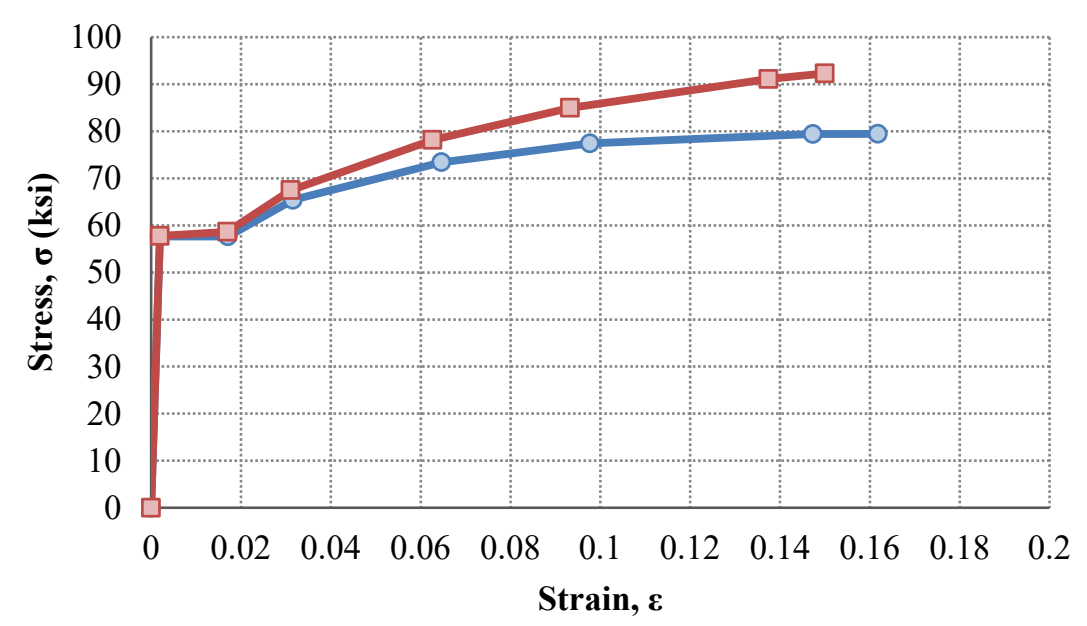

$\multimap$ Engineering $\quad \square-$ True

Figure 7.6: Multi-linear Stress-Strain Curve

Table 7.1: Expressions for Computing Steel Stress-Strain Behavior (Galindez, 2009)

Point Strain

1

$$
\varepsilon_{1}=\frac{\sigma_{y}}{E}
$$

2

$3 \quad \varepsilon_{3}=\frac{1}{10}\left(\varepsilon_{u}-\varepsilon_{s t}\right)+\varepsilon_{s t}$

4

$5 \quad \varepsilon_{5}=\frac{2}{7}\left(\varepsilon_{6}-\varepsilon_{3}\right)+\varepsilon_{4}$

$6 \quad \varepsilon_{6}=\varepsilon_{u}-\frac{1}{10}\left(\varepsilon_{u}-\varepsilon_{s t}\right)$

$7 \quad \varepsilon_{7}=\varepsilon_{u}$
Stress

$\sigma_{1}=\sigma_{y}$

$\sigma_{2}=\sigma_{y}$

$\sigma_{3}=\frac{E_{s t}}{10}\left(\varepsilon_{u}-\varepsilon_{s t}\right)+\sigma_{y}$

$\sigma_{4}=\frac{4}{7}\left(\sigma_{6}-\sigma_{3}\right)+\sigma_{3}$

$\sigma_{5}=\frac{2}{7}\left(\sigma_{6}-\sigma_{3}\right)+\sigma_{4}$

$\sigma_{6}=\left(\frac{\sigma_{y}}{\sigma_{0.2 \%}}\right) \sigma_{u}-\frac{100}{E_{s t}}\left(\varepsilon_{u}-\varepsilon_{s t}\right)$

$\sigma_{7}=\left(\frac{\sigma_{y}}{\sigma_{0.2 \%}}\right) \sigma_{u}$ 


\subsubsection{Element Selection}

Abaqus (2014) provides complete geometric modeling capabilities with a variety of available element types. General shell elements with reduced integration (S4R) are used for modeling the steel girders in this study. As shown by several researchers (Barth, 1996; Yang, 2004; Roberts, 2004; Righman, 2005), S4R shell elements are very accurate in modeling the physical behavior of non-composite steel plate girders. These 4-node general-purpose elements are intended to provide accurate solutions for both thin and thick shells, using classical (Kirchoff) shell theory when appropriate for thin shells and (Mindlin) shell theory as the thickness increases.

These elements allow for finite membrane strains and rotations of the shell, change in shell thickness as a function of the membrane strain, and transverse shear deformation. Therefore, they are suitable for large-strain analysis involving inelastic deformation of materials. The S4R element is a first-order element having only one integration point used to form the element stiffness matrix. S4R elements offer many advantages over traditional shell elements these include: strains and stresses are computed at the locations providing optimal accuracy and fewer integration points result in reduced computing time and storage requirements.

The primary disadvantage of using reduced integration is that deformation modes which cause no strain at the integration points may develop. This may lead to inaccurate results if these zero-energy modes propagate through the structure in a phenomenon commonly known as hourglassing. However, this can be prevented by the user by introducing a small artificial stiffness associated with zero-energy deformation modes using the *SECTION CONTROLS command in an Abaqus input file (Kelly 2014; Michaelson, 2014). 


\subsubsection{Riks Loading Algorithm}

The girders studied in this work are analyzed using the modified Riks algorithm available in Abaqus (2014). This solution method captures the nonlinear load deflection response of the FEA model at and beyond maximum loading. The modified Riks method is capable of obtaining a complete nonlinear solution and giving information on girder behavior in both loading and unloading regions (Yang, 2004).

It is assumed the loading is proportional and the response is smooth (no sudden bifurcations). Furthermore, this method uses the load magnitude as an additional unknown and solves simultaneously for loads and displacements. Because the progress of the solution is independent of the load increment, Abaqus uses the "arc length" to control the increment size. The arc length is the distance along the static equilibrium path in the load-displacement space. This value is initially proved by the user and later adjusted by the Abaqus automatic load increment algorithm, which is based on convergence rate.

The essence of this method is that the solution is viewed as the discovery of a single equilibrium path in a space that is defined by the nodal variables and loading parameter. The solution is found during each increment by moving a given distance along a tangent to the current solution point and searching for equilibrium in the plane that not only passes through the point, but also is orthogonal to the same tangent line (Yang, 2004). The total path length is determined by the load magnitudes the user specifies. The user also determines the number of increments. (Kelly, 2014) 


\subsubsection{Comparison with Kelly's Model}

Once the finite element model was developed, an evaluation of an unbraced girder was performed as a benchmark with the experimental and analytical data that Kelly (2014) had recorded. A plot of the comparisons between the two analyses is presented in Figure 7.7. Note that little discrepancy exists between the two models; when full load is applied, approximately a 0.05 " difference between the vertical displacement of each model exists. Therefore, this developed finite element model is suitable for use in comparison between bracing options and an unbraced girder.

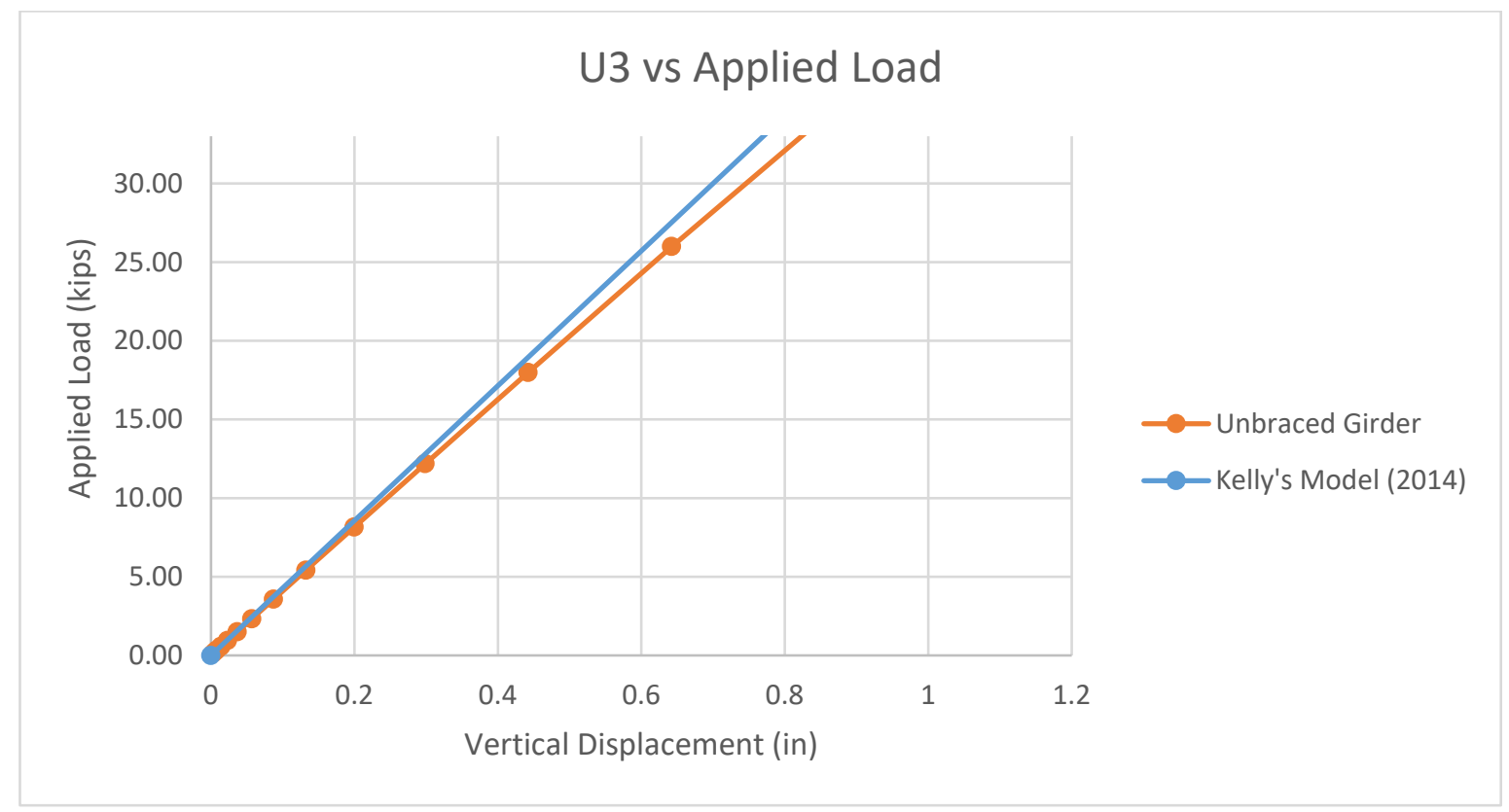

Figure 7.7: Vertical Deflection at Midspan for Unbraced Girder and Kelly (2014) 


\subsection{BraCing SCENARIOS}

\subsubsection{Internal Bracing Scenarios}

Bracing schemes were examined for both the interior and exterior of the girder. Braces were modeled on a press-brake-formed tub girder constructed from an 84 " $\mathrm{x}^{7} / 16$ " plate. Four different bracing scenarios were implemented, each using L $4 x 4 x^{5} / 8$ " angle for the brace members. Each transverse brace was spaced at three times the depth of the girder from one another, or 69" in the case of the modeled girder. A visual representation of the four internal bracing scenarios is provided in Figure 7.8.

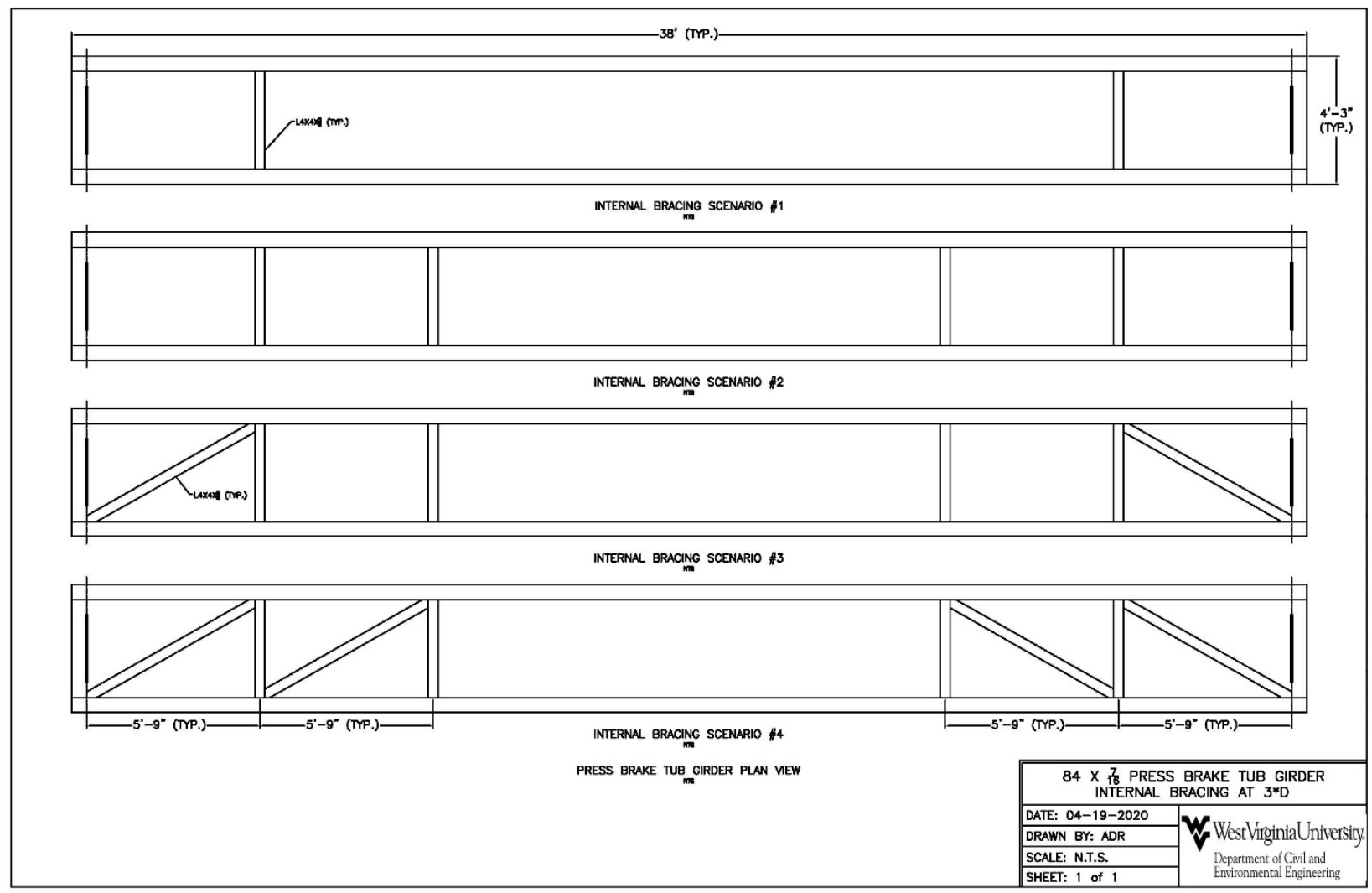

Figure 7.8: Internal Bracing Scenarios 


\subsubsection{External Bracing Scenarios}

In addition to the internal bracing scenarios, three external bracing options were modeled. A press-brake-formed tub girder constructed from $84 " x 7 / 16$ " plate was used for each external bracing scenario so that adequate comparisons could be made. External braces were placed at midspan for scenario 1, third points for scenario 2, and quarter points for scenario 3. External bracing was modeled in Abaqus/CAE through the use of boundary conditions to provide lateral support at the locations of interest. A visual representation of the three external bracing scenarios is provided in Figure 7.9.

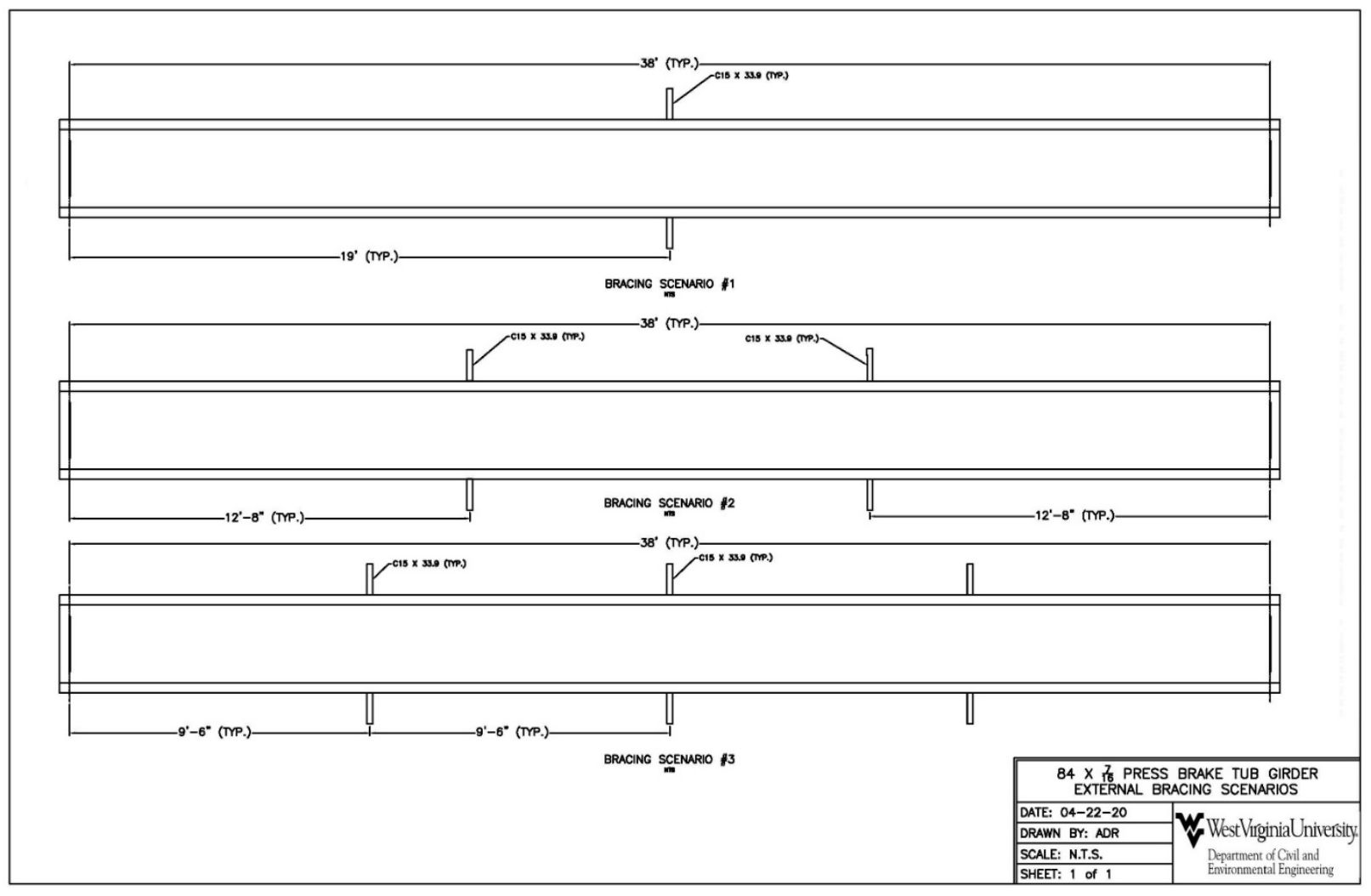

Figure 7.9: External Bracing Scenarios 


\subsection{Results of Finite Element ANAlysis}

This section discusses the results that were achieved as a function of the finite element analysis. Both the set of internal braces and external braces were compared to the unbraced girder as a benchmark to assess resistant to torsion. Static Riks loading was applied to the structure and plots were developed from the load proportionality factors available in the Abaqus/CAE .dat file. For the purposes of these plots, U1 refers to the lateral displacement and U3 refers to the vertical displacement. The plots stop at 33 kips of applied load because this was the critical load to induce buckling in the unbraced girder in Kelly’s Experiment (2014).

\subsubsection{Comparison of Internal Bracing Scenarios}

The first analyses were performed on the internal bracing options. L $4 x 4 x^{5} / 8$ " angle was used for each interior bracing member and each member was modeled as a beam element in the finite element model. From the load proportionality factors, plots of U1 and U3 for each load increment were produced. Figure 7.10 shows the lateral displacement for each of the internal bracing options and Figure 7.11 shows the vertical displacement for each of the internal bracing

options. It should be noted that while internal bracing has little effect on the vertical displacement at midspan, lateral displacement is reduced. Specifically, in the cases of internal bracing options where a diagonal brace is used, the decrease in lateral displacement is significant. 


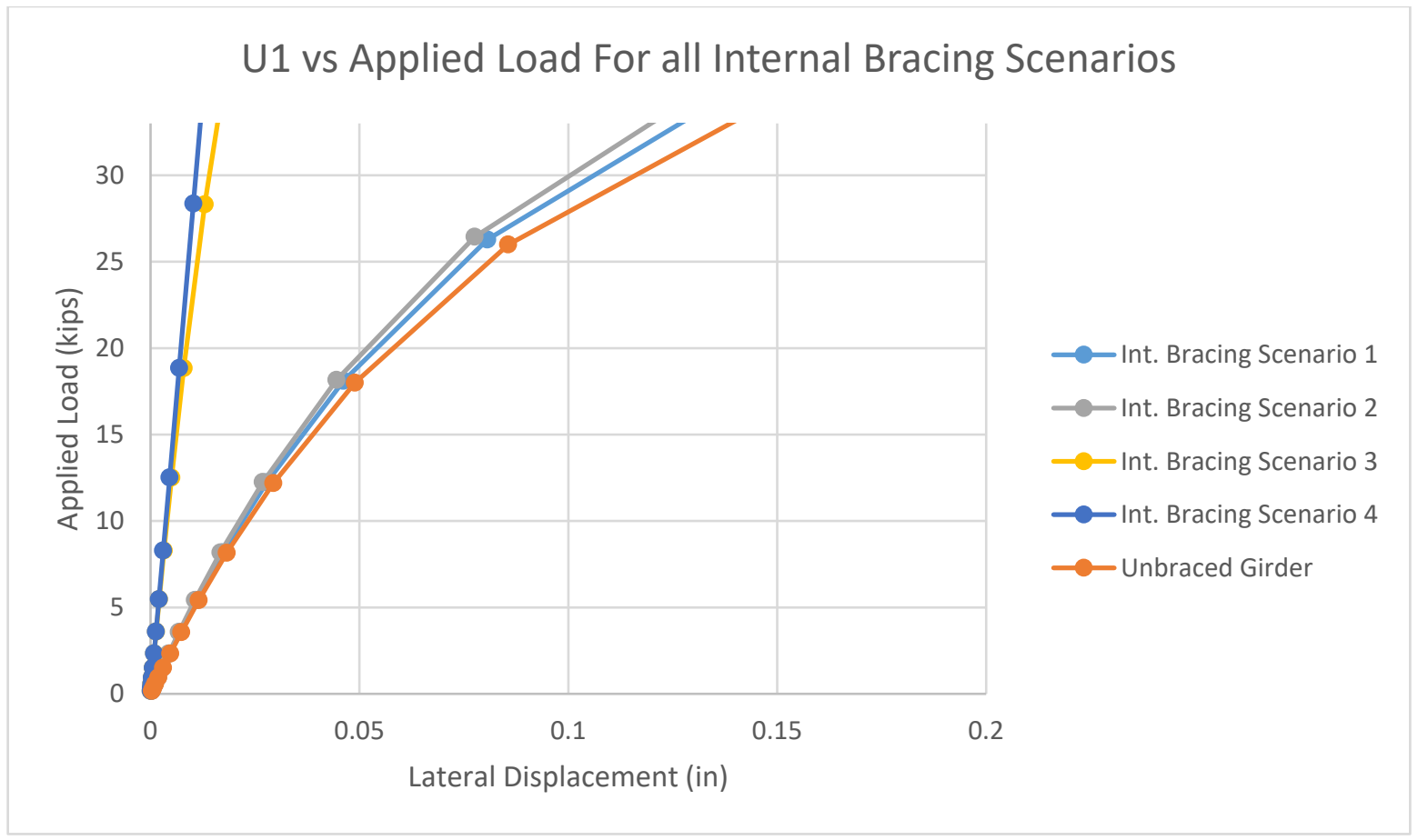

Figure 7.10: Lateral Displacement Comparison for Internal Bracing Scenarios

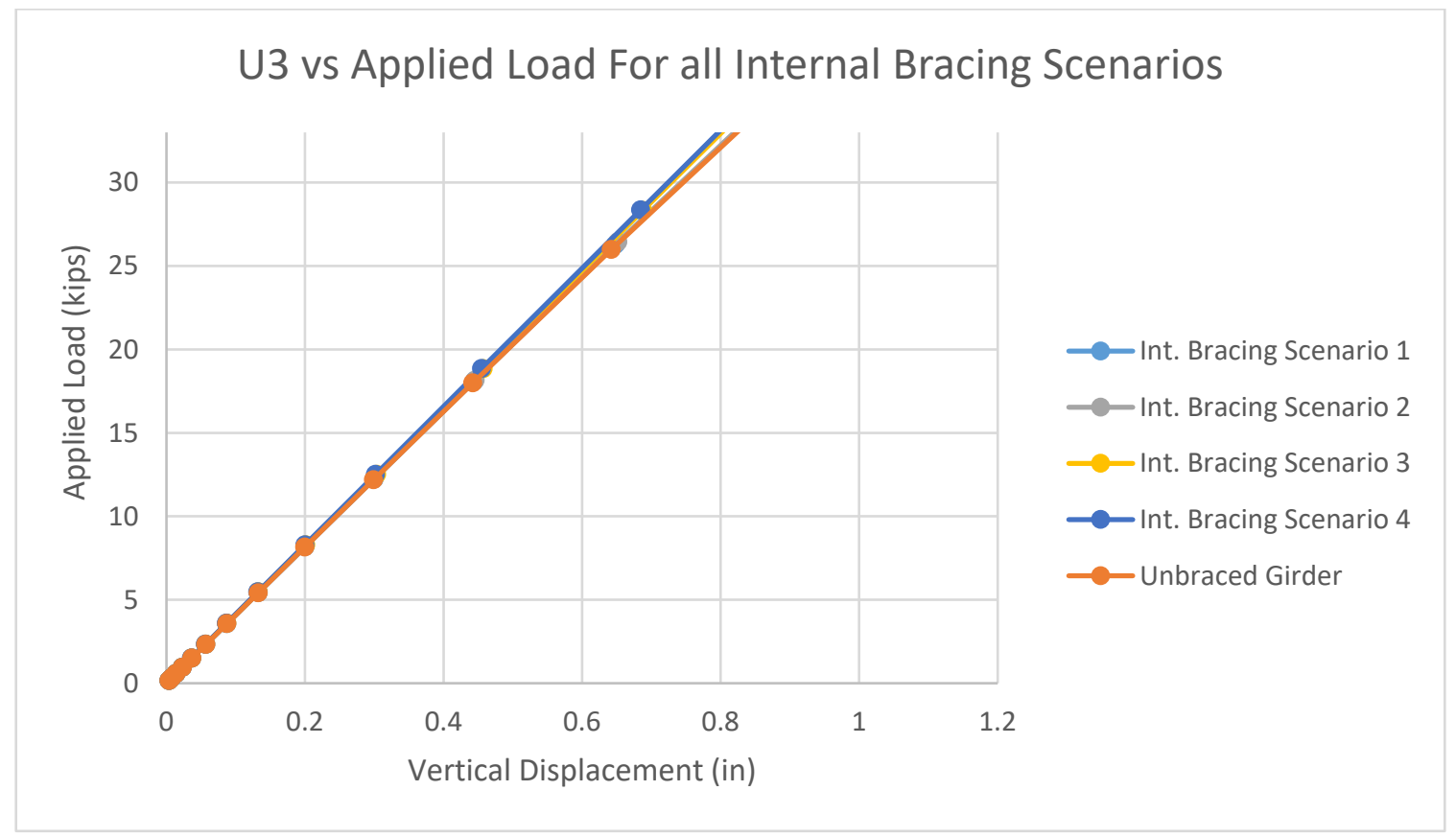

Figure 7.11: Lateral Displacement Comparison for Internal Bracing Scenarios 


\subsubsection{Comparison of External Bracing Scenarios}

After the internal bracing analyses were completed, analyses were performed on the external bracing options. Lateral support was added at points of interest through boundary conditions at the web to resist lateral movement. From the load proportionality factors, plots of U1 and U3 for each load increment were produced. Figure 7.12 shows the lateral displacement for each of the external bracing options and Figure 7.13 shows the vertical displacement for each of the external bracing options. Similar to the internal bracing, external bracing has little effect on the vertical displacement at midspan. However, all three exterior bracing options have comparable resistance to lateral displacement, which is significantly less than the unbraced girder.

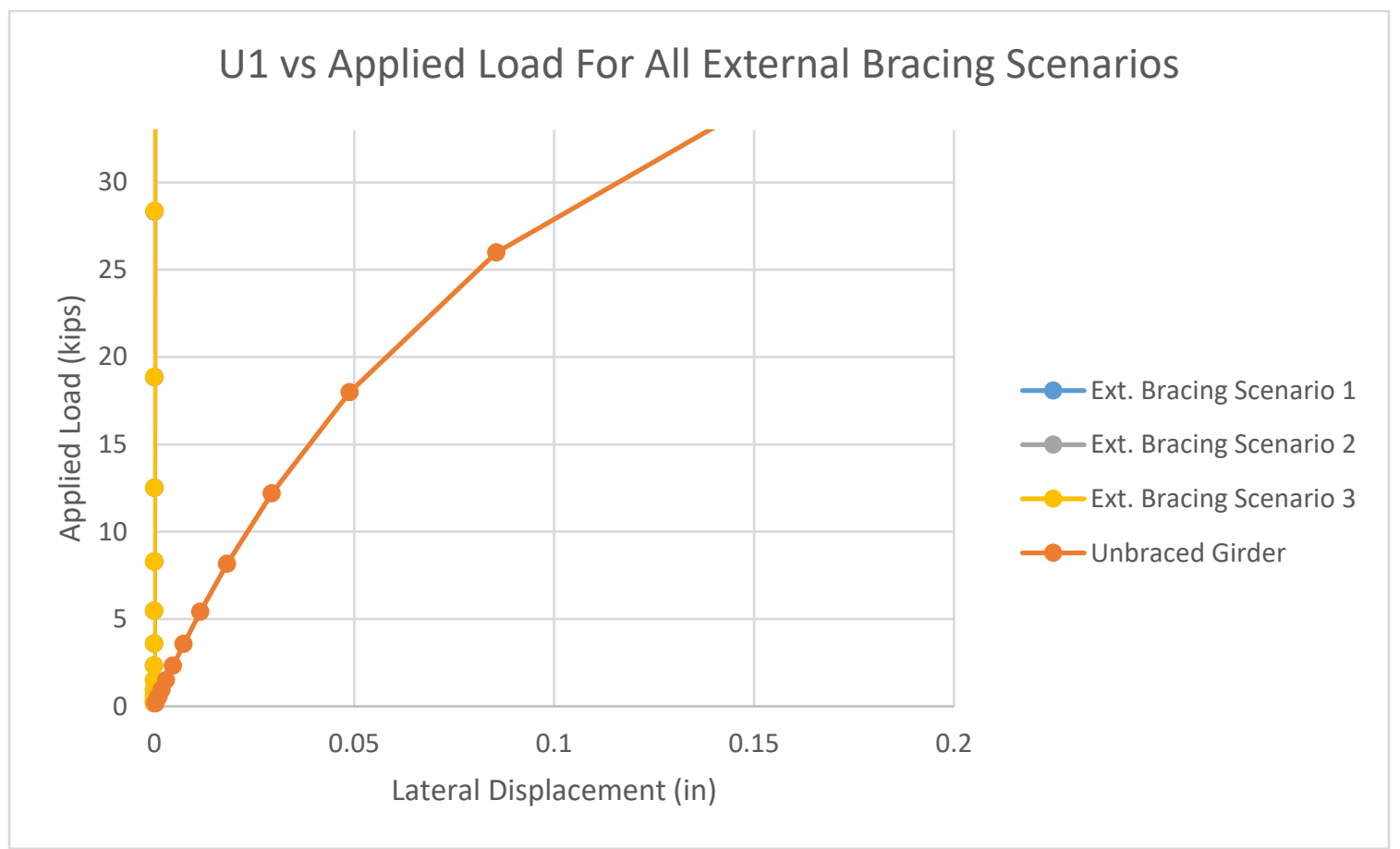

Figure 7.12: Lateral Displacement Comparison for External Bracing Scenarios 


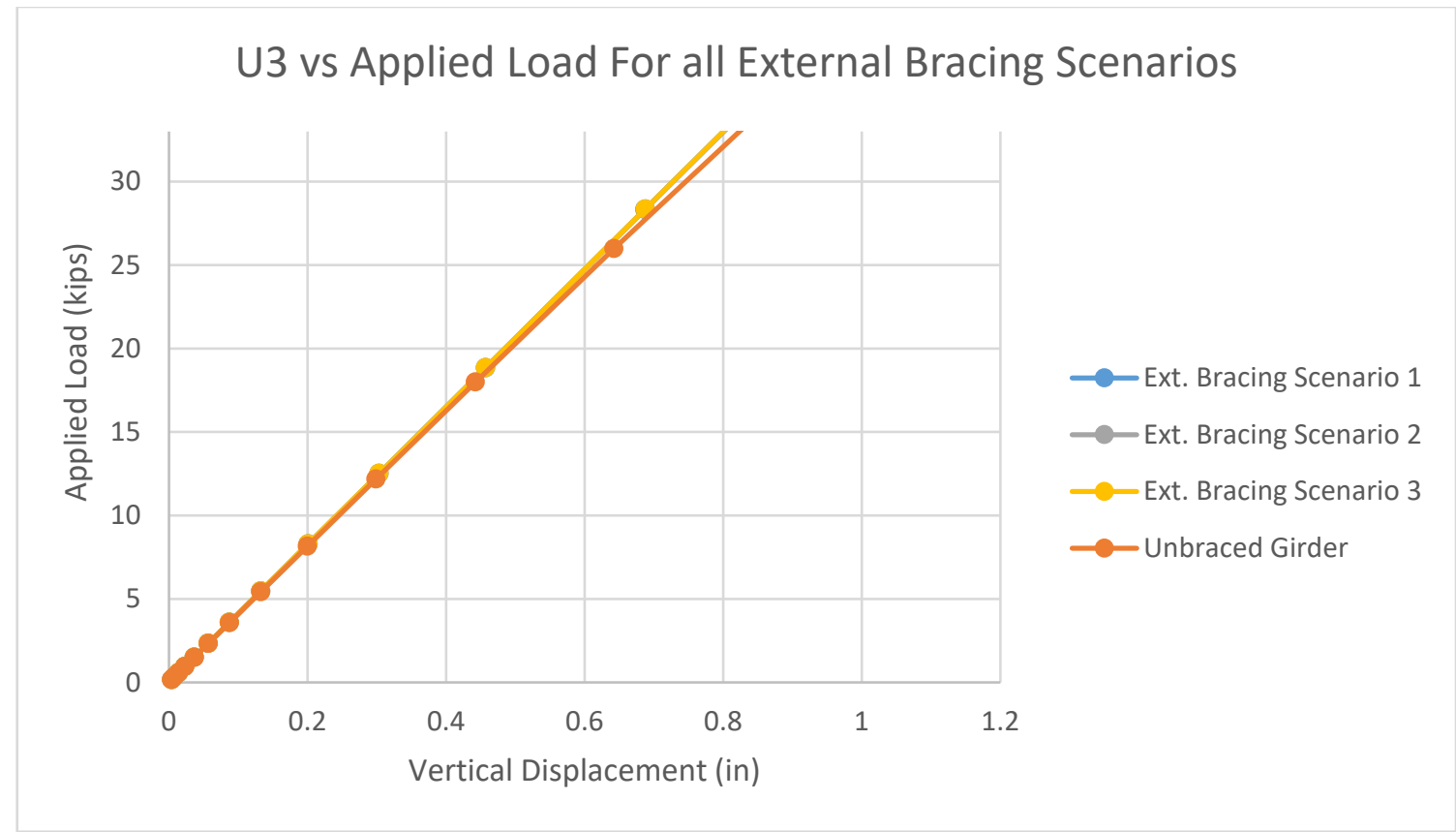

Figure 7.13: Vertical Displacement Comparison for External Bracing Scenarios

\subsection{CONCLUSIONS}

When employing a cast-in-place reinforced concrete deck in conjunction with press-brakeformed steel tub girders, it is important to consider the stability of the non-composite section under the effect of construction loading from placement of the wet concrete. Significant torsional amplification is possible, and the non-composite girder must have adequate lateral support to resist rotation and buckling. From the analyses ran, it was observed that the effect of diagonal struts for internal braces as in cases 3 and 4 lead to a greater reduction in lateral displacement than the use of transverse braces alone. All external bracing options performed similar and each provided a significant reduction in lateral displacement. Further work is necessary to extend this initial qualitative modeling into sound reasoning for best practices for maintaining stability of the noncomposite girder. 


\section{CHAPTER 8: CONCLUSIONS AND RECOMMENDATIONS}

\subsection{Project Summary ANd Conclusions}

The scope of this thesis was to evaluate the field performance of a modular press-brakeformed steel tub girder topped with a precast reinforced concrete deck in an application including skew and significant superelevation and compare that to analytical testing through finite element analysis and expected performance determined by AASHTO LRFD specifications. Bottom flange strain was recorded, and the LLDFs were determined for each method. The LLDFs determined with the experimental data and the analytical results showed little discrepancy, but both were lower than the LLDFs computed per AASHTO LRFD specifications. However, AASHTO does not specify a different expression for the calculation of LLDFs in regards to interior and exterior girder or the loading of single or multiple lanes. In either case, the AASHTO LLDFs were conservative, and are therefore safe to use in the design of press-brake-formed-tub girder systems.

\subsection{RECOMMENDATIONS FOR CONTINUED WORK}

The following are recommended for future work in this area:

- Current manufacturing methods limit the span length of press-brake-formed steel tub girders to 80 '-0”'. Research could be performed to determine methods that the span length may be increased and to determine the economic feasibility of longer spans. 
- In cases where several spans are used, preferred detailing of the pier region should be examined to understand how the girders behave in the negative bending regions.

- An initial assessment of different bracing option for the non-composite girder was performed in this thesis. Further work can investigate the ideal detailing and best practices for this bracing.

- Additional work could be performed to further define the lateral torsional buckling behavior of the press-brake-formed tub girders as a function of unbraced length. 


\section{REFERENCES}

(2017). AASHTO LRFD Bridge Design Specifications. Washington, DC: American Association of State Highway and Transportation Officials.

Barth, K. E. (1996). Moment-Rotation Characteristics for Inelastic Design of Steel Bridge Beams and Girders. School of Civil Engineering. West Lafayette, IN, Purdue University. Doctor of Philosophy.

Barth, K. E., Barth, A. S., Michaelson, G. K., Gibbs, C. L., \& Tennant, R. M. (2017). Evaluation of SMDI short span steel bridge design standards.

Bertoldi, A. G. (2009). A strength and serviceability assessement of high performance steel bridge 10462 (Master's thesis). Available from ProQuest.

Bridge Diagnostics, Inc. (n.d.). STS-WiFI Operations Manual. Boulder, CO.

Bridge Engineering Software \& Technology (BEST) Center. (2000). Report on the Determination of Redundancy of the U.S. Bridge Corporation Bridge 3000. University of Maryland, Civil Engineering.

Burgueño, R., \& Pavlich, B. S. (2008). Evaluation of prefabricated composite steel box girder systems for rapid bridge construction. (Report No. RC-1507).

Burner, K. A. (2010). Experimental investigation of folded plate girders and slap joints used in modular construction (Master's Thesis). Available from University of Nebraska-Lincoln Database.

Chandar, G., Hyzak, M. D., \& Wolf, L. M. (2010). Rapid, economical bridge replacement. Available from Modern Steel Construction. 
Connor, R. J., Dexter, R., \& Mahmoud, H. (2005). NCHRP Synthesis 354: Inspection and Management of Bridges with Fracture-Critical Details. National Cooperative Highway Research Program.

Culmo, M. P. (2011). Accelerated bridge construction: Experience in design, fabrication and erection of prefabricated bridge elements and systems (Report No. FHWA-HIF-12-013). U. S. Department of Transportation, Federal Highway Administration.

Dassault Systèmes (n.d.) Abaqus/CAE User's Guide. Providence, RI.

Galindez, N. Y. (2009). Levels of Lateral Flange Bending in Straight, Skewed and Curved Steel IGirder Bridges During Deck Placement (Doctoral dissertation). Available from ProQuest.

Gibbs, C. L. (2017). Field performance assessment of press-brake-formed steel tub girder superstructures (Master's thesis). Available from ProQuest.

Glaser, L. A. (2010). Constructability testing of folded plate girders (Master's Thesis). Available from University of Nebraska-Lincoln Database.

Graybeal, B.A. and Swenty, M., "UHPFRC for Prefabricated Bridge Component Connections," Proceedings of Hipermat 2012 3rd International Symposium on UHPC and Nanotechnology for High Performance Construction Materials, Ed., Schmidt, M., Fehling, E., Glotzbach, C., Fröhlich, S., and Piotrowski, S., Kassel University Press, Kassel, Germany, 2012, pp. 663-668.

Helwig, T. A., \& Fan, Z. (2000). Field and computational studies of steel trapezoidal box girder bridges (Report No. 1395-3). Austin, Texas: Texas Department of Transportation.

Kassimali, A. (2015). Structural analysis (5th ed.). Stamford, CT: Cengage Learning. 
Kelly, L. T. (2014). Experimental evaluation of non-composite shallow press-brake-formed steel tub girders (Master's thesis). Available from ProQuest.

Kozhokin, P. (2016). Evaluation of modular press-brake-formed tub girders with UHPC joints (Master's thesis). Available from ProQuest.

Michaelson, G. K. (2010). Live Load Distribution Factors for Exterior Girders in Steel I-Girder Bridges (Master's thesis). Available from ProQuest.

Michaelson, G. K. (2014). Development and feasibility assessment of shallow press-brake-formed steel tub girders for short-span bridge applications (Doctoral dissertation). Available from ProQuest.

Nakamura, S. (2002). Bending behavior of composite girders with cold formed steel U section. ASCE Journal of Structural Engineering, 128(9), 1169-1176. Doi: 10.1061-(ASCE)07339455(2002)128:9(1169).

National Steel Bridge Alliance. (2010). Redundancy. In NSBA, Steel Bridge Design Handbook.

Righman, J. E. (2005). Rotation Compatibility Approach to Moment Redistribution for Design and Rating of Steel I-Girders. Department of Civil \& Environmental Engineering. Morgantown, WV, West Virginia University. Doctor of Philosophy.

Roberts, N. R. (2004). Evaluation of the Ductility of Composite Steel I-Girders in Positive Bending. Department of Civil \& Environmental Engineering. Morgantown, WV, West Virginia University. Master of Science.

Phares, B., Deng, Y., \& Steffens, O. (2017). Evaluation of a folded plate girder bridge system. (Report No. InTrans Project 13-458). 
Taly, N. B., \& GangaRao, H. V. S. (1976). Development and design of standardized short span bridge superstructural. (Report No. FHWA-WV-76-5).

The Mathworks, Inc. (2020). MATLAB. Natick, MA, The Mathworks, Inc.

Tennant, R. M. (2018). Fatigue Performance of Uncoated and Galvanized Composite Press-

Brake-Formed Tub Girders (Master's thesis). Available from ProQuest.

Tricon Engineering Group, Ltd. (2008). Standard design and details of press-brake-formed steel tub girder. Tricon Engineering Group: Michigan.

Underwood, N. M. H. (2019). Field Performance and Rating Evaluation of a Modular PressBrake-Formed Steel Tub Girder with a Steel Sandwich Plate Deck (Master's thesis). Available from ProQuest.

Yang, L. (2004). Evaluation of Moment Redistribution for Hybrid HPS 70W Bridge Girders. Department of Civil \& Environmental Engineering. Morgantown, WV, West Virginia University. Master of Science. 


\section{APPEndiX A: Results for All Truck RunS}

This appendix includes the following: results, tables, and graphs, generated from both the live load field test and finite element analysis of the Fourteen Mile Bridge. The data presented is for all girders, for all load runs.

The following is the order that the data is presented:

- $\quad$ Live Load Distribution Factors (LLDFs)

○ Live Load Test Data

- Finite Element Analysis

- Results Comparison: Live Load Test Data vs. Finite Element Analysis

○ Results Comparison: Live Load, FEA, \& AASHTO LRFD 


\title{
A.1 Live LoAd Distribution Factors
}

\author{
A.1.1 Live Load Field Test Results
}

\begin{tabular}{|c|c|c|c|c|c|c|c|c|c|c|c|}
\hline \multicolumn{12}{|c|}{ Truck Run 1, Simplified Distribution Factors (Field) } \\
\hline \multicolumn{2}{|c|}{ Panel Points } & \multicolumn{5}{|c|}{ Averages $(\mu \varepsilon)$} & \multicolumn{5}{|c|}{ Distribution Factors } \\
\hline $\mathrm{x}(\mathrm{ft})$ & $\mathrm{x} / \mathrm{L}$ & G1 & G2 & G3 & G4 & G5 & G1 & $\mathrm{G} 2$ & G3 & G4 & G5 \\
\hline 0 & 0 & 0 & 0 & 0 & 0 & 0 & --- & --- & --- & --- & --- \\
\hline 5.8 & 0.1 & 5.513 & 2.877 & 0.157 & -1.270 & -3.635 & 1.514 & 0.790 & 0.043 & -0.349 & -0.998 \\
\hline 11.6 & 0.2 & 17.992 & 14.074 & 9.539 & 5.401 & 0.336 & 0.380 & 0.297 & 0.201 & 0.114 & 0.007 \\
\hline 17.4 & 0.3 & 34.632 & 30.154 & 21.157 & 12.541 & 4.579 & 0.336 & 0.293 & 0.205 & 0.122 & 0.044 \\
\hline 23.2 & 0.4 & 52.685 & 49.797 & 30.625 & 16.274 & 6.498 & 0.338 & 0.319 & 0.196 & 0.104 & 0.042 \\
\hline 29 & 0.5 & 64.277 & 59.563 & 35.360 & 17.456 & 6.418 & 0.351 & 0.325 & 0.193 & 0.095 & 0.035 \\
\hline 34.8 & 0.6 & 66.936 & 64.148 & 37.530 & 16.816 & 5.658 & 0.350 & 0.336 & 0.196 & 0.088 & 0.030 \\
\hline 40.6 & 0.7 & 72.247 & 71.656 & 32.655 & 11.770 & 2.987 & 0.378 & 0.375 & 0.171 & 0.062 & 0.016 \\
\hline 46.4 & 0.8 & 70.454 & 65.424 & 25.459 & 7.196 & 0.984 & 0.416 & 0.386 & 0.150 & 0.042 & 0.006 \\
\hline 52.2 & 0.9 & 42.457 & 36.502 & 12.600 & 0.863 & -2.546 & 0.472 & 0.406 & 0.140 & 0.010 & -0.028 \\
\hline 58 & 1 & 0 & 0 & 0 & 0 & 0 & -- & -- & --- & -- & --- \\
\hline \multicolumn{7}{|c|}{ DF @0.5L (PP 5) } & 0.351 & 0.325 & 0.193 & 0.095 & 0.035 \\
\hline & & & & & \multicolumn{2}{|c|}{ MPF Applied } & 0.421 & 0.390 & 0.232 & 0.114 & 0.042 \\
\hline & & & & & \multicolumn{2}{|c|}{ St. Dev. } & 0.381 & 0.154 & 0.052 & 0.147 & 0.340 \\
\hline
\end{tabular}

\begin{tabular}{|c|c|c|c|c|c|c|c|c|c|c|c|}
\hline \multirow{2}{*}{\multicolumn{2}{|c|}{ Panel Points }} & \multirow{2}{*}{\multicolumn{5}{|c|}{ Averages $(\mu \varepsilon)$}} & \multirow{2}{*}{\multicolumn{5}{|c|}{ Distribution Factors }} \\
\hline & & & & & & & & & & & \\
\hline $\mathrm{x}(\mathrm{ft})$ & $\mathrm{x} / \mathrm{L}$ & G1 & G2 & G3 & G4 & G5 & G1 & $\mathrm{G} 2$ & G3 & G4 & G5 \\
\hline 0 & 0 & 0 & 0 & 0 & 0 & 0 & -- & --- & --- & -- & -- \\
\hline 5.8 & 0.1 & 8.505 & 6.033 & 4.168 & 3.289 & 0.563 & 0.377 & 0.267 & 0.185 & 0.146 & 0.025 \\
\hline 11.6 & 0.2 & 22.117 & 17.984 & 14.678 & 11.505 & 5.427 & 0.308 & 0.251 & 0.205 & 0.160 & 0.076 \\
\hline 17.4 & 0.3 & 36.747 & 32.747 & 26.117 & 18.402 & 9.268 & 0.298 & 0.266 & 0.212 & 0.149 & 0.075 \\
\hline 23.2 & 0.4 & 51.932 & 50.893 & 35.910 & 21.822 & 10.490 & 0.304 & 0.298 & 0.210 & 0.128 & 0.061 \\
\hline 29 & 0.5 & 63.244 & 61.446 & 40.824 & 22.688 & 10.049 & 0.319 & 0.310 & 0.206 & 0.114 & 0.051 \\
\hline 34.8 & 0.6 & 64.947 & 64.901 & 42.363 & 21.576 & 9.032 & 0.320 & 0.320 & 0.209 & 0.106 & 0.045 \\
\hline 40.6 & 0.7 & 68.440 & 73.760 & 39.378 & 16.644 & 6.491 & 0.334 & 0.360 & 0.192 & 0.081 & 0.032 \\
\hline 46.4 & 0.8 & 65.714 & 68.033 & 31.426 & 11.322 & 3.890 & 0.364 & 0.377 & 0.174 & 0.063 & 0.022 \\
\hline 52.2 & 0.9 & 40.242 & 37.619 & 16.690 & 4.385 & 0.289 & 0.406 & 0.379 & 0.168 & 0.044 & 0.003 \\
\hline 58 & 1 & 0 & 0 & 0 & 0 & 0 & --- & --- & --- & -- & --- \\
\hline \multicolumn{7}{|c|}{ DF @ 0.5L (PP 5) } & 0.319 & 0.310 & 0.206 & 0.114 & 0.051 \\
\hline & & & & & \multicolumn{2}{|c|}{ MPF Applied } & 0.383 & 0.372 & 0.247 & 0.137 & 0.061 \\
\hline & & & & & \multicolumn{2}{|c|}{ St. Dev. } & 0.037 & 0.049 & 0.016 & 0.040 & 0.025 \\
\hline
\end{tabular}




\begin{tabular}{|c|c|c|c|c|c|c|c|c|c|c|c|}
\hline \multicolumn{12}{|c|}{ Truck Run 3, Simplified Dis tribution Factors (Field) } \\
\hline \multicolumn{2}{|c|}{ Panel Points } & \multicolumn{5}{|c|}{ Averages $(\mu \varepsilon)$} & \multicolumn{5}{|c|}{ Distribution Factors } \\
\hline $\mathrm{x}(\mathrm{ft})$ & $\mathrm{x} / \mathrm{L}$ & G1 & G2 & G3 & G4 & G5 & G1 & $\mathrm{G} 2$ & G3 & G4 & 53 \\
\hline 0 & 0 & 0 & 0 & 0 & 0 & 0 & --- & --- & --- & --- & --- \\
\hline 5.8 & 0.1 & 10.424 & 8.054 & 6.671 & 8.875 & 7.108 & 0.253 & 0.196 & 0.162 & 0.216 & 0.173 \\
\hline 11.6 & 0.2 & 19.645 & 16.209 & 14.286 & 17.690 & 13.036 & 0.243 & 0.200 & 0.177 & 0.219 & 0.161 \\
\hline 17.4 & 0.3 & 26.596 & 25.038 & 24.290 & 26.307 & 16.946 & 0.223 & 0.210 & 0.204 & 0.221 & 0.142 \\
\hline 23.2 & 0.4 & 32.323 & 37.612 & 39.361 & 34.264 & 19.479 & 0.198 & 0.231 & 0.241 & 0.210 & 0.119 \\
\hline 29 & 0.5 & 38.505 & 50.209 & 50.322 & 39.875 & 20.914 & 0.193 & 0.251 & 0.252 & 0.200 & 0.105 \\
\hline 34.8 & 0.6 & 40.285 & 53.099 & 54.568 & 41.034 & 19.320 & 0.193 & 0.255 & 0.262 & 0.197 & 0.093 \\
\hline 40.6 & 0.7 & 34.296 & 58.382 & 63.334 & 36.887 & 14.382 & 0.165 & 0.282 & 0.306 & 0.178 & 0.069 \\
\hline 46.4 & 0.8 & 26.985 & 56.118 & 57.170 & 29.157 & 9.991 & 0.150 & 0.313 & 0.319 & 0.163 & 0.056 \\
\hline 52.2 & 0.9 & 17.820 & 33.427 & 31.944 & 18.003 & 5.581 & 0.167 & 0.313 & 0.299 & 0.169 & 0.052 \\
\hline 58 & 1 & 0 & 0 & 0 & 0 & 0 & --- & --- & --- & --- & --- \\
\hline \multicolumn{7}{|c|}{ DF @ 0.5L (PP 5) } & 0.193 & 0.251 & 0.252 & 0.200 & 0.105 \\
\hline & & & & & \multicolumn{2}{|c|}{ MPF Applied } & 0.231 & 0.302 & 0.302 & 0.239 & 0.126 \\
\hline & & & & & \multicolumn{2}{|c|}{ St. Dev. } & 0.035 & 0.045 & 0.057 & 0.022 & 0.045 \\
\hline
\end{tabular}

\begin{tabular}{|c|c|c|c|c|c|c|c|c|c|c|c|}
\hline \multirow{2}{*}{\multicolumn{2}{|c|}{ Panel Points }} & \multirow{2}{*}{\multicolumn{5}{|c|}{ Averages $(\mu \varepsilon)$}} & \multirow{2}{*}{\multicolumn{5}{|c|}{ Distribution Factors }} \\
\hline & & & & & & & & & & & \\
\hline $\mathrm{x}(\mathrm{ft})$ & $\mathrm{x} / \mathrm{L}$ & G1 & $\mathrm{G} 2$ & G3 & G4 & G5 & G1 & $\mathrm{G} 2$ & G3 & G4 & G5 \\
\hline 0 & 0 & 0 & 0 & 0 & 0 & 0 & --- & -- & --- & --- & -- \\
\hline 5.8 & 0.1 & 7.419 & 6.902 & 4.758 & 6.622 & 7.862 & 2.038 & 1.896 & 1.307 & 1.819 & 2.159 \\
\hline 11.6 & 0.2 & 14.049 & 14.062 & 11.014 & 14.329 & 15.004 & 0.297 & 0.297 & 0.233 & 0.303 & 0.317 \\
\hline 17.4 & 0.3 & 19.815 & 22.314 & 20.415 & 24.759 & 21.447 & 0.192 & 0.217 & 0.198 & 0.240 & 0.208 \\
\hline 23.2 & 0.4 & 24.036 & 31.182 & 35.360 & 38.414 & 25.988 & 0.154 & 0.200 & 0.227 & 0.246 & 0.167 \\
\hline 29 & 0.5 & 26.808 & 39.315 & 47.951 & 46.401 & 28.264 & 0.146 & 0.215 & 0.262 & 0.253 & 0.154 \\
\hline 34.8 & 0.6 & 26.434 & 41.748 & 49.072 & 47.439 & 26.622 & 0.138 & 0.218 & 0.257 & 0.248 & 0.139 \\
\hline 40.6 & 0.7 & 21.341 & 39.722 & 58.573 & 49.935 & 20.828 & 0.112 & 0.208 & 0.306 & 0.261 & 0.109 \\
\hline 46.4 & 0.8 & 14.110 & 33.535 & 57.812 & 42.109 & 14.042 & 0.083 & 0.198 & 0.341 & 0.248 & 0.083 \\
\hline 52.2 & 0.9 & 6.266 & 19.831 & 28.734 & 21.032 & 5.861 & 0.070 & 0.221 & 0.320 & 0.234 & 0.065 \\
\hline 58 & 1 & 0 & 0 & 0 & 0 & 0 & --- & --- & --- & -- & --- \\
\hline \multicolumn{7}{|c|}{ DF @ 0.5L (PP 5) } & 0.146 & 0.215 & 0.262 & 0.253 & 0.154 \\
\hline & & & & & \multicolumn{2}{|c|}{ MPF Applied } & 0.176 & 0.258 & 0.314 & 0.304 & 0.185 \\
\hline & & & & & \multicolumn{2}{|c|}{ St. Dev. } & 0.633 & 0.559 & 0.349 & 0.522 & 0.672 \\
\hline
\end{tabular}




\begin{tabular}{|c|c|c|c|c|c|c|c|c|c|c|c|}
\hline \multicolumn{12}{|c|}{ Truck Run 5, Simplified Dis tribution Factors (Field) } \\
\hline \multicolumn{2}{|c|}{ Panel Points } & \multicolumn{5}{|c|}{ Averages $(\mu \varepsilon)$} & \multicolumn{5}{|c|}{ Distribution Factors } \\
\hline $\mathrm{x}(\mathrm{ft})$ & $\mathrm{x} / \mathrm{L}$ & G1 & G2 & G3 & G4 & G5 & G1 & $\mathrm{G} 2$ & G3 & G4 & G5 \\
\hline 0 & 0 & 0 & 0 & 0 & 0 & 0 & --- & --- & --- & -- & -- \\
\hline 5.8 & 0.1 & 6.770 & 6.963 & 5.457 & 6.900 & 8.822 & 0.300 & 0.309 & 0.242 & 0.306 & 0.391 \\
\hline 11.6 & 0.2 & 13.043 & 13.785 & 11.549 & 14.346 & 16.233 & 0.182 & 0.192 & 0.161 & 0.200 & 0.226 \\
\hline 17.4 & 0.3 & 18.791 & 22.109 & 21.456 & 25.369 & 23.667 & 0.152 & 0.179 & 0.174 & 0.206 & 0.192 \\
\hline 23.2 & 0.4 & 22.567 & 29.653 & 35.506 & 39.254 & 28.584 & 0.132 & 0.173 & 0.208 & 0.229 & 0.167 \\
\hline 29 & 0.5 & 24.876 & 36.364 & 47.468 & 47.821 & 31.227 & 0.125 & 0.183 & 0.239 & 0.241 & 0.158 \\
\hline 34.8 & 0.6 & 23.978 & 38.349 & 48.333 & 49.065 & 29.739 & 0.118 & 0.189 & 0.238 & 0.242 & 0.147 \\
\hline 40.6 & 0.7 & 19.898 & 36.238 & 57.930 & 54.053 & 24.878 & 0.097 & 0.177 & 0.283 & 0.264 & 0.122 \\
\hline 46.4 & 0.8 & 14.699 & 31.272 & 58.569 & 48.251 & 19.207 & 0.081 & 0.173 & 0.325 & 0.267 & 0.106 \\
\hline 52.2 & 0.9 & 8.868 & 20.593 & 32.454 & 26.639 & 11.212 & 0.089 & 0.208 & 0.327 & 0.268 & 0.113 \\
\hline 58 & 1 & 0 & 0 & 0 & 0 & 0 & --- & --- & --- & --- & --- \\
\hline \multicolumn{7}{|c|}{ DF @ 0.5L (PP 5) } & 0.125 & 0.183 & 0.239 & 0.241 & 0.158 \\
\hline & & & & & \multicolumn{2}{|c|}{ MPF Applied } & 0.151 & 0.220 & 0.287 & 0.289 & 0.189 \\
\hline & & & & & \multicolumn{2}{|c|}{ St. Dev. } & 0.067 & 0.043 & 0.059 & 0.033 & 0.088 \\
\hline
\end{tabular}

\begin{tabular}{|c|c|c|c|c|c|c|c|c|c|c|c|}
\hline \multicolumn{12}{|c|}{ Truck Run 6, Simplified Distribution Factors (Field) } \\
\hline \multicolumn{2}{|c|}{ Panel Points } & \multicolumn{5}{|c|}{ Averages $(\mu \varepsilon)$} & \multicolumn{5}{|c|}{ Distribution Factors } \\
\hline $\mathrm{x}(\mathrm{ft})$ & $\mathrm{x} / \mathrm{L}$ & G1 & $\mathrm{G} 2$ & G3 & G4 & G5 & G1 & $\mathrm{G} 2$ & G3 & G4 & G5 \\
\hline 0 & 0 & 0 & 0 & 0 & 0 & 0 & --- & --- & --- & --- & --- \\
\hline 5.8 & 0.1 & 4.692 & 6.266 & 7.309 & 7.581 & 10.082 & 0.114 & 0.152 & 0.178 & 0.184 & 0.245 \\
\hline 11.6 & 0.2 & 9.066 & 12.474 & 14.712 & 15.602 & 20.162 & 0.112 & 0.154 & 0.182 & 0.193 & 0.249 \\
\hline 17.4 & 0.3 & 12.042 & 17.365 & 22.484 & 26.079 & 31.446 & 0.101 & 0.146 & 0.189 & 0.219 & 0.264 \\
\hline 23.2 & 0.4 & 14.500 & 21.298 & 30.378 & 41.059 & 44.683 & 0.089 & 0.131 & 0.186 & 0.252 & 0.274 \\
\hline 29 & 0.5 & 16.202 & 24.443 & 37.352 & 54.404 & 52.674 & 0.081 & 0.122 & 0.187 & 0.272 & 0.264 \\
\hline 34.8 & 0.6 & 16.196 & 24.853 & 40.422 & 57.132 & 54.459 & 0.078 & 0.119 & 0.194 & 0.274 & 0.261 \\
\hline 40.6 & 0.7 & 11.886 & 19.162 & 36.254 & 63.694 & 54.936 & 0.057 & 0.092 & 0.175 & 0.307 & 0.265 \\
\hline 46.4 & 0.8 & 7.708 & 12.997 & 29.689 & 62.683 & 47.209 & 0.043 & 0.072 & 0.165 & 0.349 & 0.263 \\
\hline 52.2 & 0.9 & 5.491 & 8.489 & 20.109 & 37.463 & 28.538 & 0.051 & 0.079 & 0.188 & 0.351 & 0.267 \\
\hline 58 & 1 & 0 & 0 & 0 & 0 & 0 & --- & --- & --- & --- & --- \\
\hline \multicolumn{7}{|c|}{ DF @ 0.5L (PP 5) } & 0.081 & 0.122 & 0.187 & 0.272 & 0.264 \\
\hline & & & & & \multicolumn{2}{|c|}{ MPF Applied } & 0.097 & 0.147 & 0.224 & 0.327 & 0.316 \\
\hline & & & & & \multicolumn{2}{|c|}{ St. Dev. } & 0.026 & 0.031 & 0.009 & 0.062 & 0.009 \\
\hline
\end{tabular}




\begin{tabular}{|c|c|c|c|c|c|c|c|c|c|c|c|}
\hline \multicolumn{12}{|c|}{ Truck Runs 1 and 4, Simplified Distribution Factors (Field) } \\
\hline \multicolumn{2}{|c|}{ Panel Points } & \multicolumn{5}{|c|}{ Averages $(\mu \varepsilon)$} & \multicolumn{5}{|c|}{ Distribution Factors } \\
\hline $\mathrm{x}(\mathrm{ft})$ & $\mathrm{x} / \mathrm{L}$ & G1 & G2 & G3 & G4 & G5 & G1 & $\mathrm{G} 2$ & G3 & G4 & G5 \\
\hline 0 & 0 & 0 & 0 & 0 & 0 & 0 & --- & --- & --- & --- & --- \\
\hline 5.8 & 0.1 & 12.932 & 9.779 & 4.914 & 5.352 & 4.227 & 0.348 & 0.263 & 0.132 & 0.144 & 0.114 \\
\hline 11.6 & 0.2 & 32.041 & 28.135 & 20.554 & 19.731 & 15.341 & 0.277 & 0.243 & 0.177 & 0.170 & 0.132 \\
\hline 17.4 & 0.3 & 54.448 & 52.468 & 41.572 & 37.300 & 26.026 & 0.257 & 0.248 & 0.196 & 0.176 & 0.123 \\
\hline 23.2 & 0.4 & 76.721 & 80.979 & 65.985 & 54.688 & 32.486 & 0.247 & 0.261 & 0.212 & 0.176 & 0.105 \\
\hline 29 & 0.5 & 91.085 & 98.877 & 83.310 & 63.857 & 34.681 & 0.245 & 0.266 & 0.224 & 0.172 & 0.093 \\
\hline 34.8 & 0.6 & 93.370 & 105.896 & 86.602 & 64.255 & 32.280 & 0.244 & 0.277 & 0.226 & 0.168 & 0.084 \\
\hline 40.6 & 0.7 & 93.589 & 111.379 & 91.229 & 61.705 & 23.815 & 0.245 & 0.292 & 0.239 & 0.162 & 0.062 \\
\hline 46.4 & 0.8 & 84.565 & 98.959 & 83.272 & 49.304 & 15.026 & 0.255 & 0.299 & 0.251 & 0.149 & 0.045 \\
\hline 52.2 & 0.9 & 48.723 & 56.333 & 41.333 & 21.895 & 3.316 & 0.284 & 0.328 & 0.241 & 0.128 & 0.019 \\
\hline 58 & 1 & 0 & 0 & 0 & 0 & 0 & -- & --- & -- & --- & --- \\
\hline \multicolumn{7}{|c|}{ DF @ 0.5L (PP 5) } & 0.245 & 0.266 & 0.224 & 0.172 & 0.093 \\
\hline & & & & & \multicolumn{2}{|c|}{ MPF Applied } & 0.490 & 0.532 & 0.448 & 0.343 & 0.187 \\
\hline & & & & & \multicolumn{2}{|c|}{ St. Dev. } & 0.034 & 0.027 & 0.038 & 0.017 & 0.038 \\
\hline
\end{tabular}

\begin{tabular}{|c|c|c|c|c|c|c|c|c|c|c|c|}
\hline \multicolumn{2}{|c|}{ Panel Points } & \multicolumn{5}{|c|}{ Averages $(\mu \varepsilon)$} & \multicolumn{5}{|c|}{ Distribution Factors } \\
\hline $\mathrm{x}(\mathrm{ft})$ & $\mathrm{x} / \mathrm{L}$ & G1 & $\mathrm{G} 2$ & G3 & G4 & G5 & G1 & $\mathrm{G} 2$ & G3 & G4 & G5 \\
\hline 0 & 0 & 0 & 0 & 0 & 0 & 0 & --- & -- & -- & --- & --- \\
\hline 5.8 & 0.1 & 15.275 & 12.995 & 9.626 & 10.189 & 9.385 & 0.266 & 0.226 & 0.167 & 0.177 & 0.163 \\
\hline 11.6 & 0.2 & 35.160 & 31.769 & 26.227 & 25.851 & 21.660 & 0.250 & 0.226 & 0.186 & 0.184 & 0.154 \\
\hline 17.4 & 0.3 & 55.539 & 54.856 & 47.573 & 43.771 & 32.935 & 0.237 & 0.234 & 0.203 & 0.187 & 0.140 \\
\hline 23.2 & 0.4 & 74.498 & 80.546 & 71.417 & 61.077 & 39.075 & 0.228 & 0.247 & 0.219 & 0.187 & 0.120 \\
\hline 29 & 0.5 & 88.119 & 97.811 & 88.293 & 70.508 & 41.275 & 0.228 & 0.253 & 0.229 & 0.183 & 0.107 \\
\hline 34.8 & 0.6 & 88.925 & 103.251 & 90.696 & 70.641 & 38.770 & 0.227 & 0.263 & 0.231 & 0.180 & 0.099 \\
\hline 40.6 & 0.7 & 88.338 & 109.998 & 97.308 & 70.697 & 31.370 & 0.222 & 0.277 & 0.245 & 0.178 & 0.079 \\
\hline 46.4 & 0.8 & 80.413 & 99.305 & 89.996 & 59.574 & 23.098 & 0.228 & 0.282 & 0.255 & 0.169 & 0.066 \\
\hline 52.2 & 0.9 & 49.111 & 58.211 & 49.144 & 31.024 & 11.501 & 0.247 & 0.293 & 0.247 & 0.156 & 0.058 \\
\hline 58 & 1 & 0 & 0 & 0 & 0 & 0 & --- & -- & -- & --- & --- \\
\hline \multicolumn{7}{|c|}{ DF@0.5L (PP 5) } & 0.228 & 0.253 & 0.229 & 0.183 & 0.107 \\
\hline & & & & & \multicolumn{2}{|c|}{ MPF Applied } & 0.457 & 0.507 & 0.457 & 0.365 & 0.214 \\
\hline & & & & & \multicolumn{2}{|c|}{ St. Dev. } & 0.014 & 0.025 & 0.030 & 0.010 & 0.038 \\
\hline
\end{tabular}




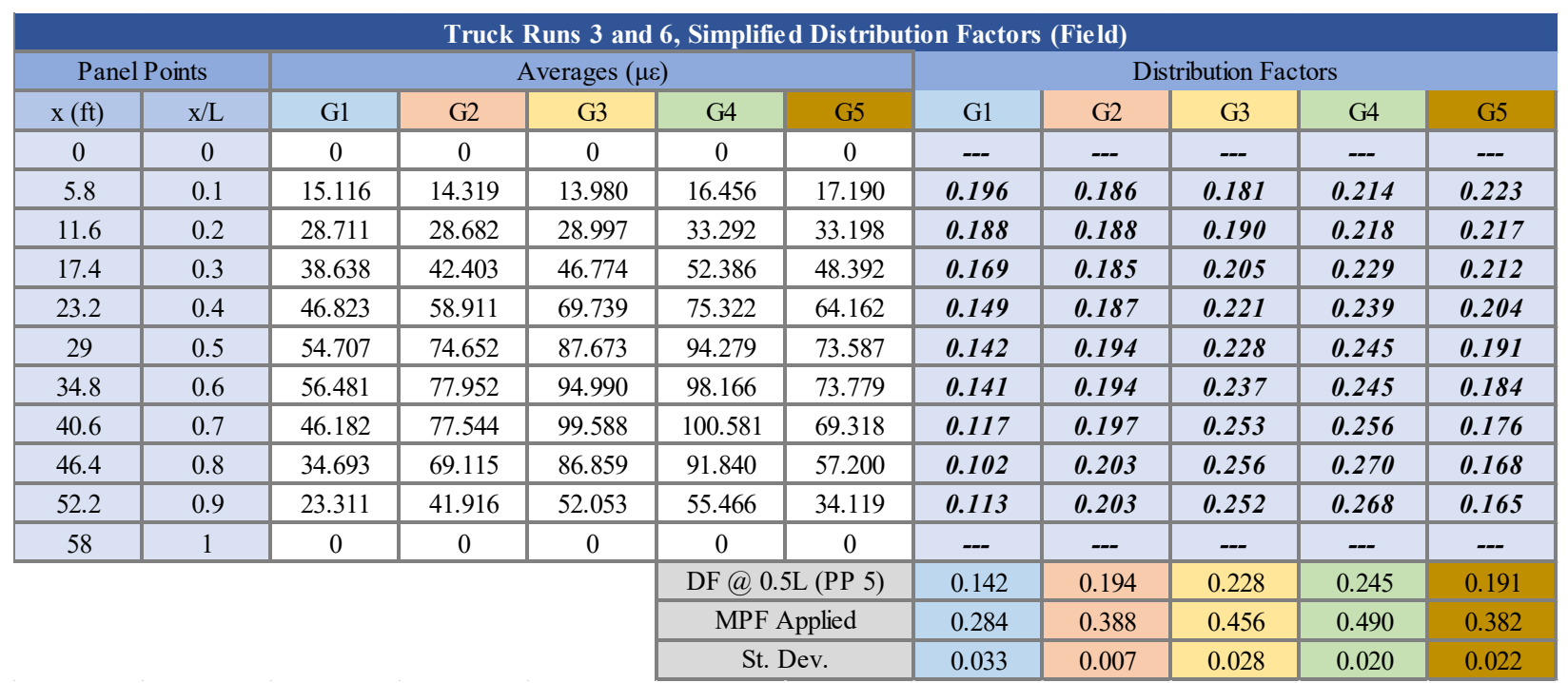

\section{A.1.2 Finite Element Analysis Results}

\begin{tabular}{|c|c|c|c|c|c|}
\hline \multicolumn{6}{|c|}{ Summary of Live Load Distribution Factors (FEA) } \\
\hline Truck Run & G1 & G2 & G3 & G4 & G5 \\
\hline Run 1 & 0.440 & 0.355 & 0.217 & 0.116 & 0.072 \\
\hline Run 2 & 0.411 & 0.354 & 0.231 & 0.127 & 0.077 \\
\hline Run 3 & 0.237 & 0.305 & 0.304 & 0.222 & 0.133 \\
\hline Run 4 & 0.164 & 0.249 & 0.311 & 0.284 & 0.193 \\
\hline Run 5 & 0.149 & 0.232 & 0.307 & 0.299 & 0.214 \\
\hline Run 6 & 0.088 & 0.132 & 0.236 & 0.349 & 0.396 \\
\hline Runs 1+4 & 0.502 & 0.503 & 0.440 & 0.334 & 0.221 \\
\hline Runs 2+5 & 0.464 & 0.487 & 0.449 & 0.356 & 0.243 \\
\hline Runs 3+6 & 0.269 & 0.362 & 0.449 & 0.477 & 0.443 \\
\hline
\end{tabular}



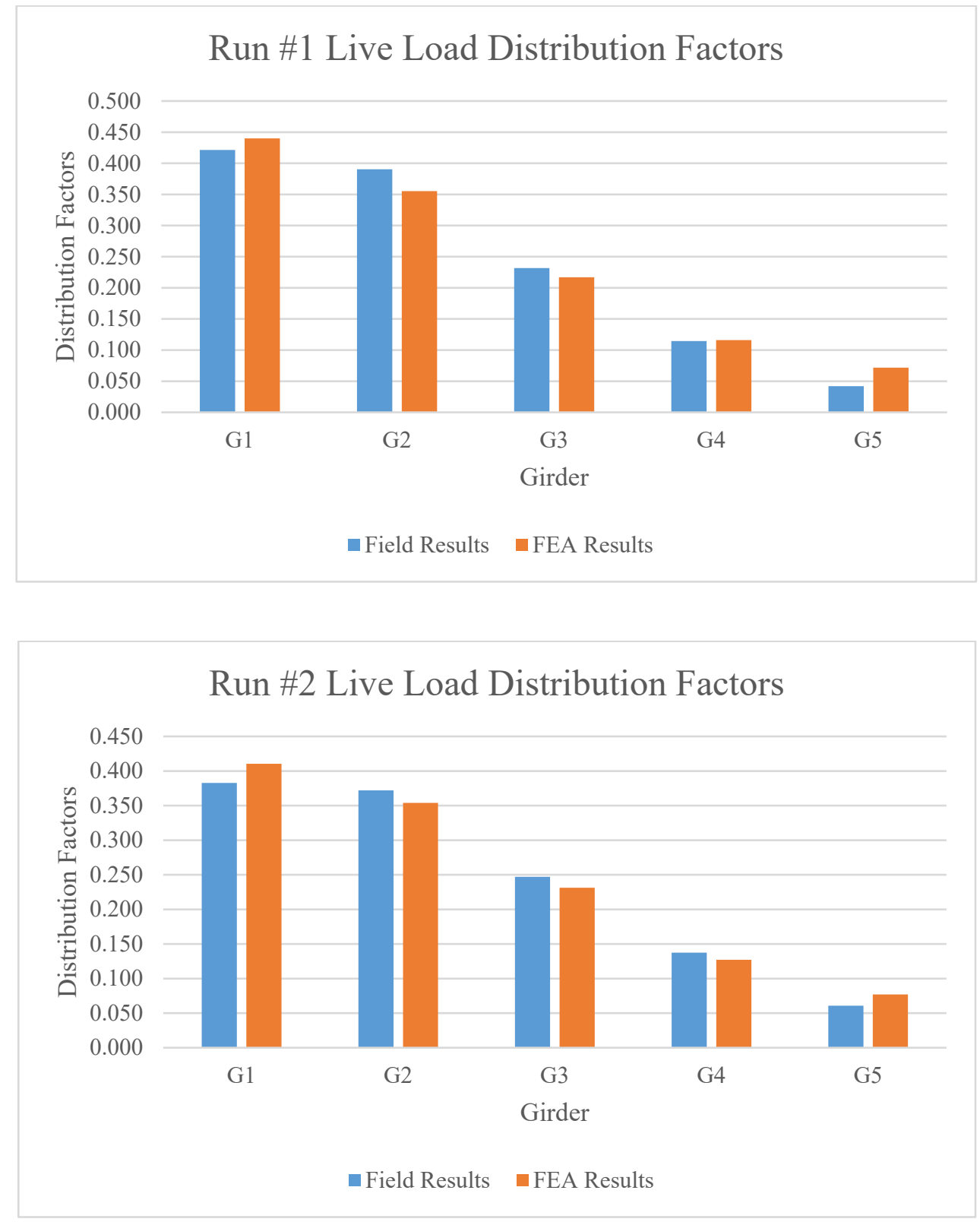

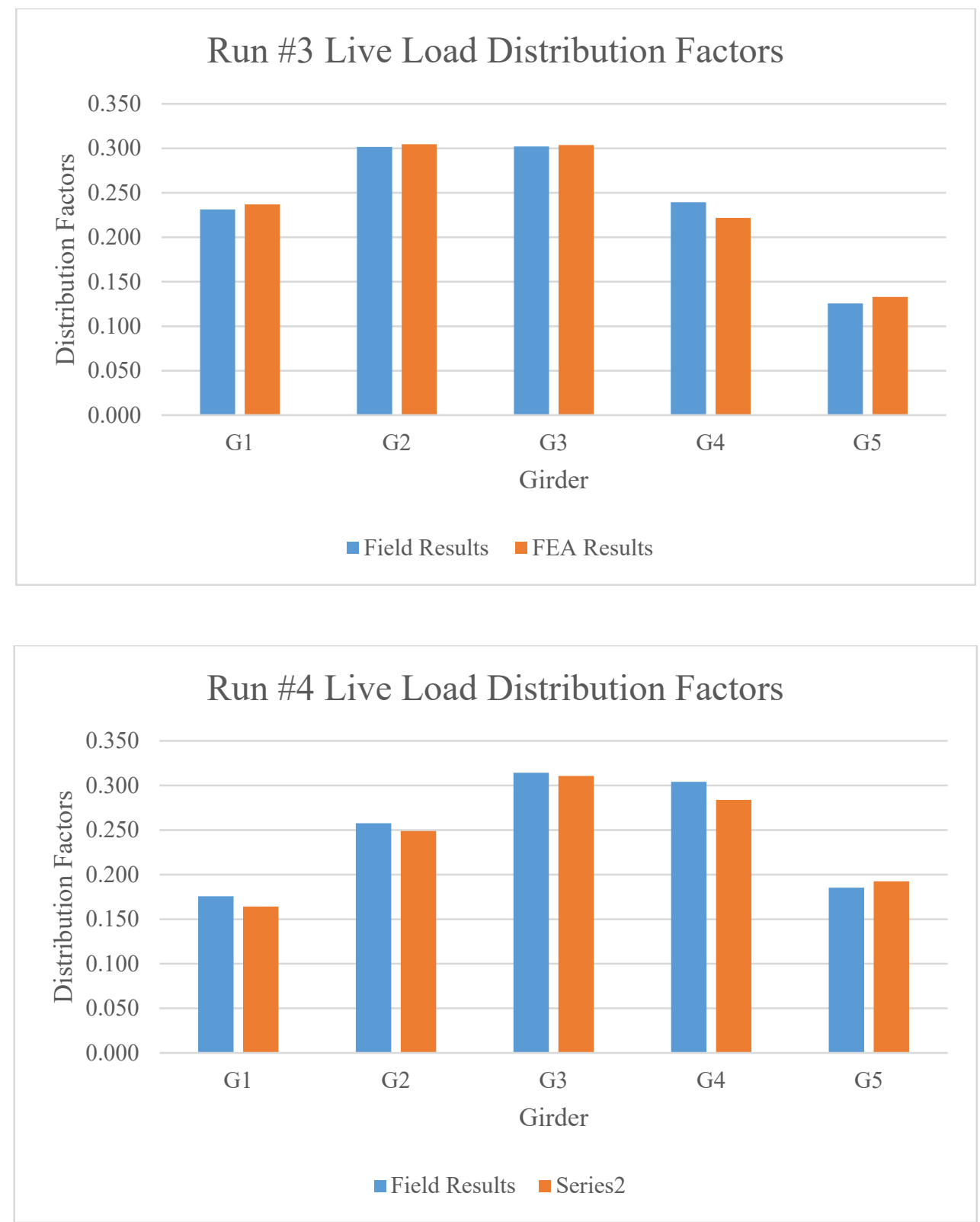

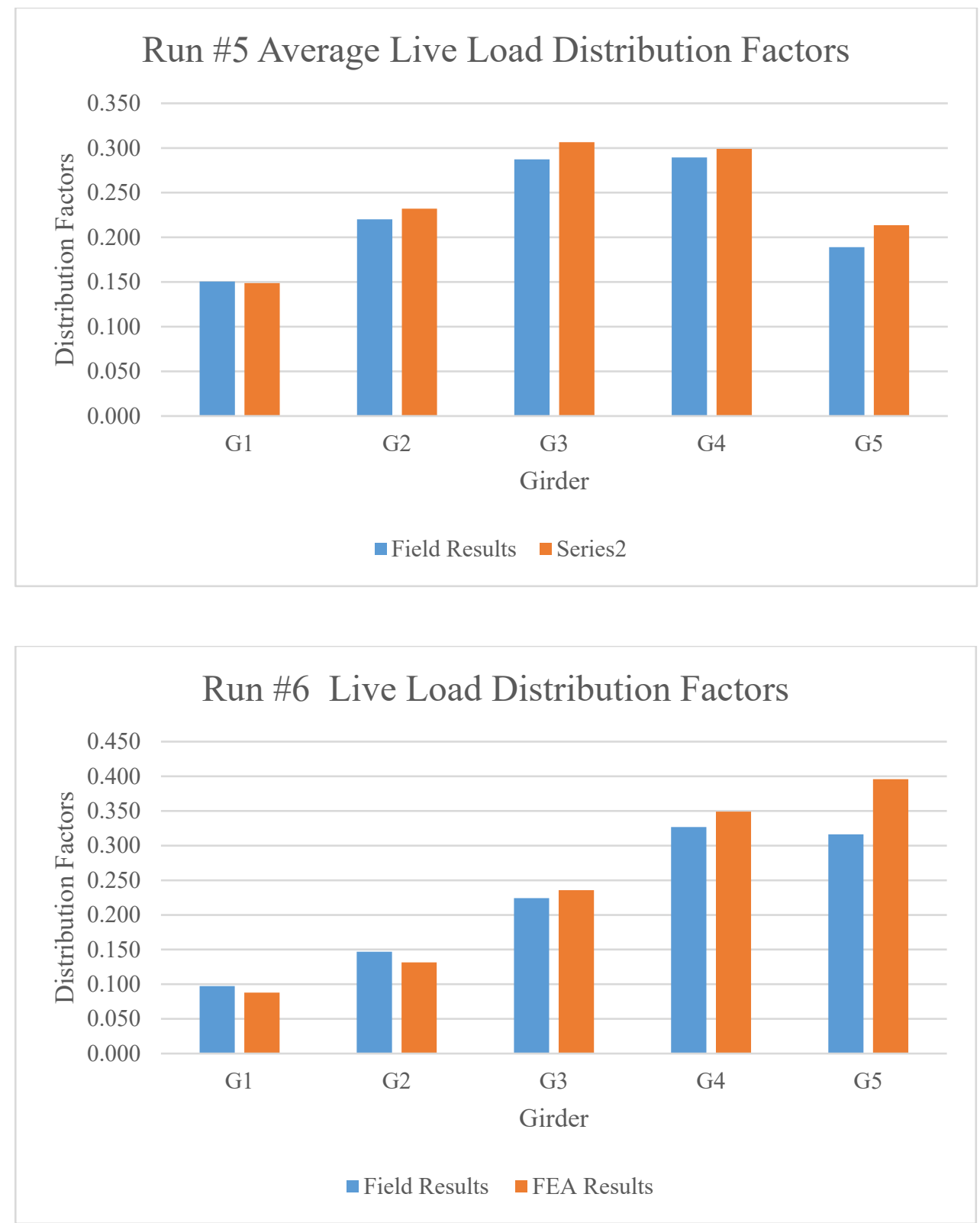

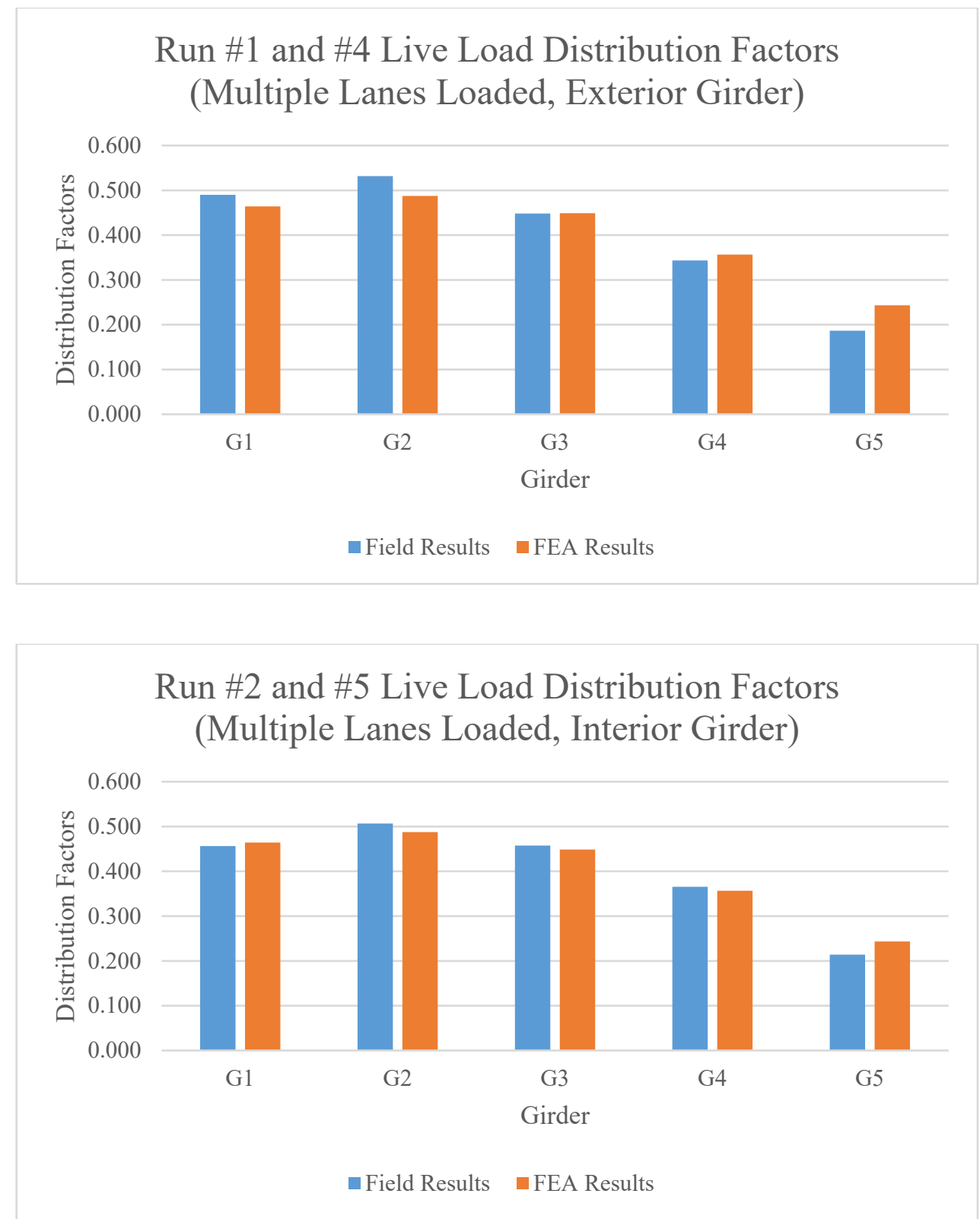


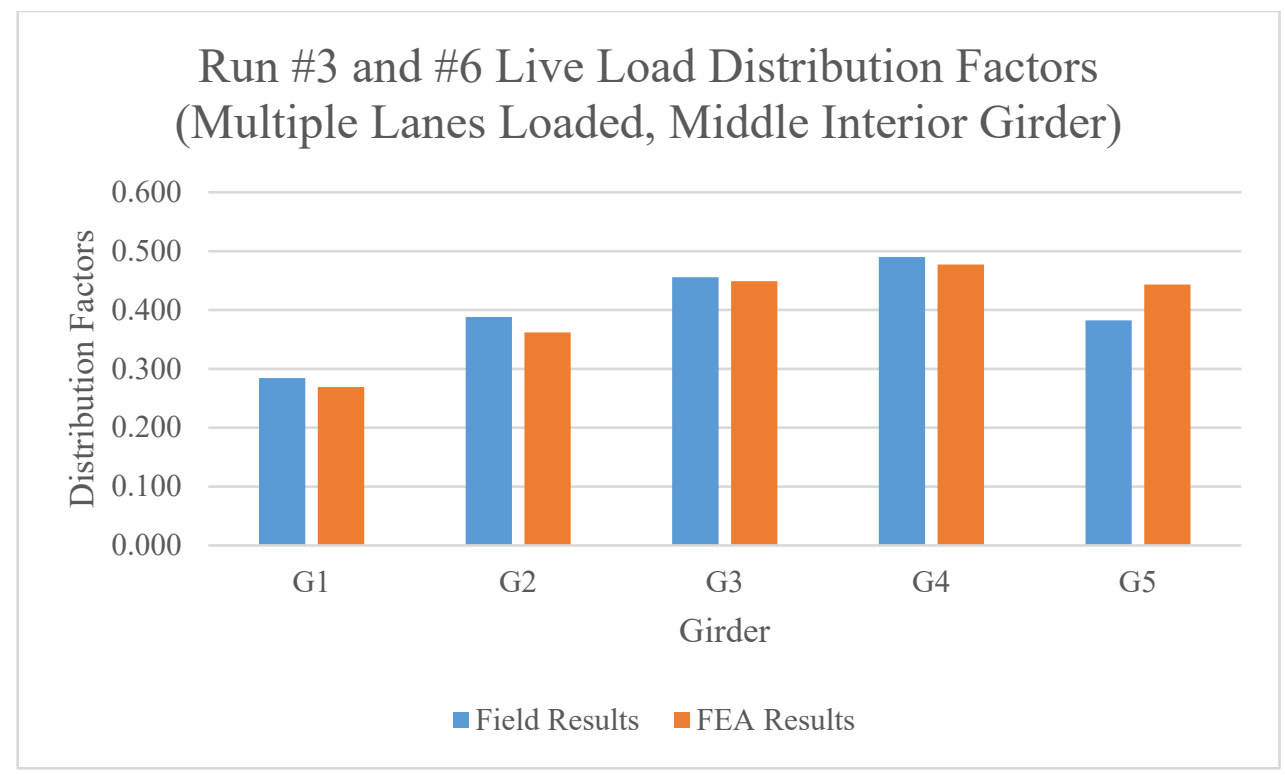



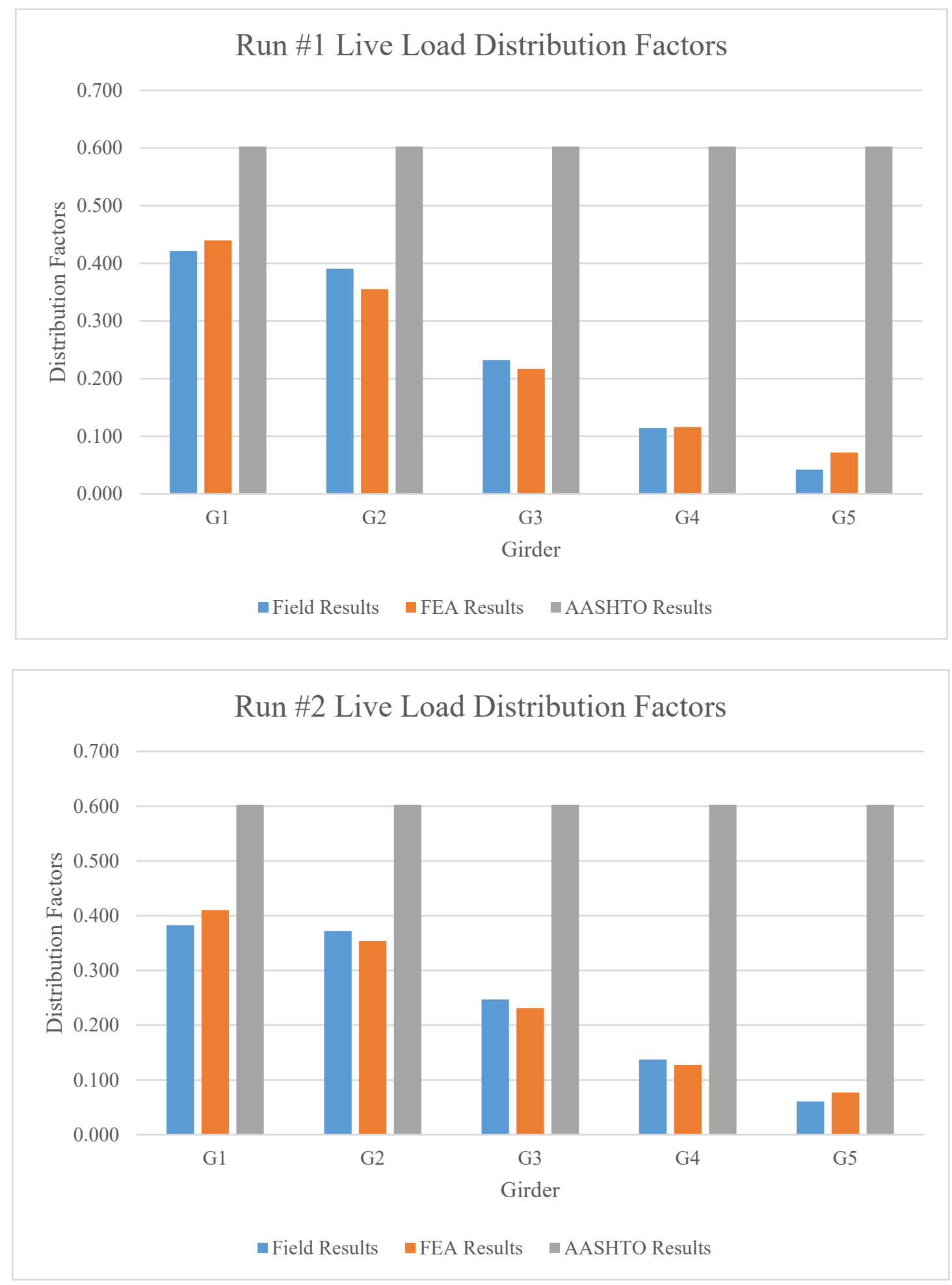

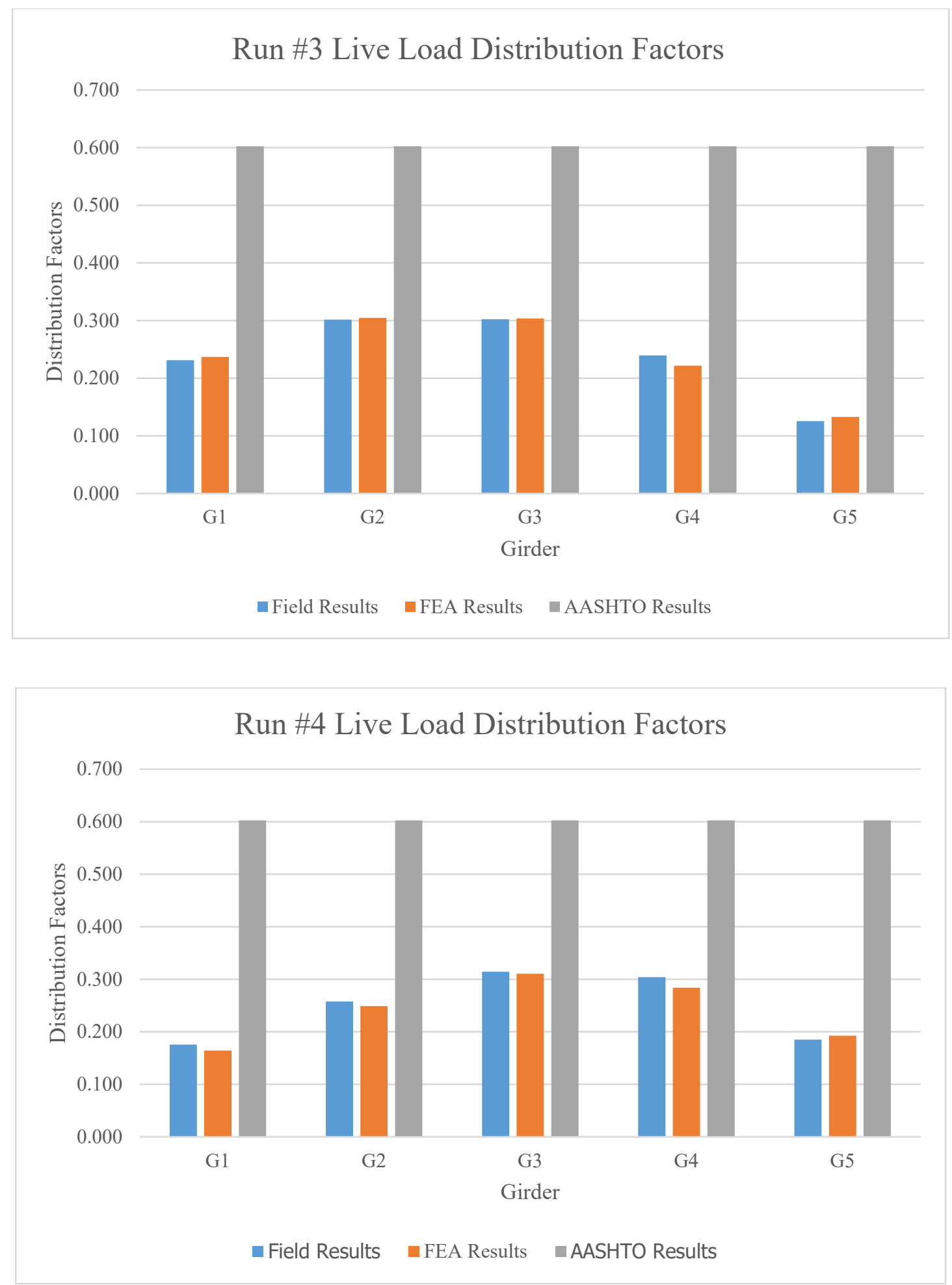

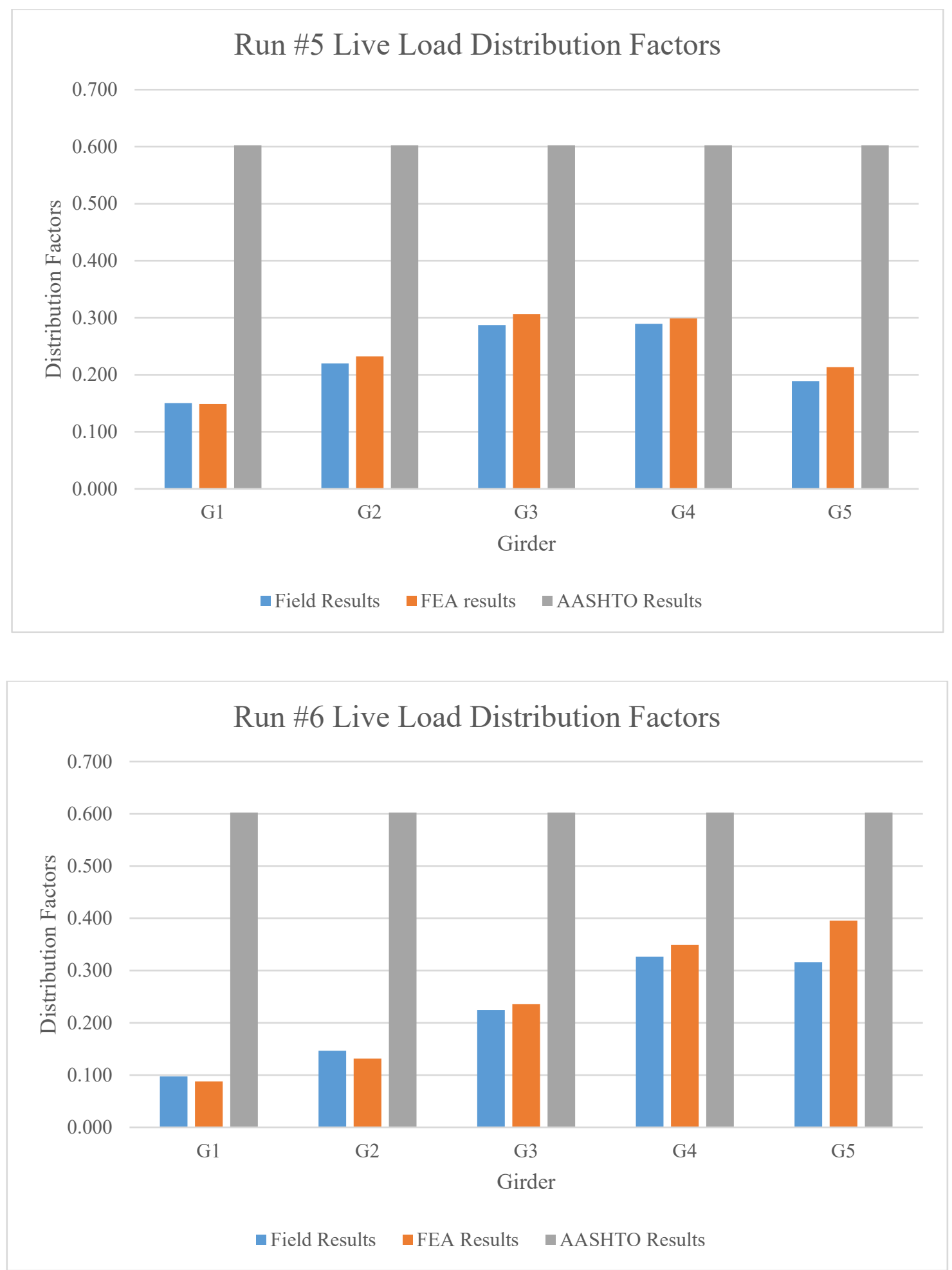

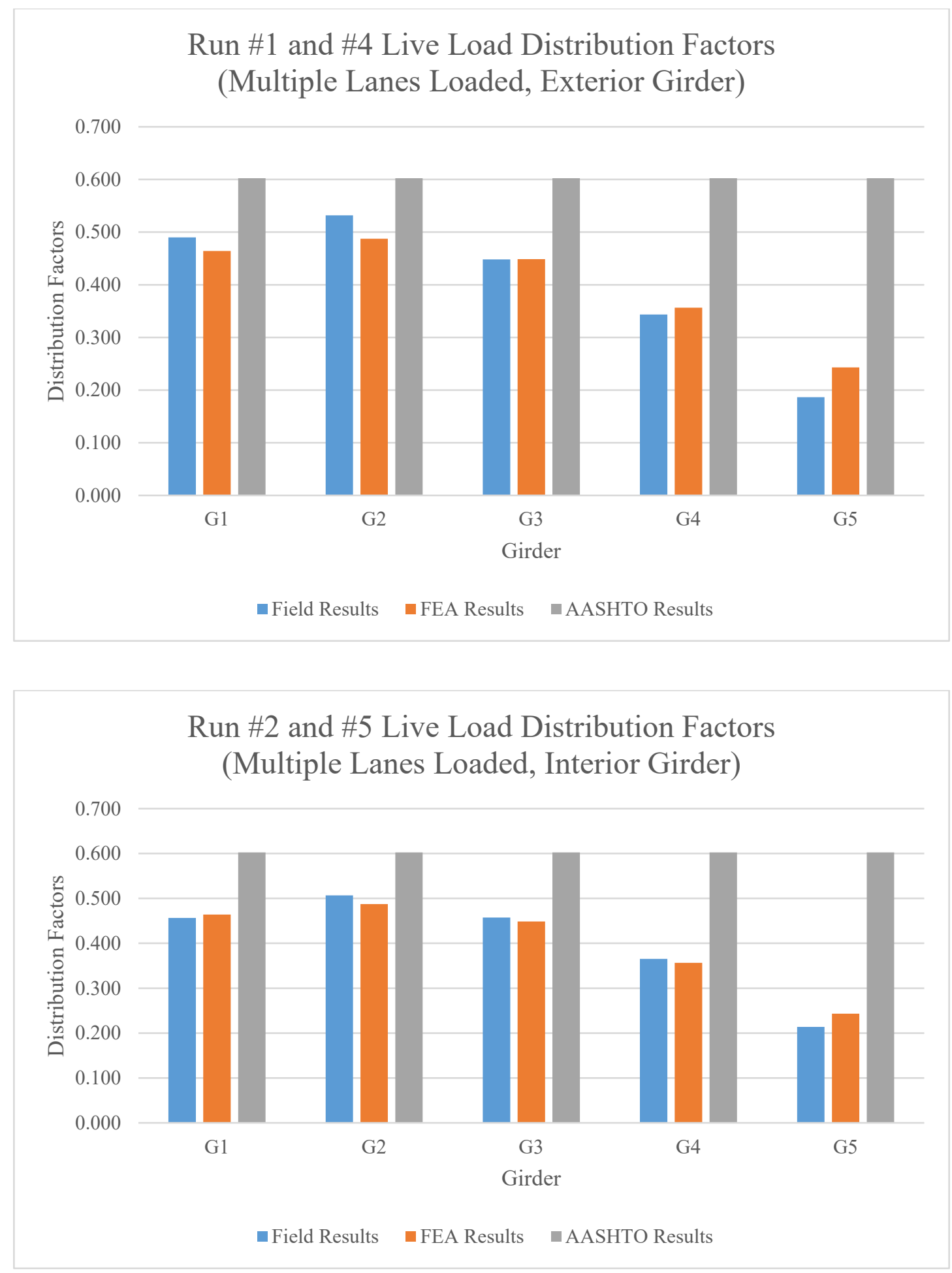


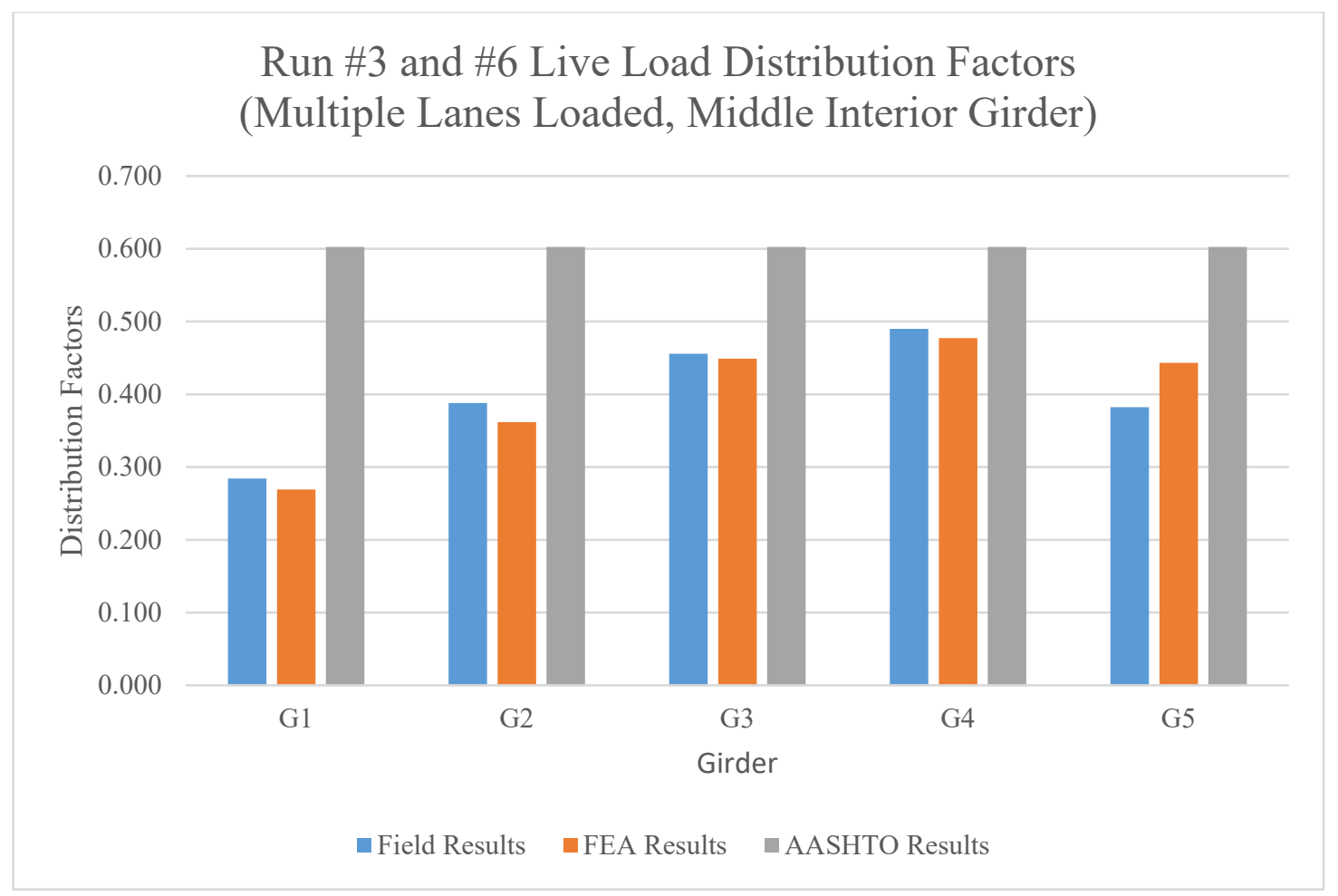




\section{Appendix B: Finite Element Modeling Program}

This appendix documents the program written in MATALB (The Mathworks, Inc., 2020) that were used in this research. The program "noncompv2.m" is used to preprocess .inp files that Abaqus will read to produce a finite element model. User inputs are used to generate the nodes and elements for the model under investigation. An outline of each section of the program is presented below:

- Part 0 reads the data necessary to generate the finite element mesh.

- Part 1 defines the longitudinal node layout of the girder.

- Part 2 defines the transverse node layout of the girder.

- Part 3 combines Part 3 and 4 to generate the three-dimensional mesh of the steel press-brake-formed tub girder.

- Part 4 defines the transverse node layout for the stiffener.

- Part 5 uses Part 4 to generate the three-dimensional mesh of the stiffener plates.

- Part 6 alters the geometry to consider geometric imperfection 1, flange tilt.

- Part 7 determines the centroid and shear center of the assembly.

- Part 8 alters the geometry to consider geometric imperfection 2, girder twist.

- Part 9 alters the girder geometry to consider geometric imperfection 3, web out of flatness.

- Part 10 alters the geometry of the stiffener plate to consider geometric imperfection 3 , web out of flatness.

- Part 11 applies the loading and boundary conditions to specified nodes.

- Part 12 writes the .inp file with the information from Parts 0 through 11. 


\section{The MATLAB file is as follows (inputs for material properties and geometric}

\section{imperfections are outlined in chapter 7):}

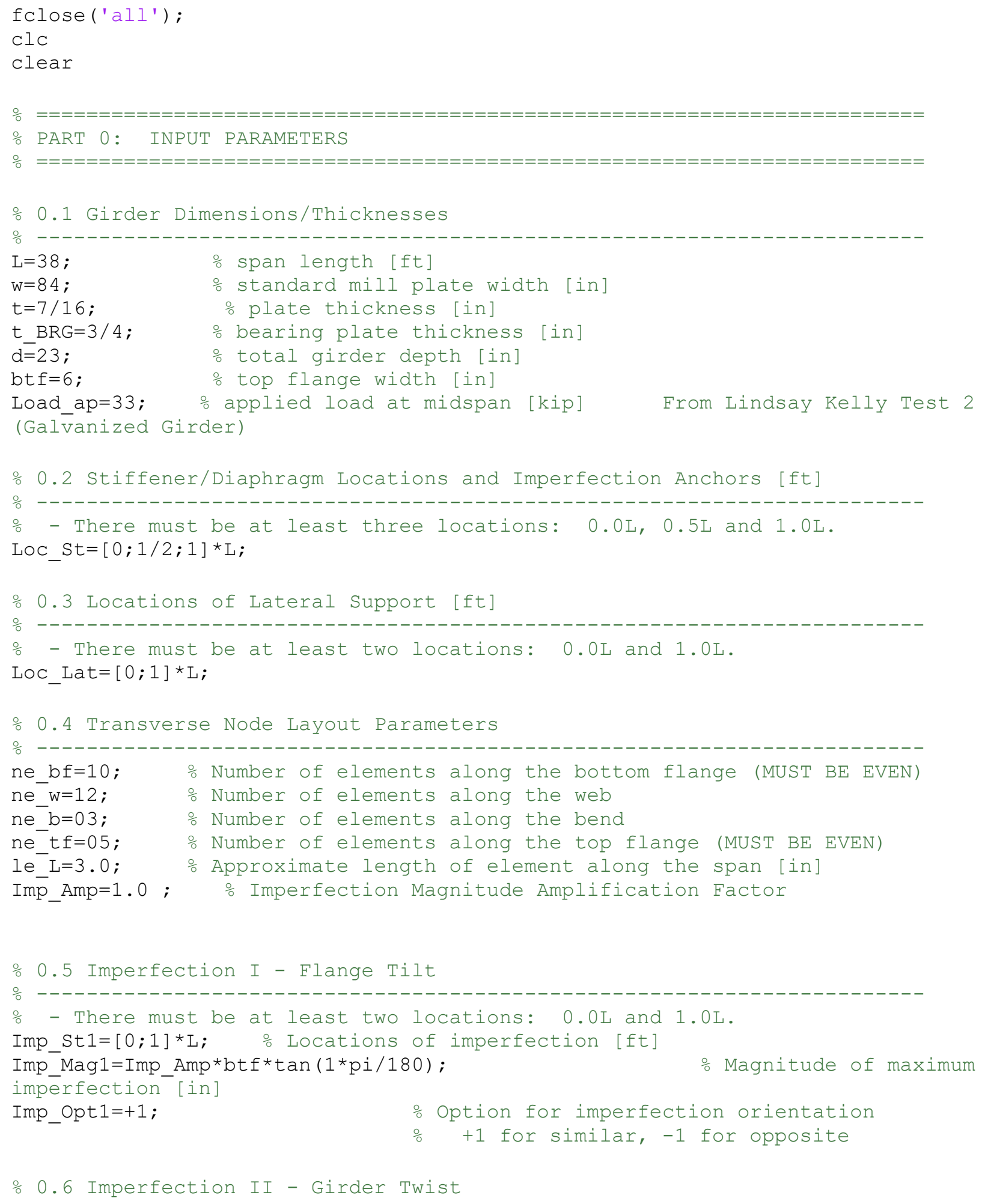




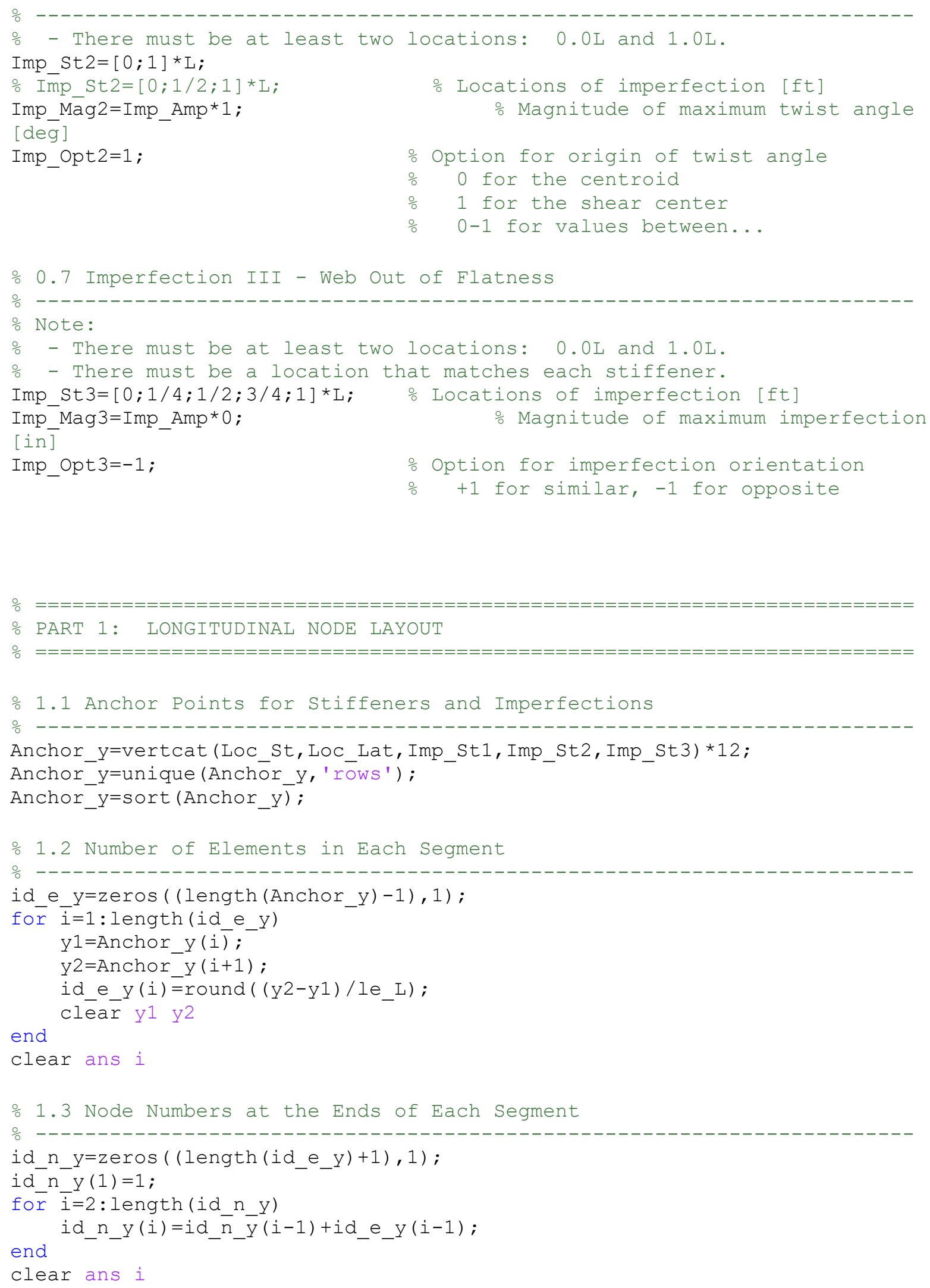




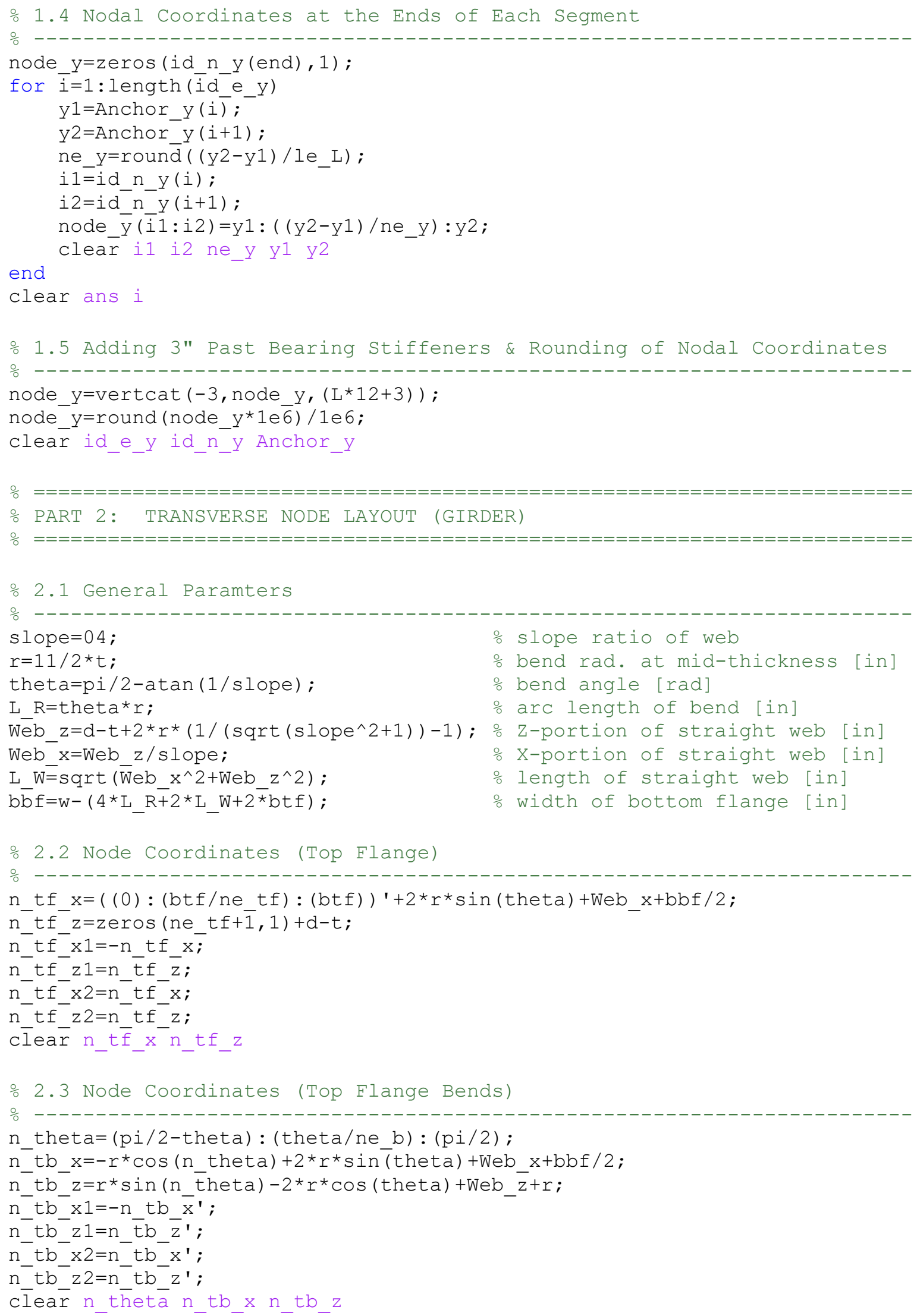




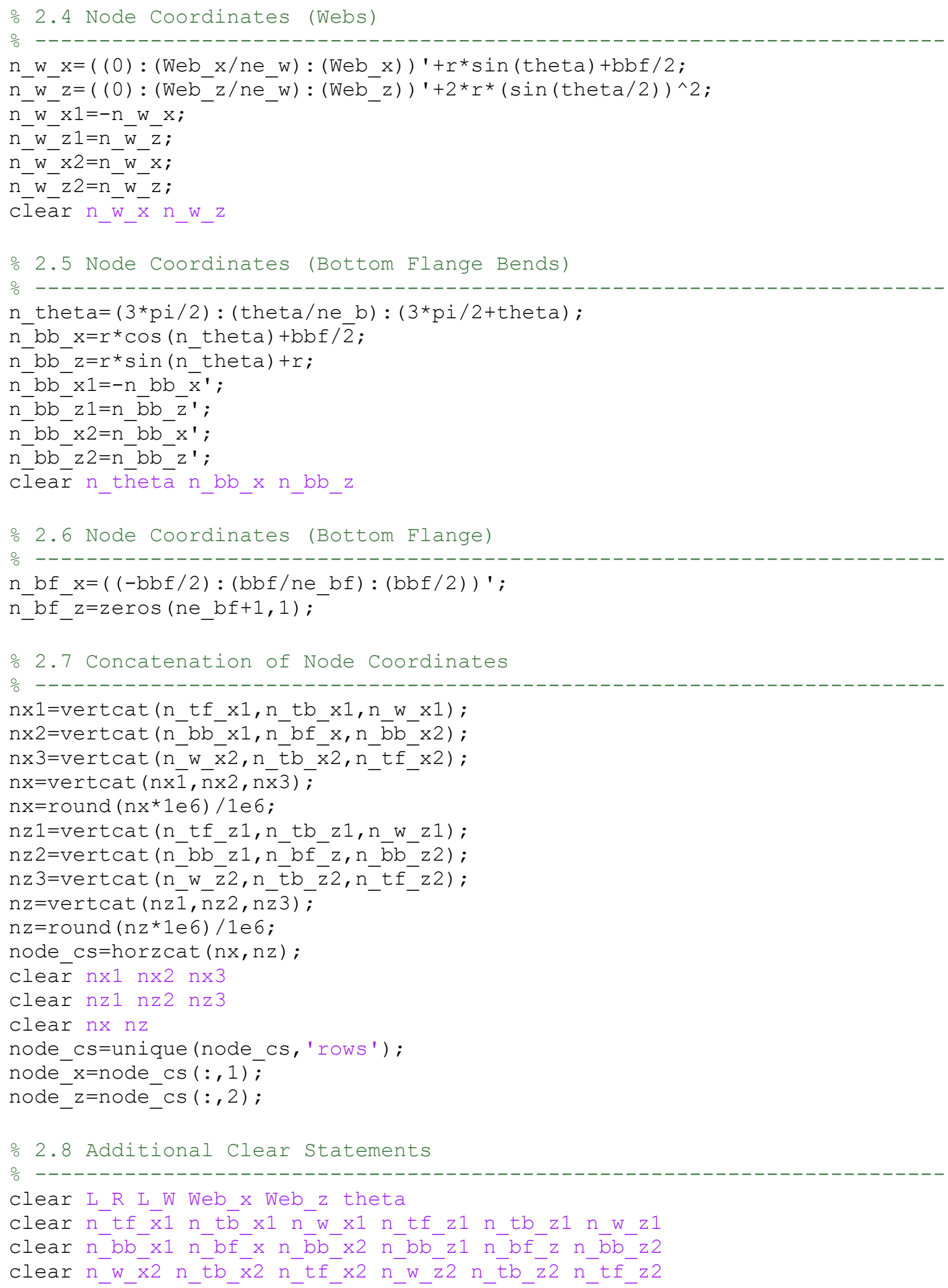




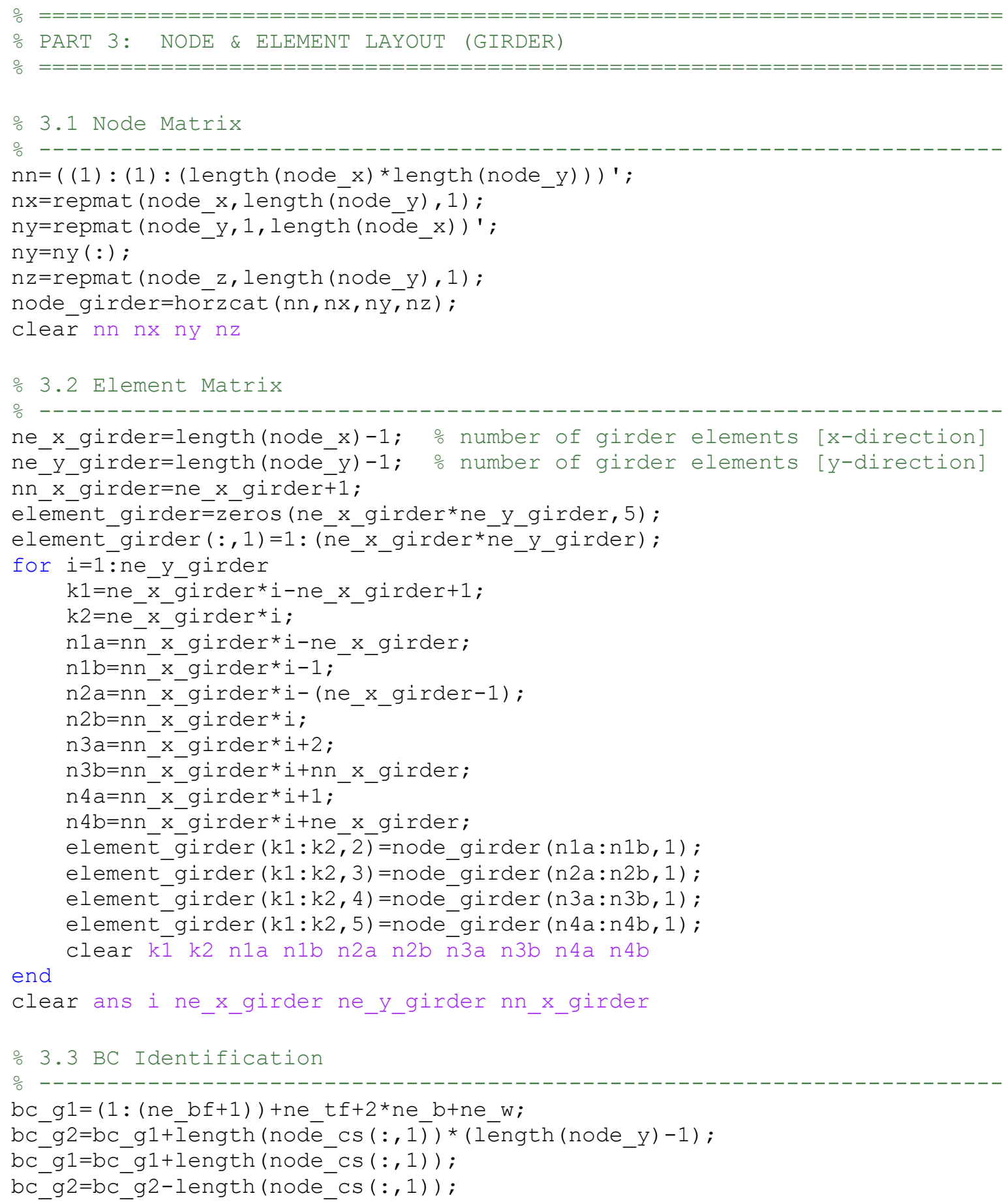




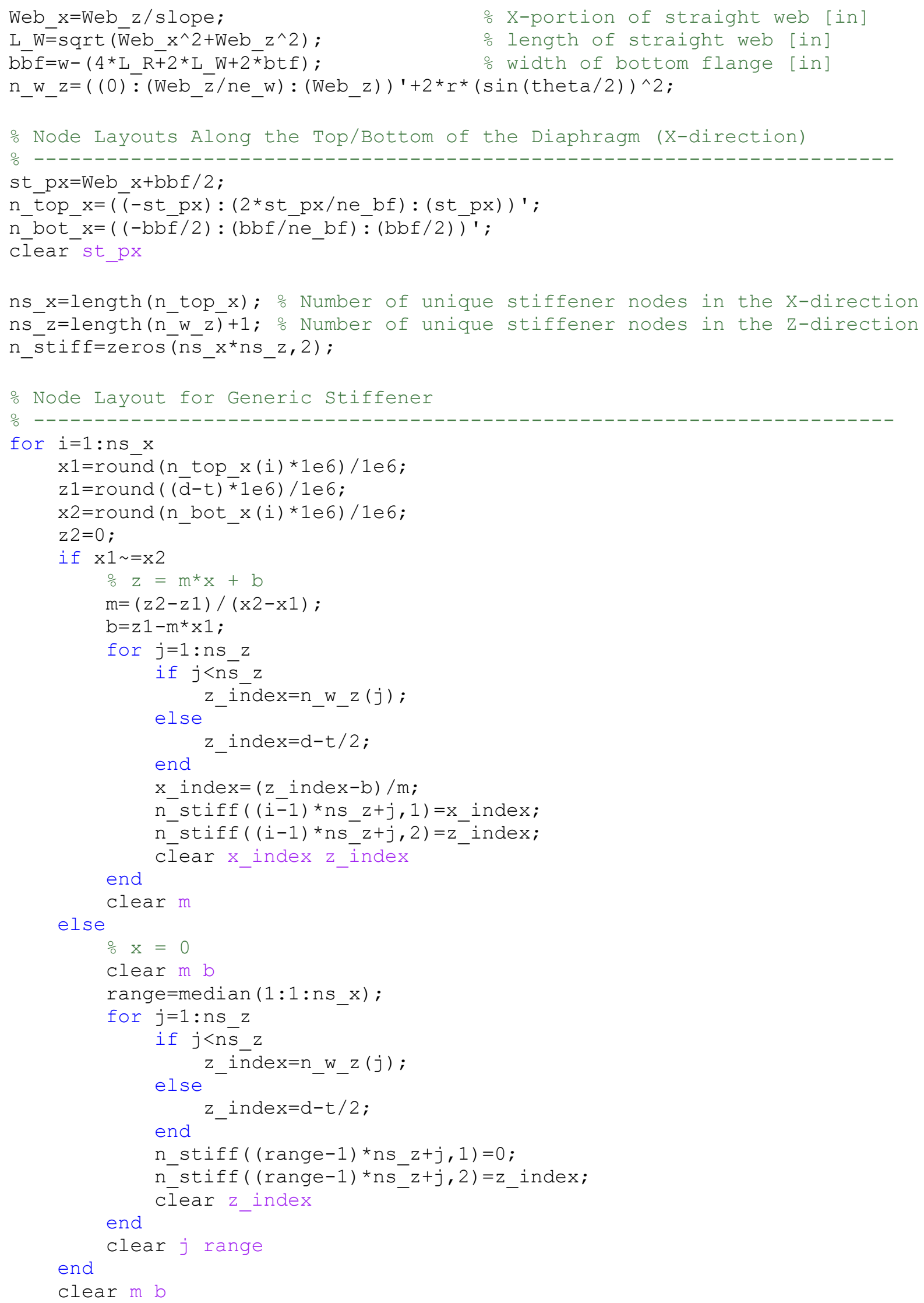




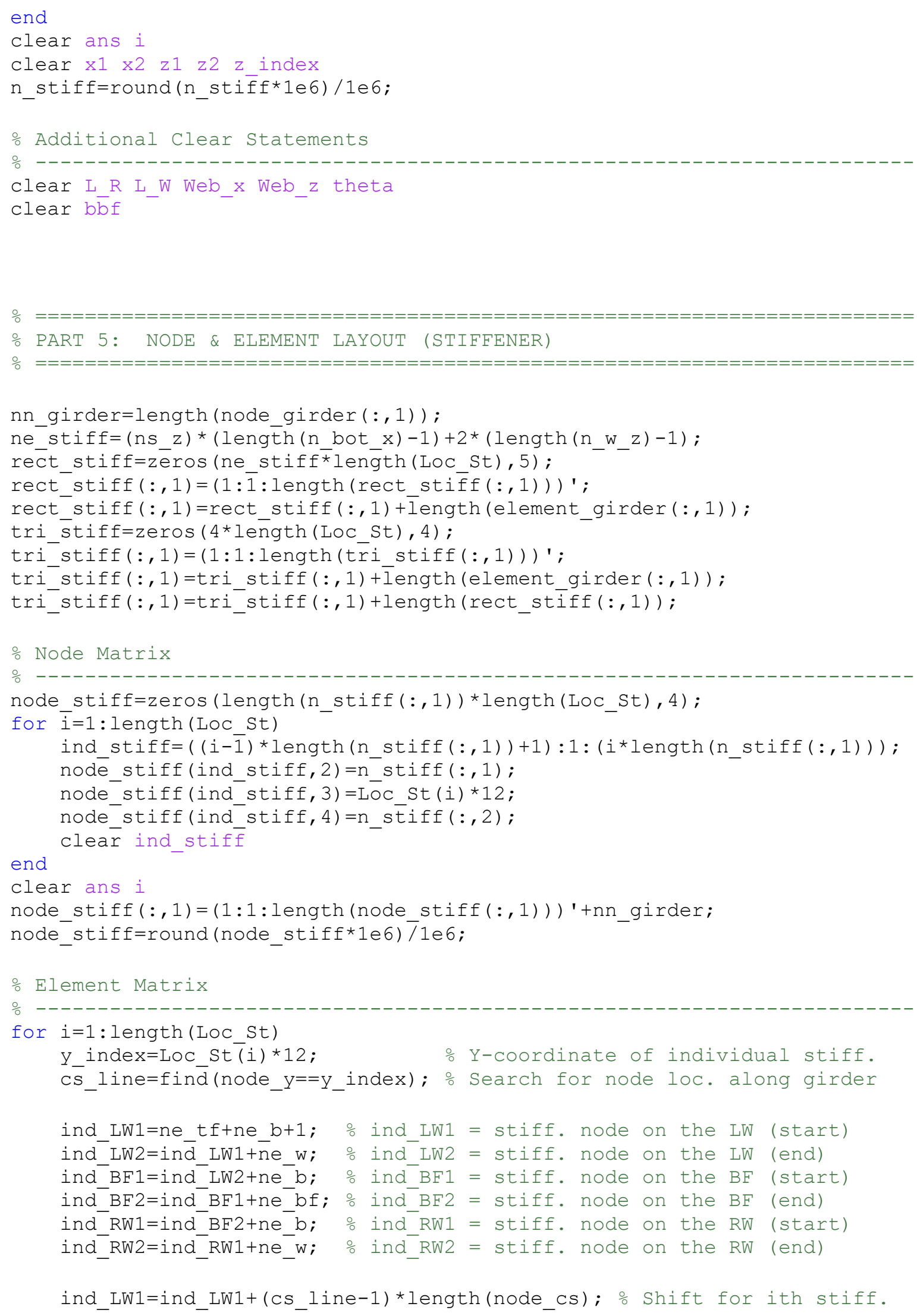




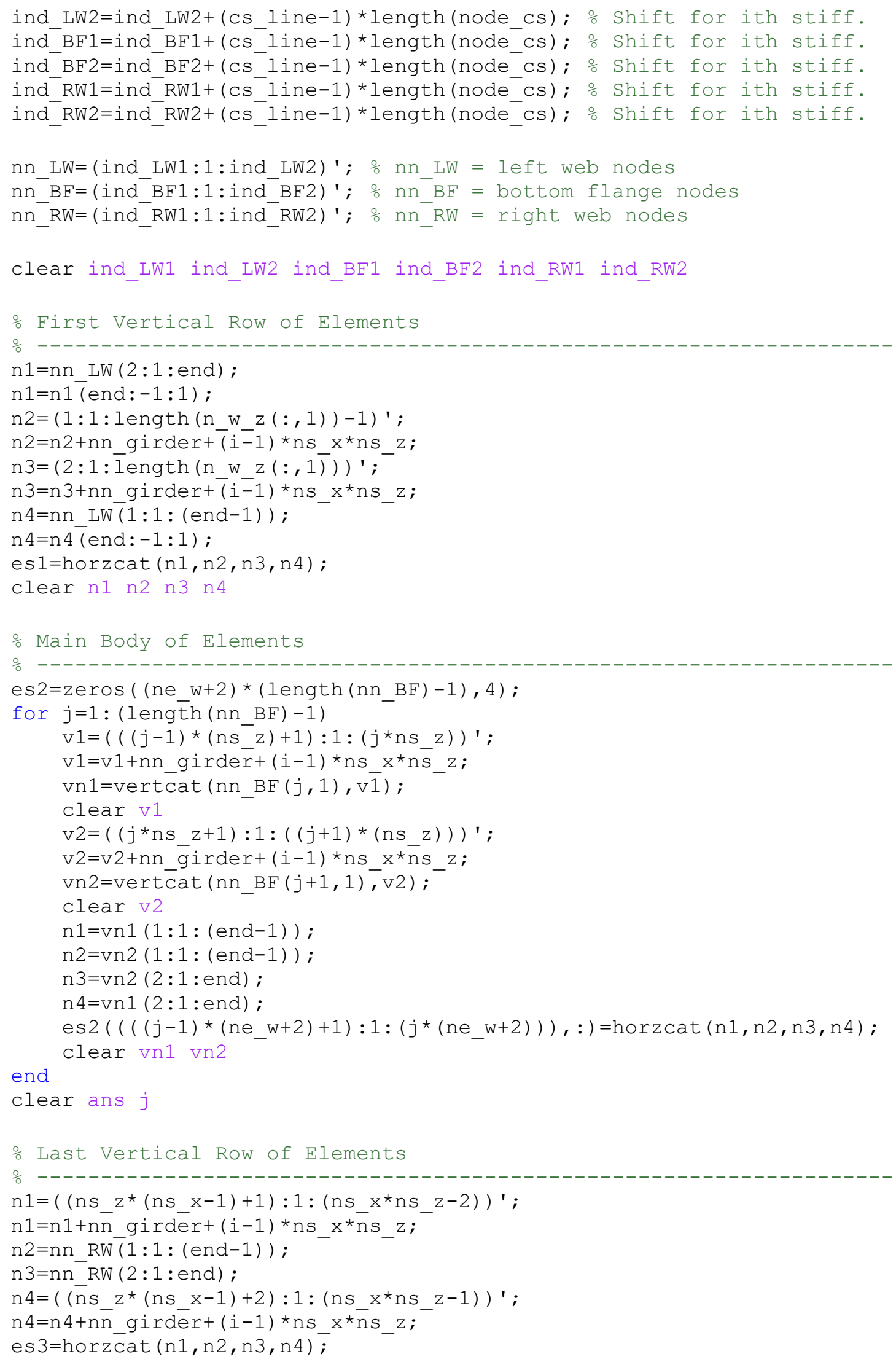




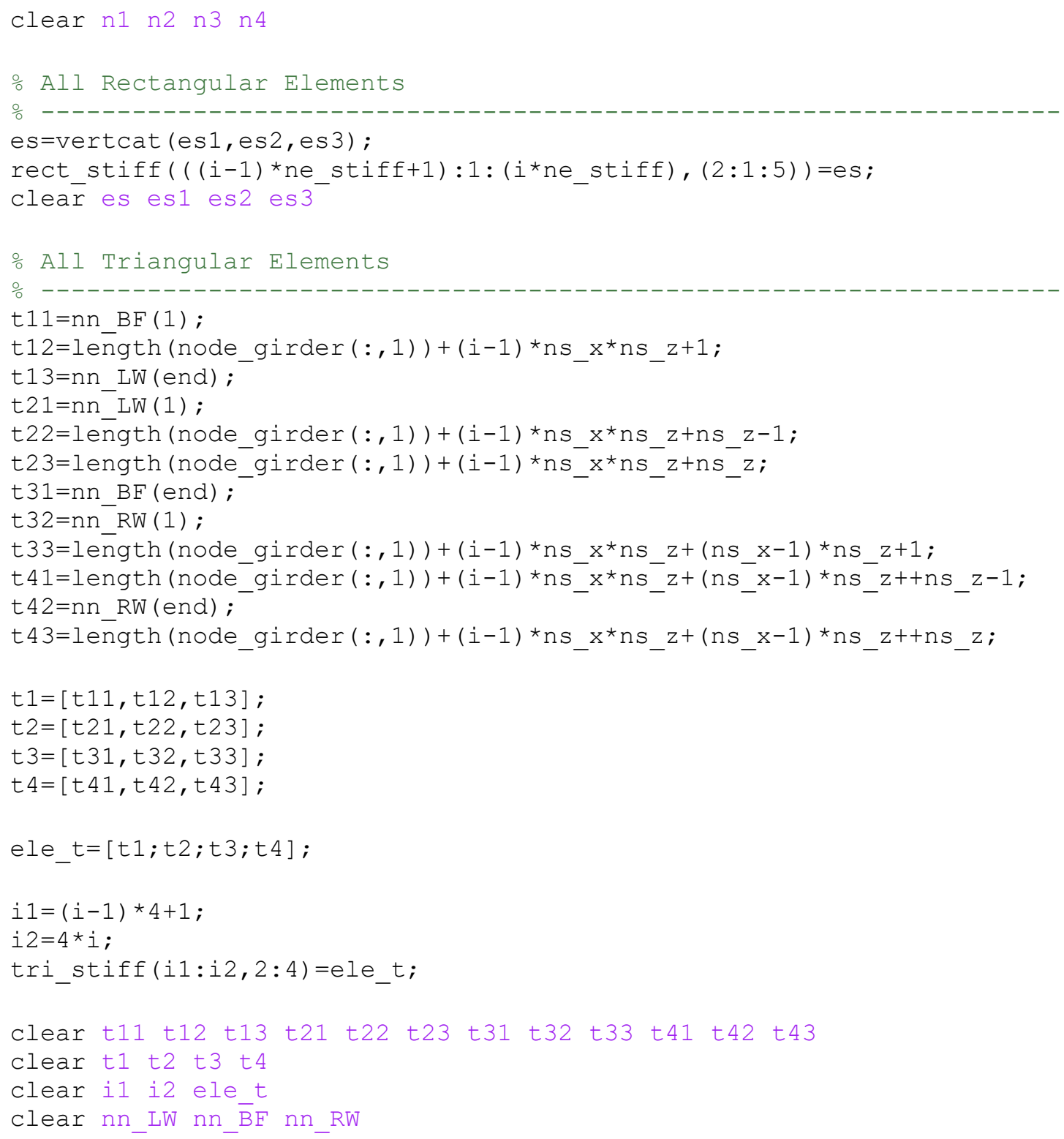




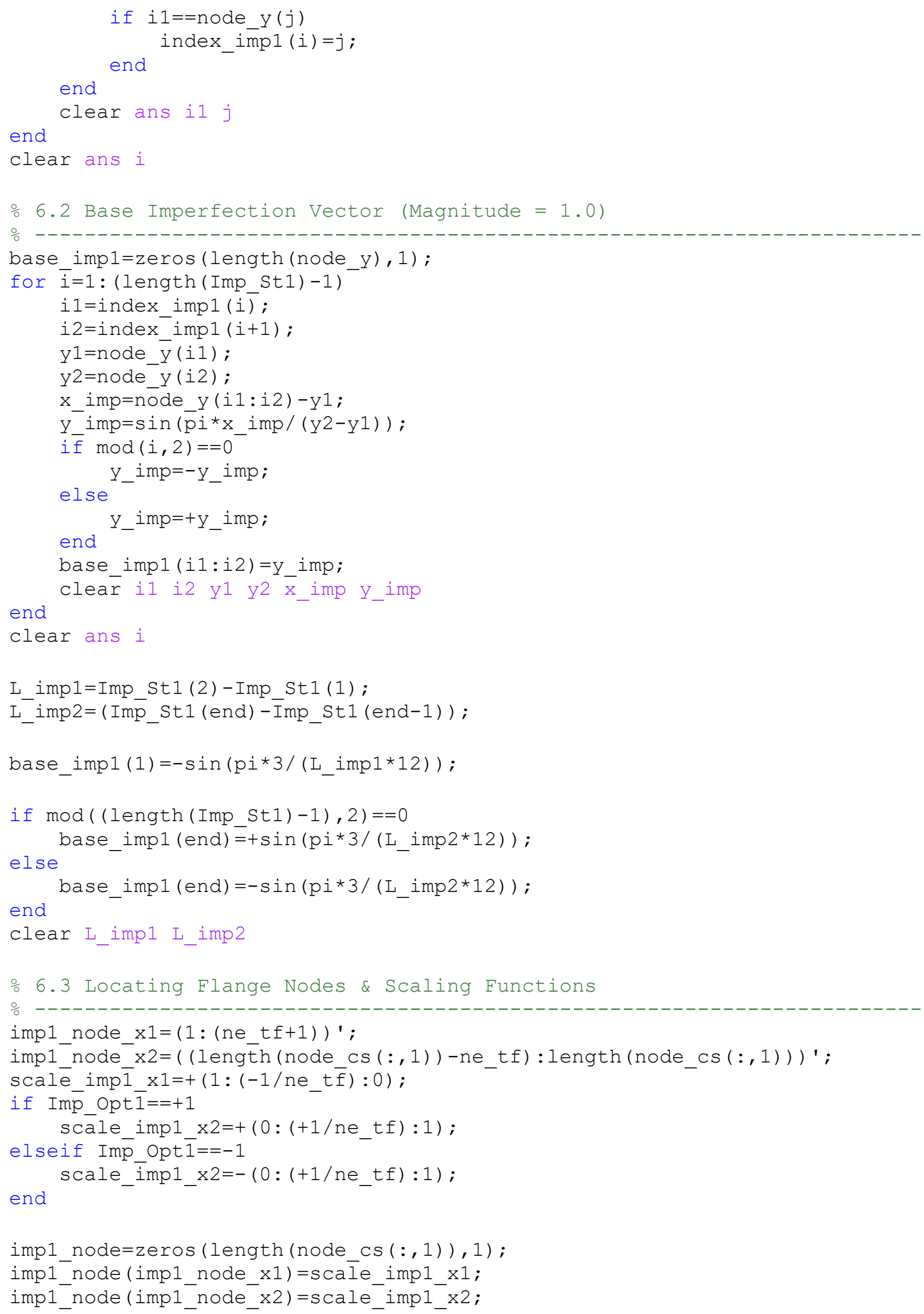




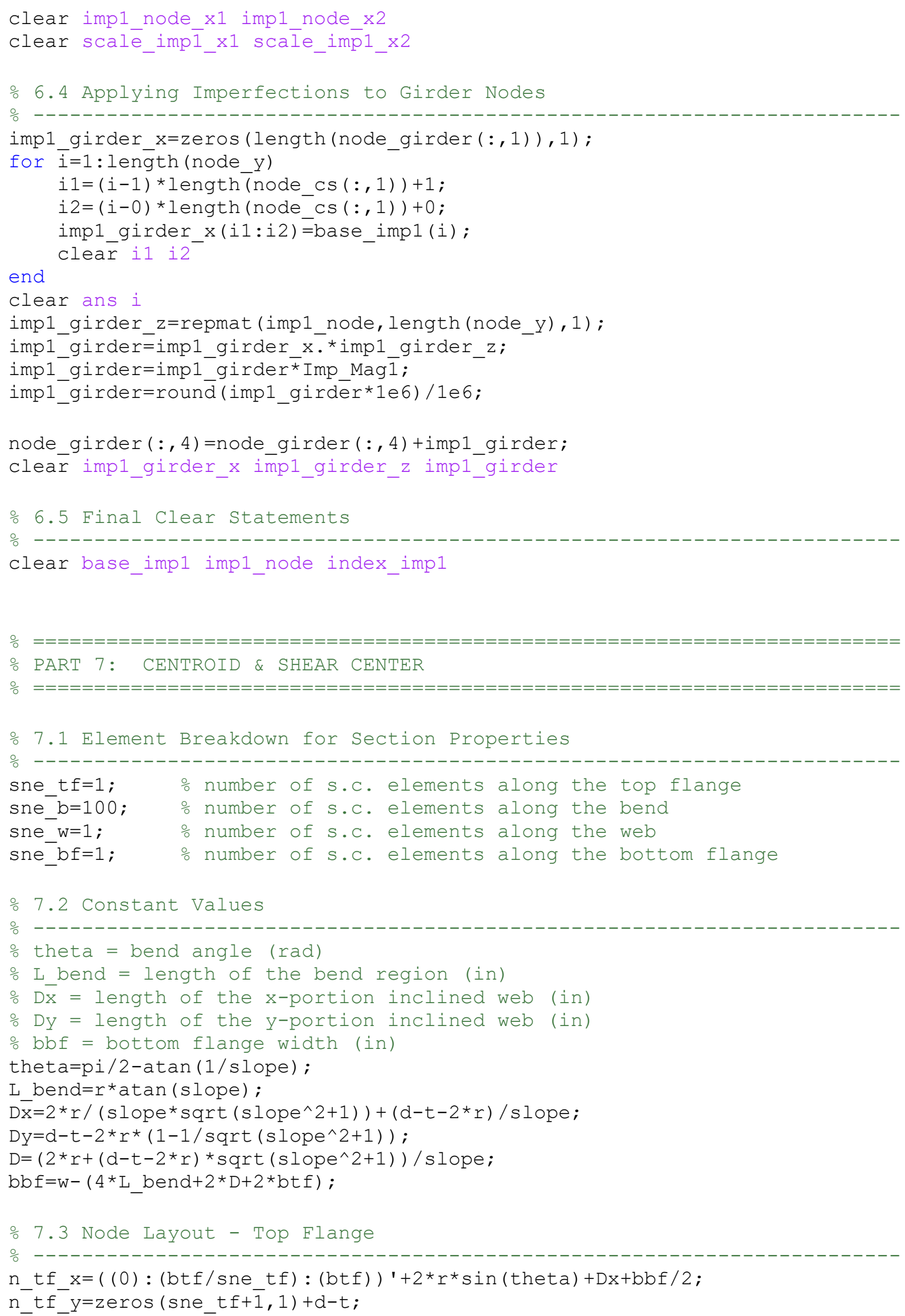




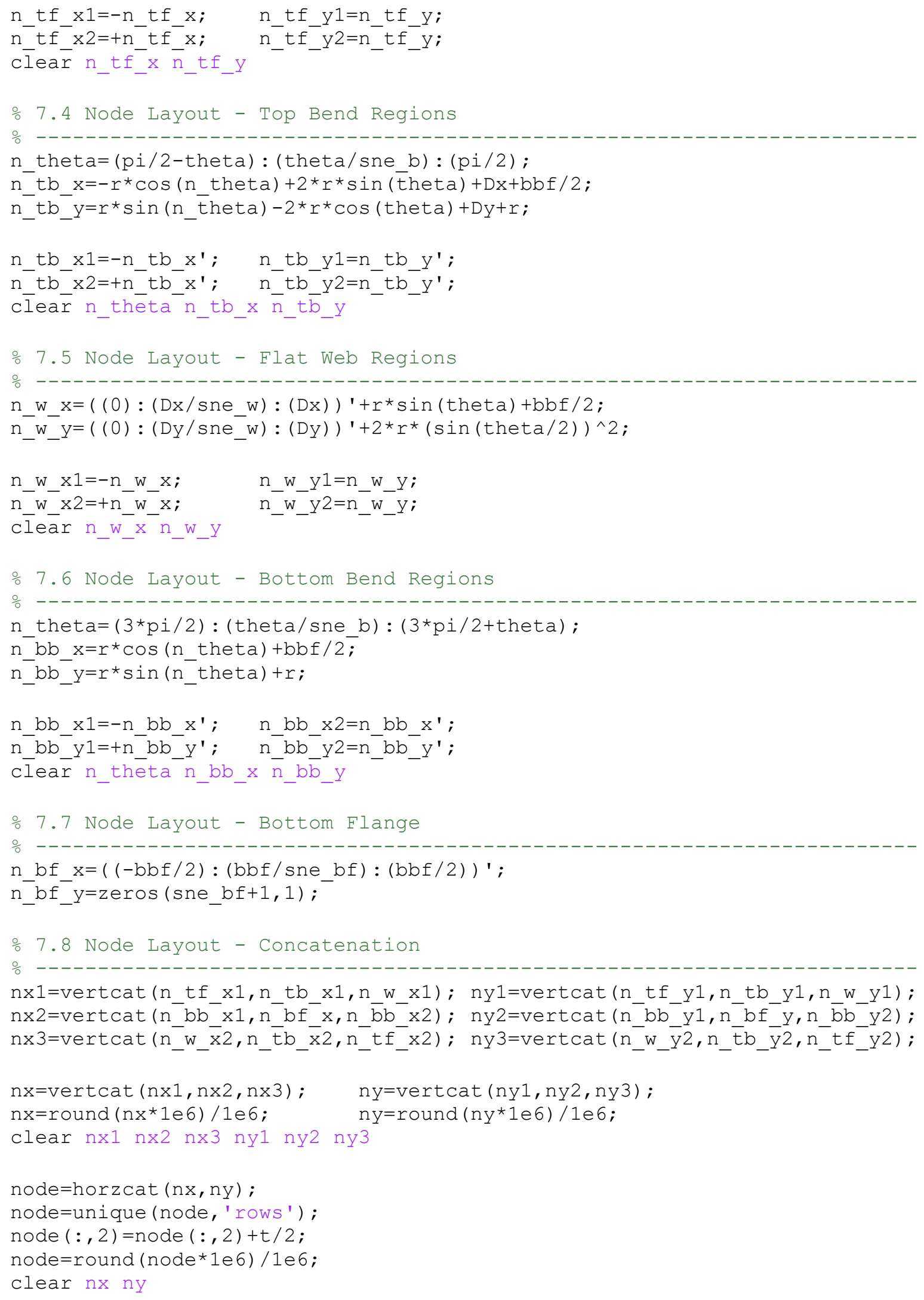




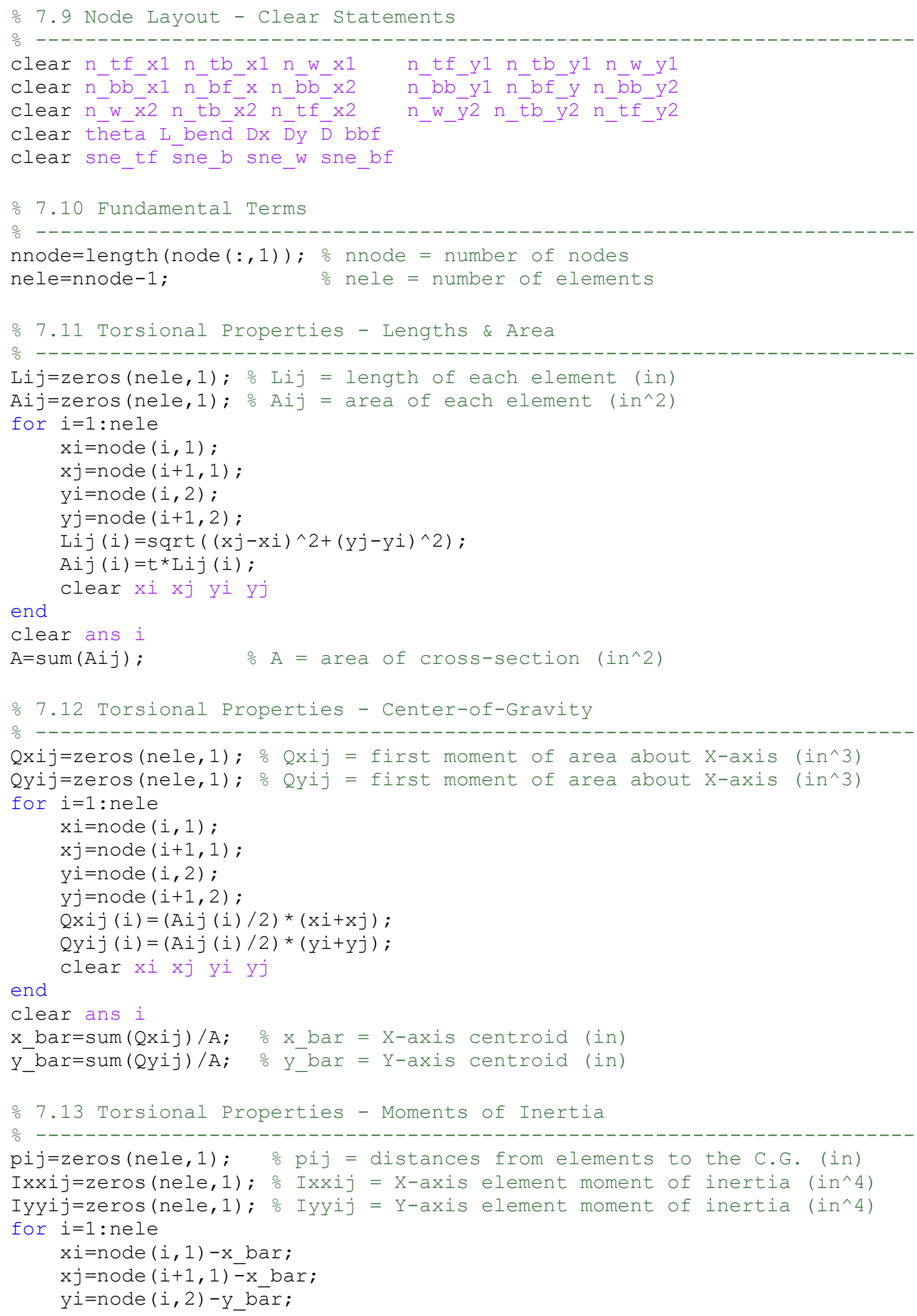




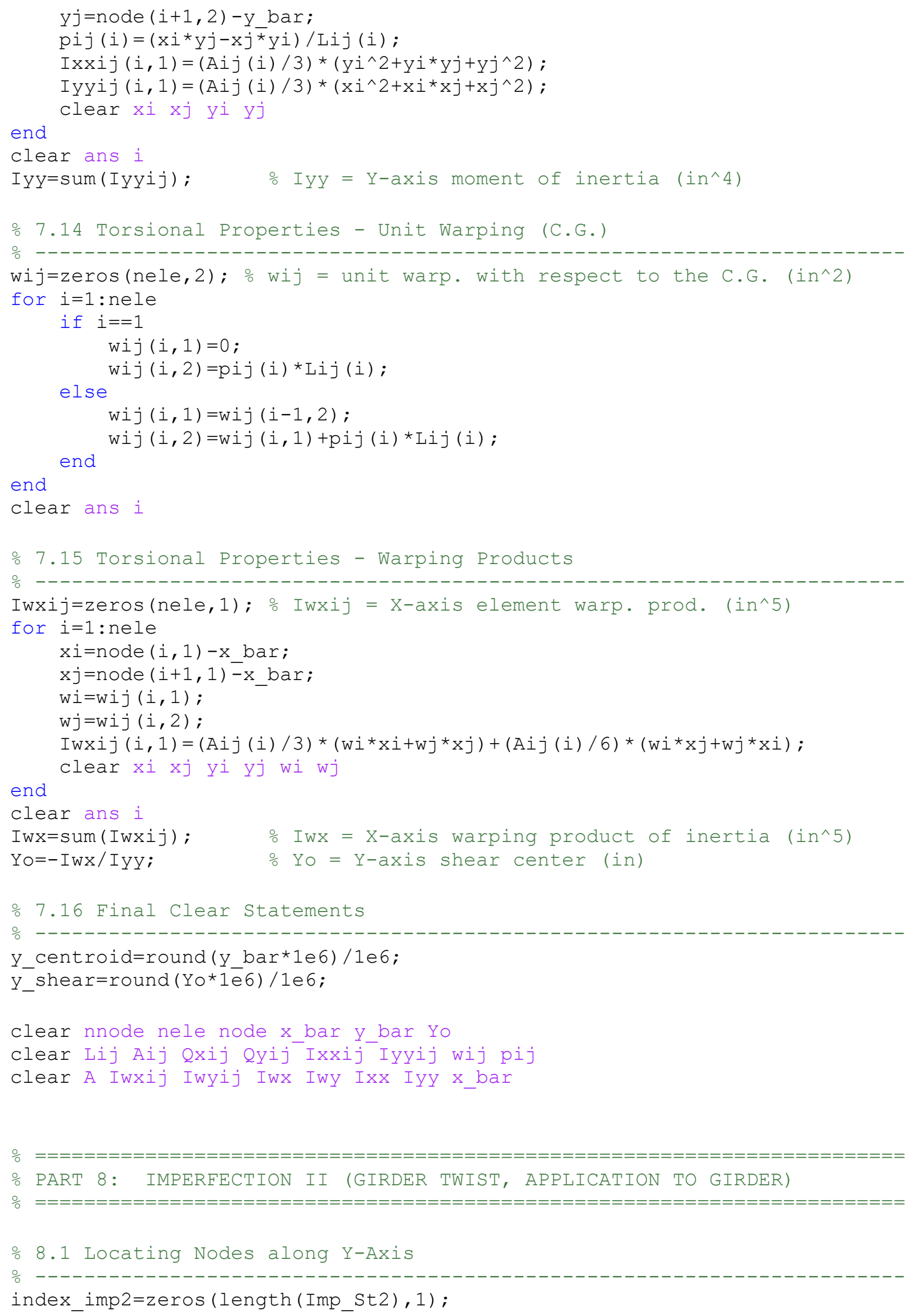




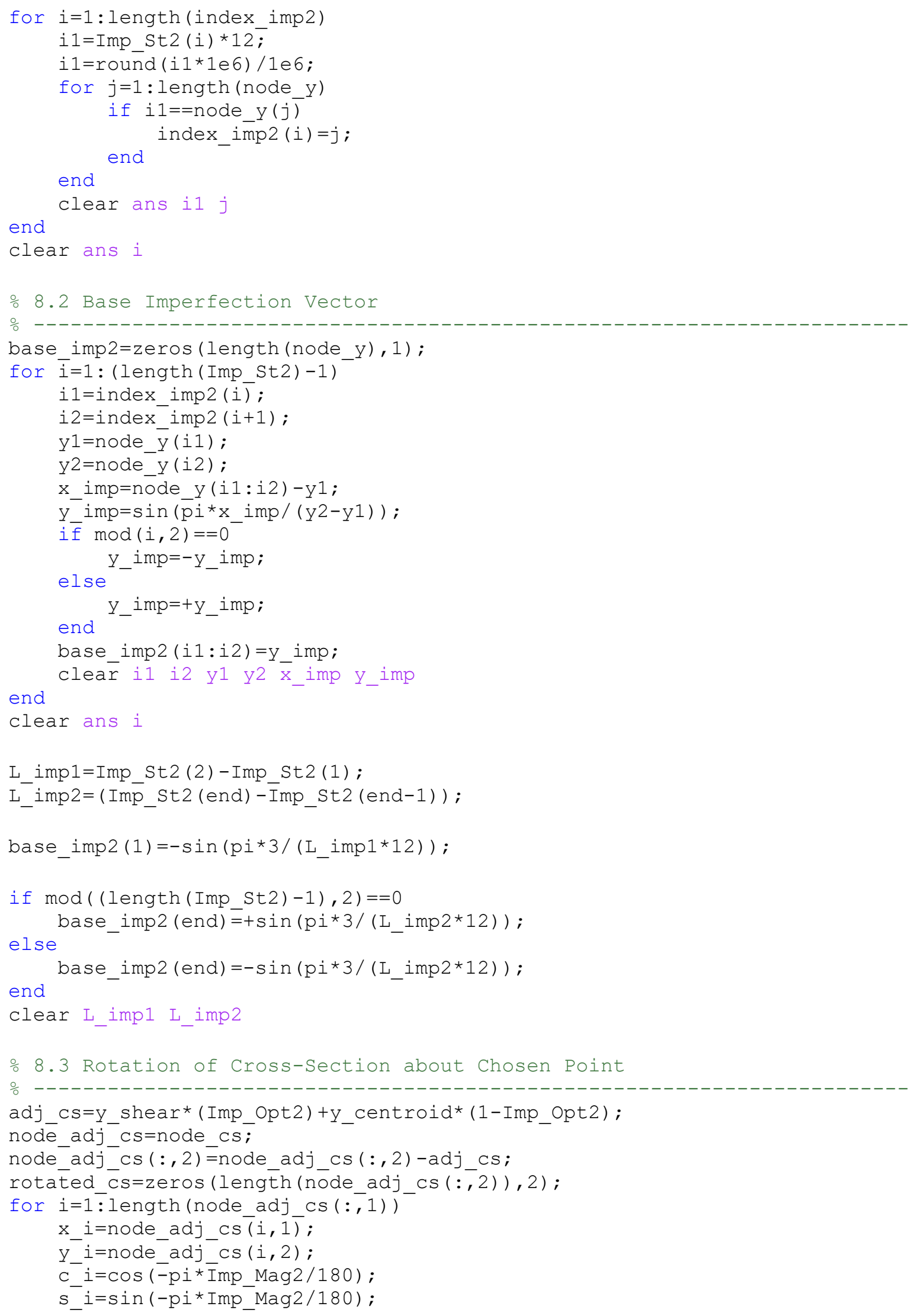




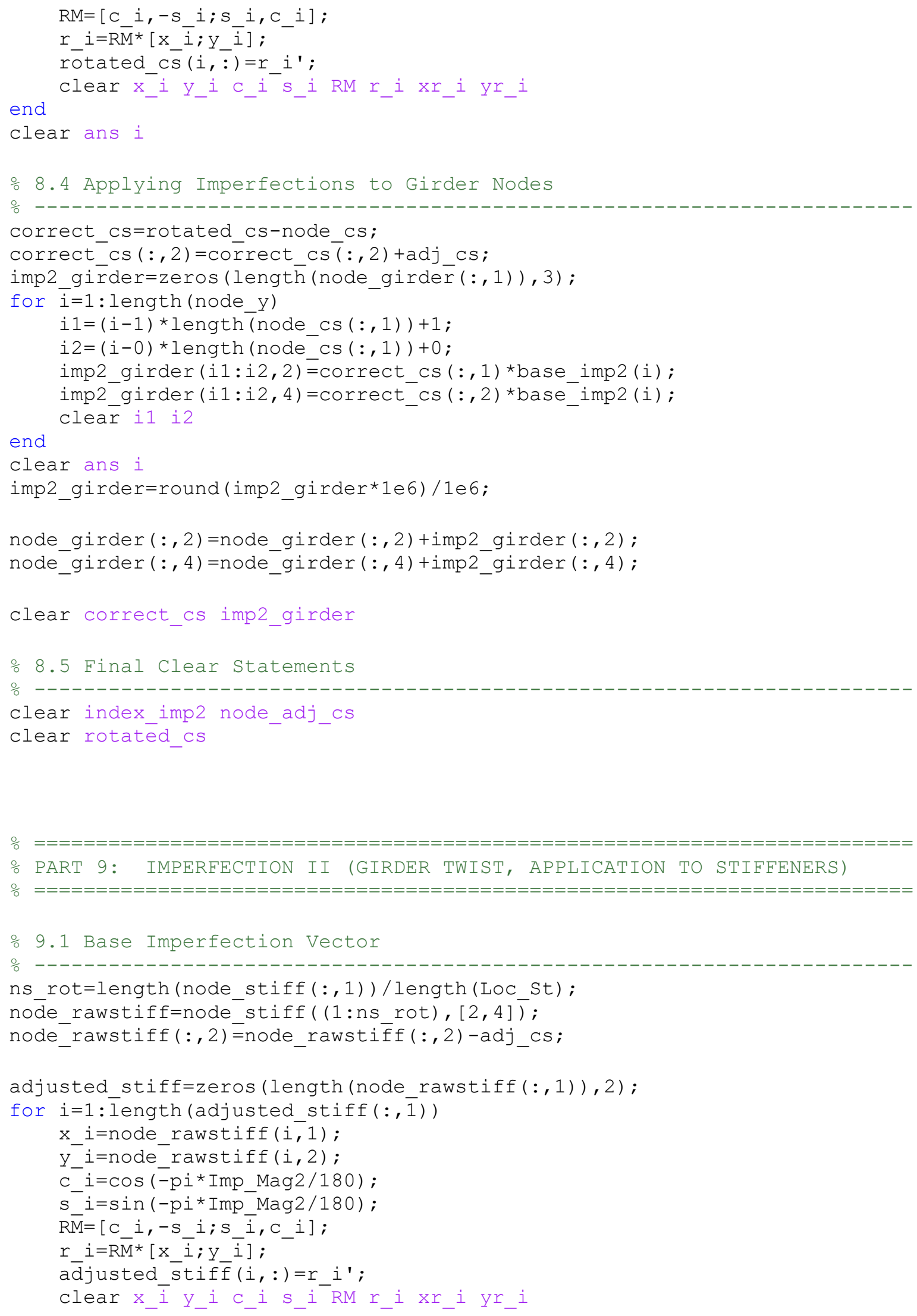




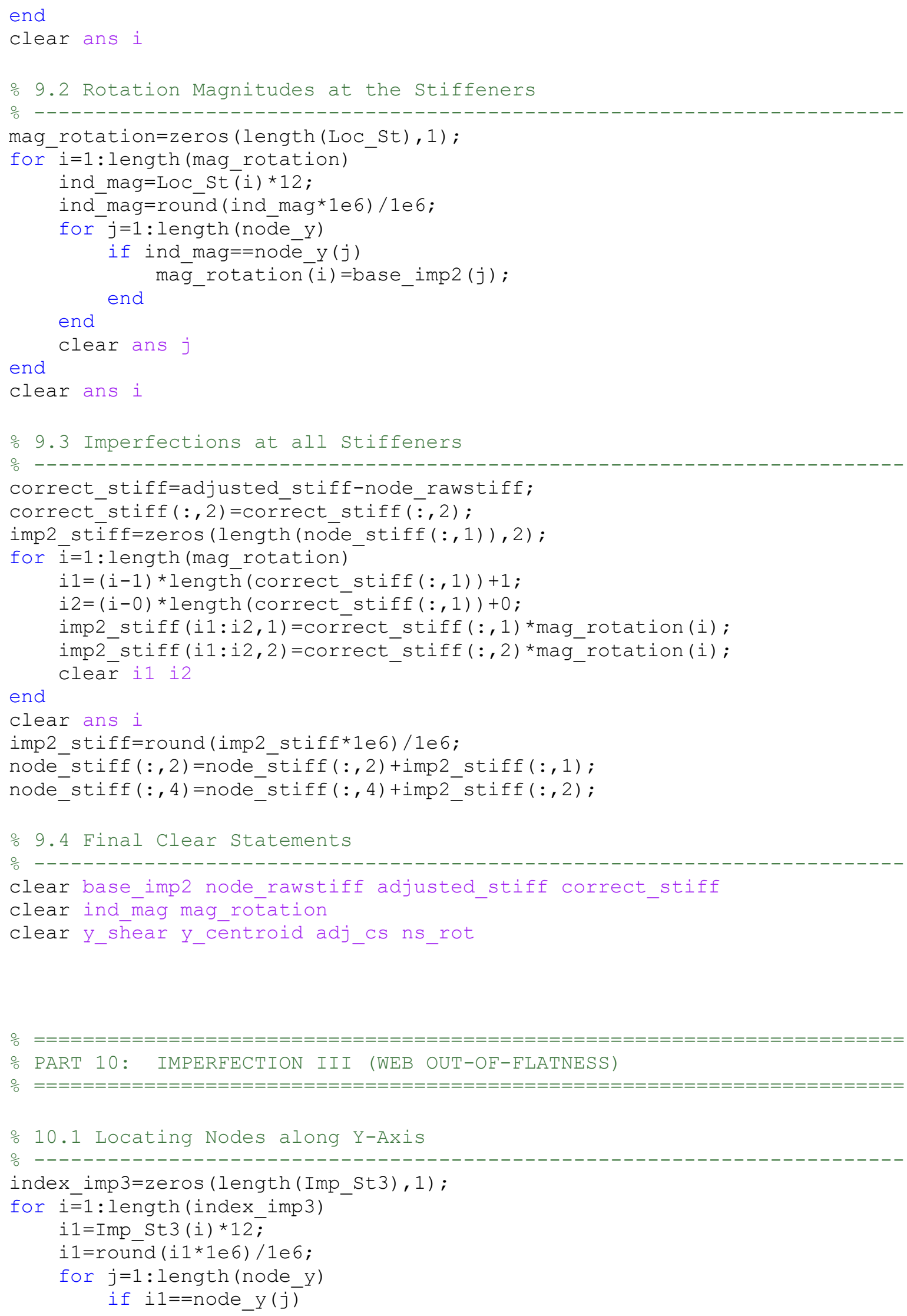




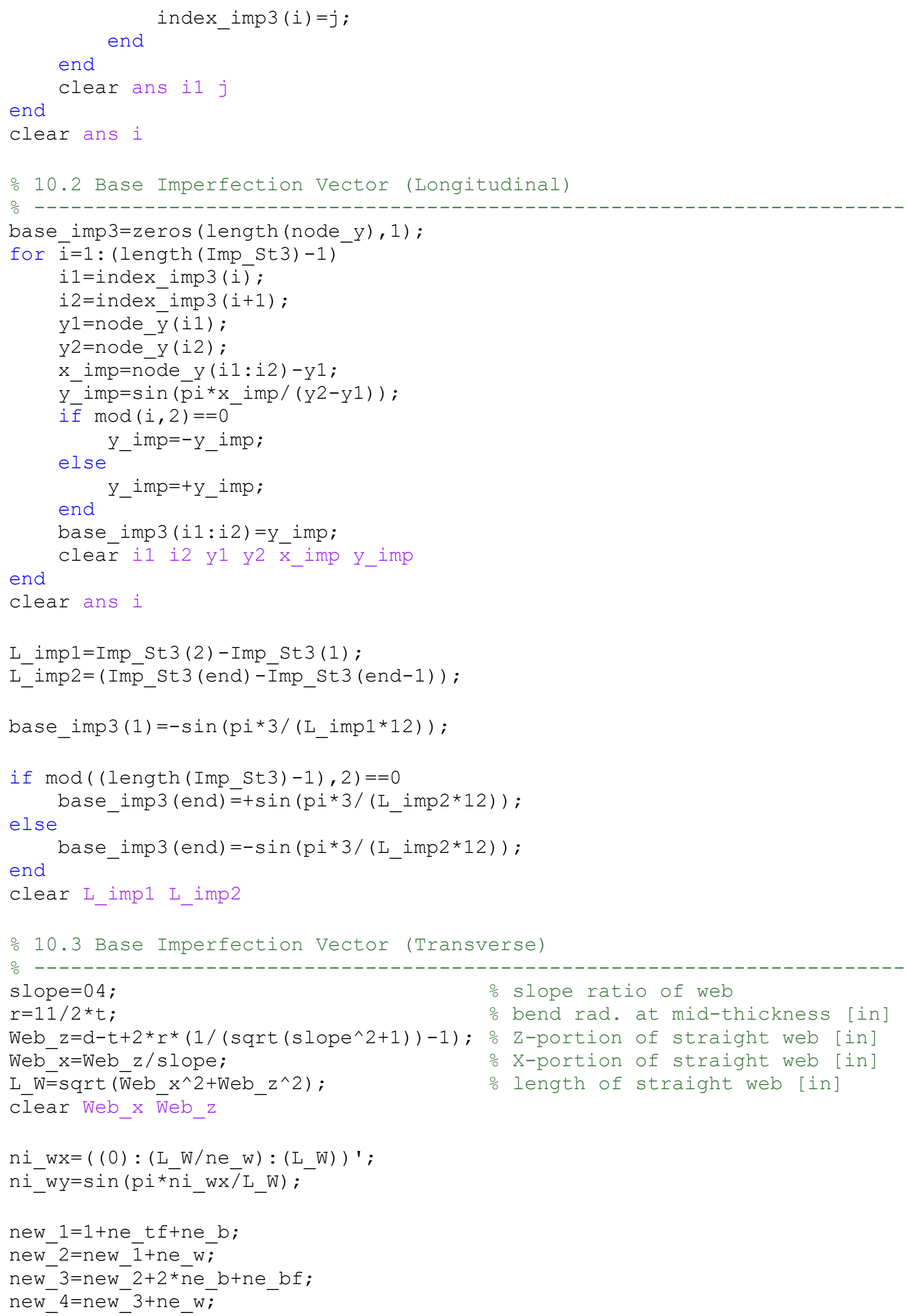




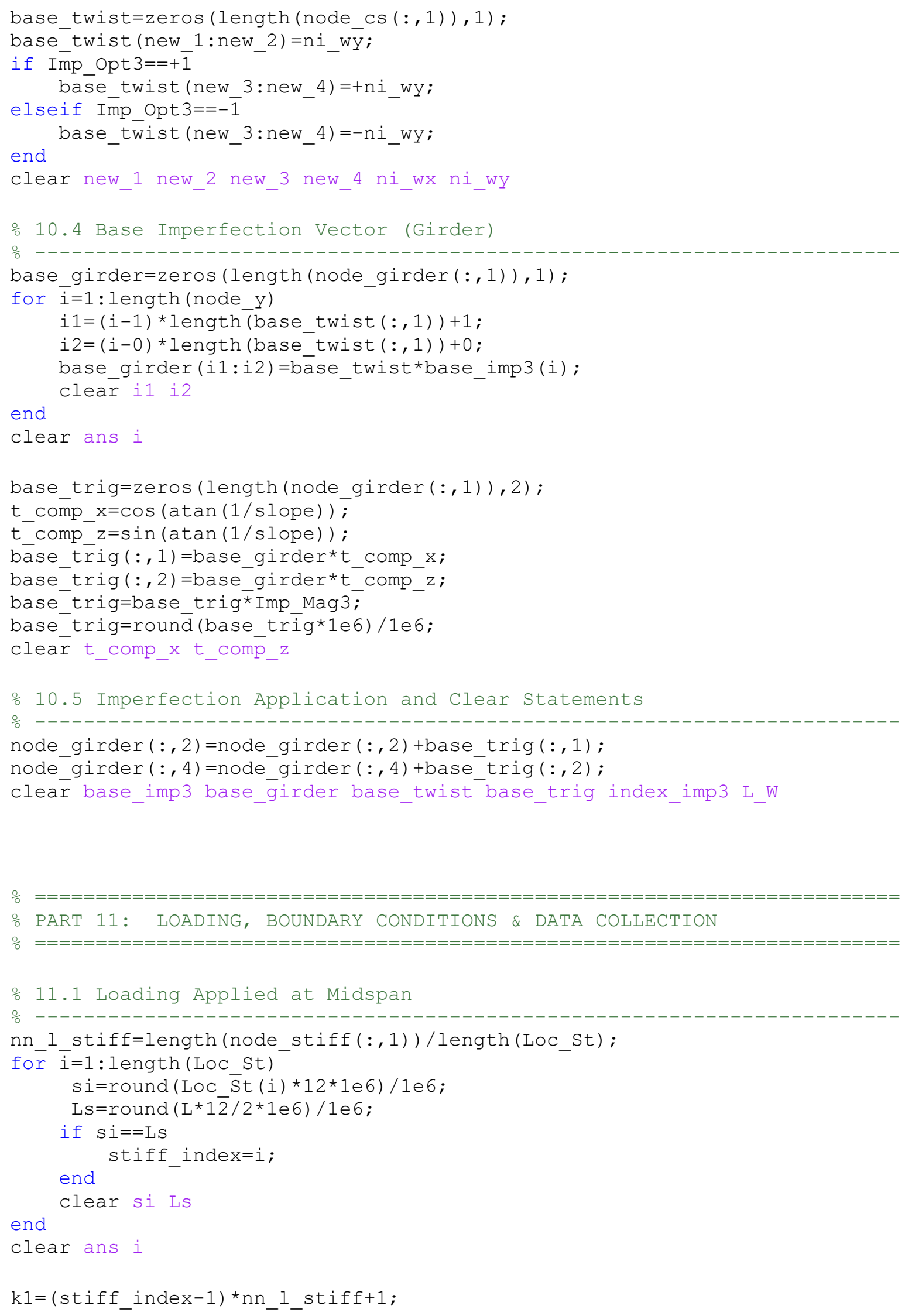




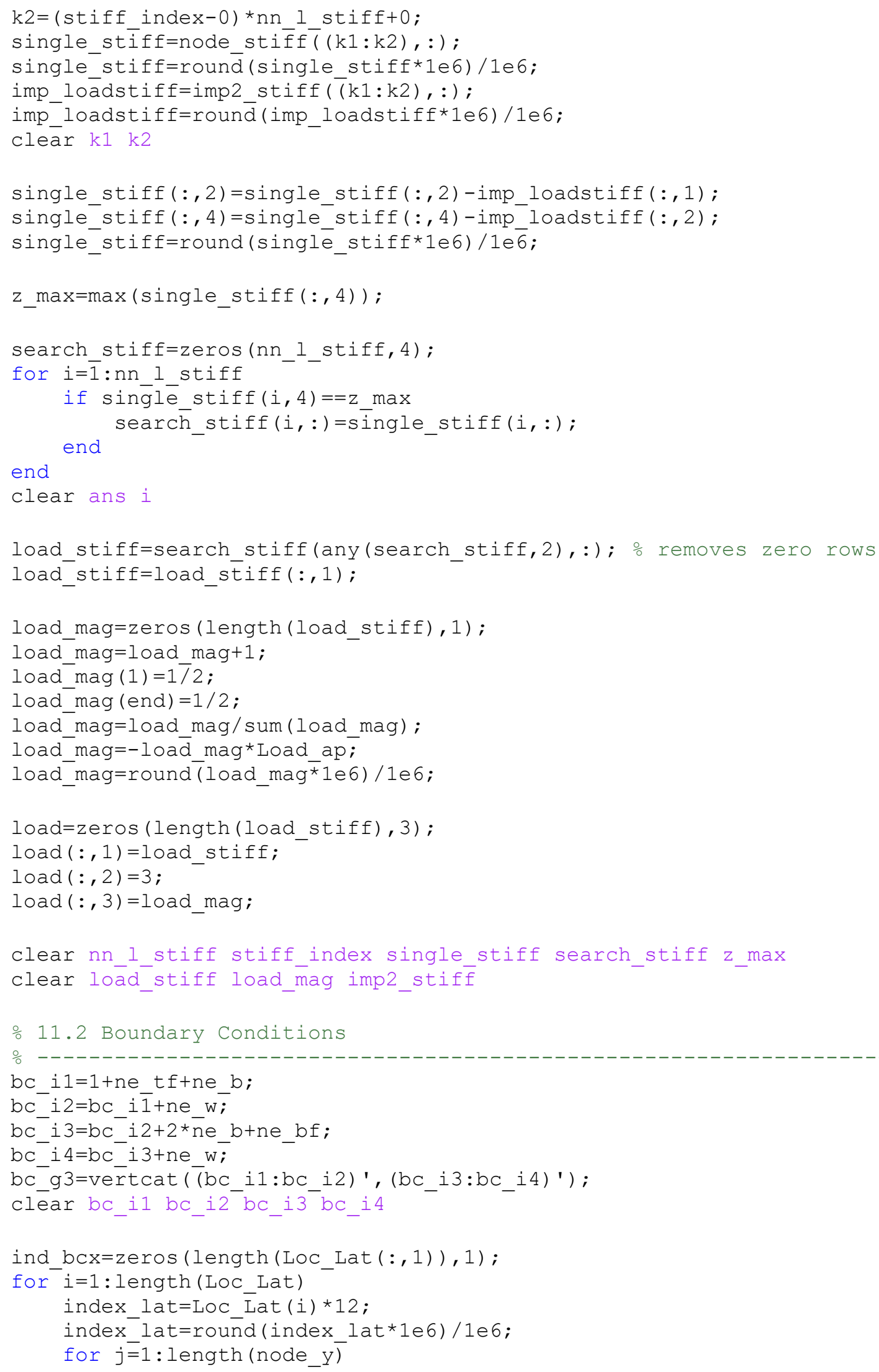




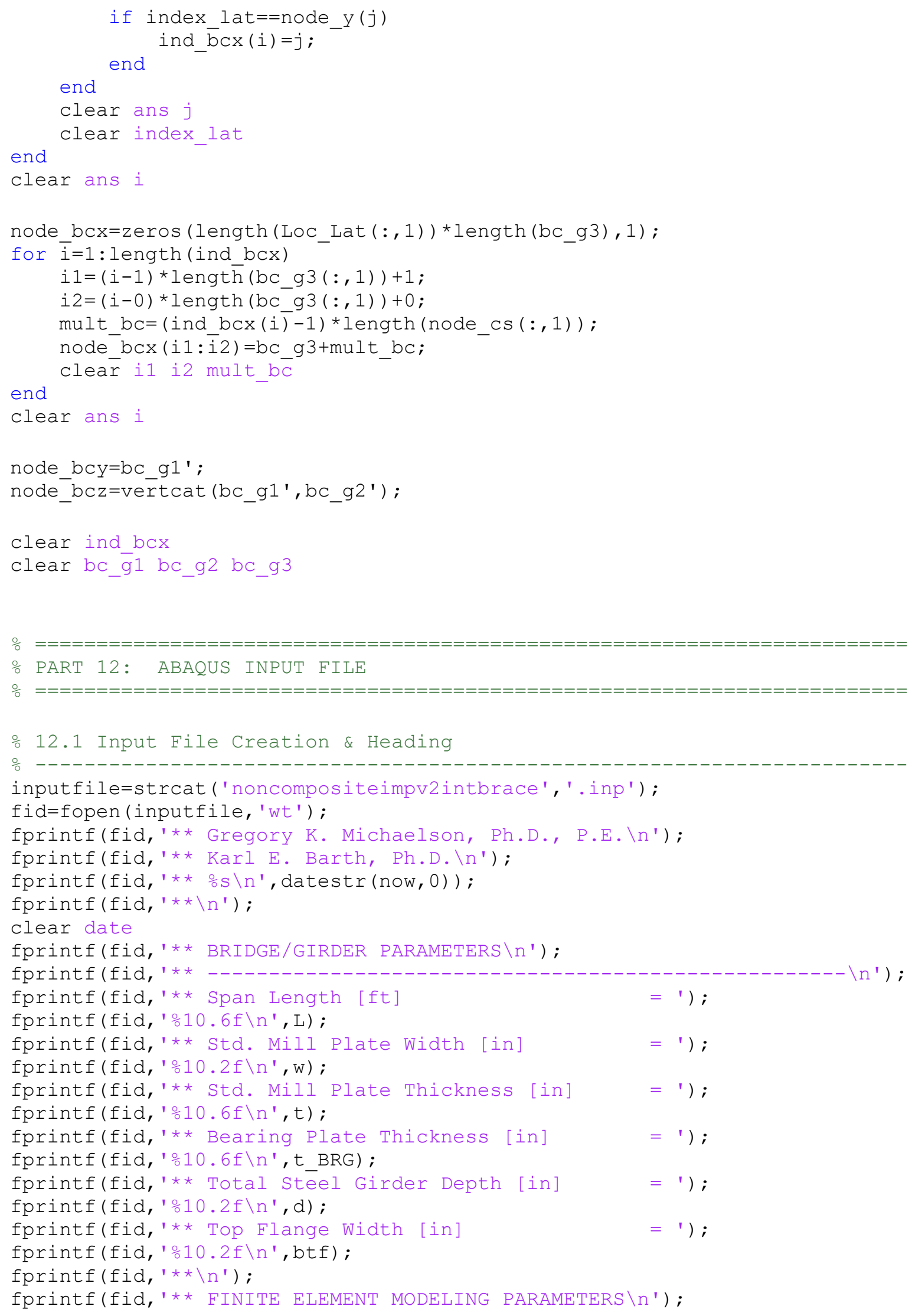




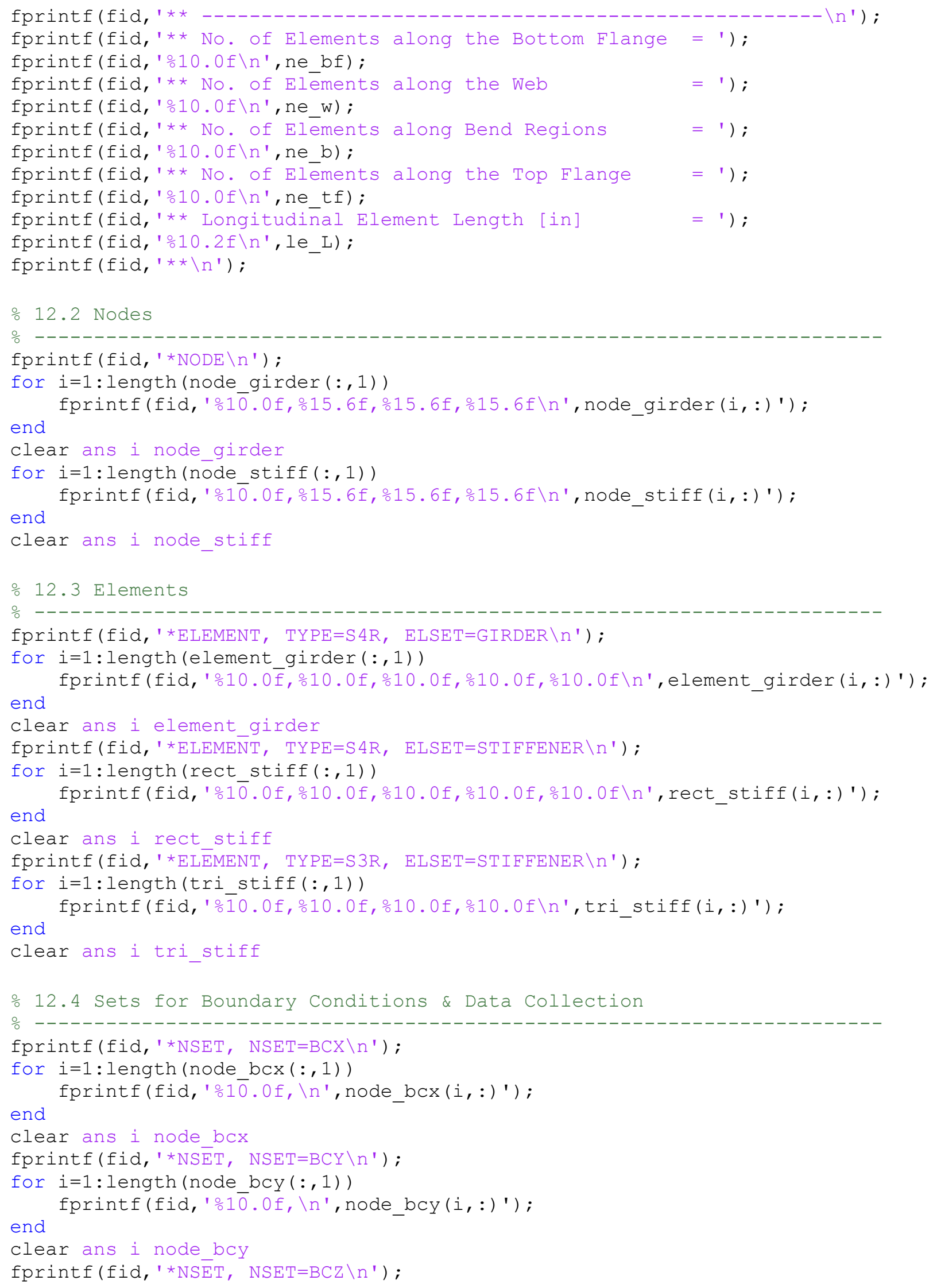




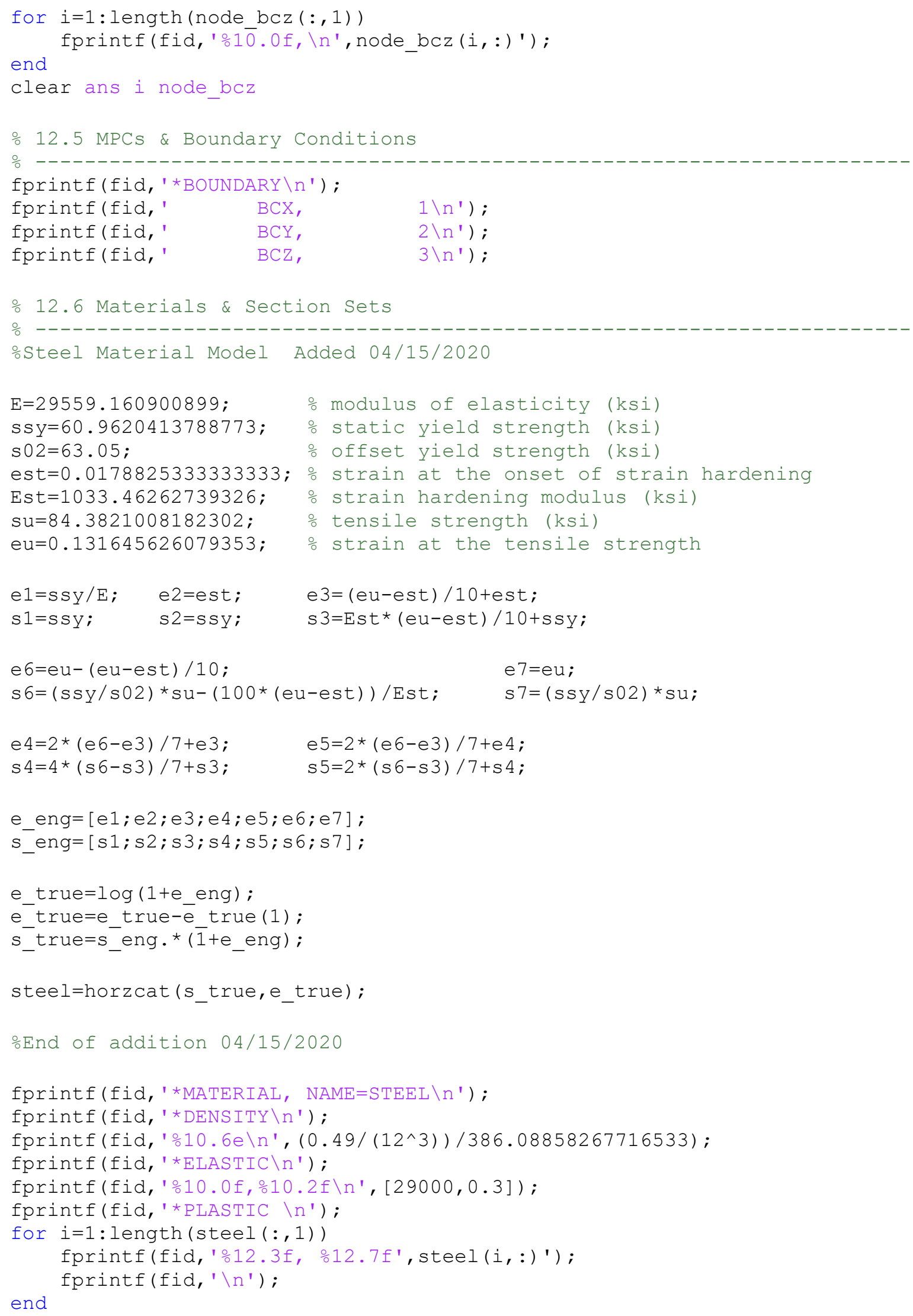




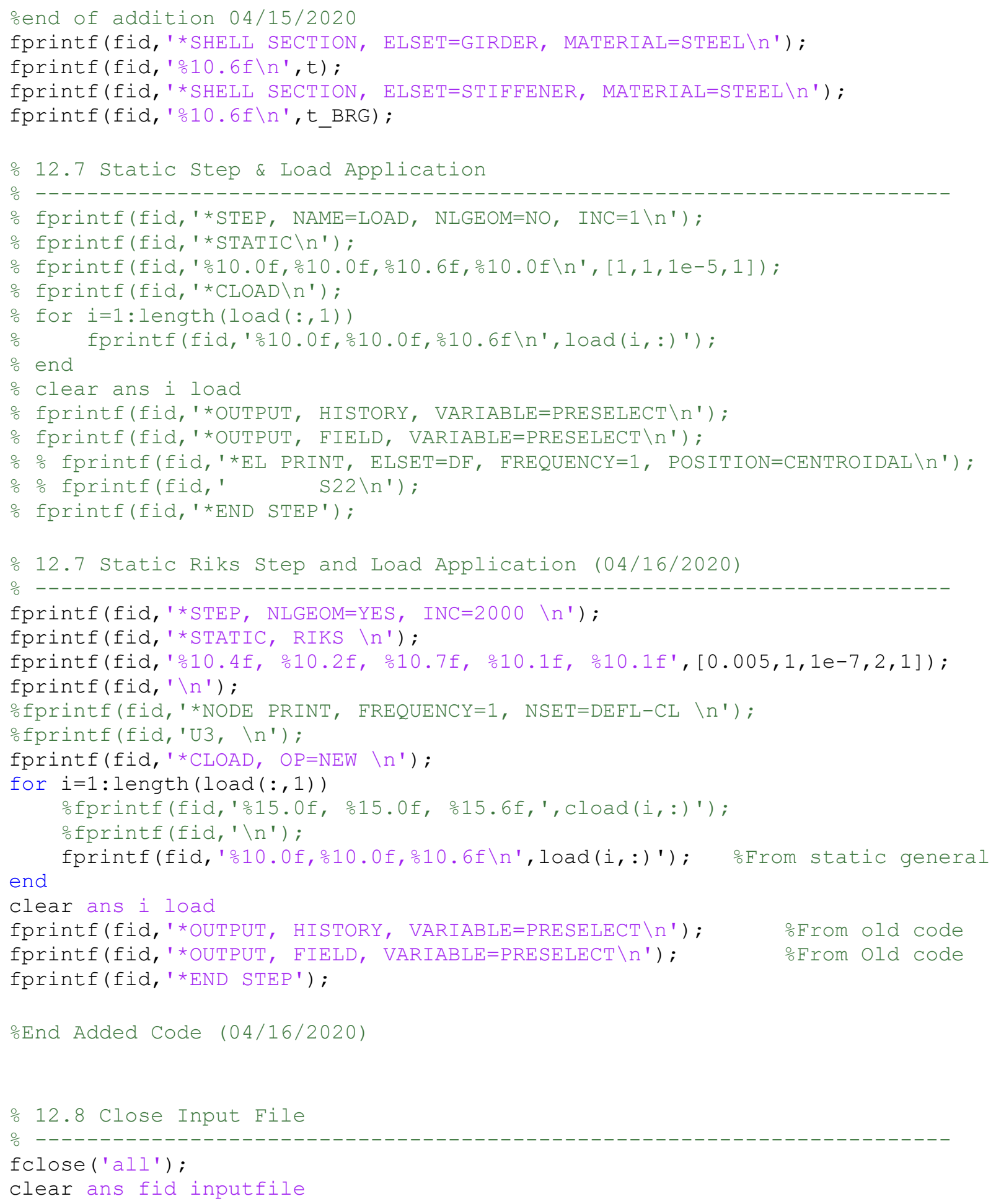




\section{ApPendix C: Fourteen Mile Bridge Design Plans}

The following appendix includes the detail plans from J.B. Turman Engineering, PLLC for the Fourteen Mile Bridge. These plans are not the final construction plans on file with the West Virginia Division of Highways. Note that these plans have been converted from their original 11 "x 17 " format to $81 \frac{1 / 2}{}$ " 11 " for presentation in this report. 


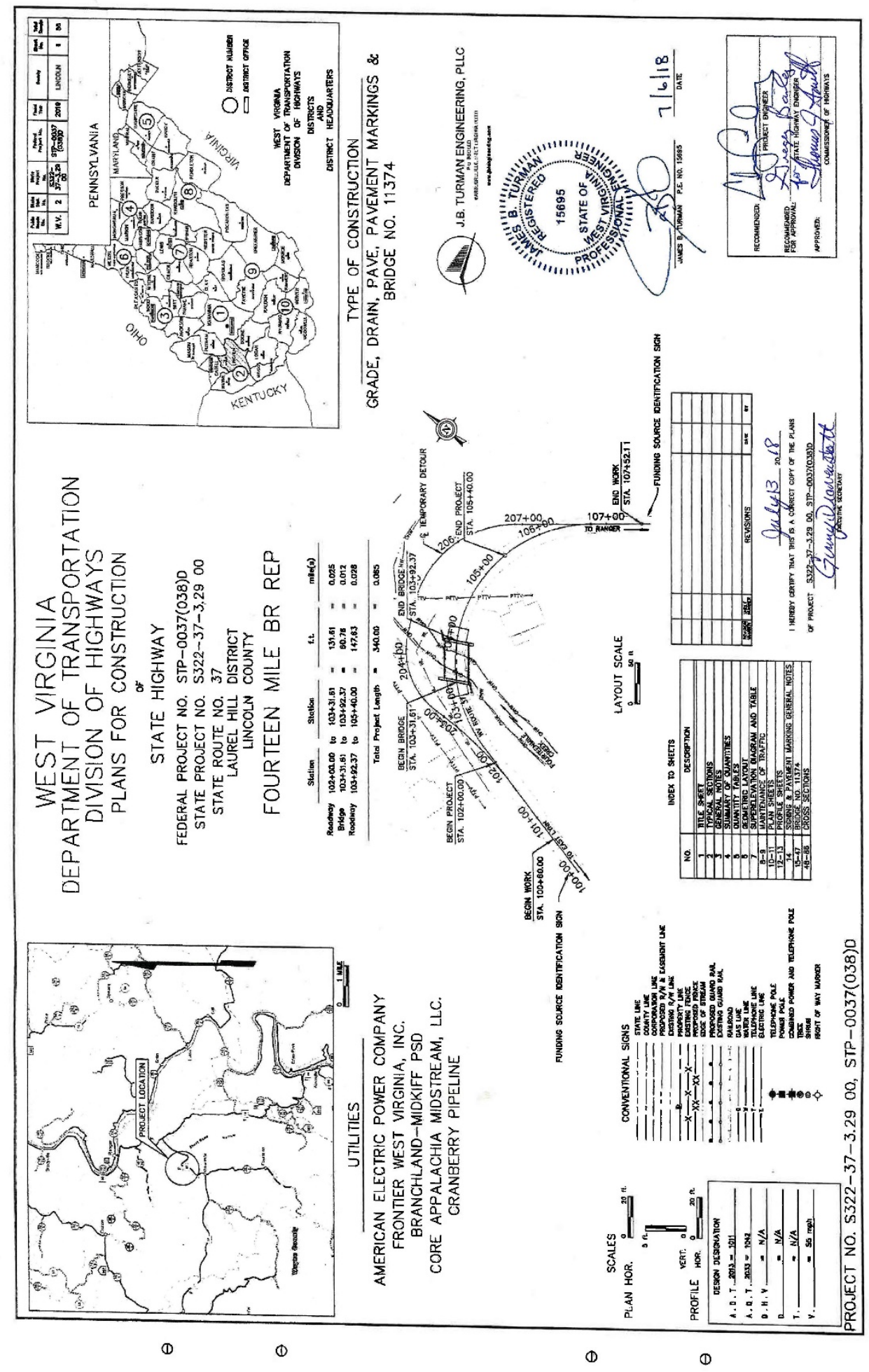




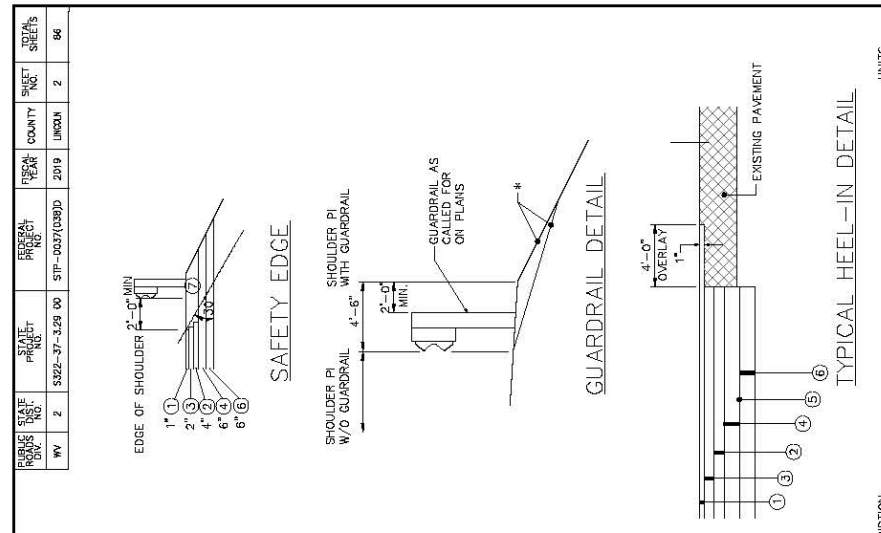

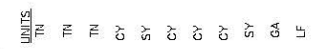

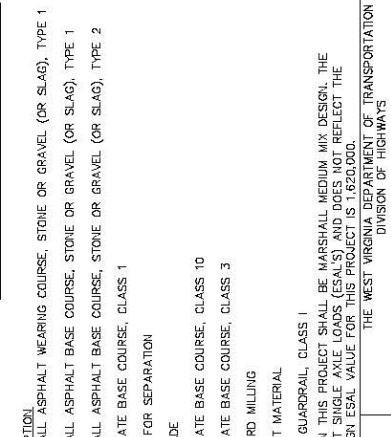

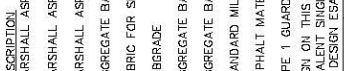
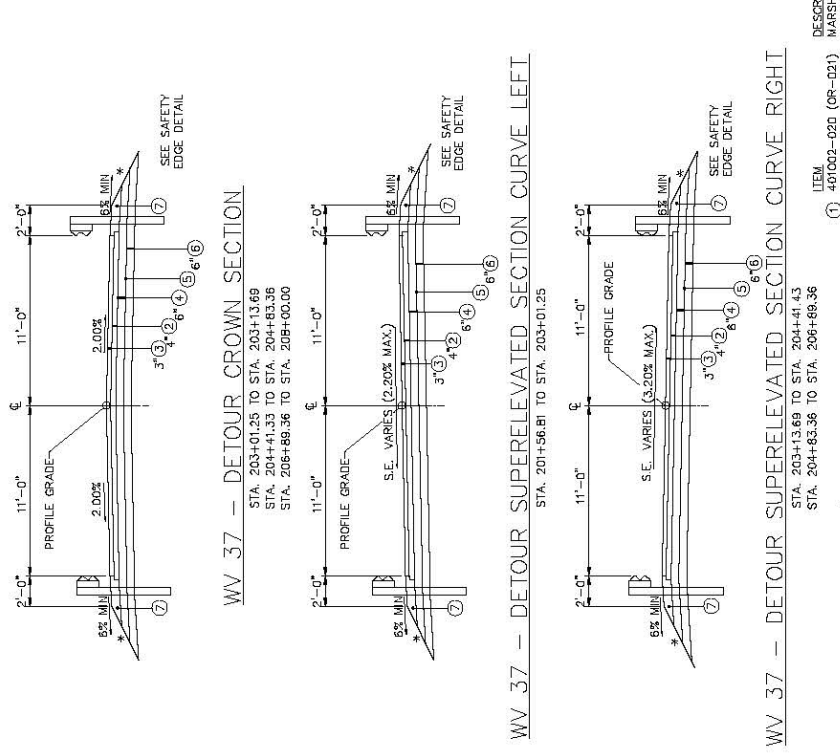

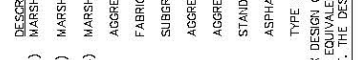

空

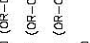

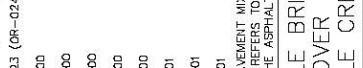

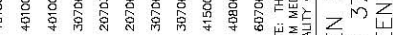

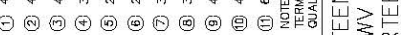
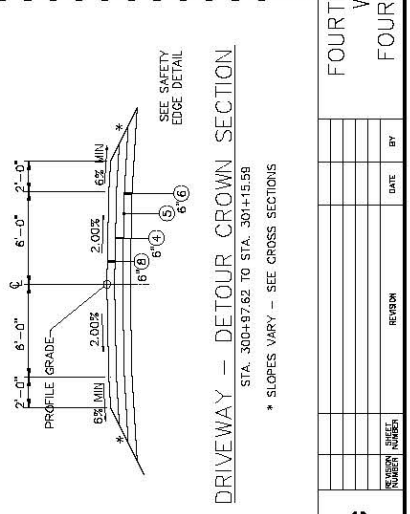

○
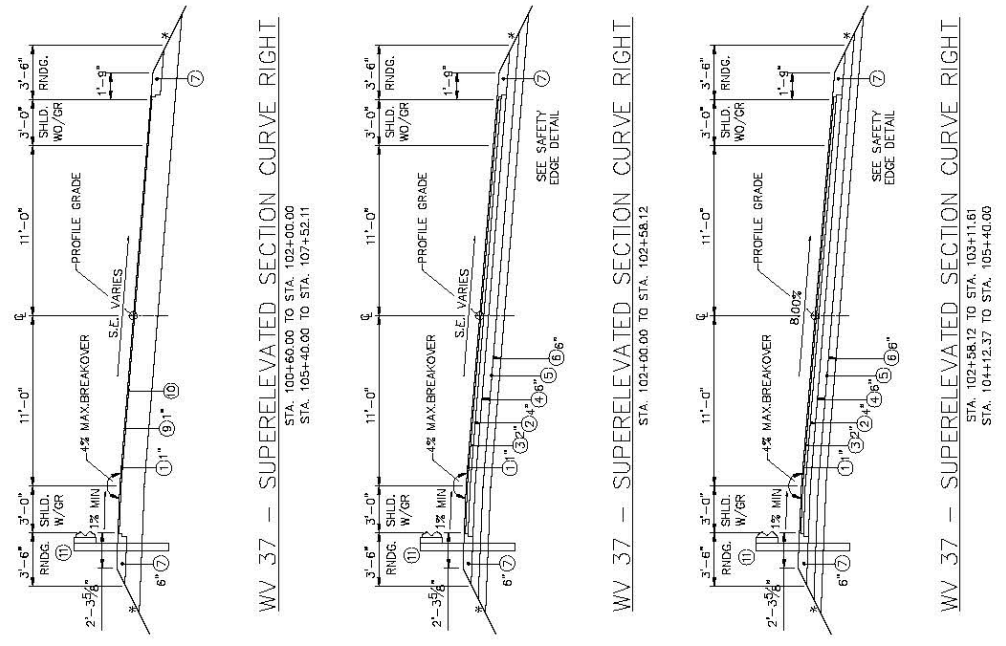

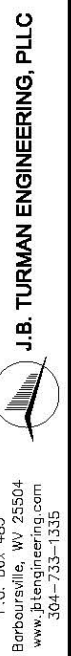

(1)

(1)

(1)

(1) 


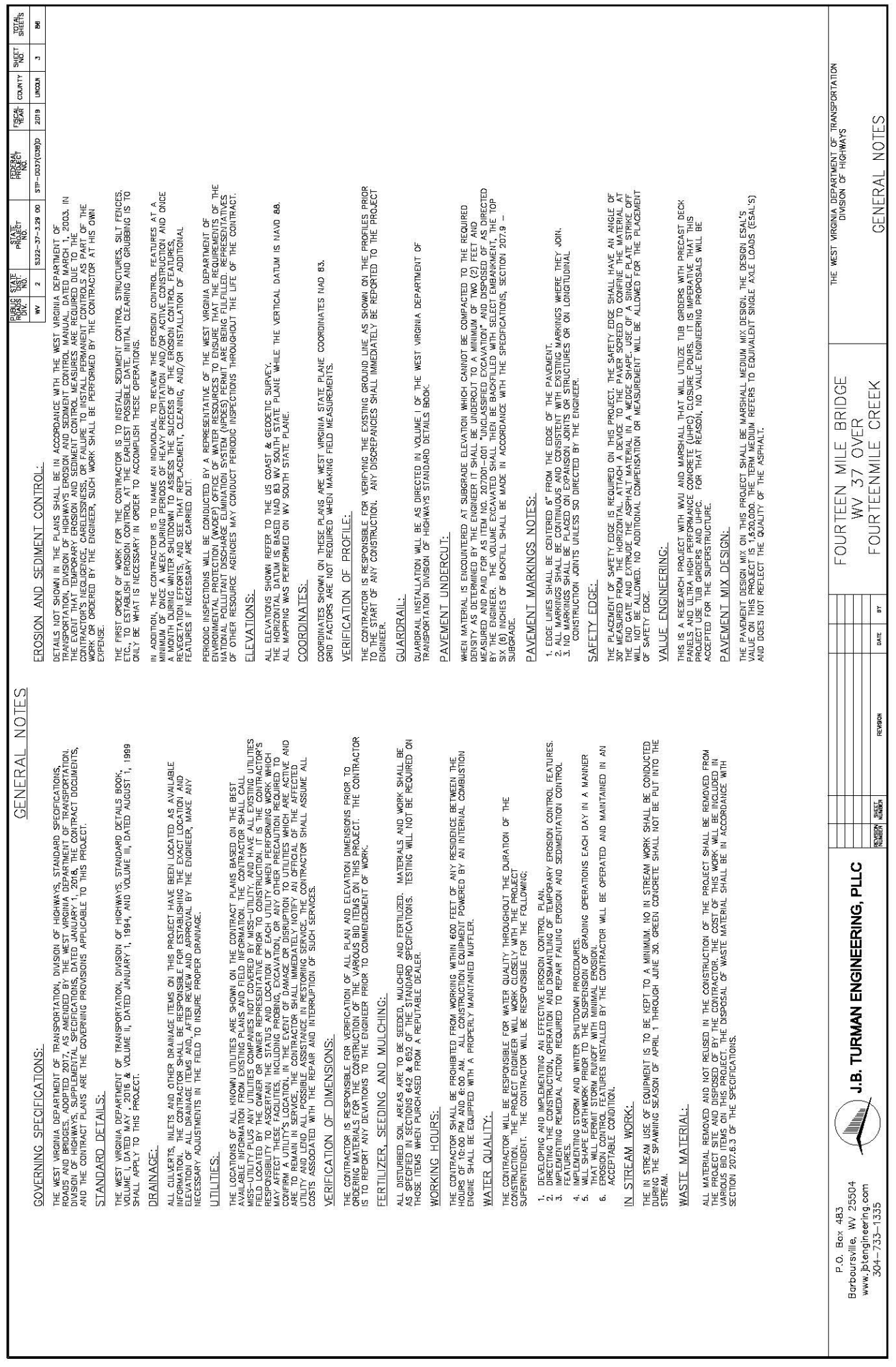




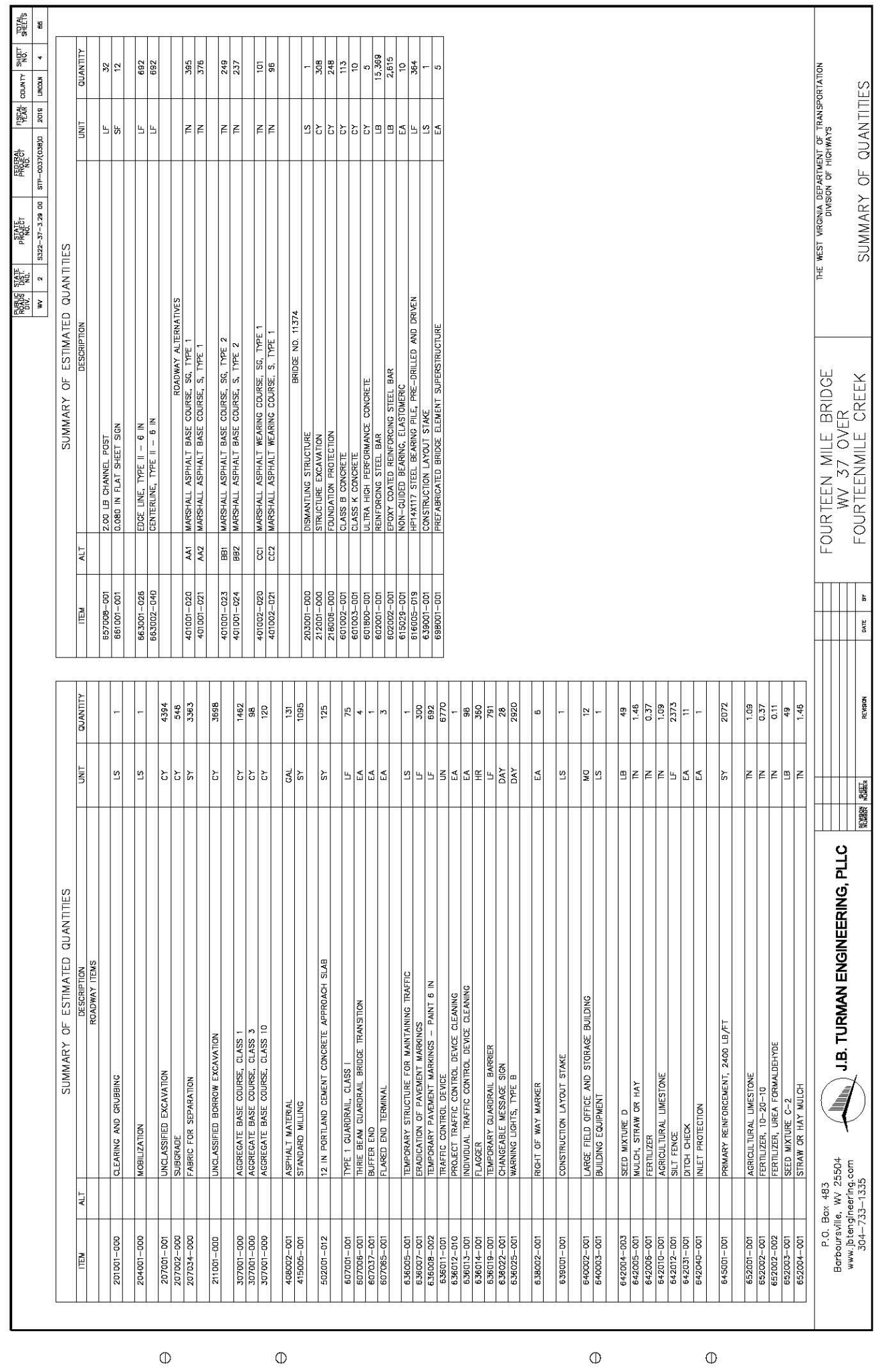




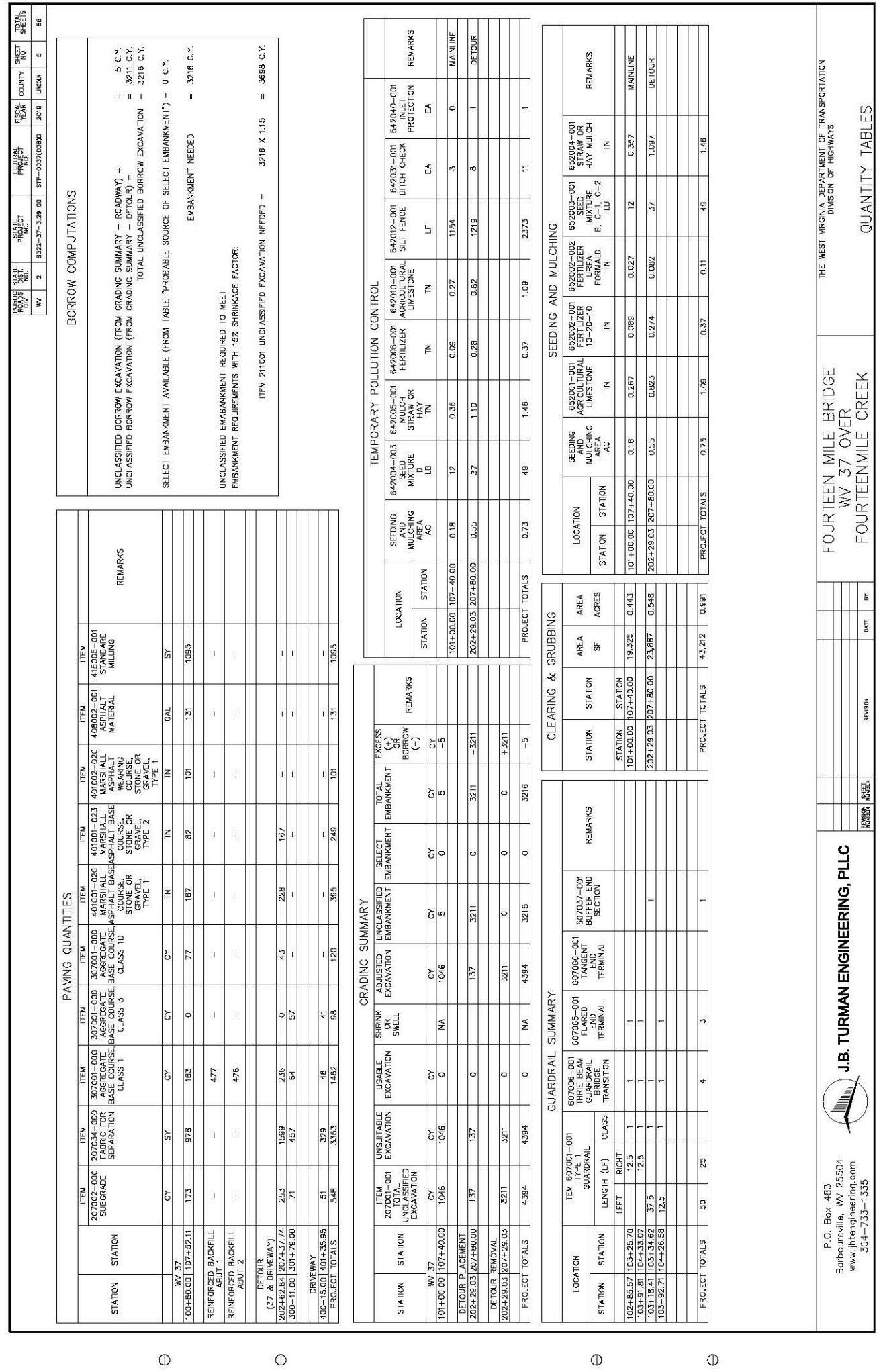




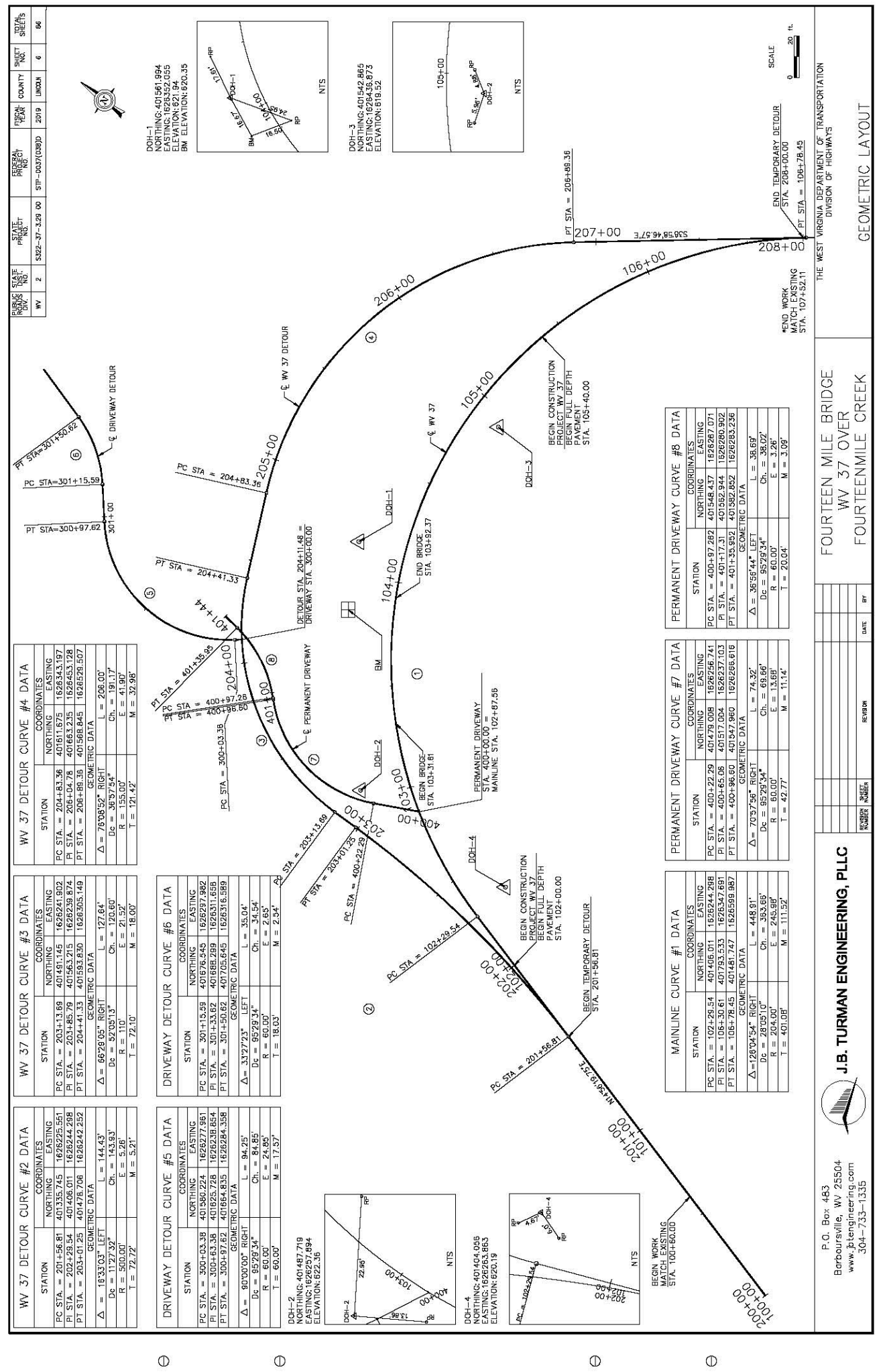




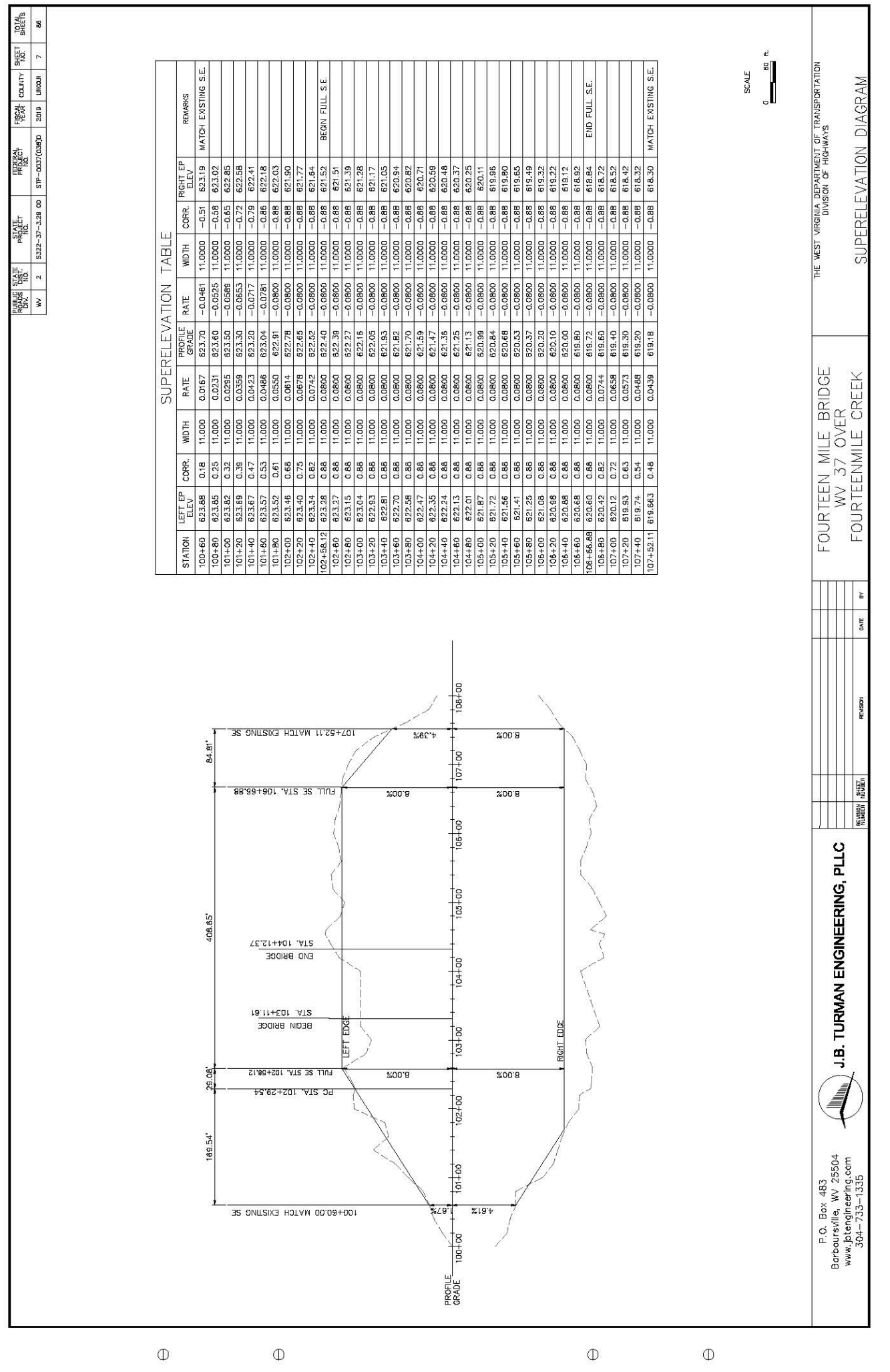




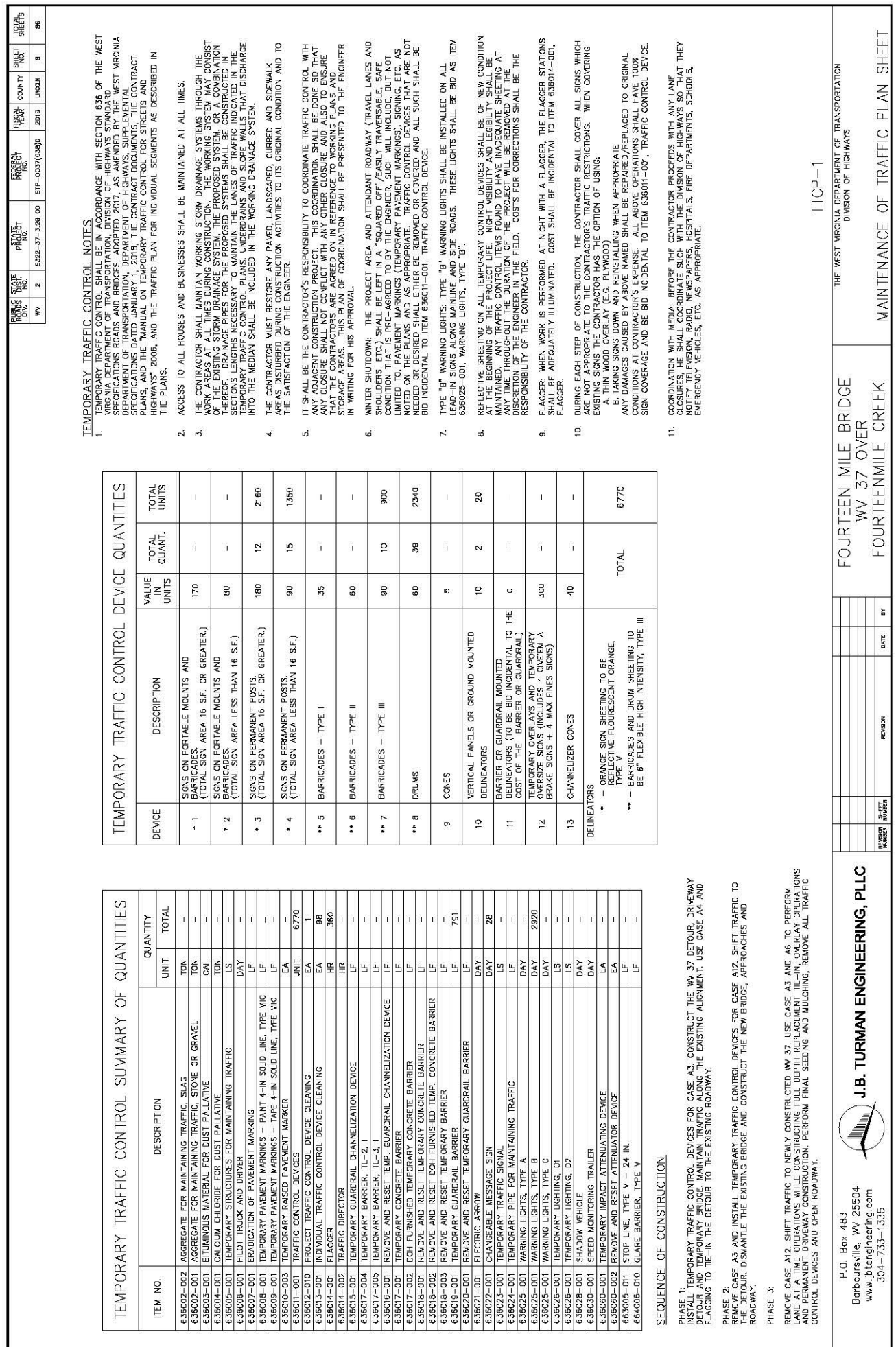

(1)

(1) 


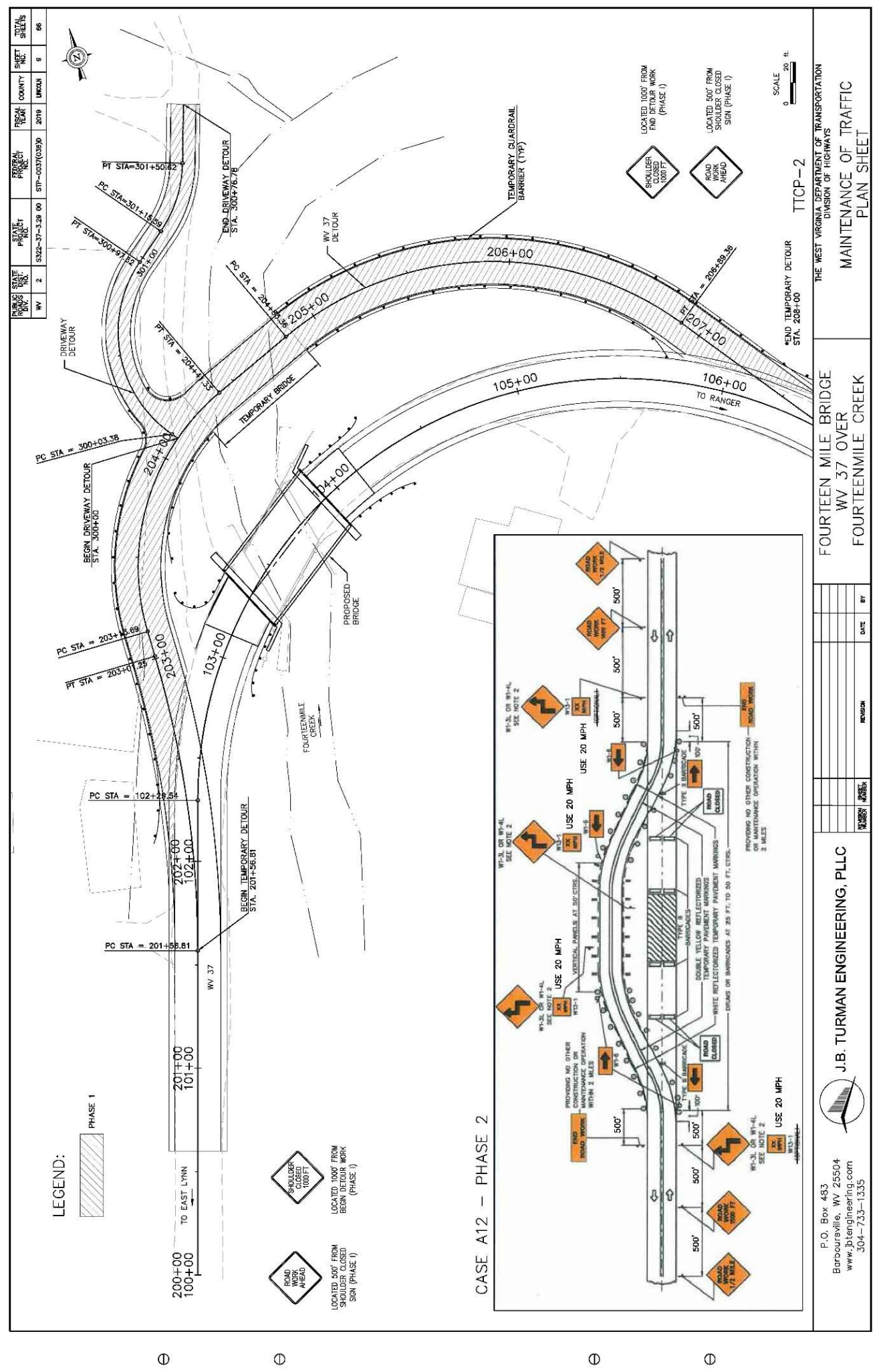




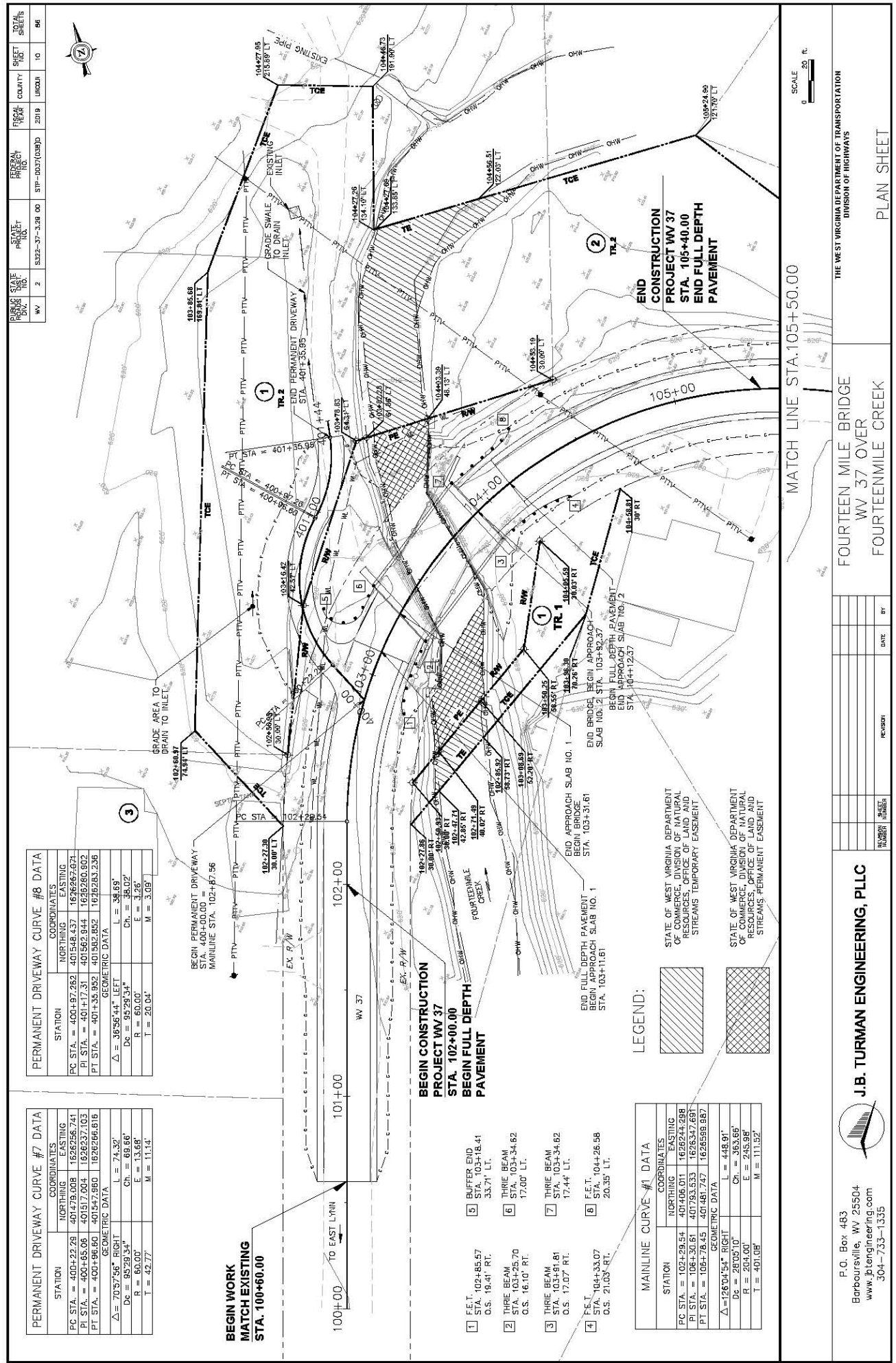

(1)

(1)

(1) 


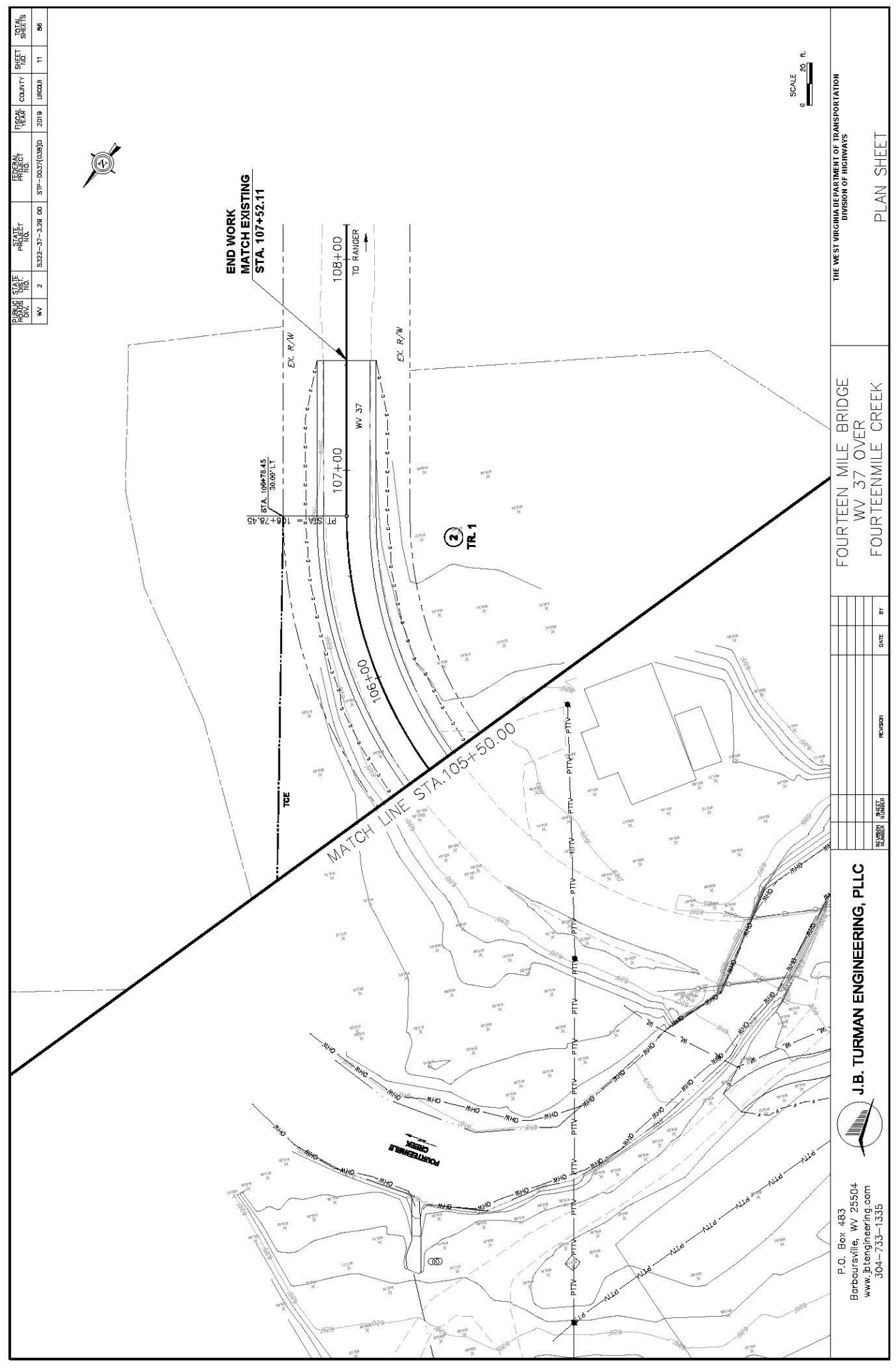

(1)

(1) 


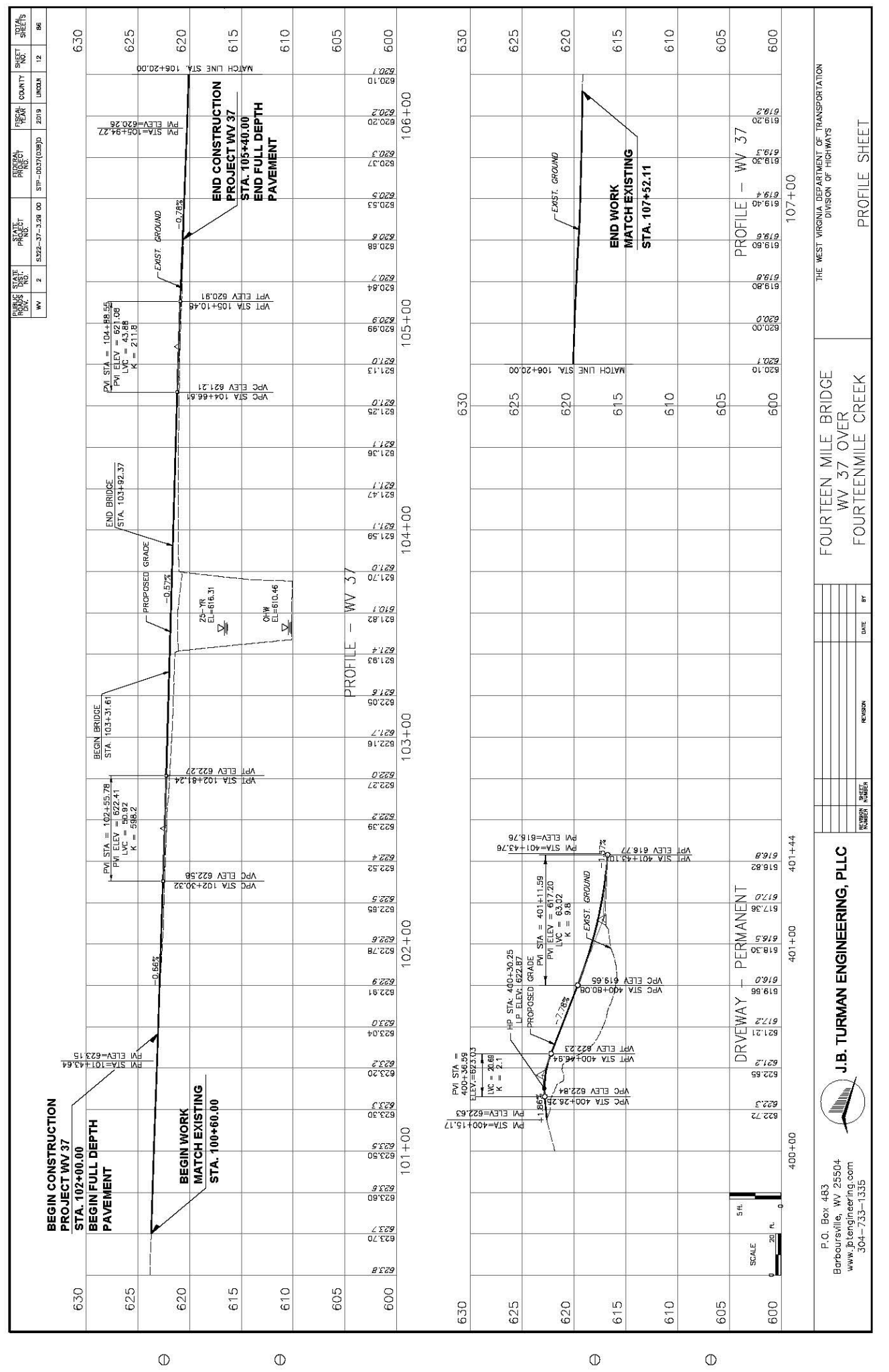




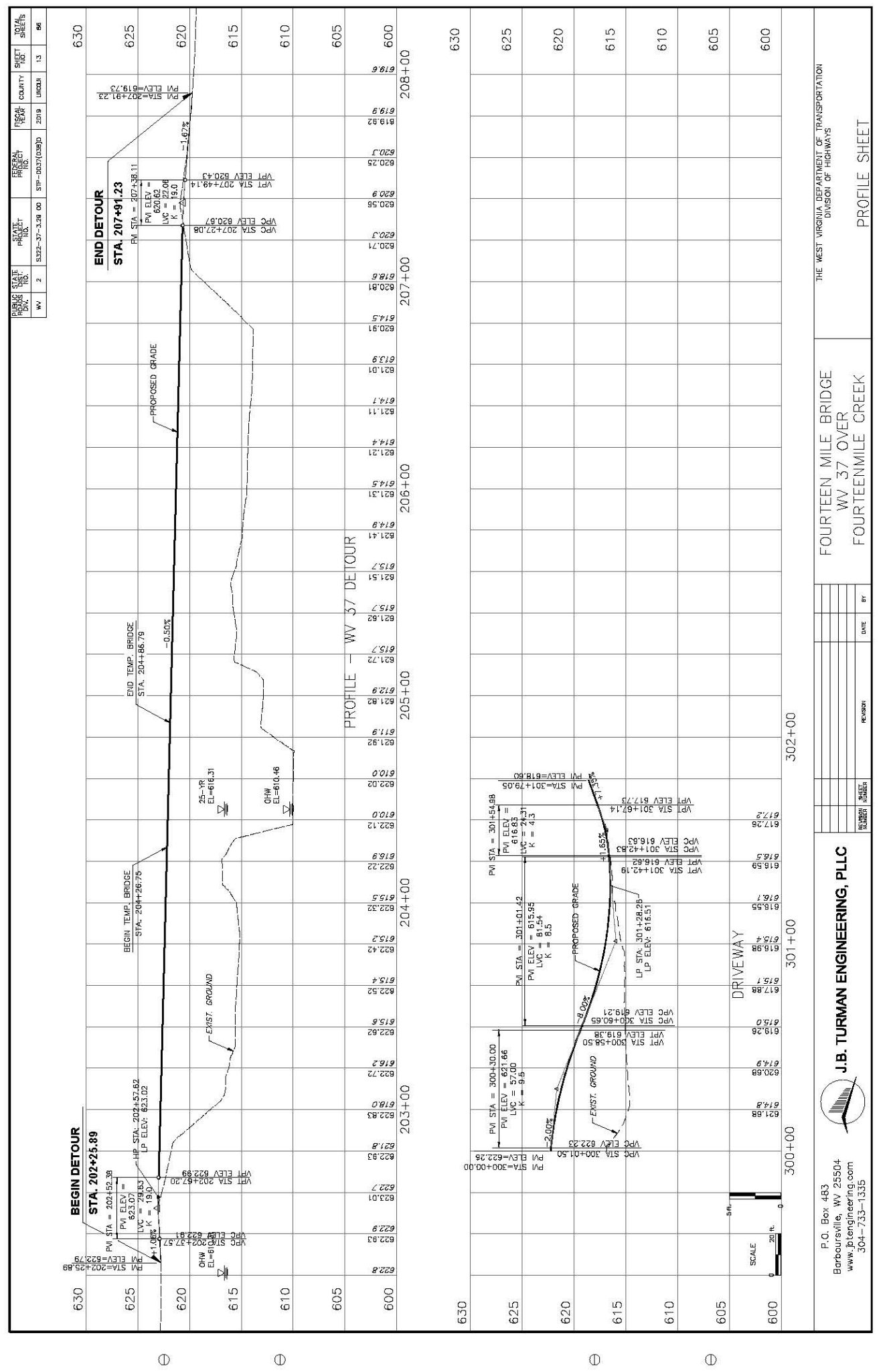




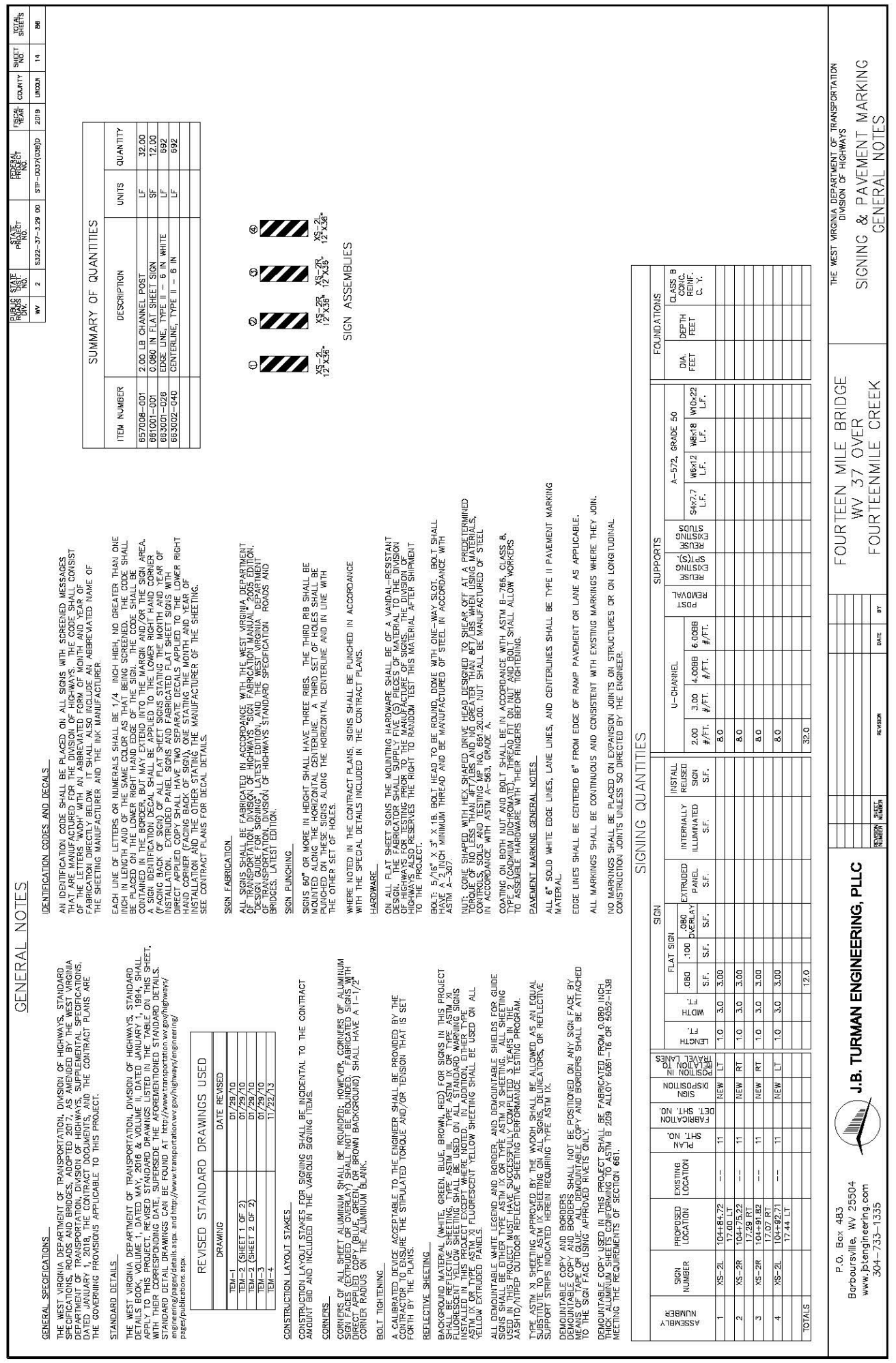




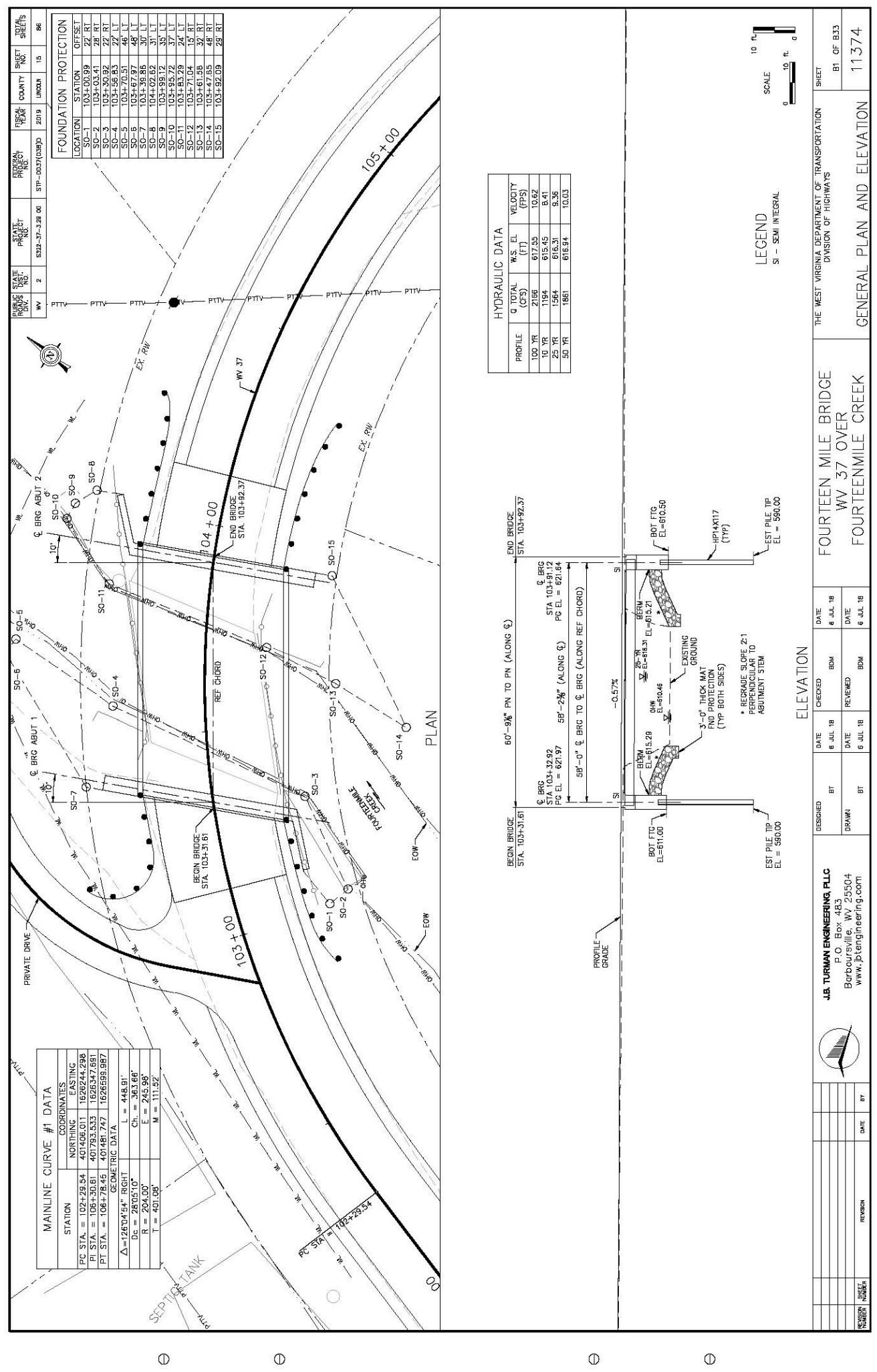




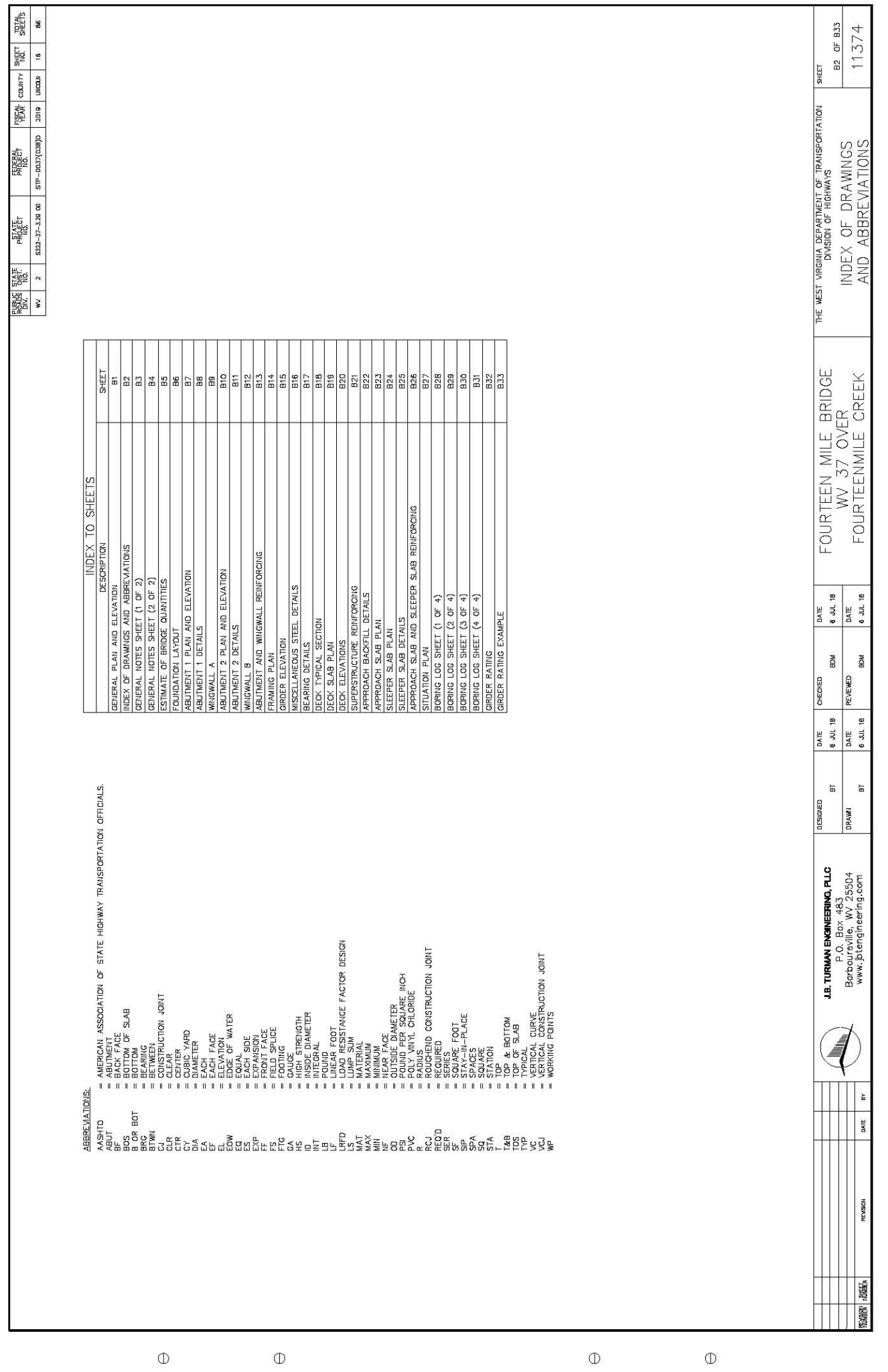




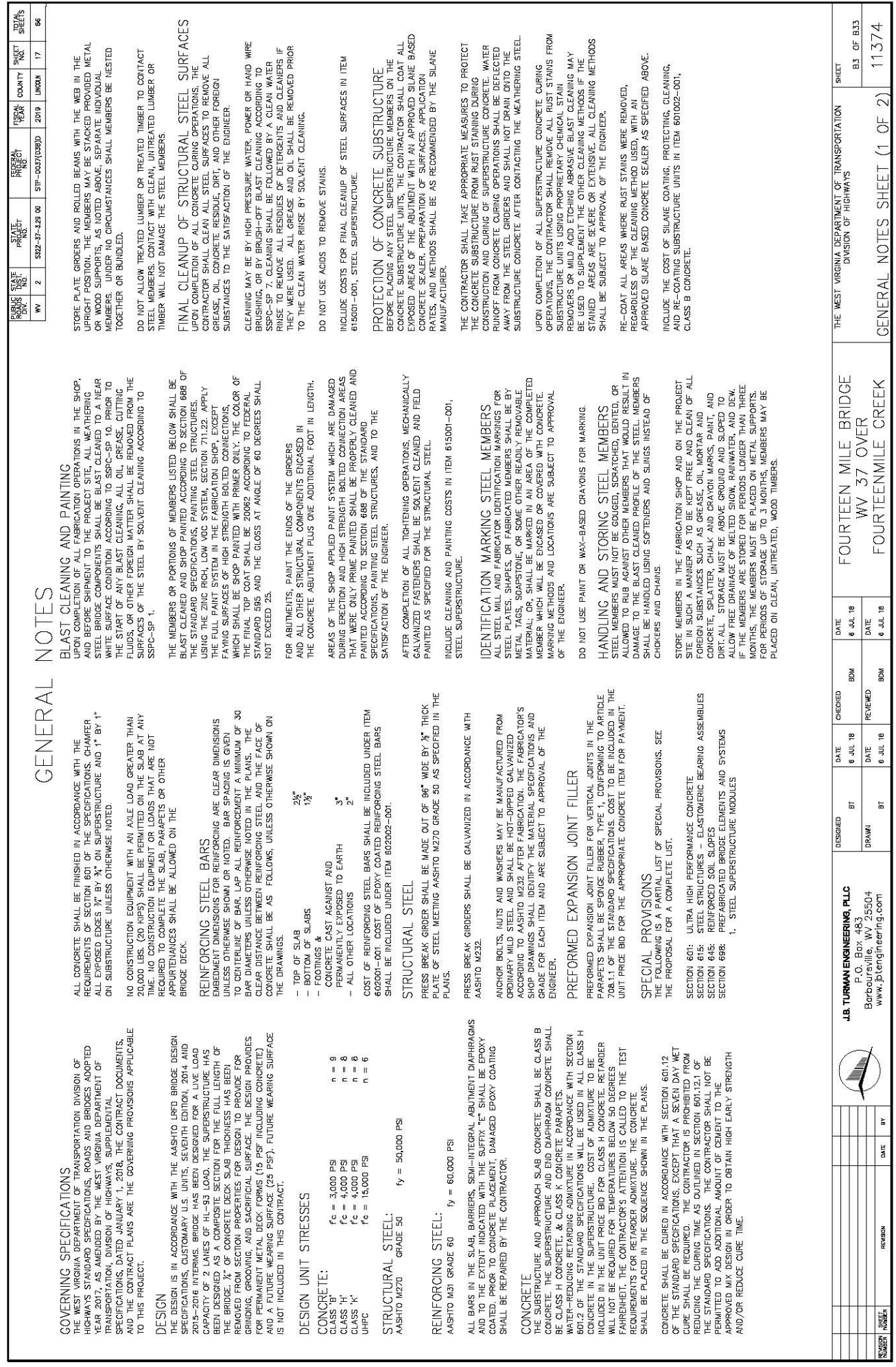

(1)

(1) 

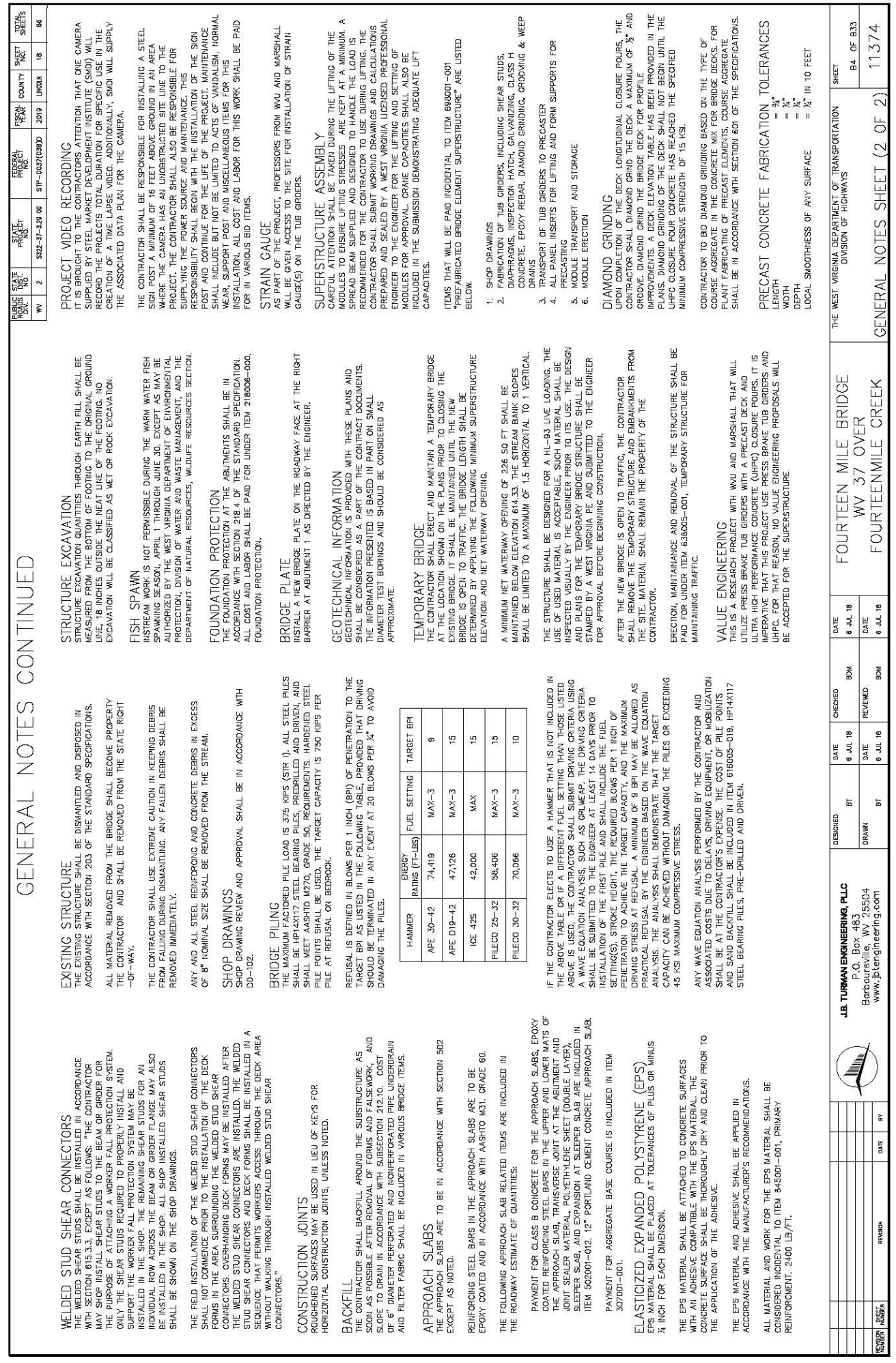

(1)

(1) 


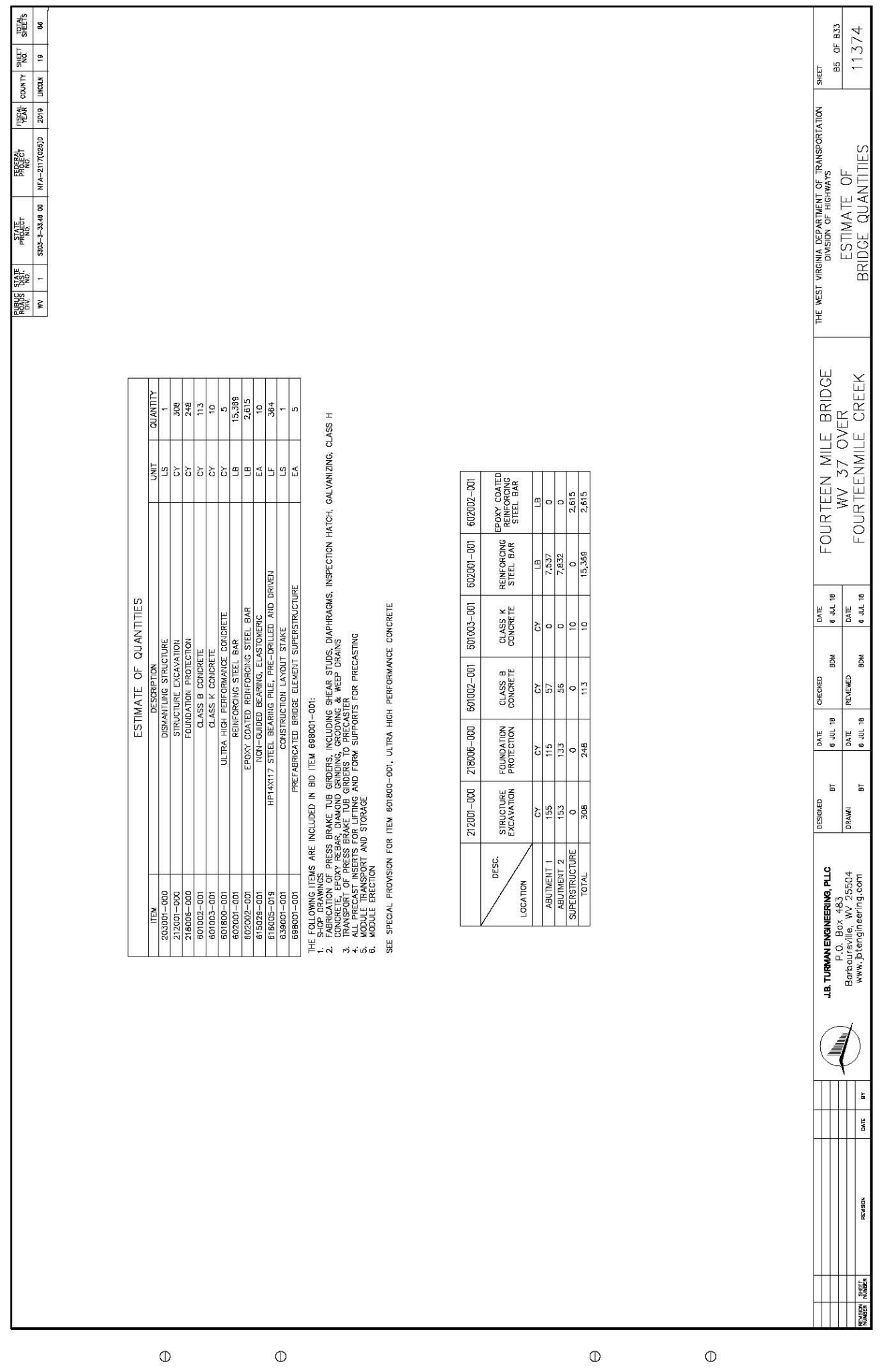




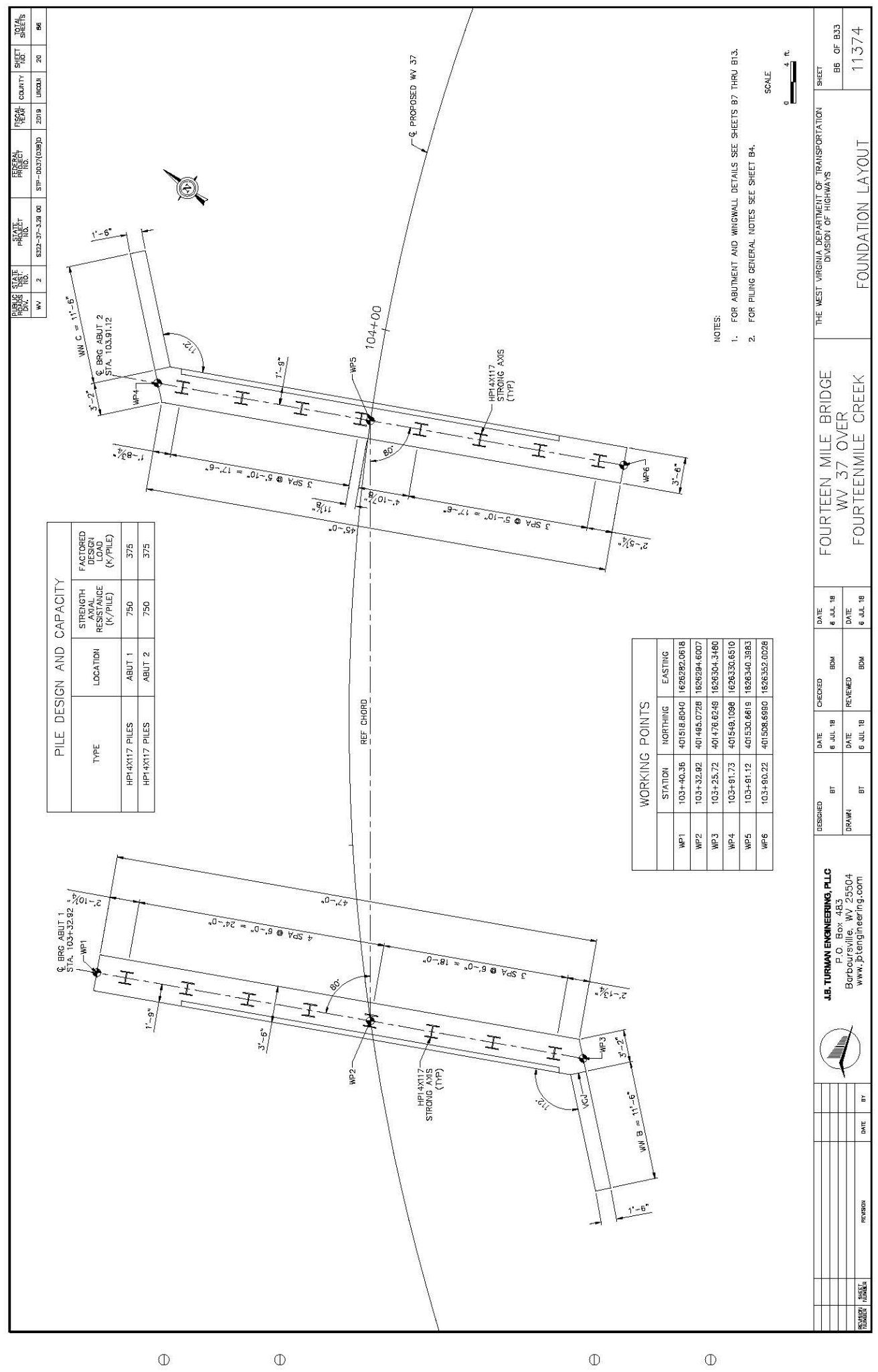




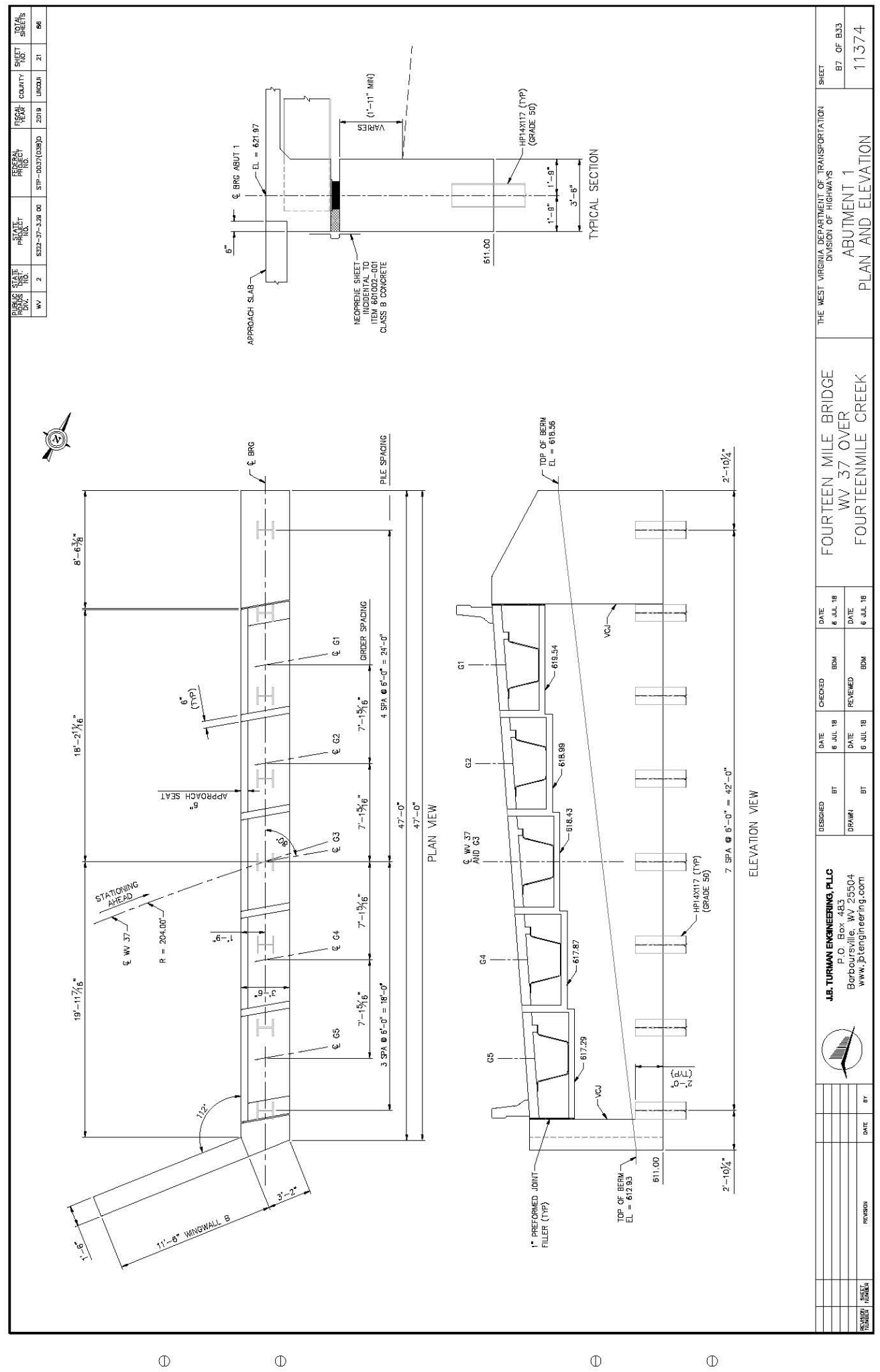




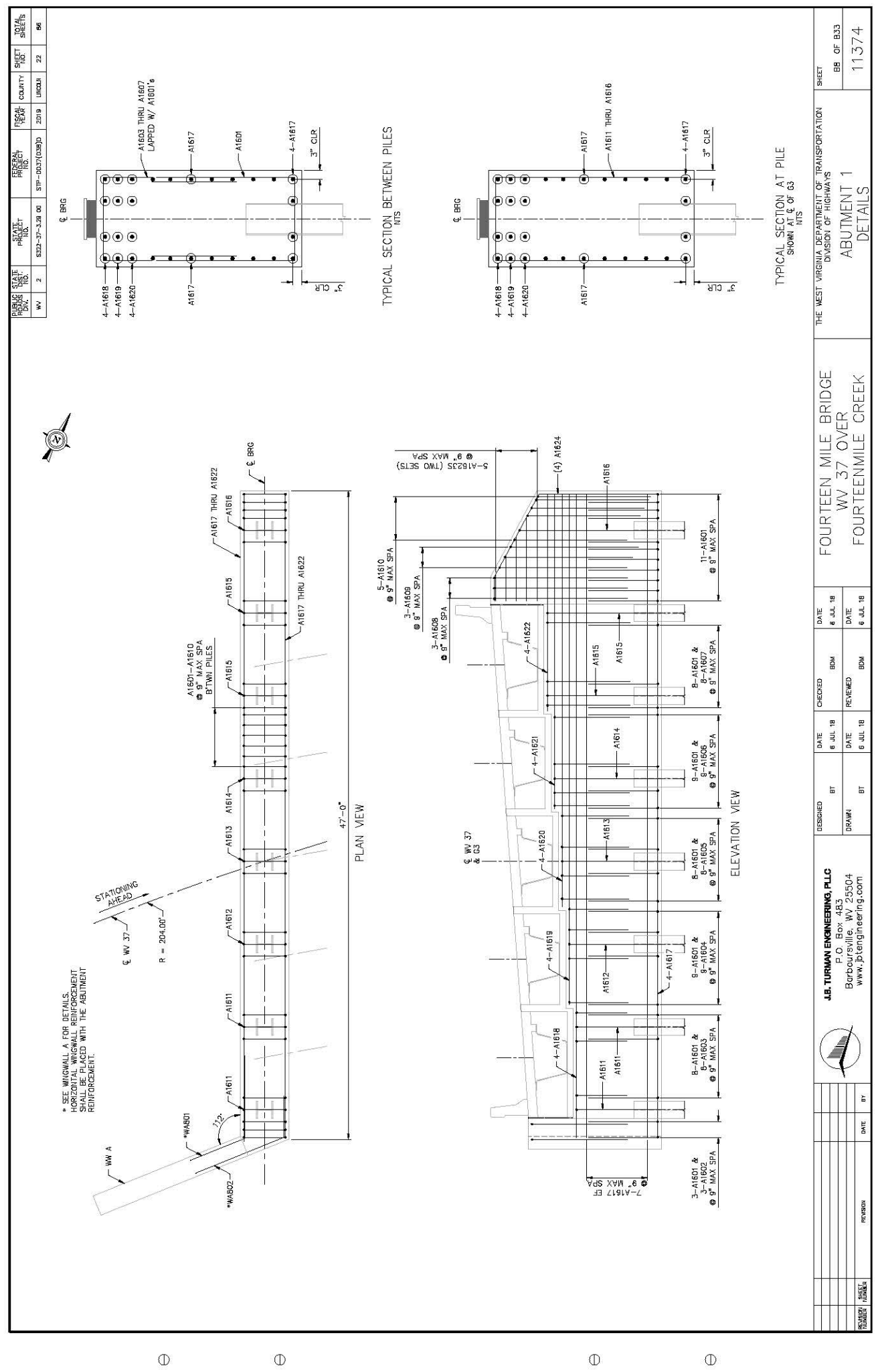




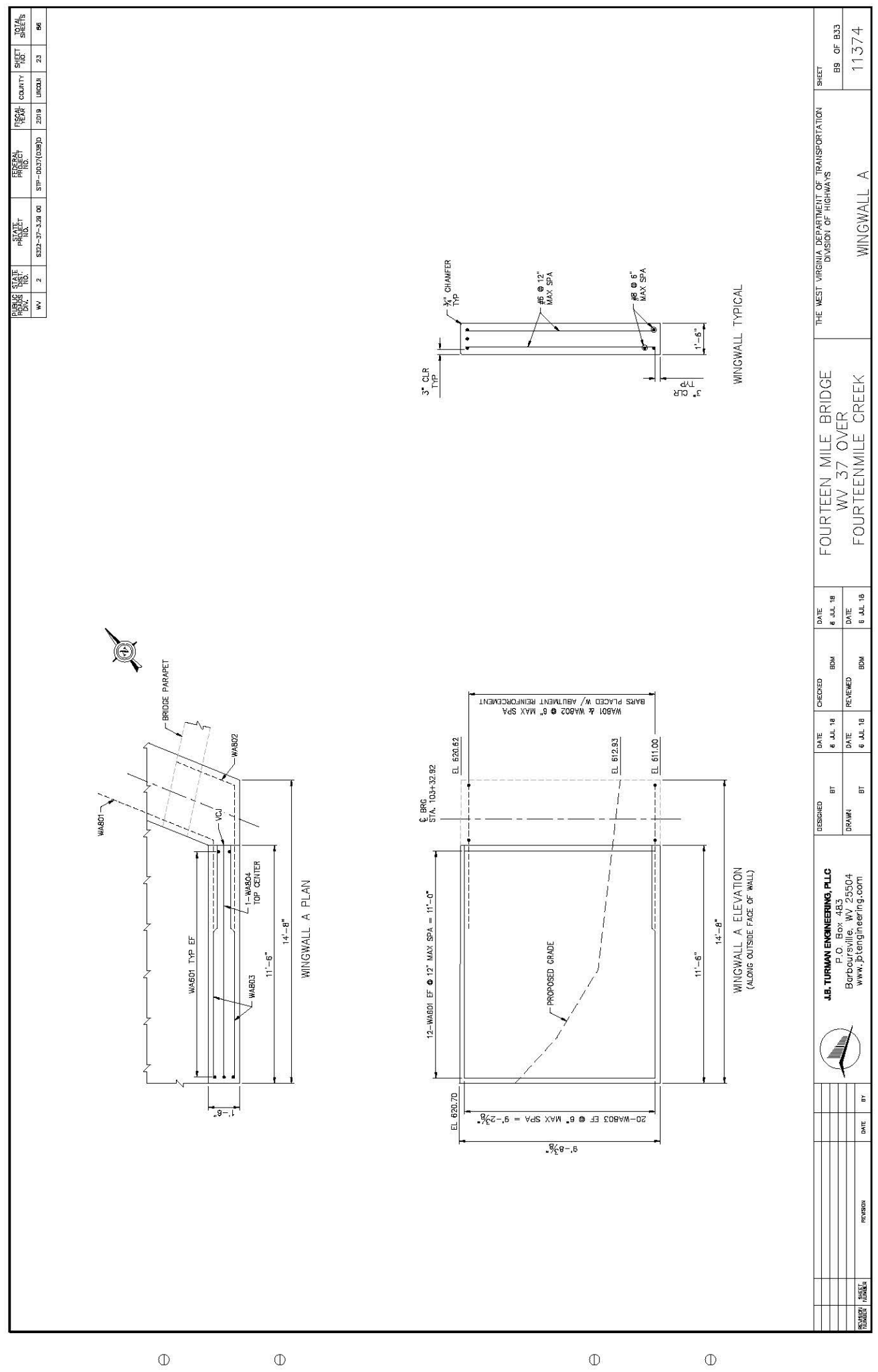




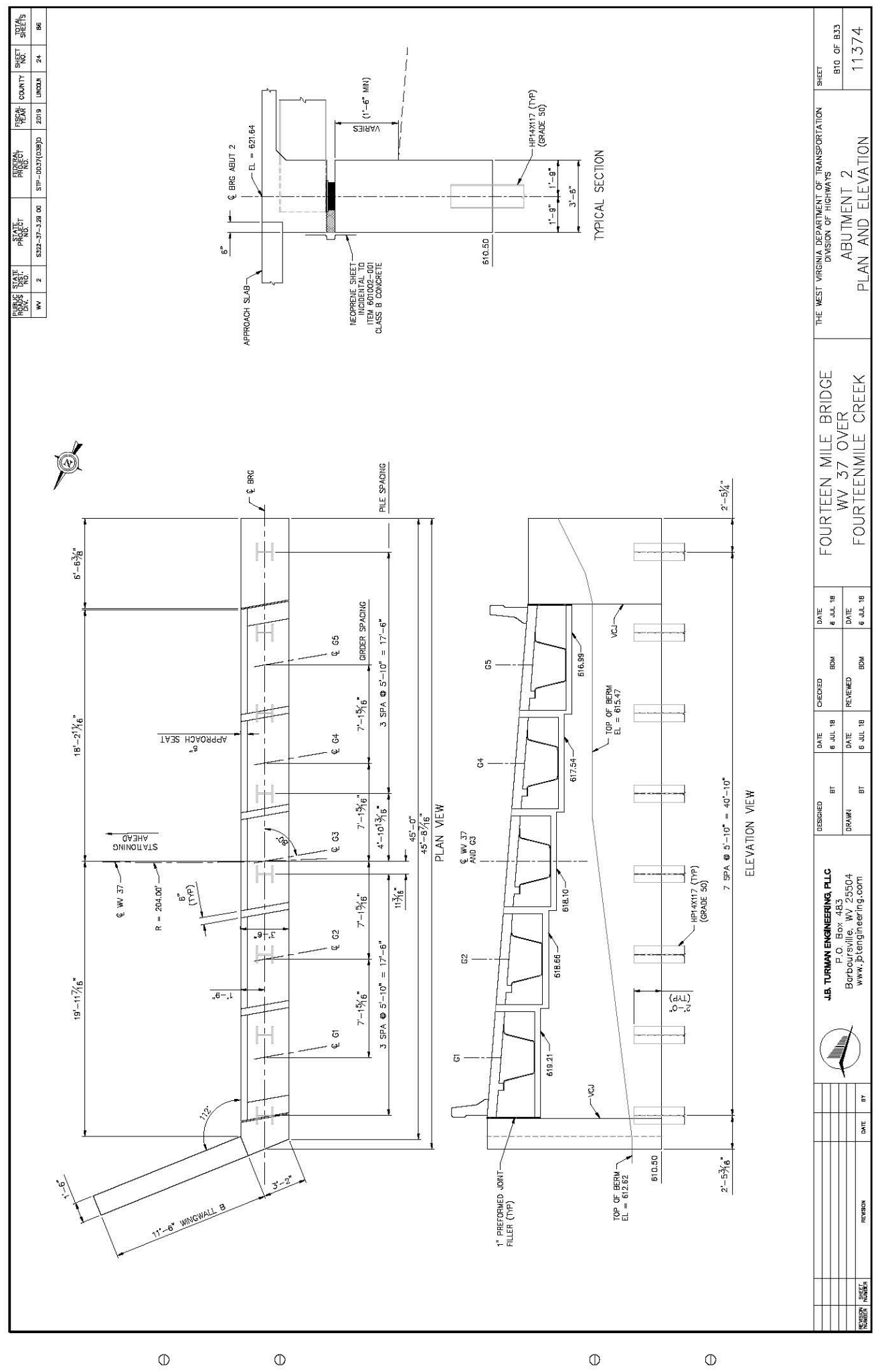




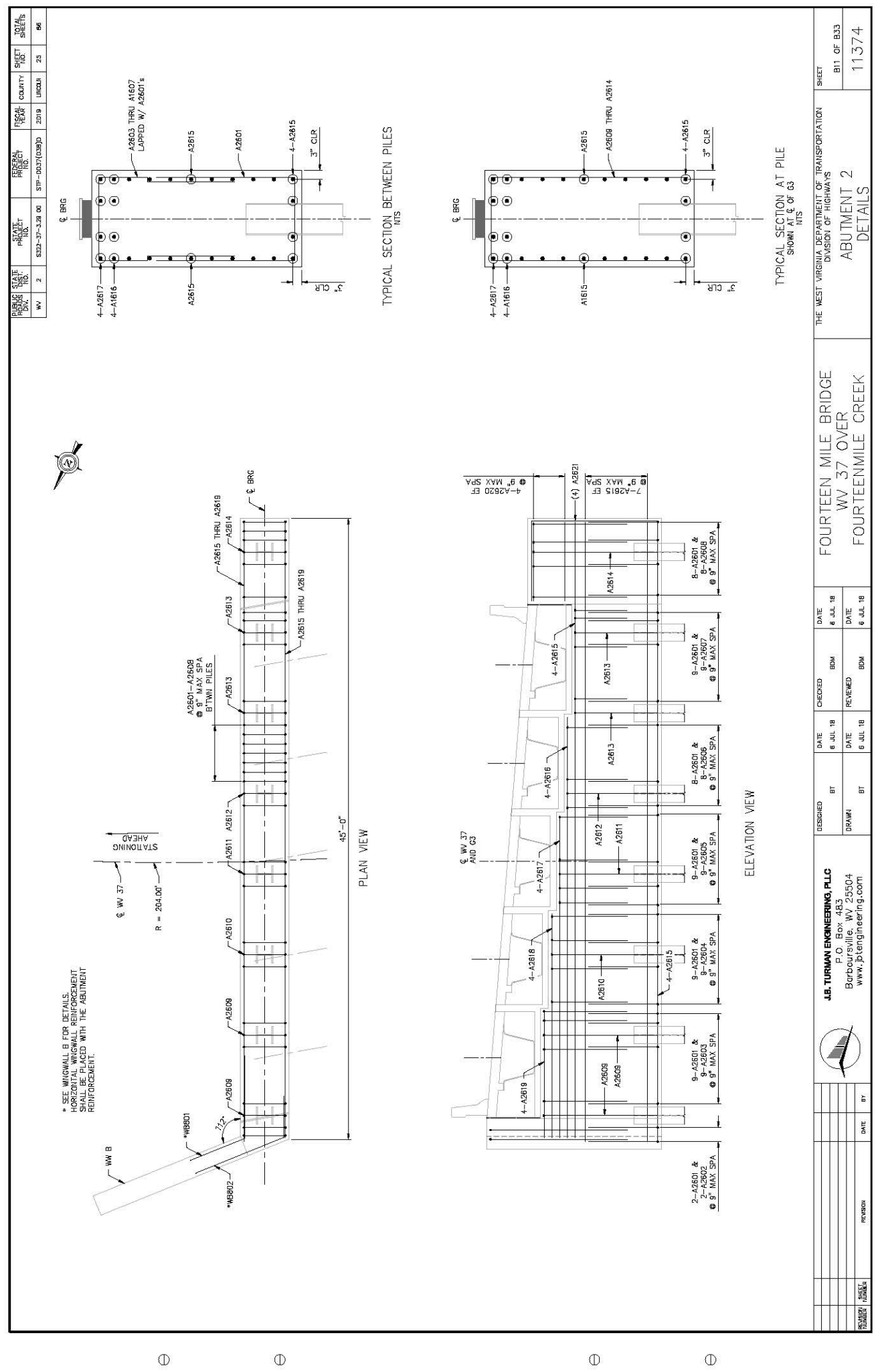




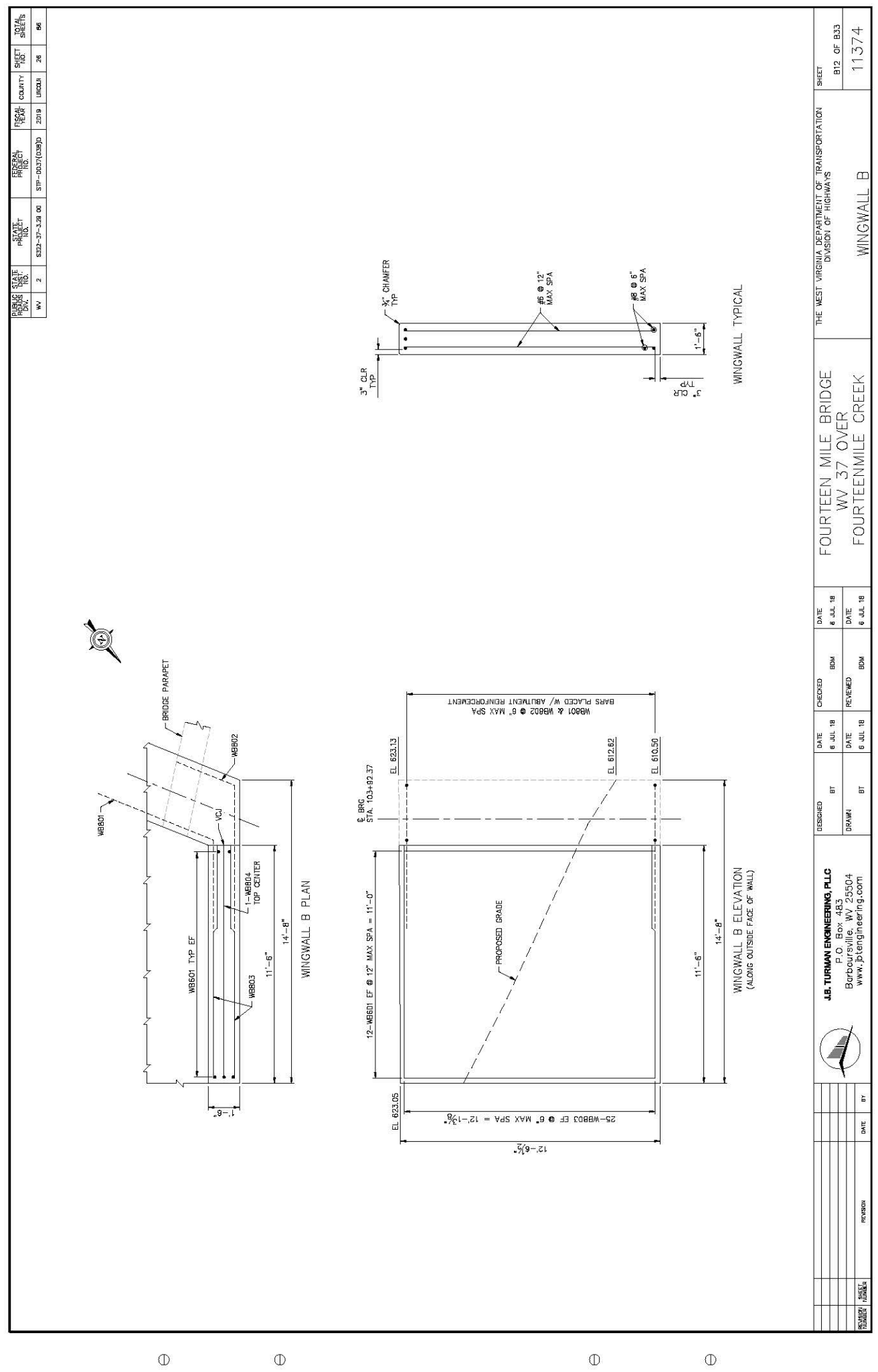




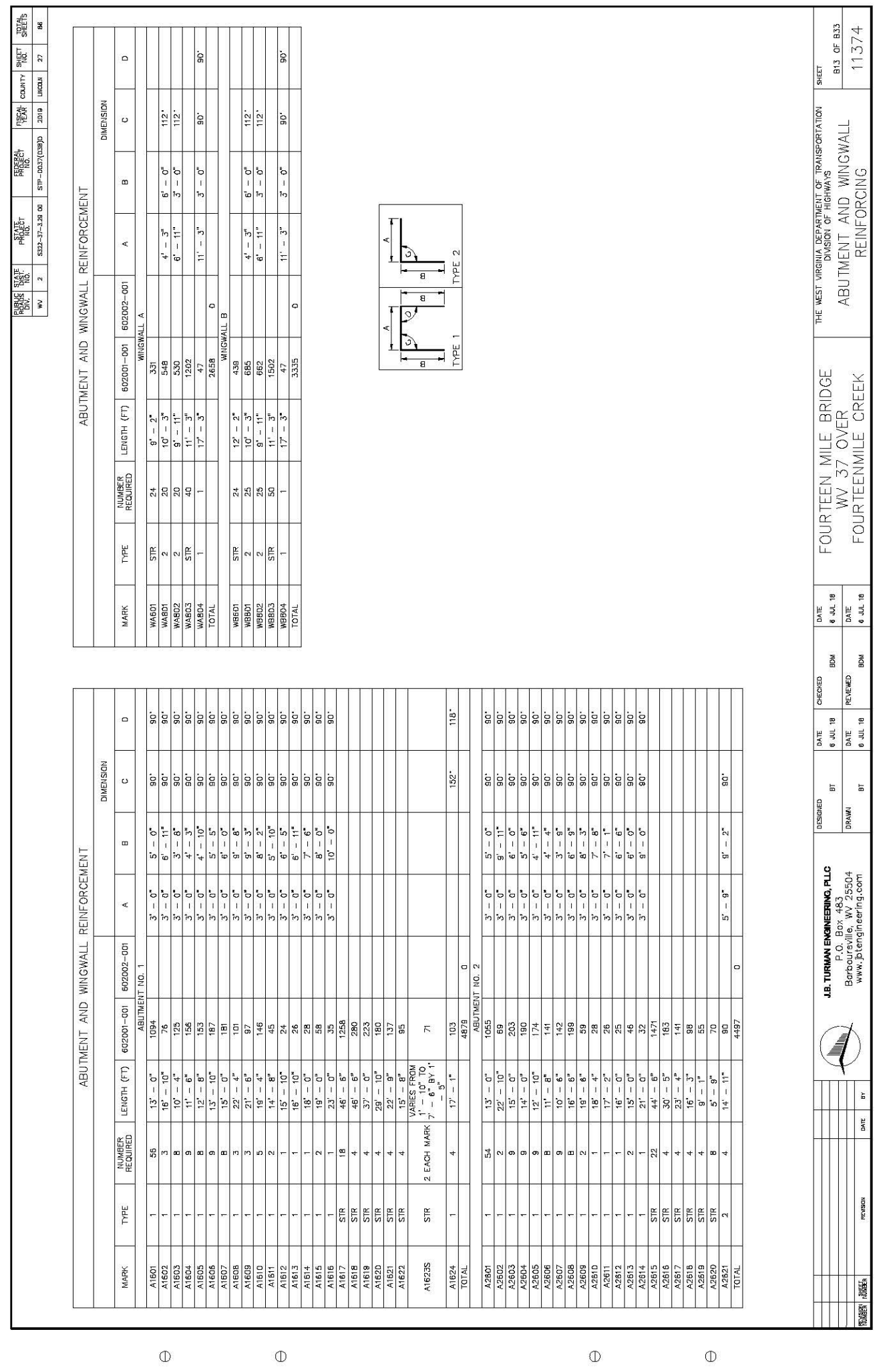




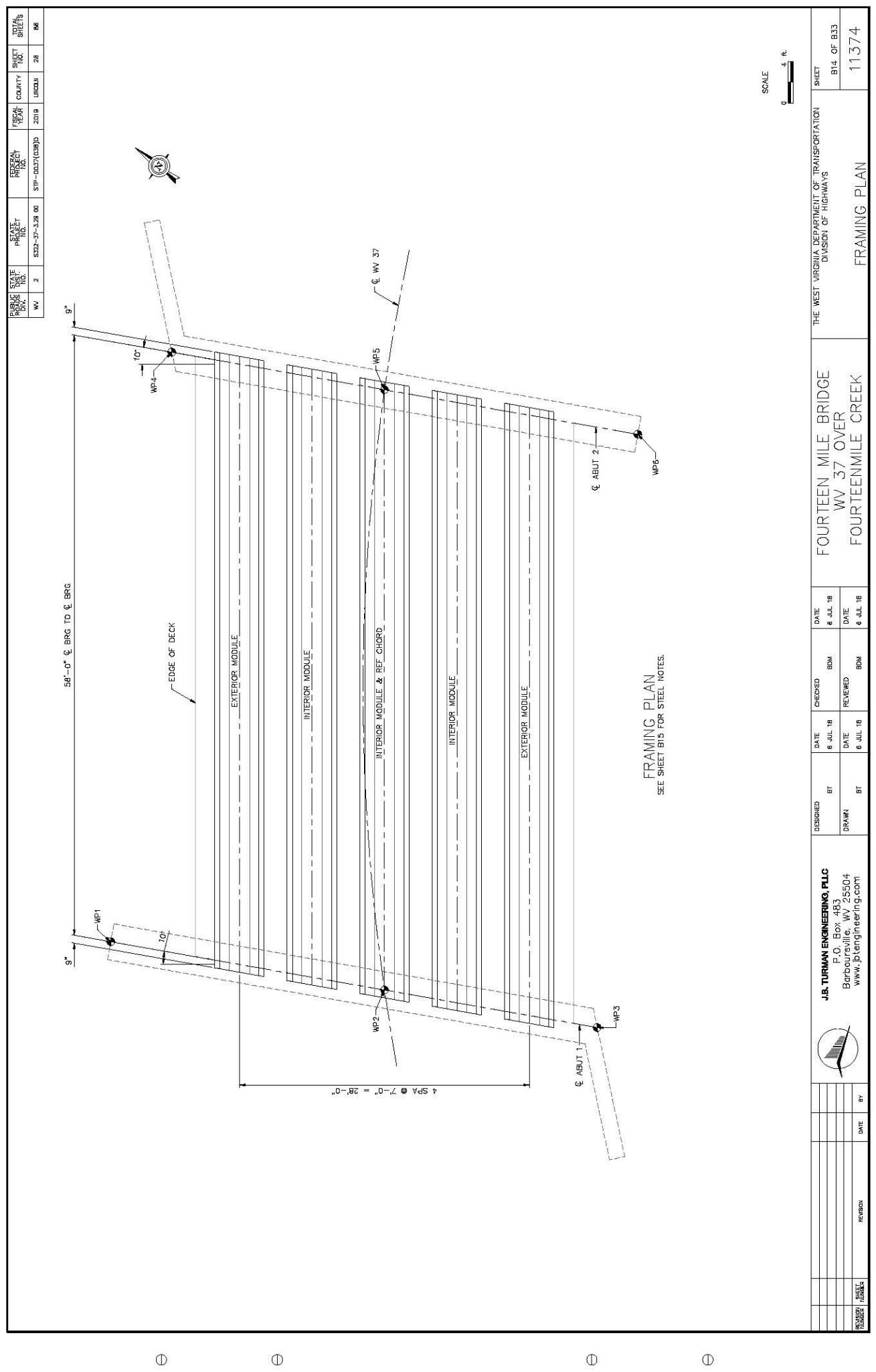




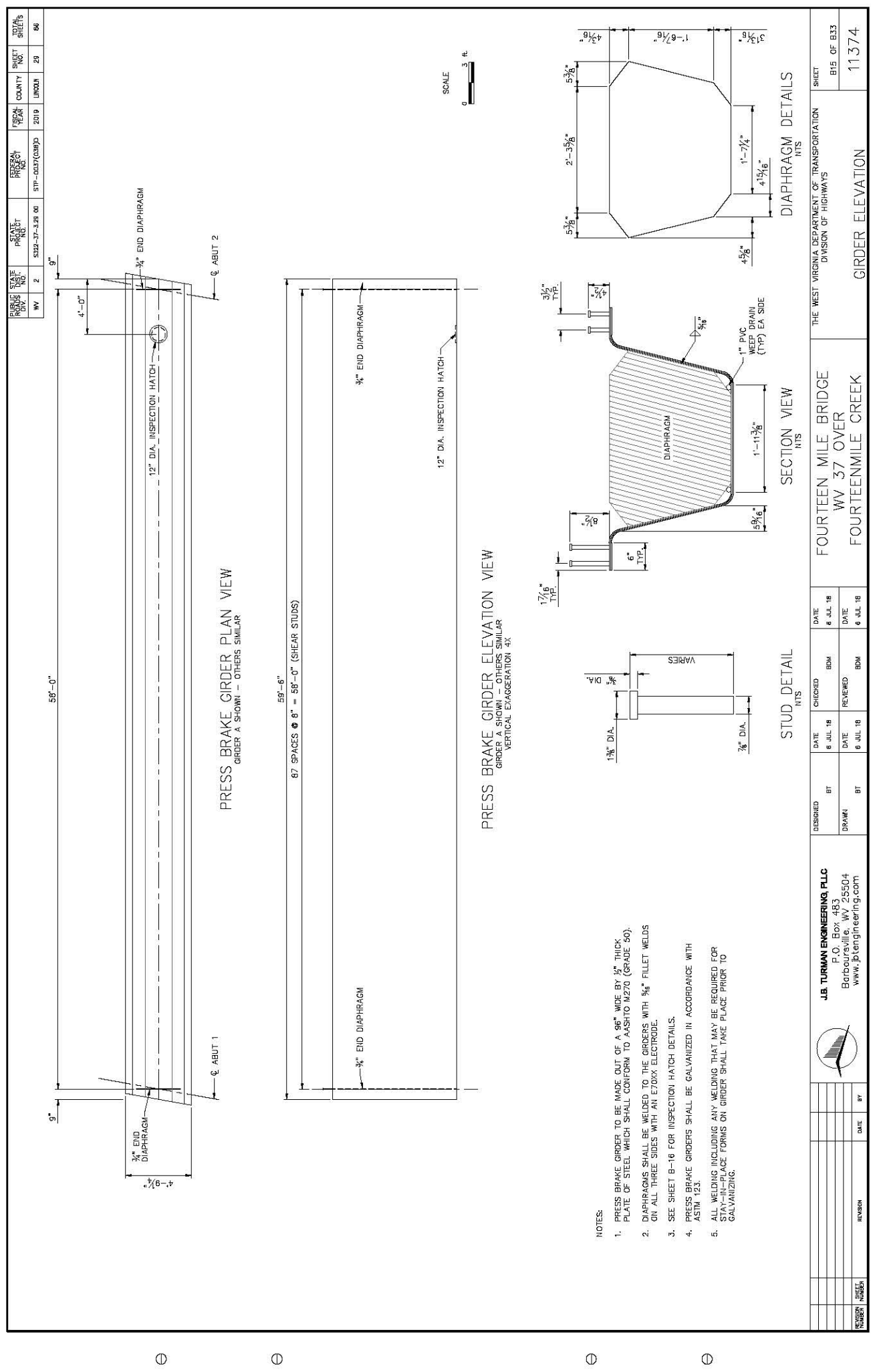




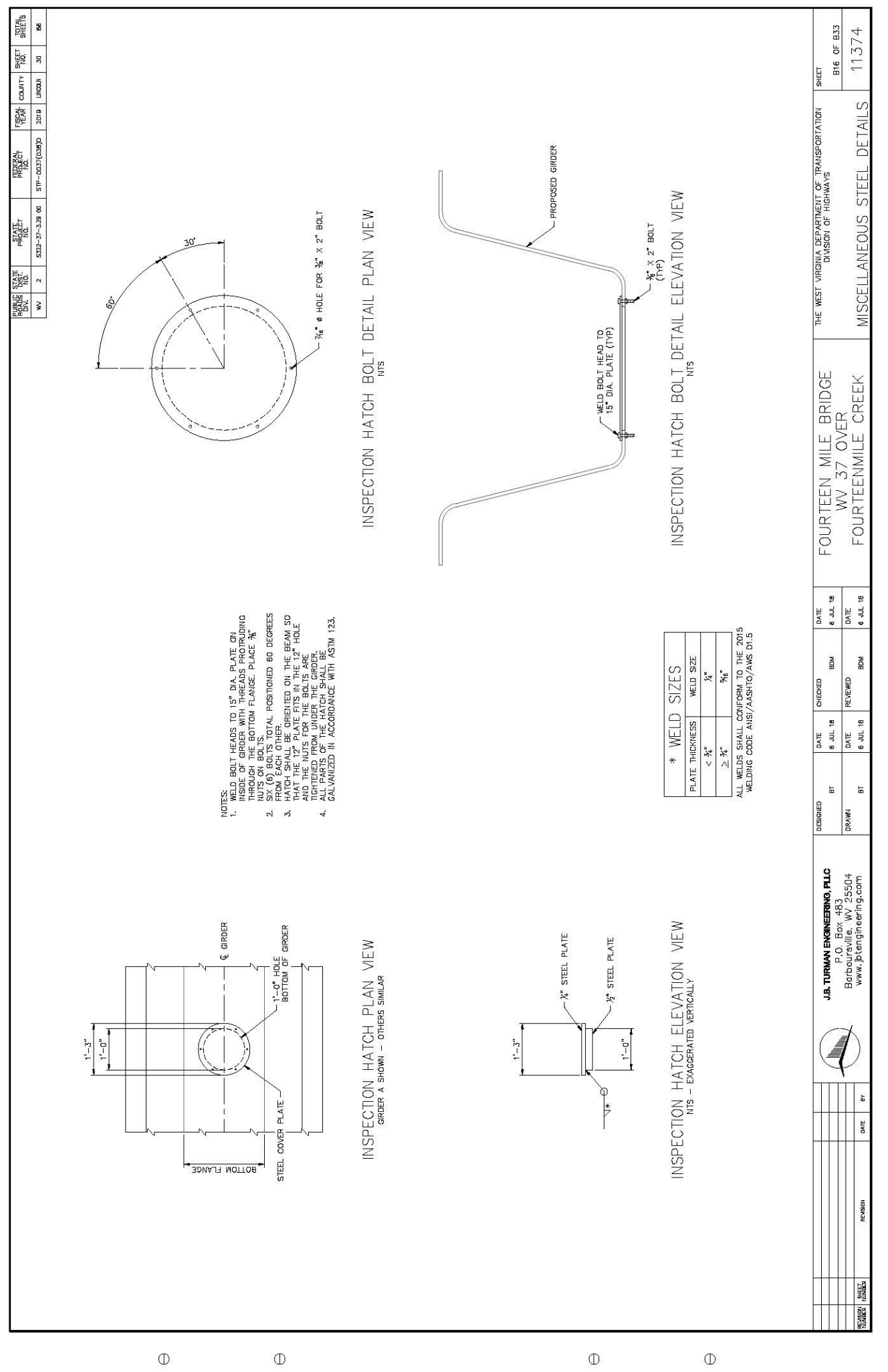




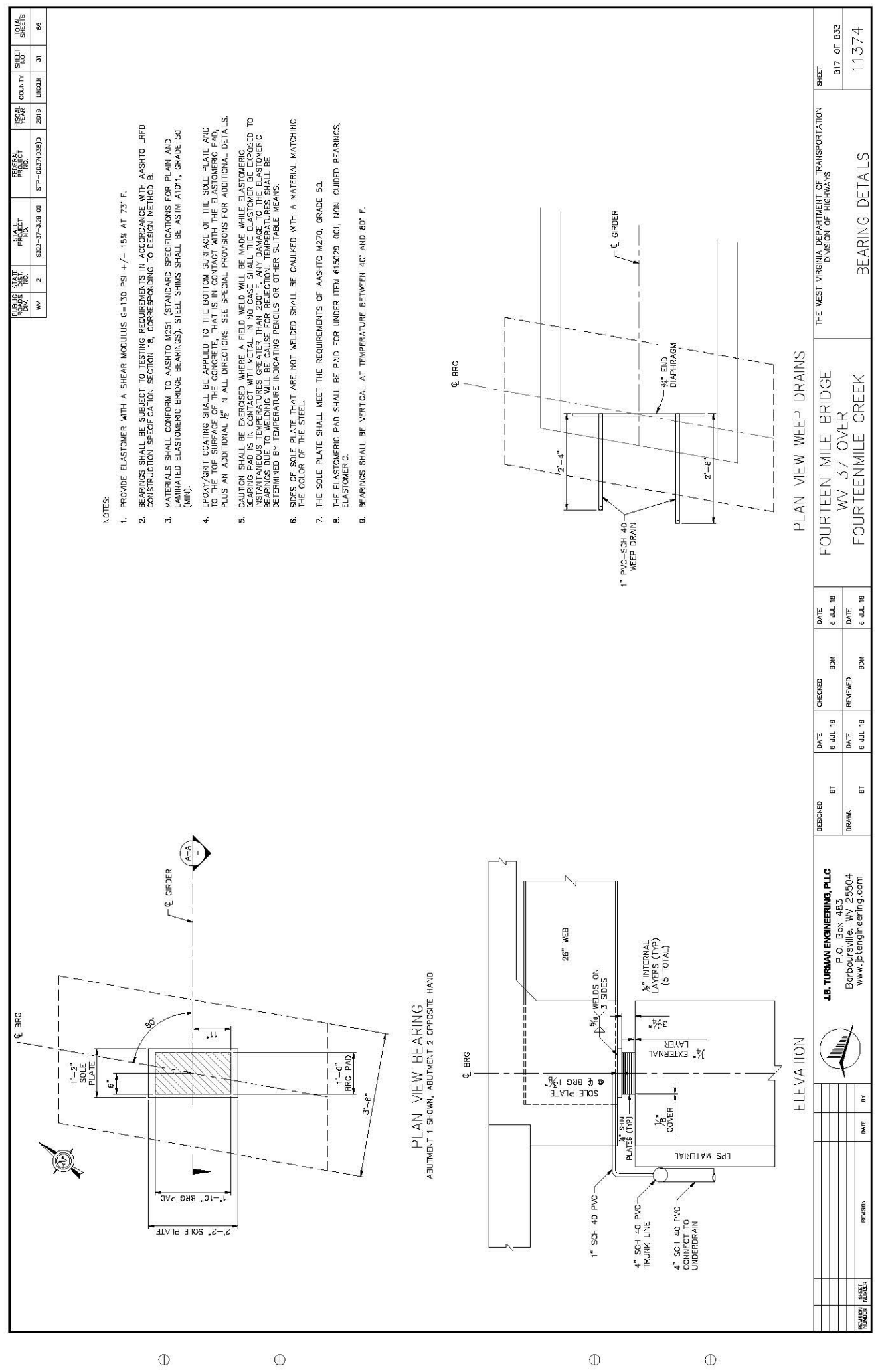




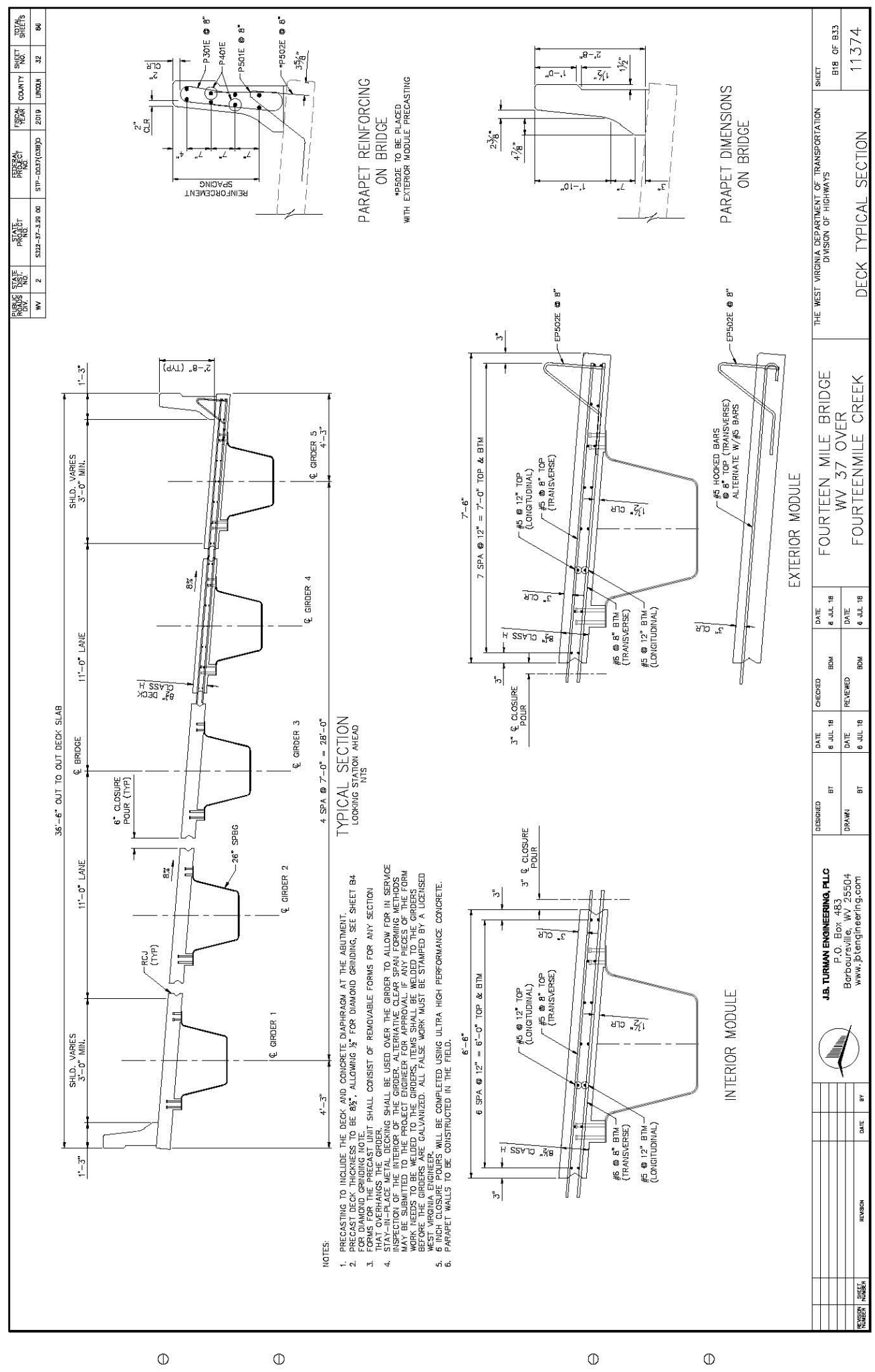




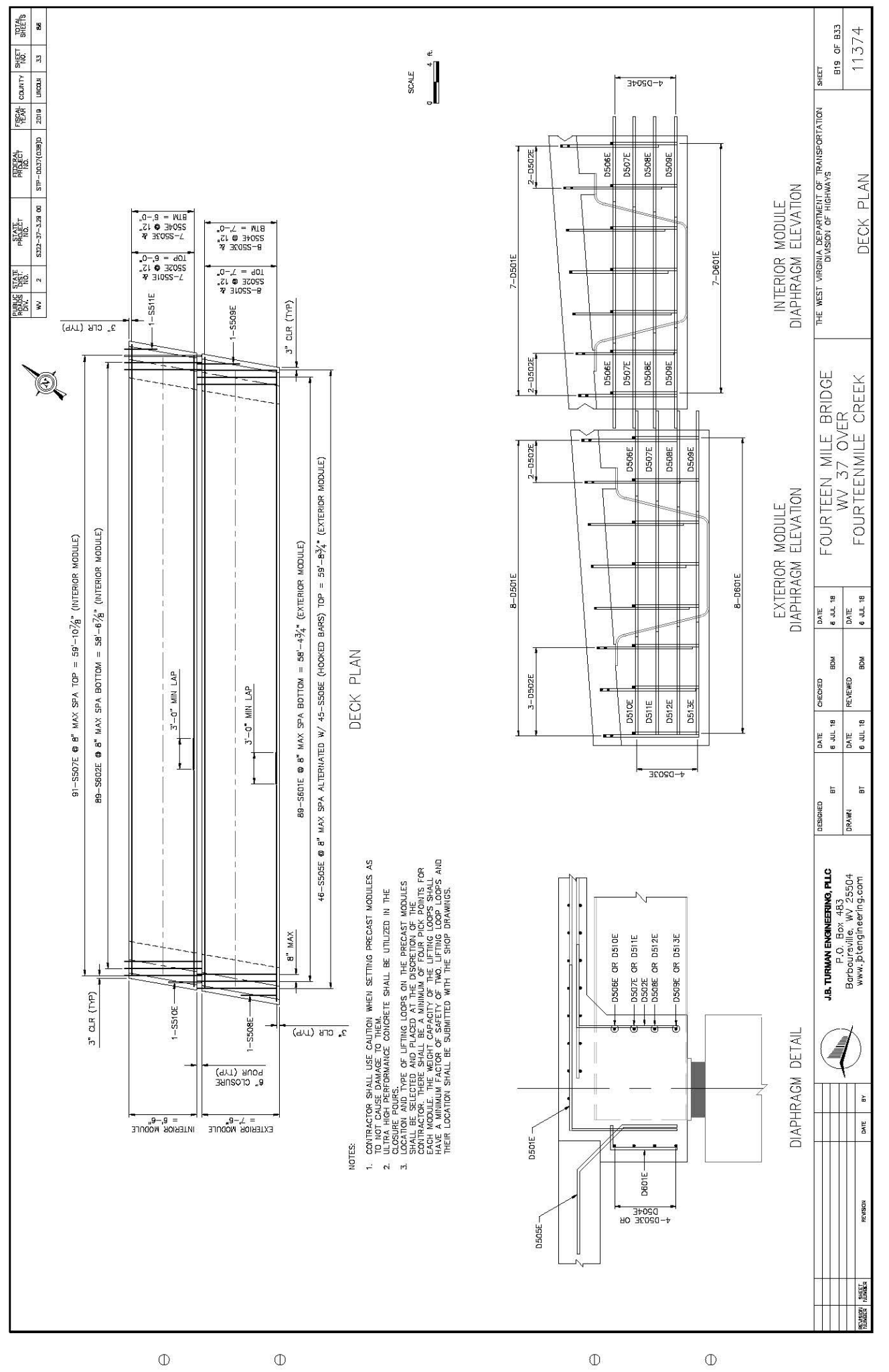




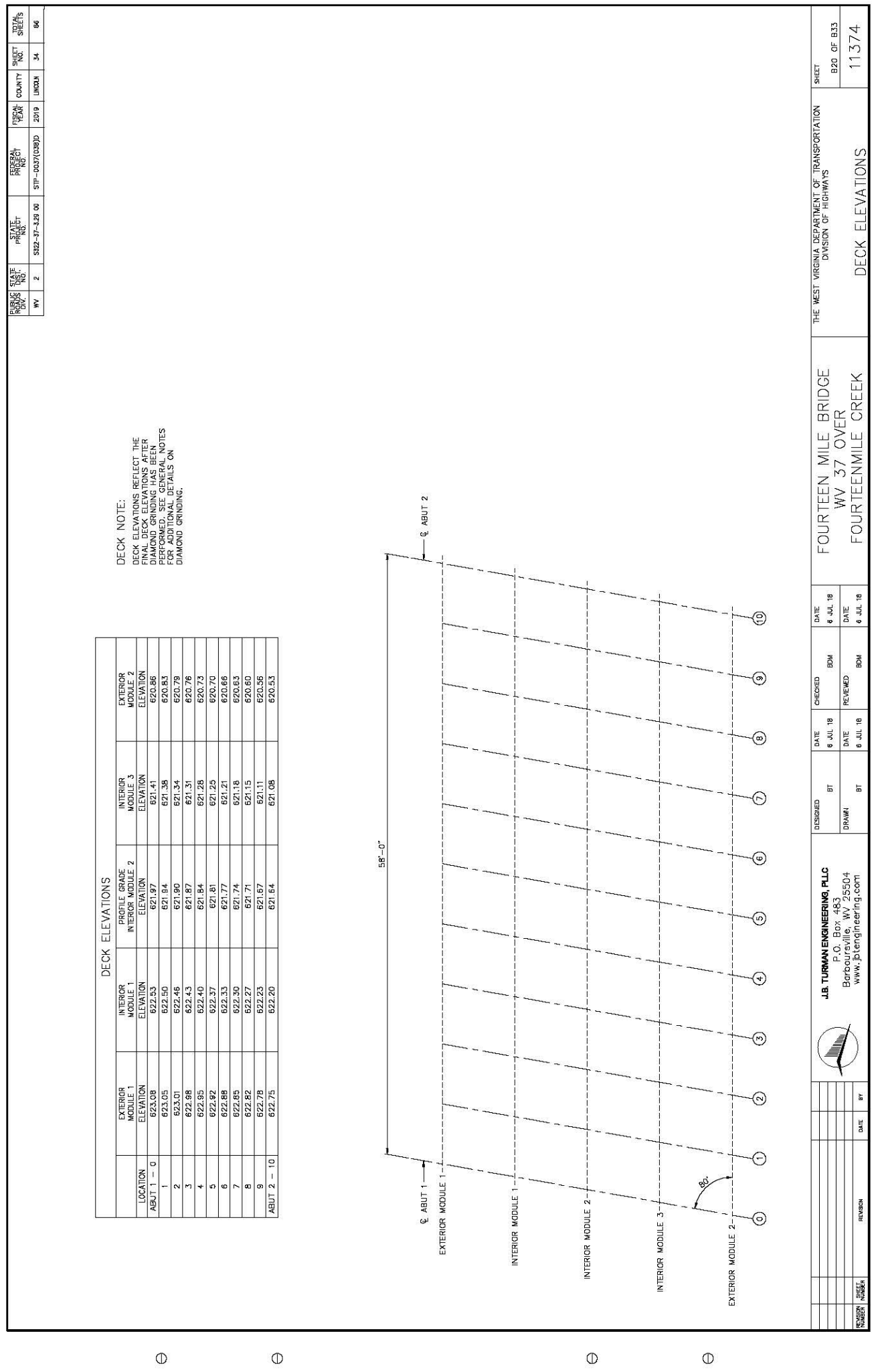




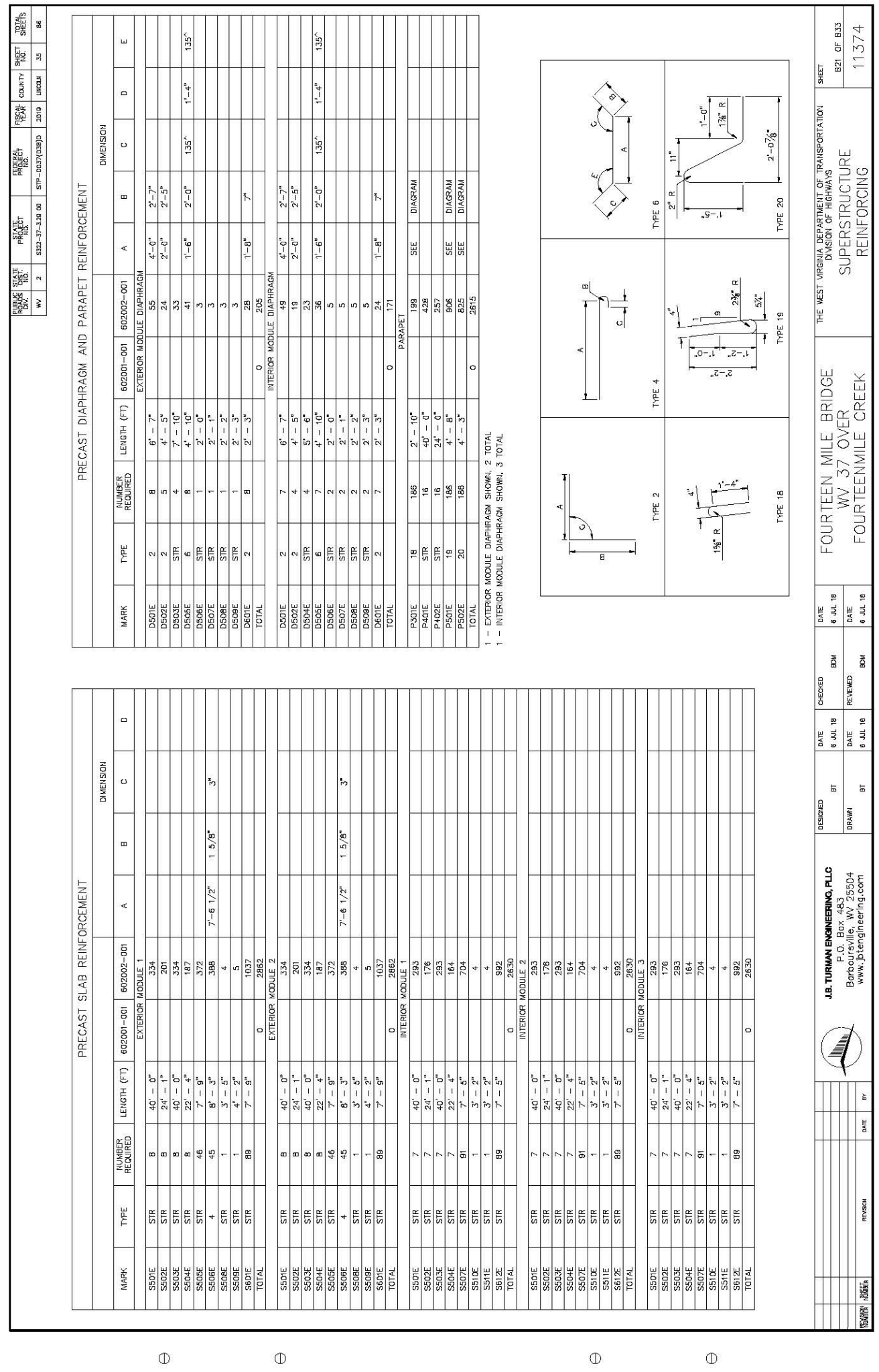




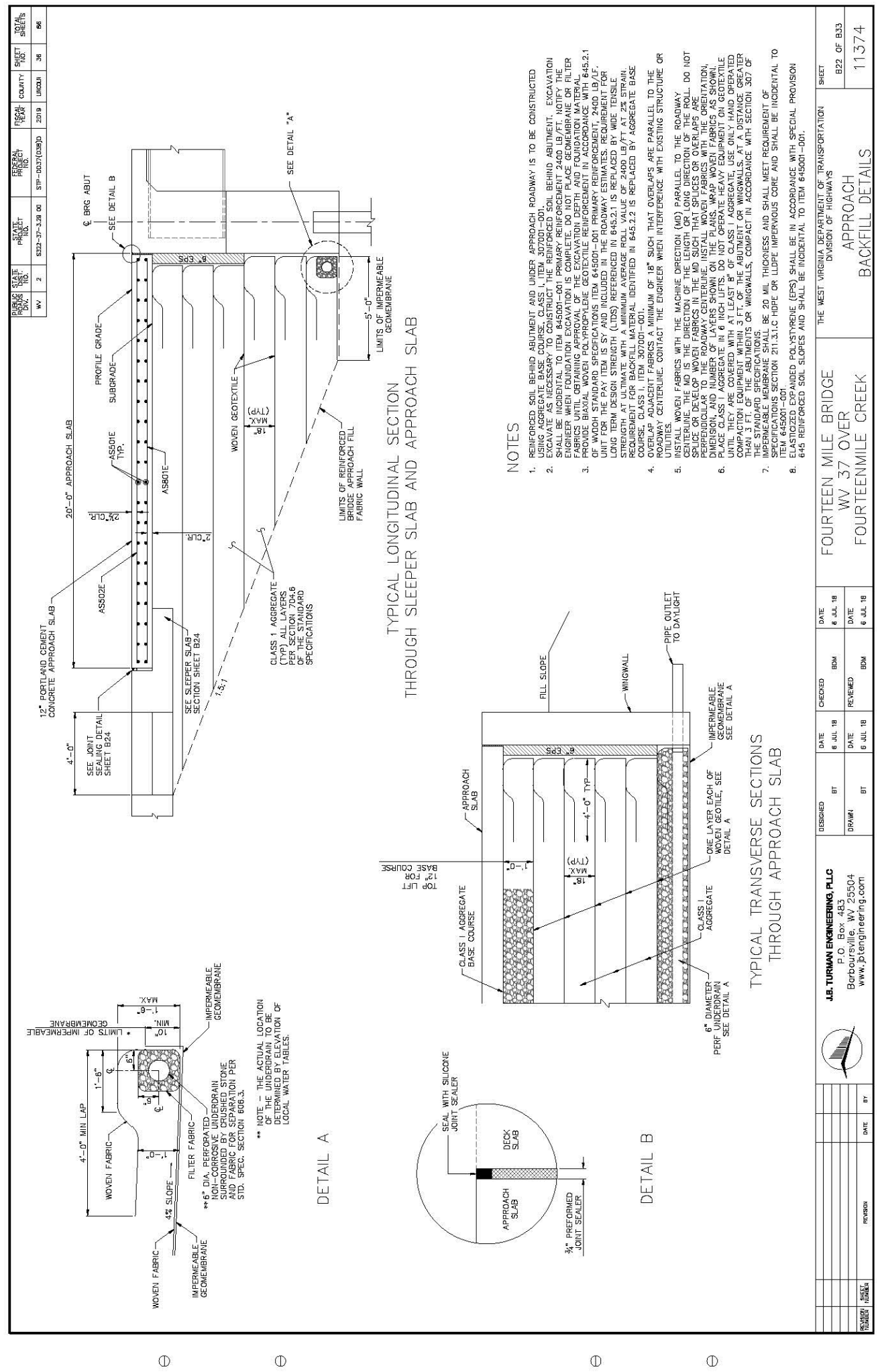




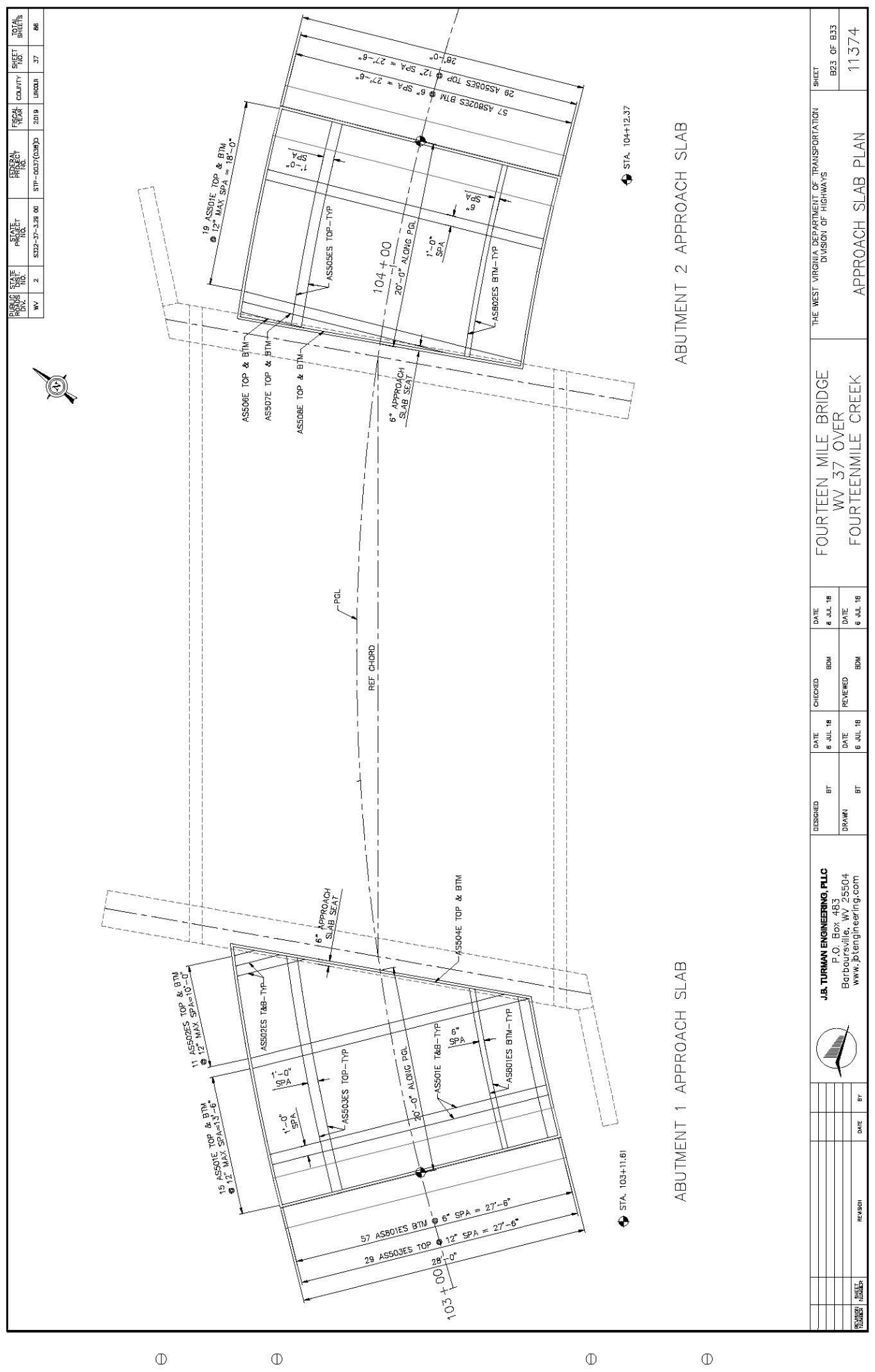




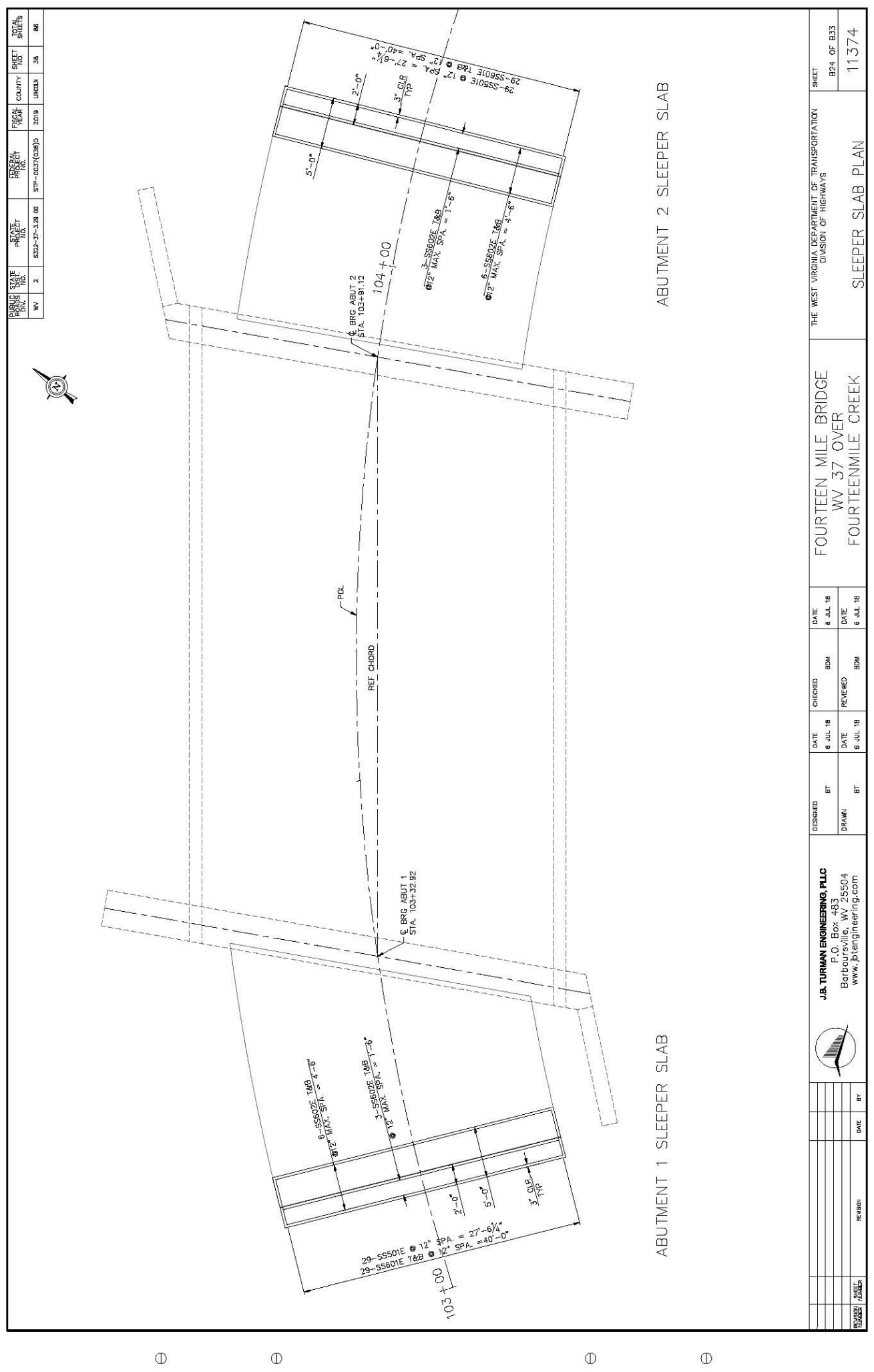




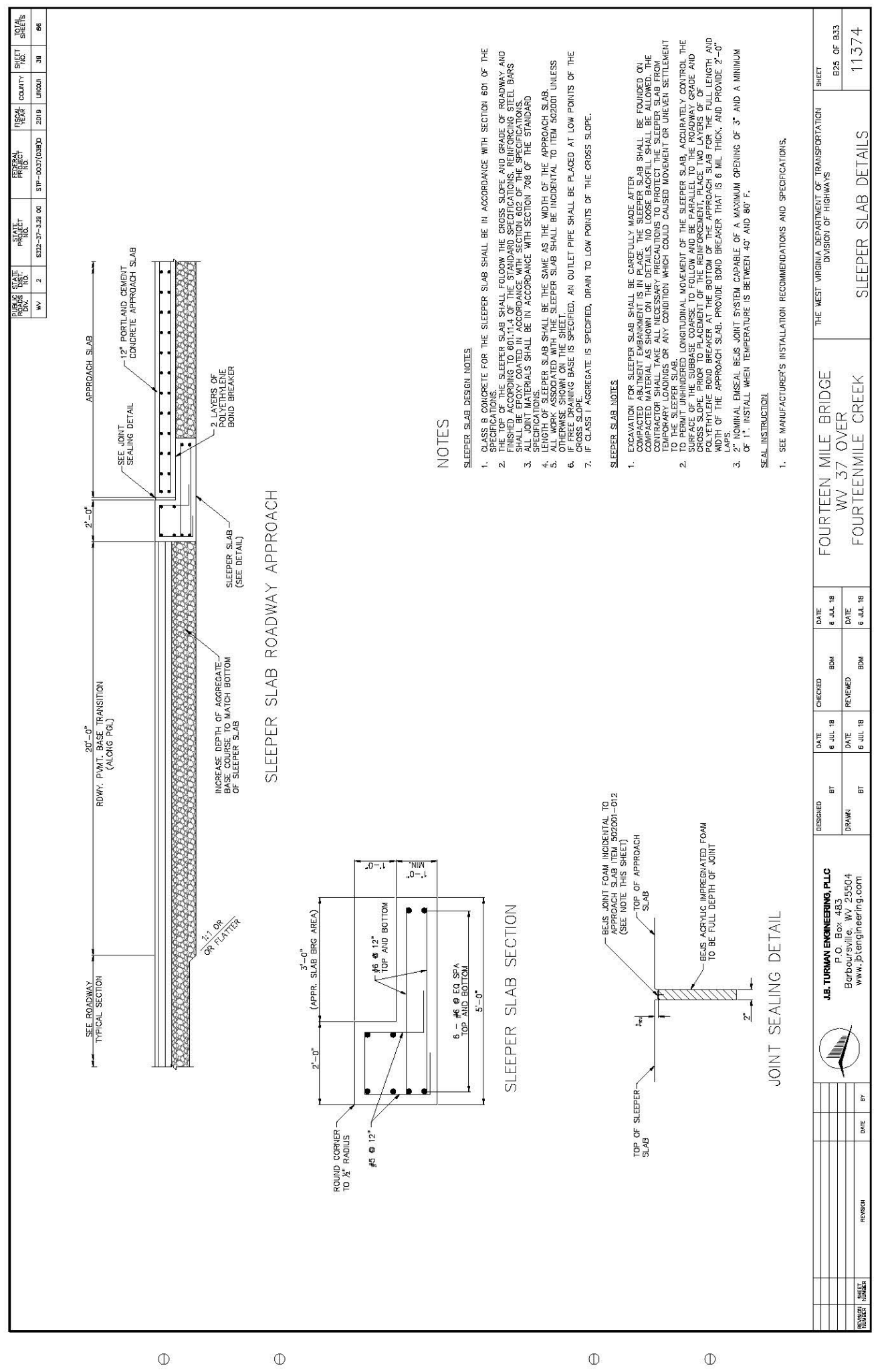




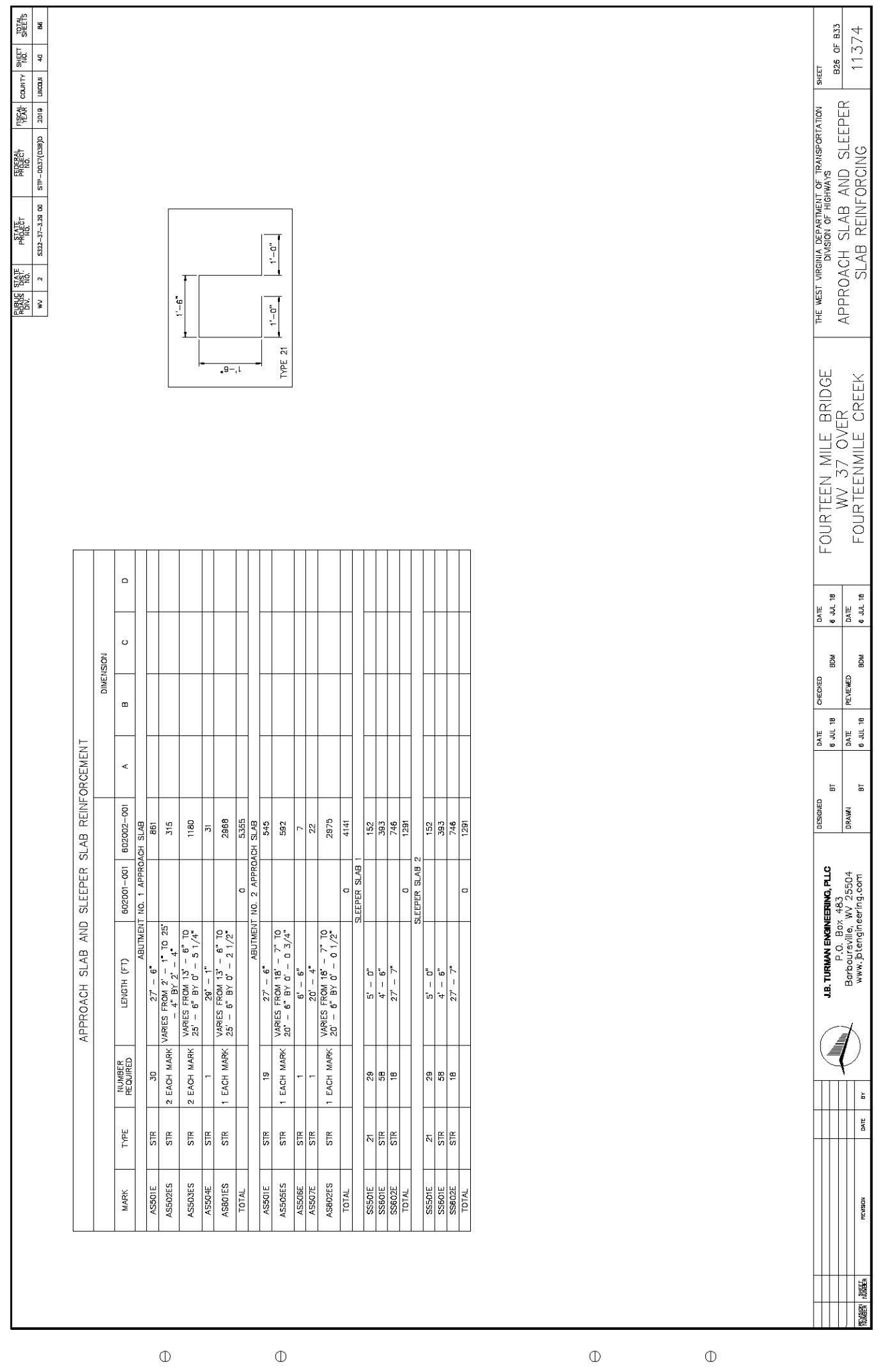




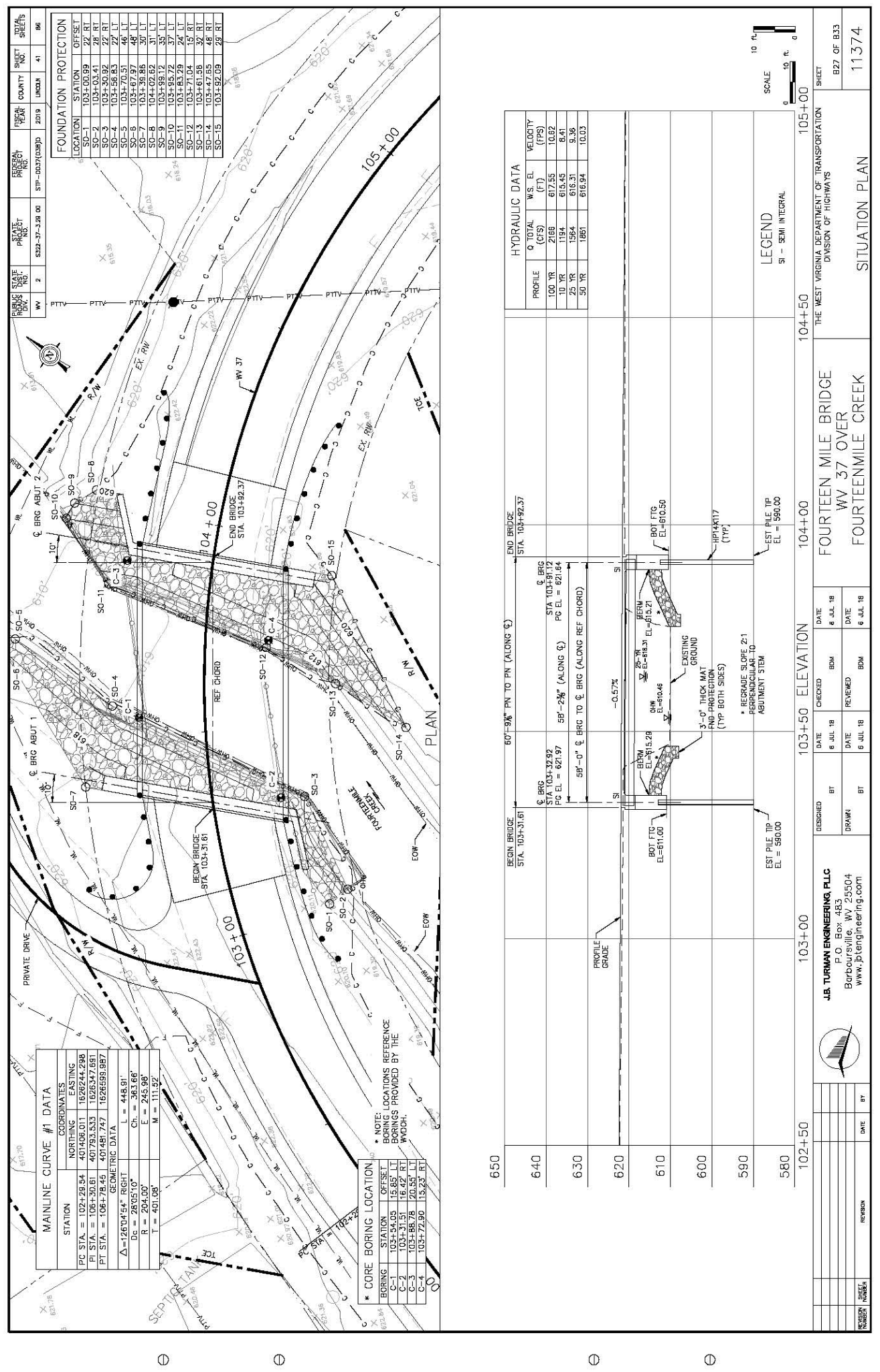



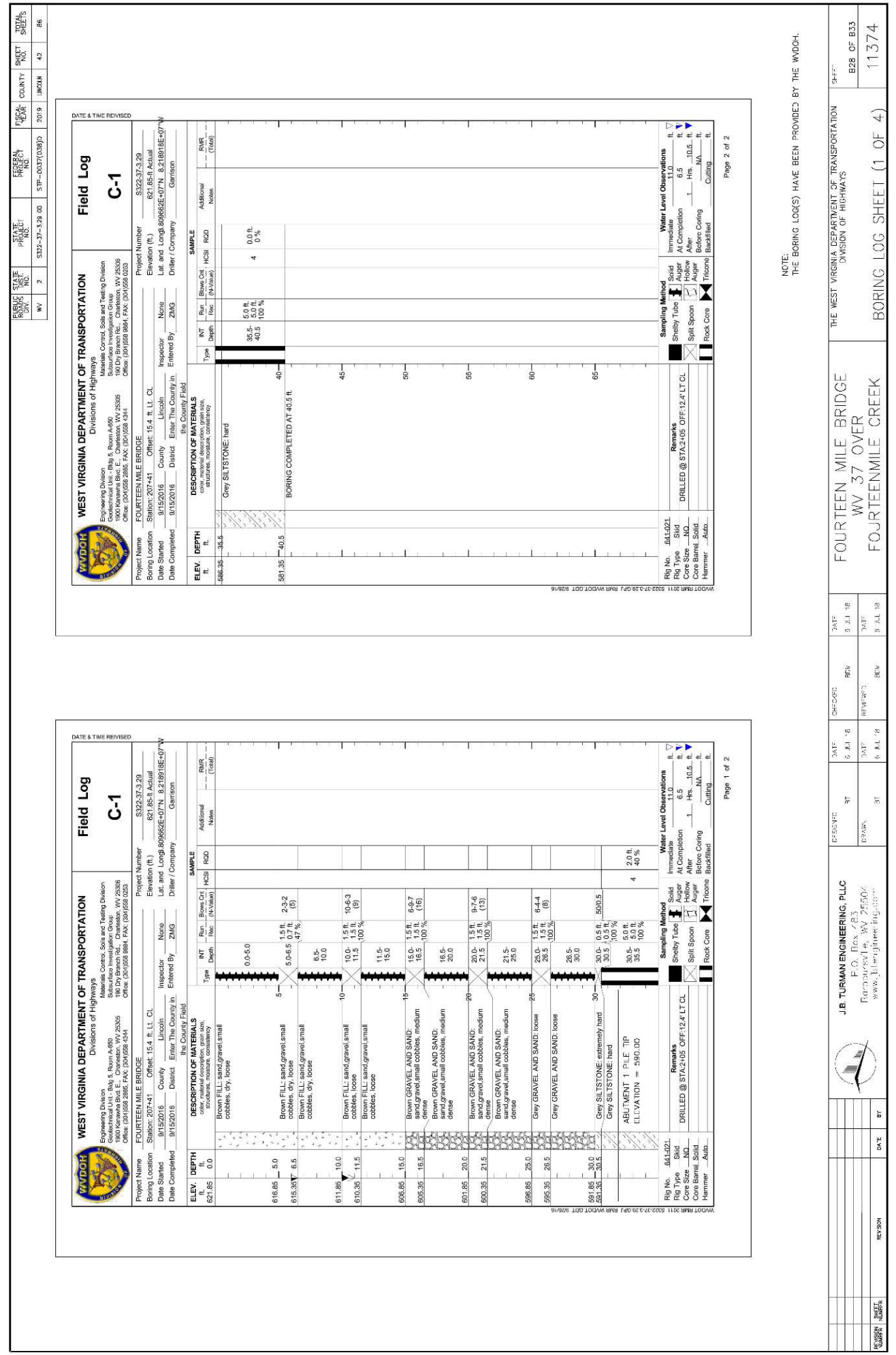

(1)

(1) 

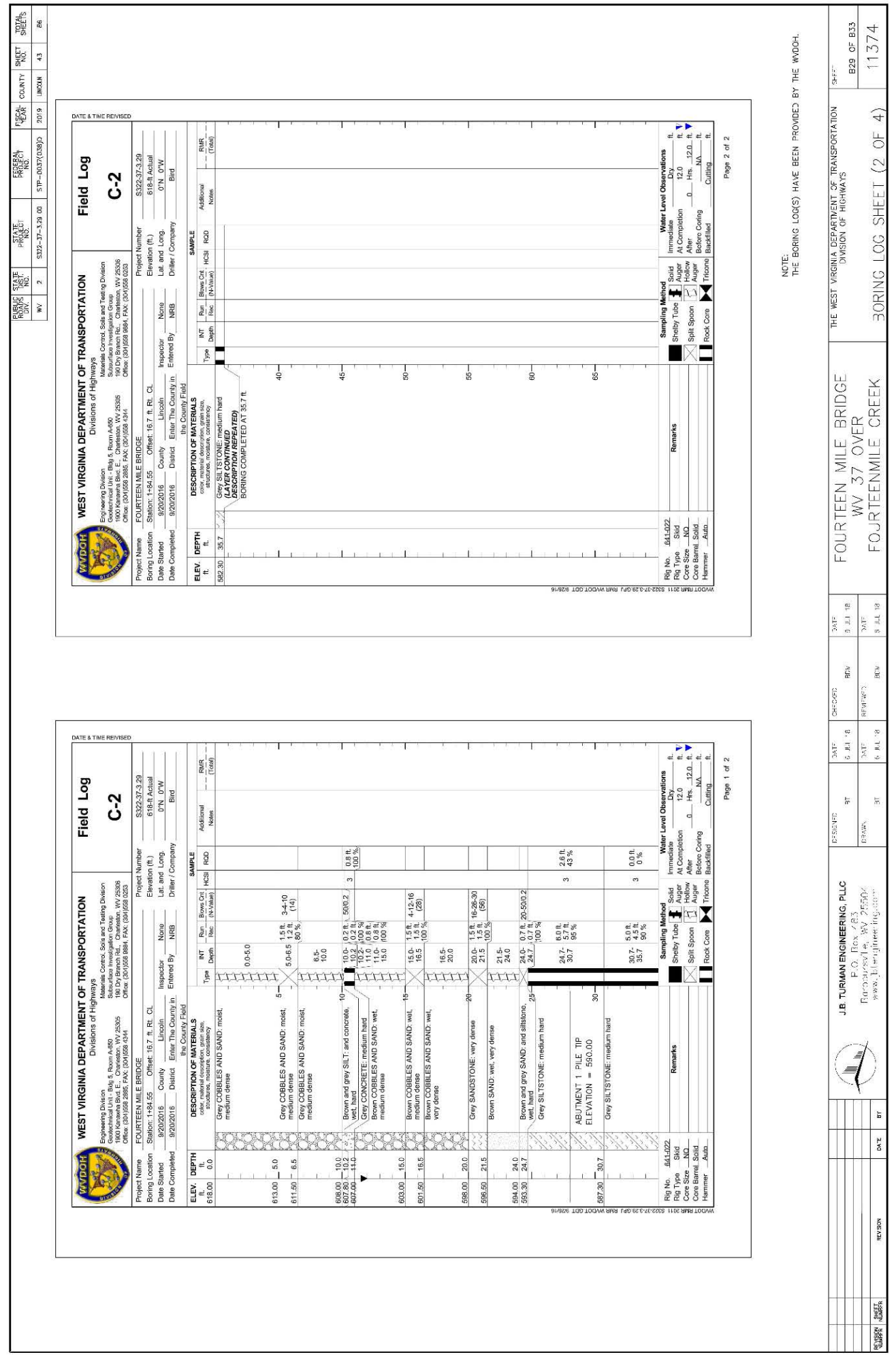

(1)

(1) 

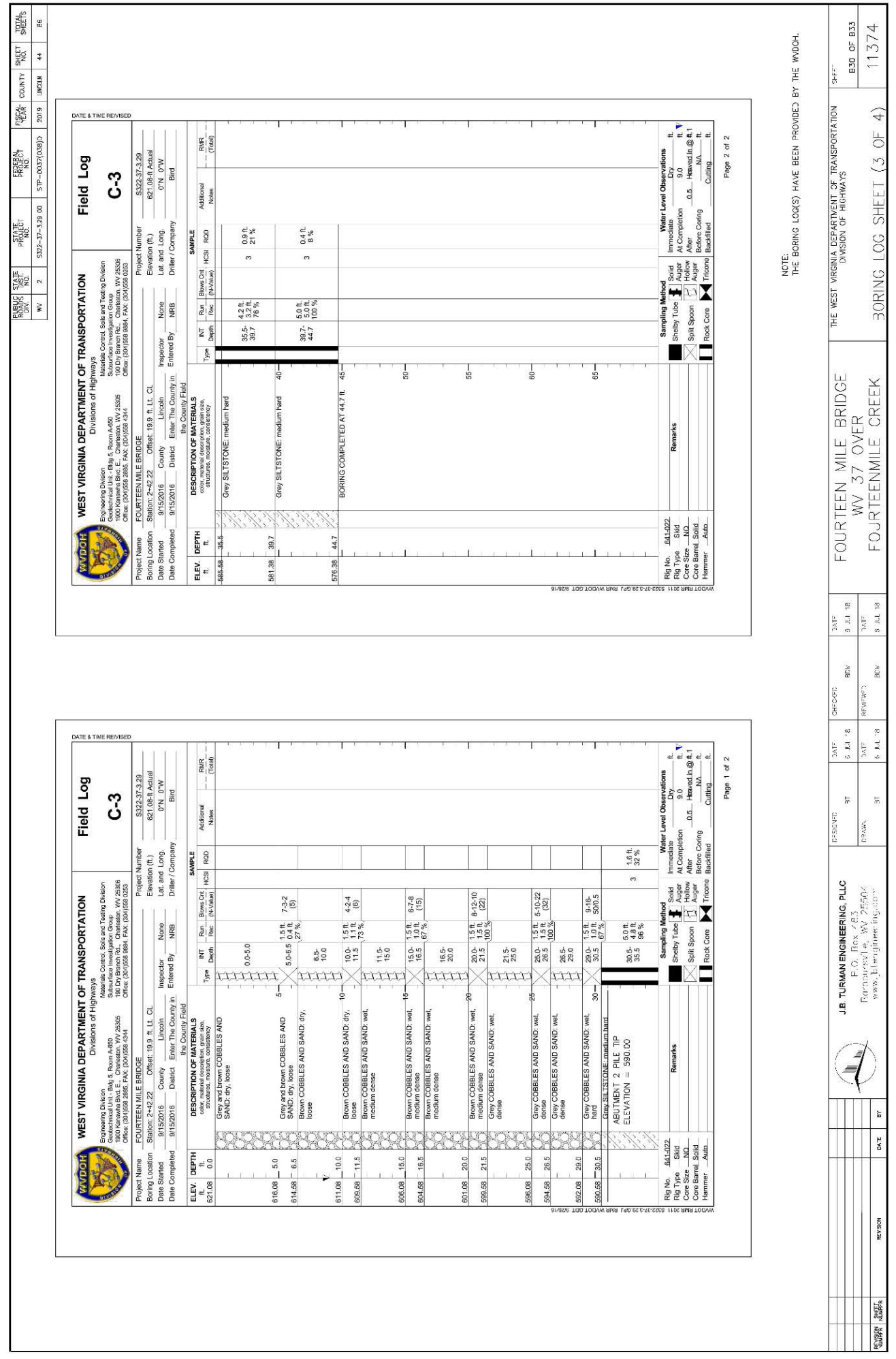

(1)

(1)

(1) 

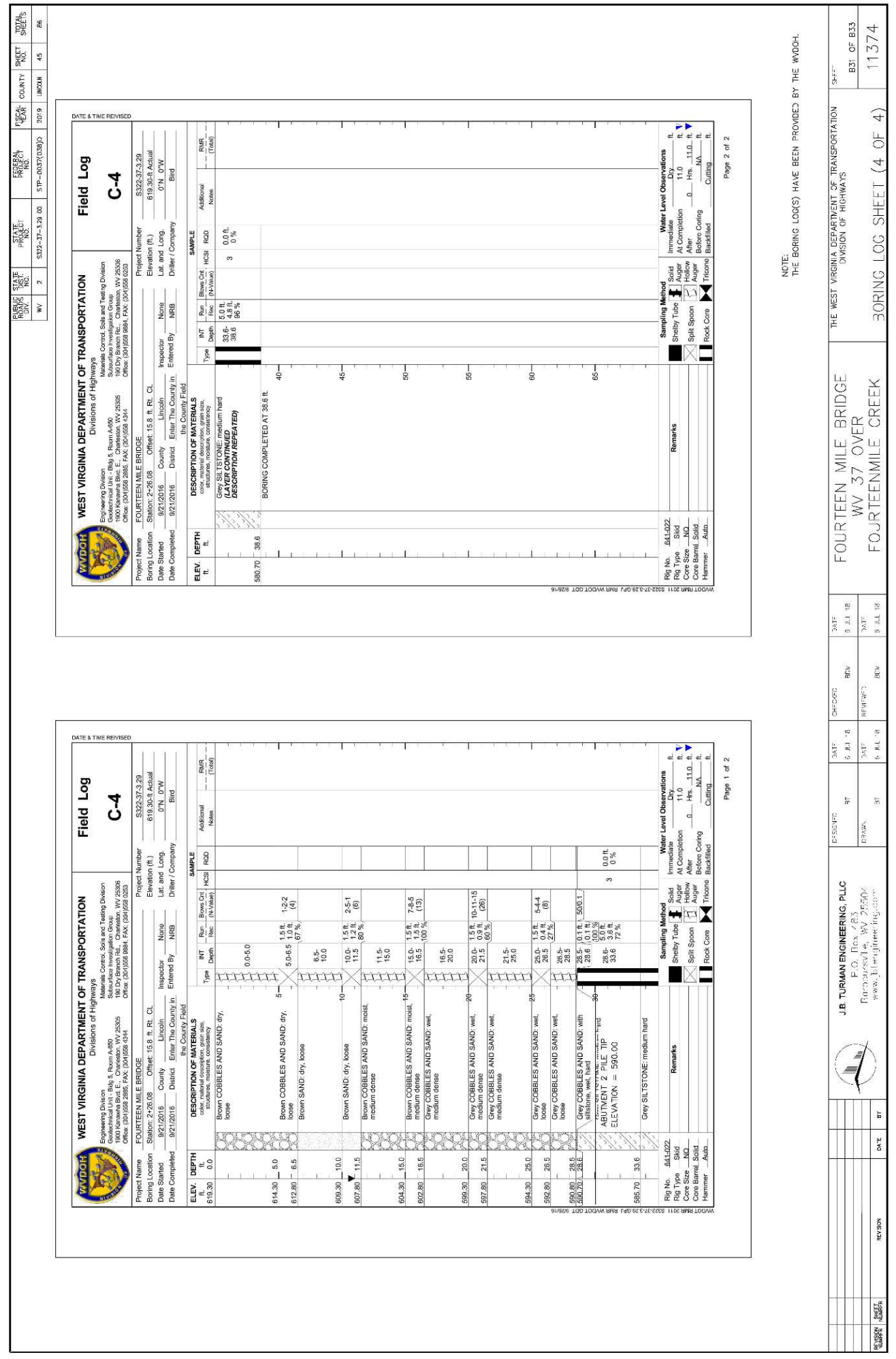

(1)

(1) 


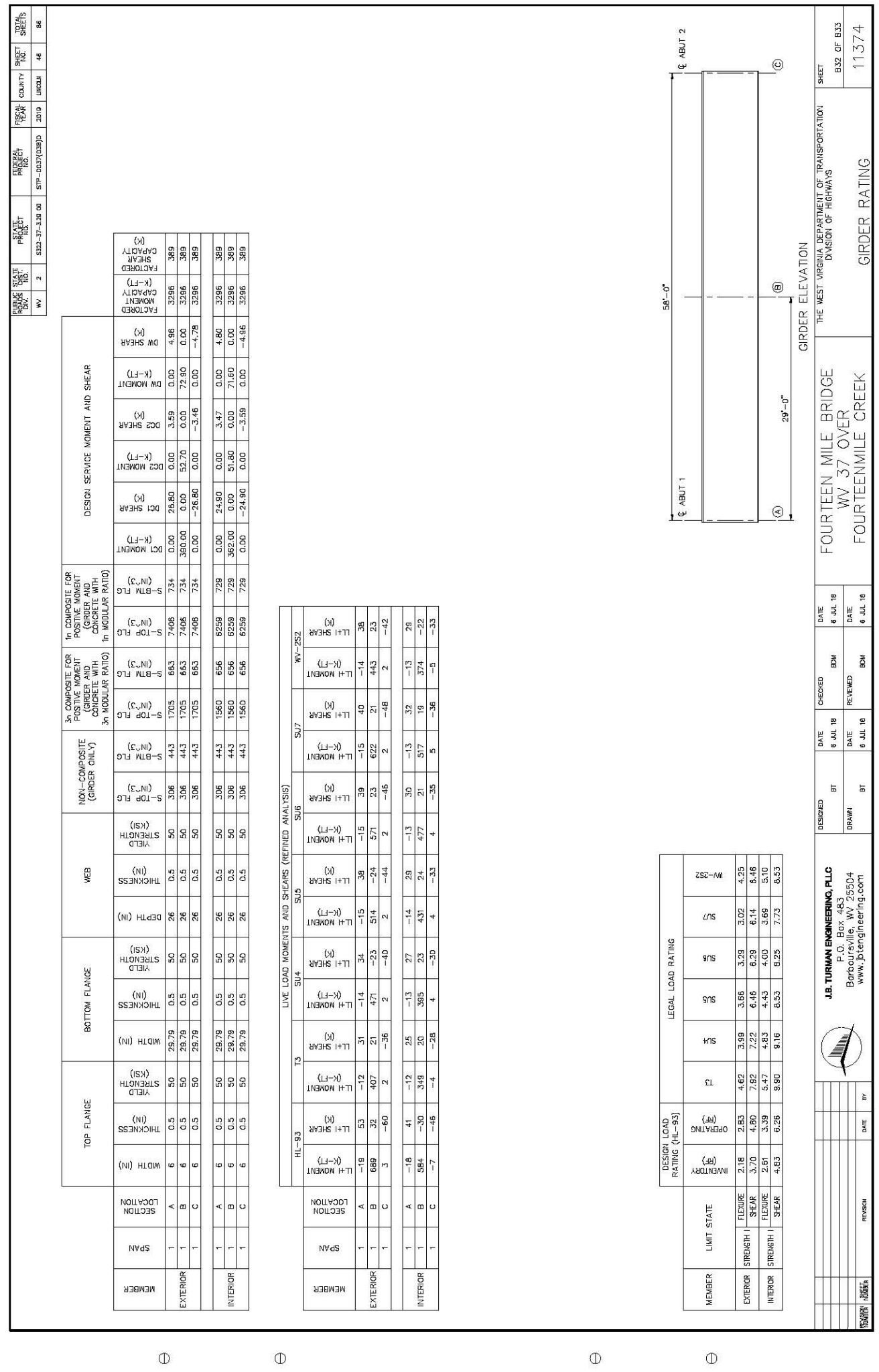




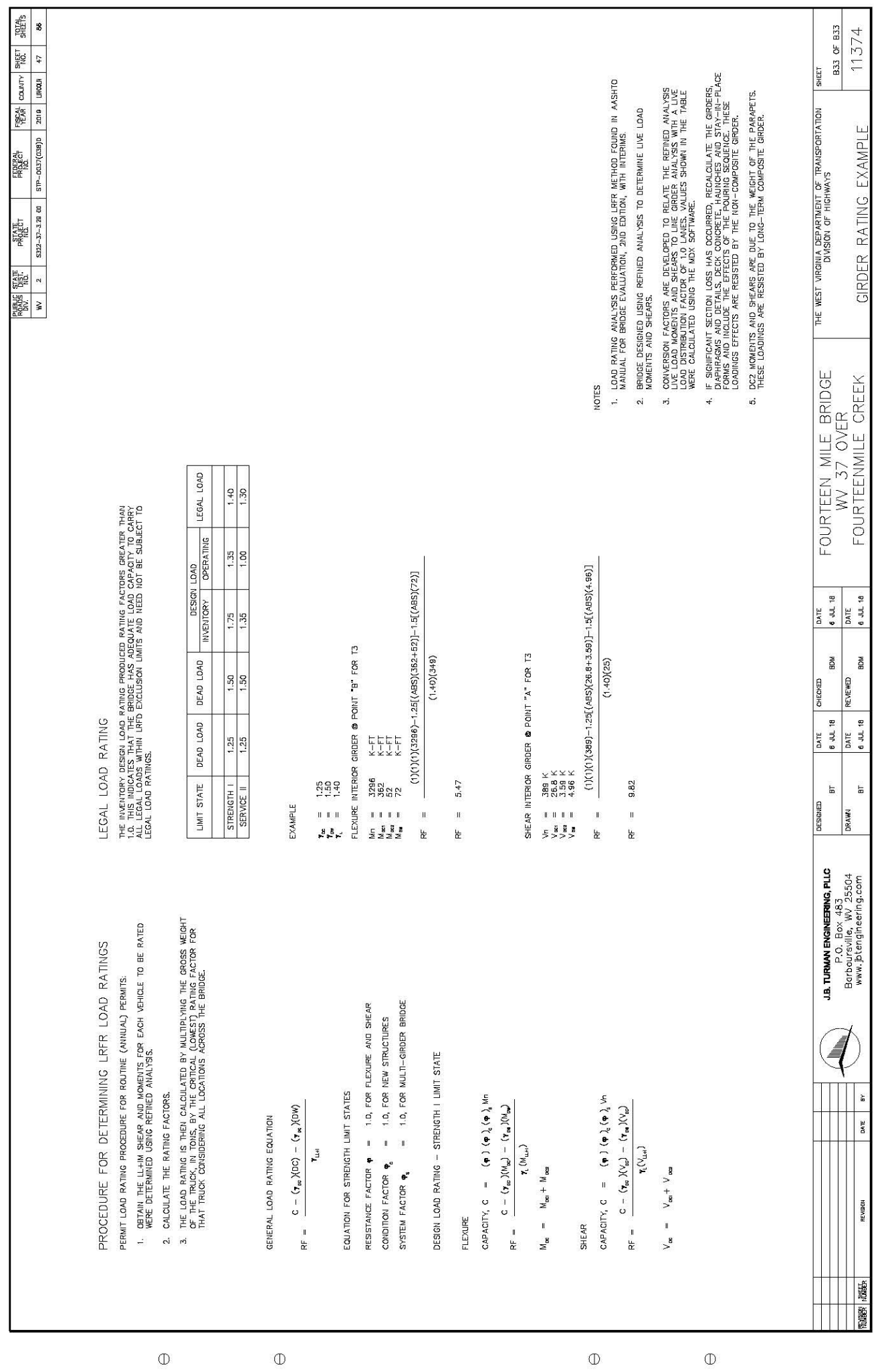




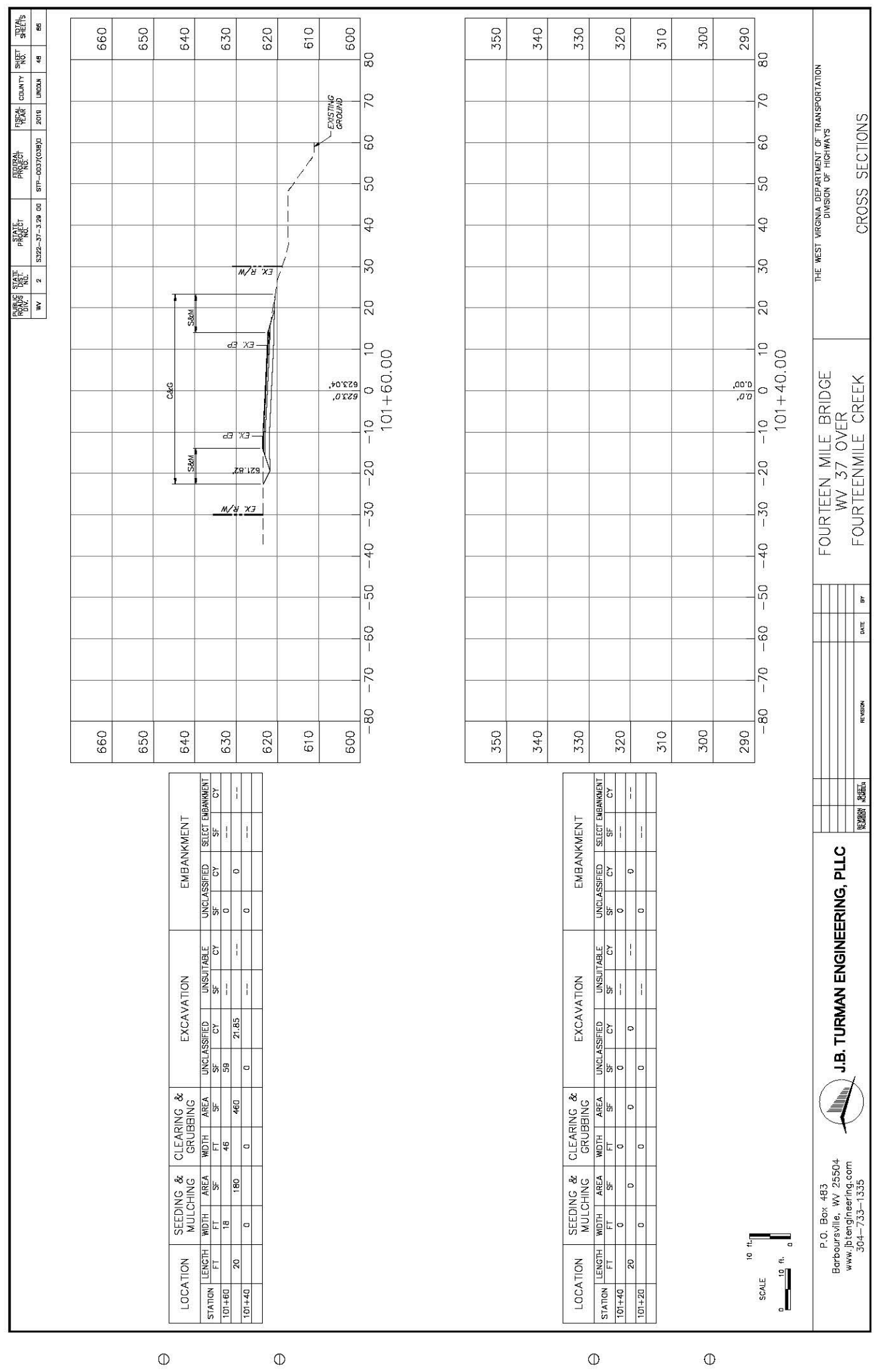




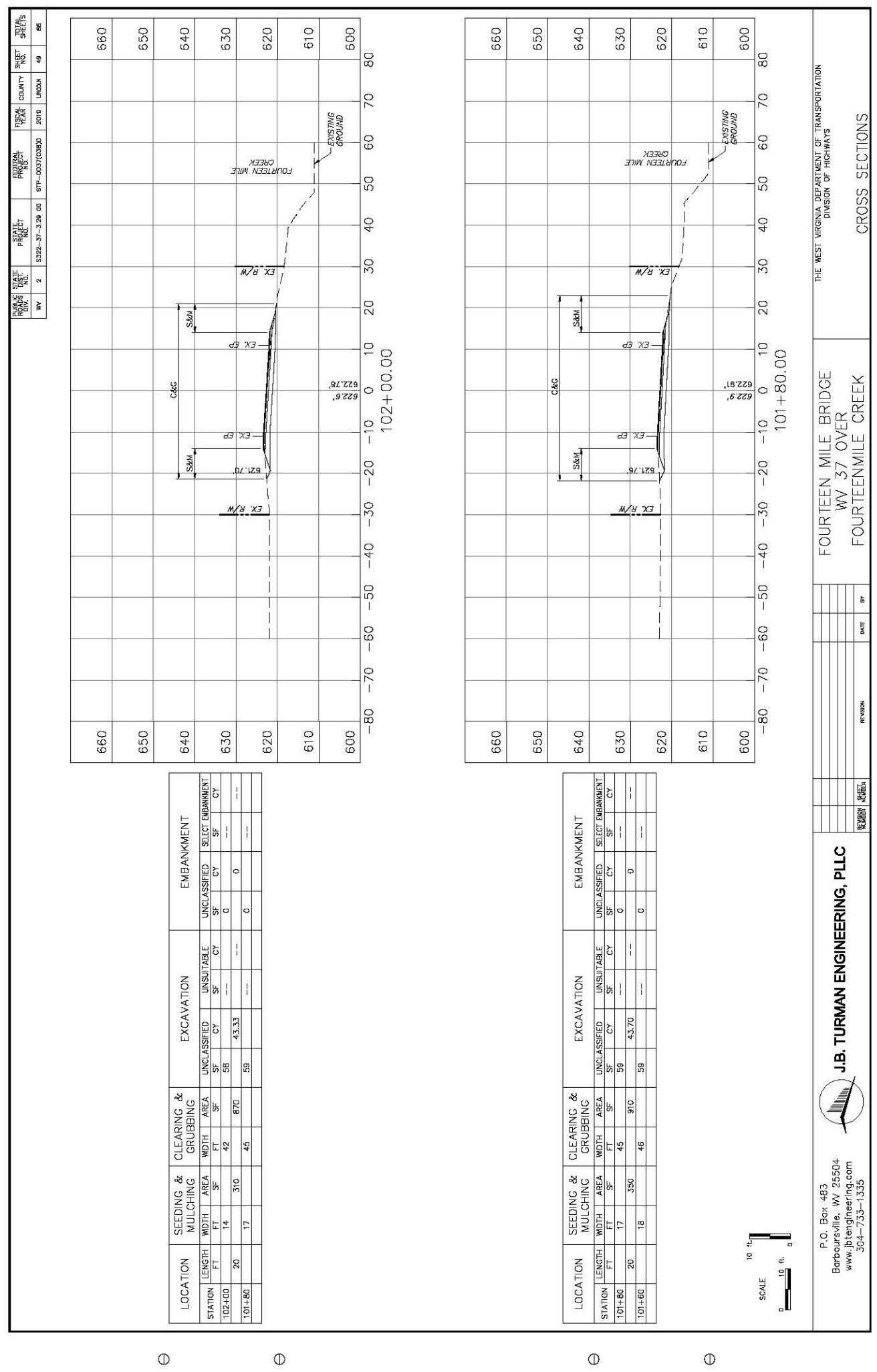




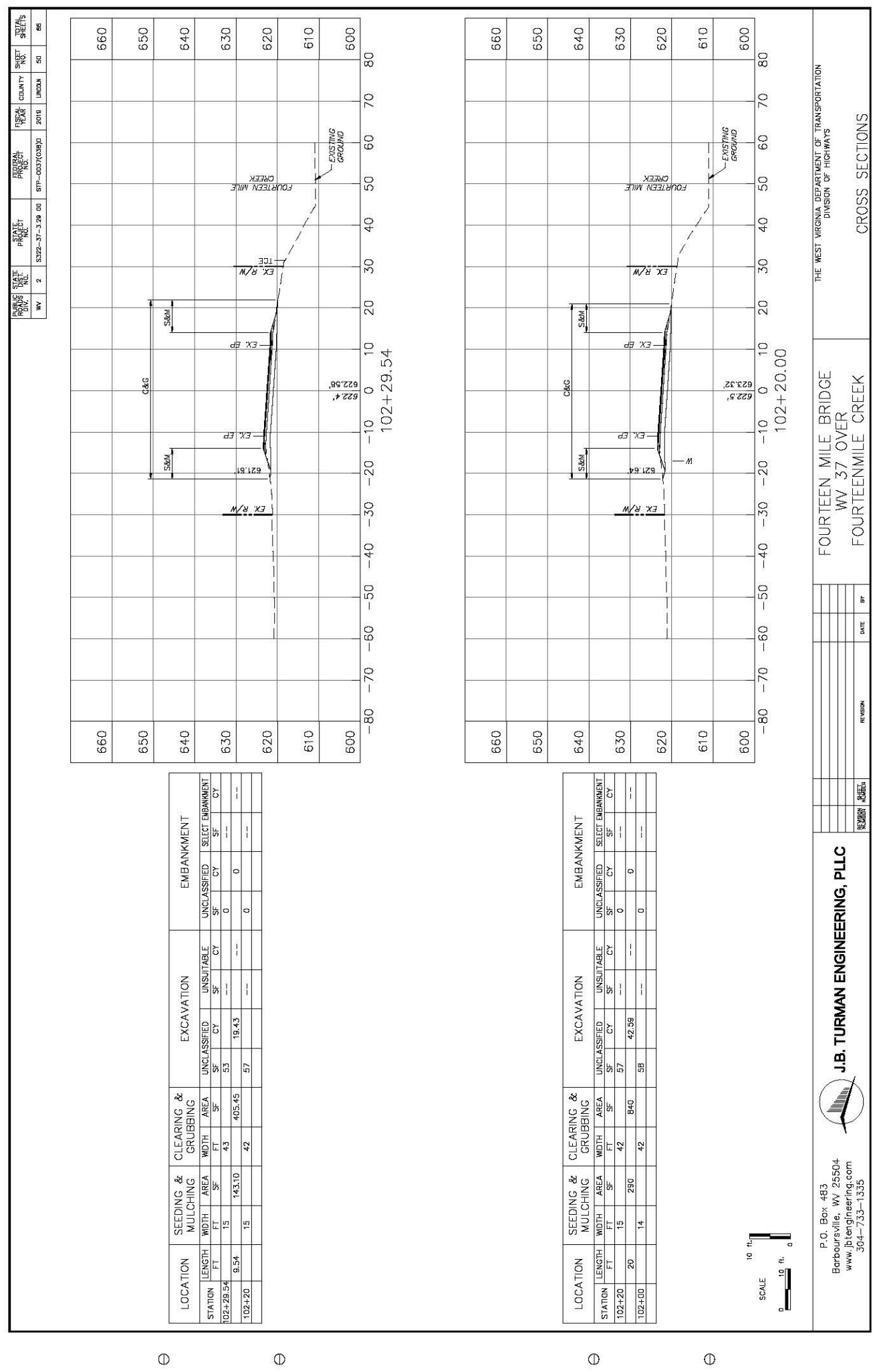




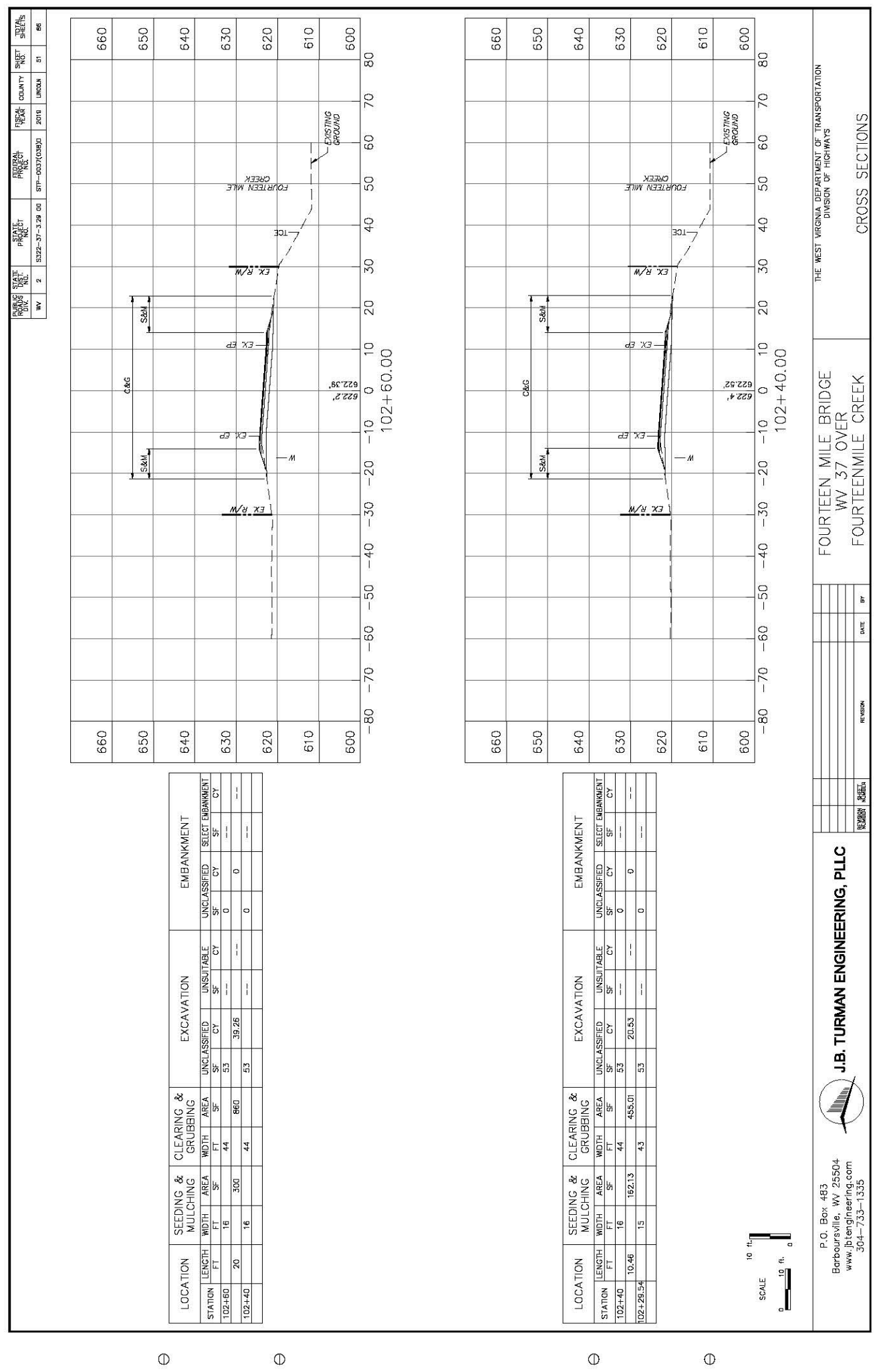




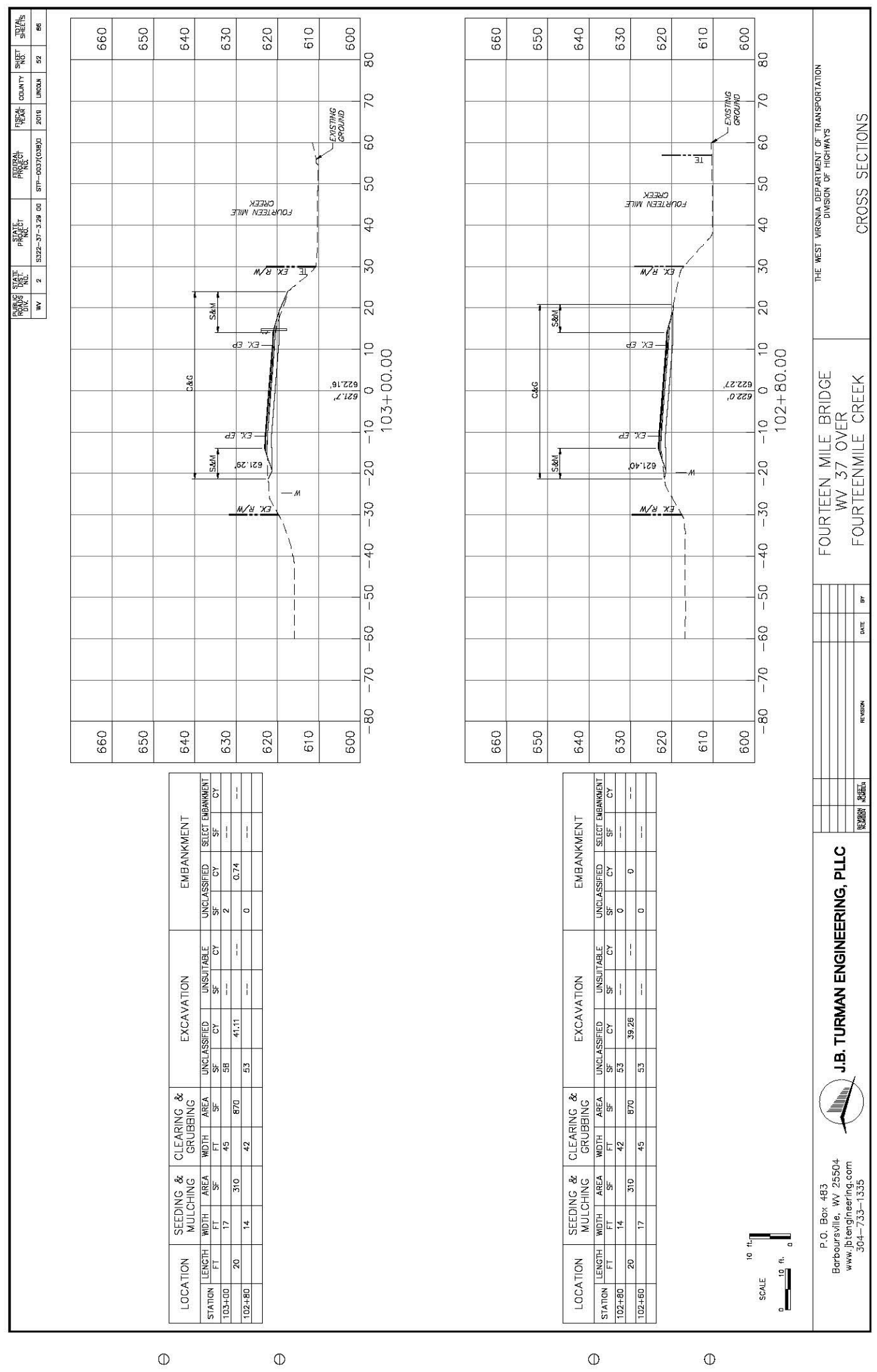




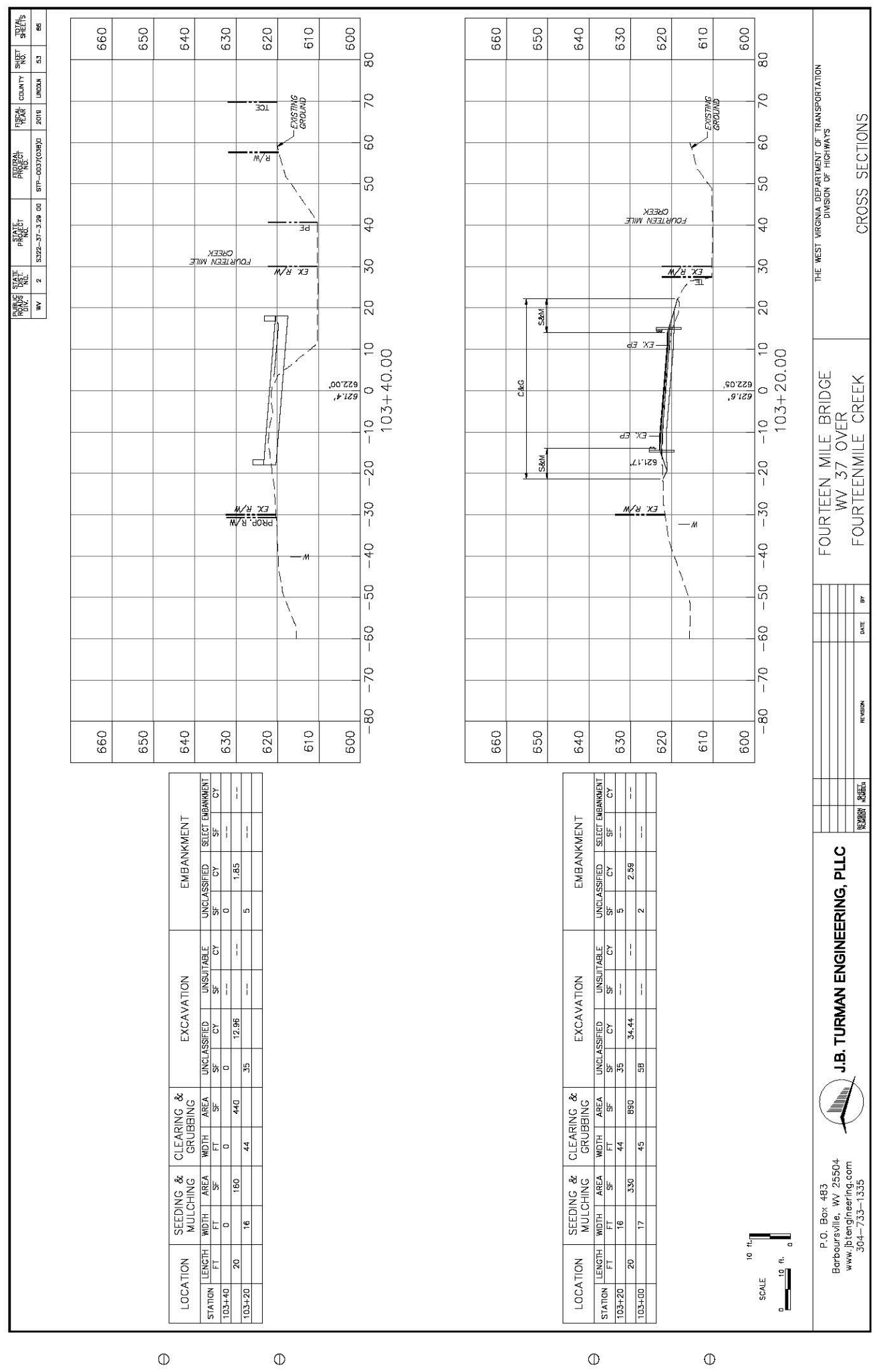




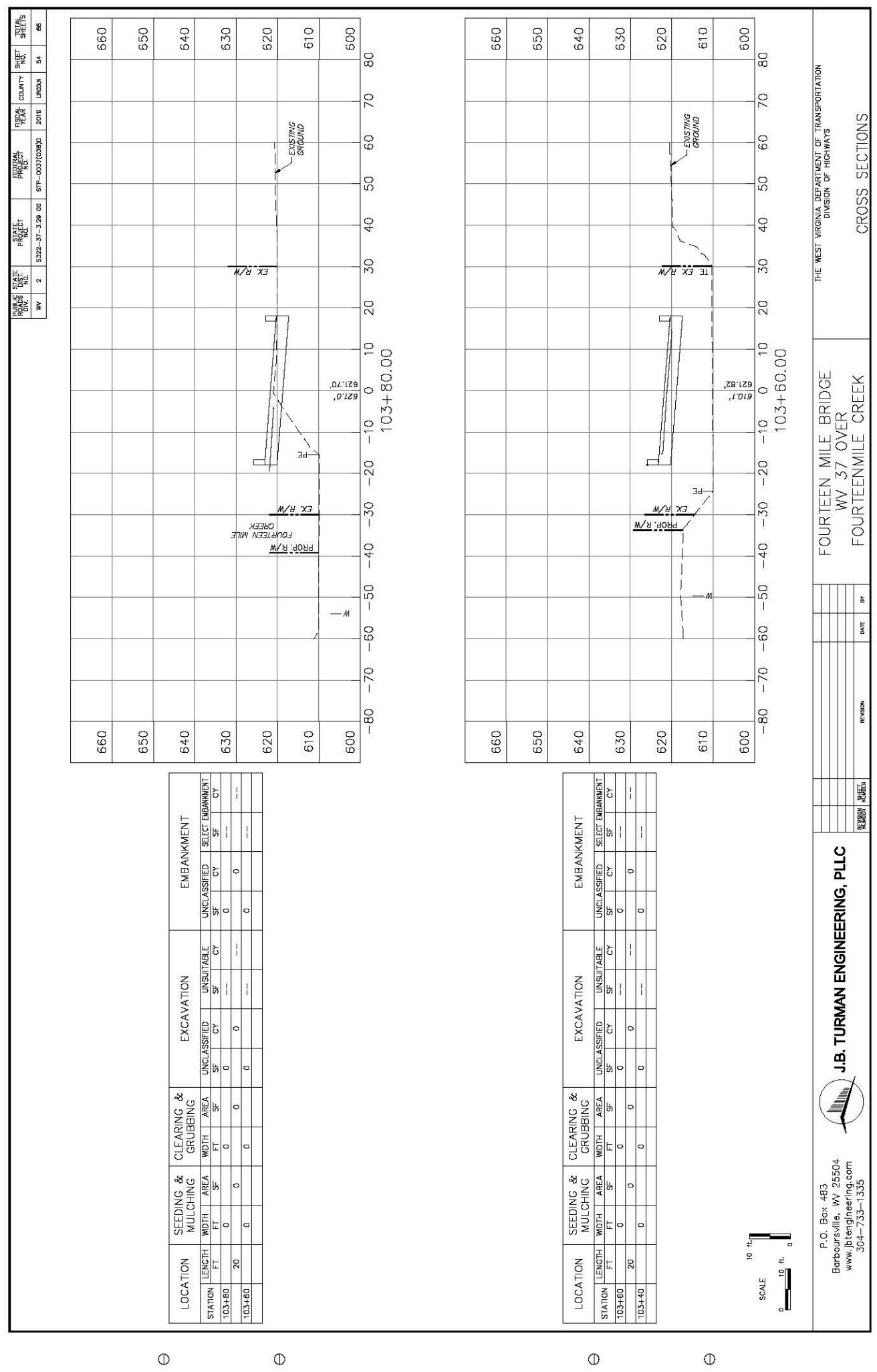




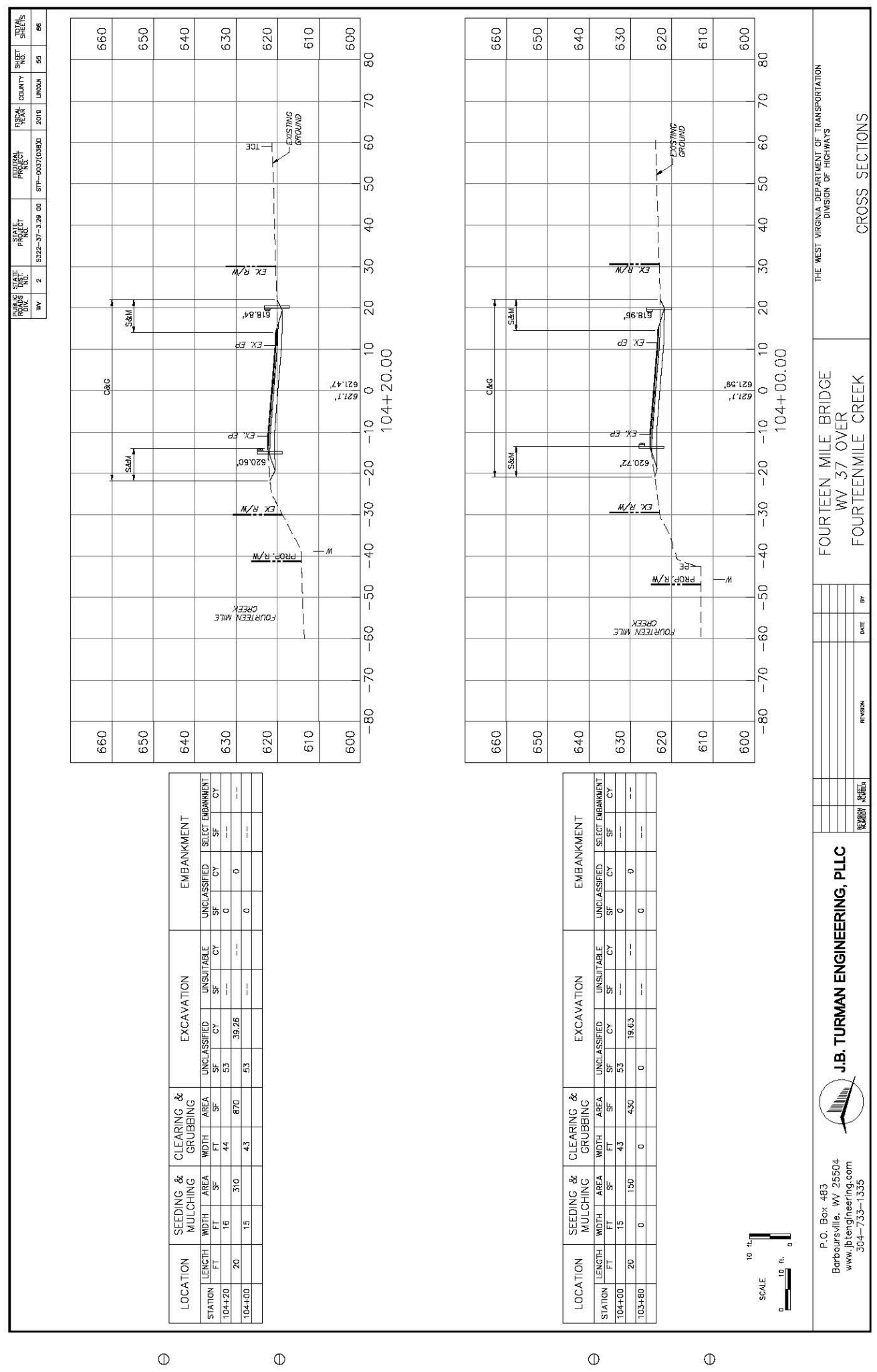




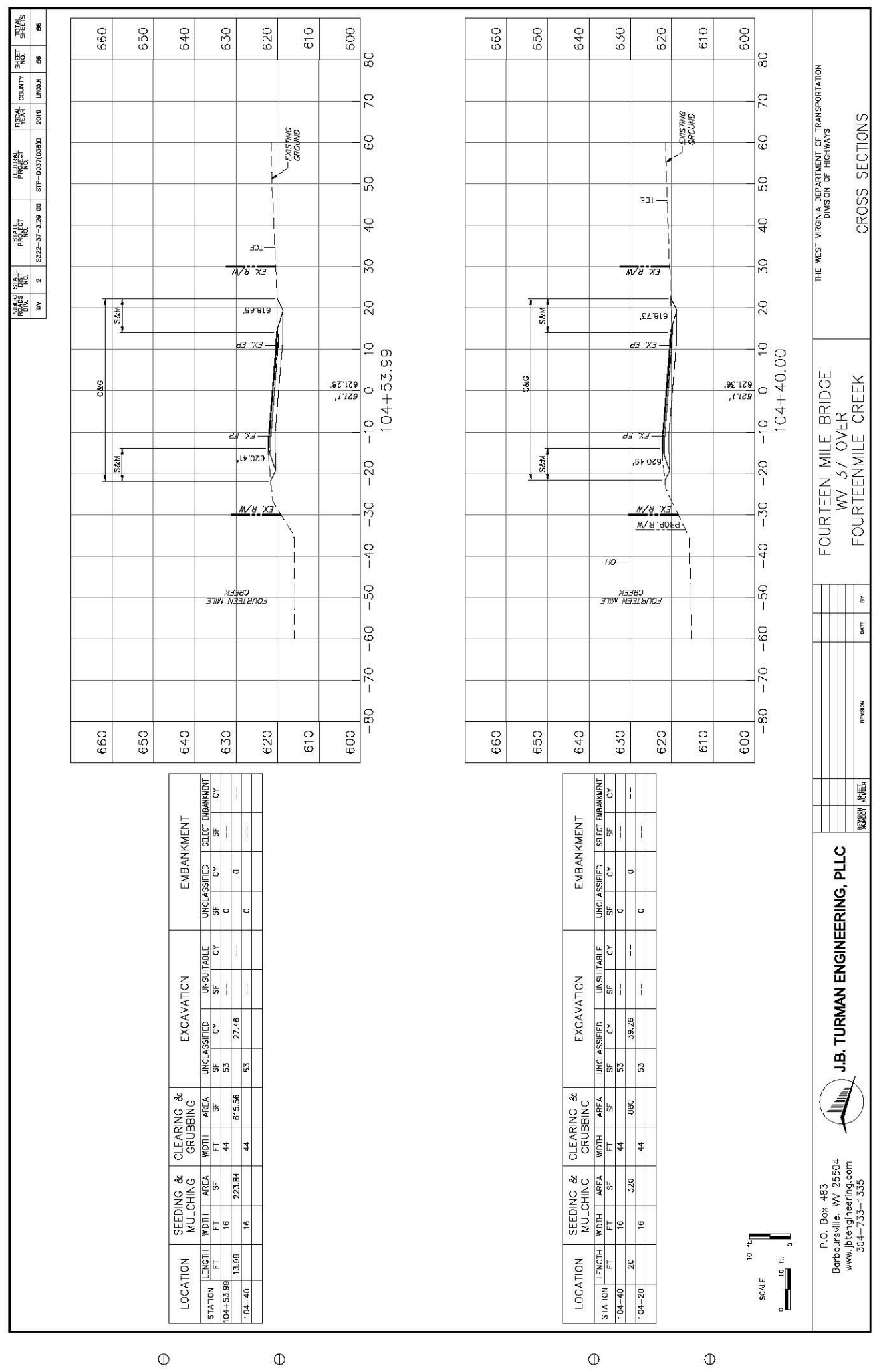




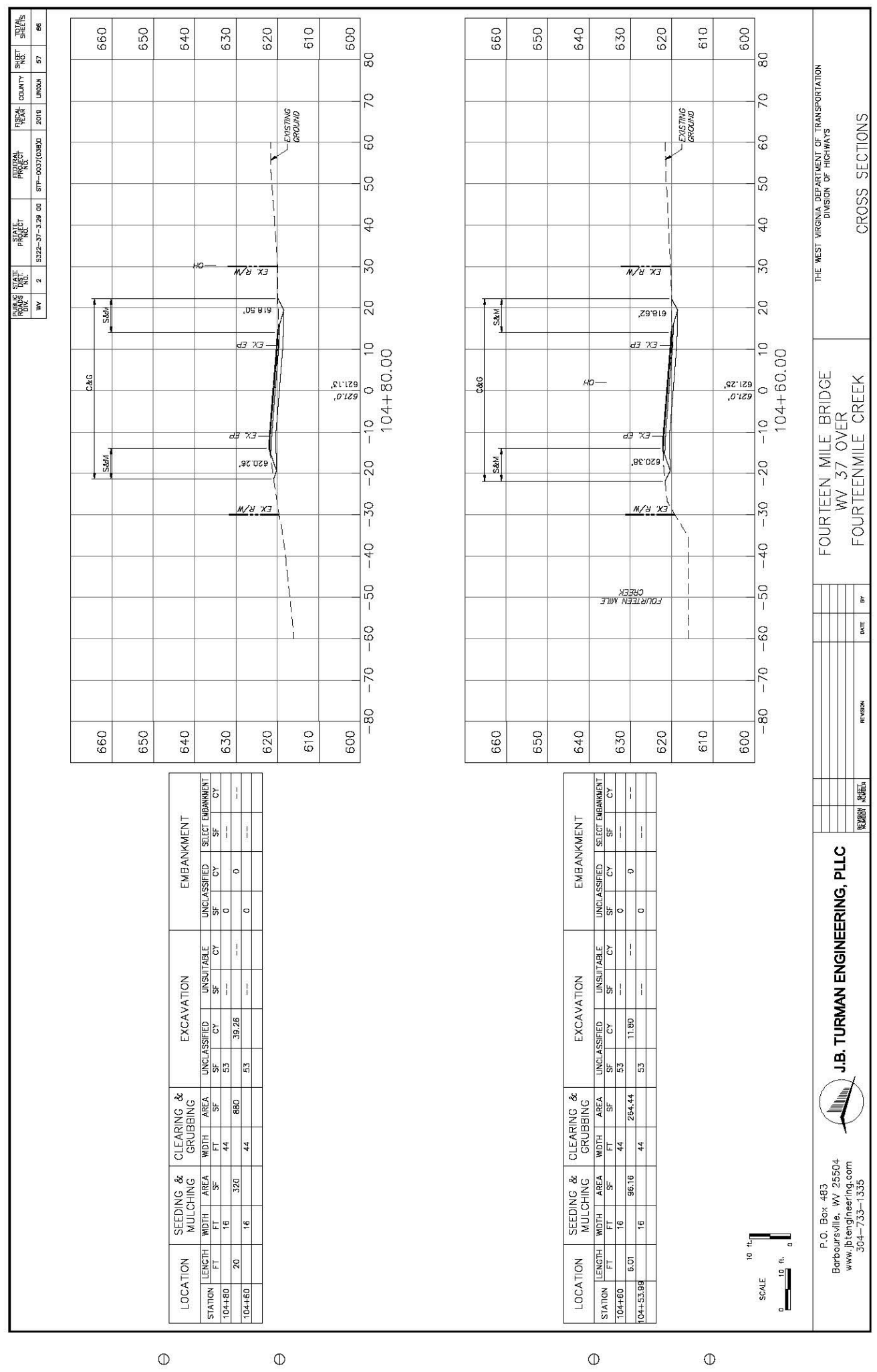




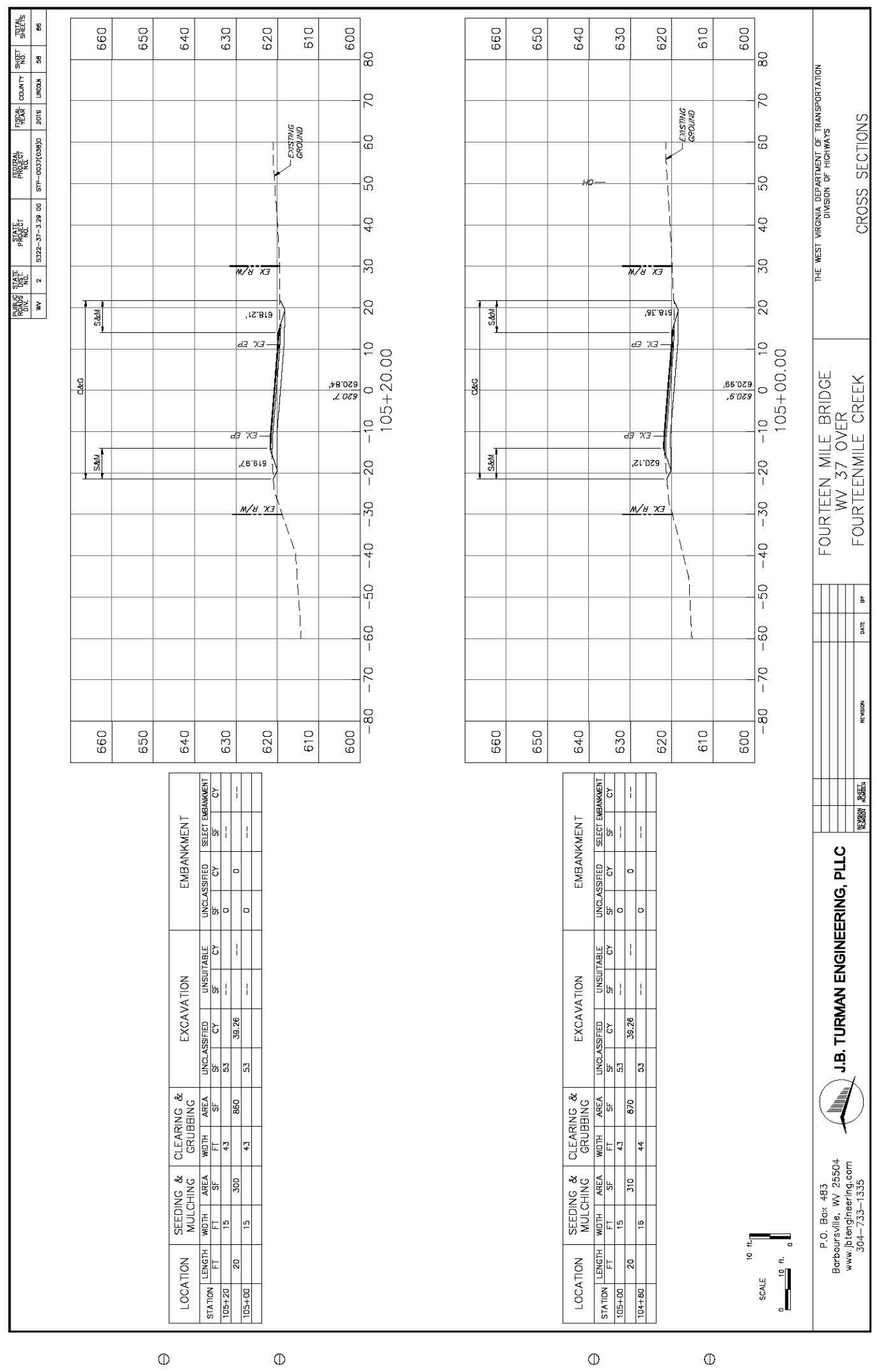




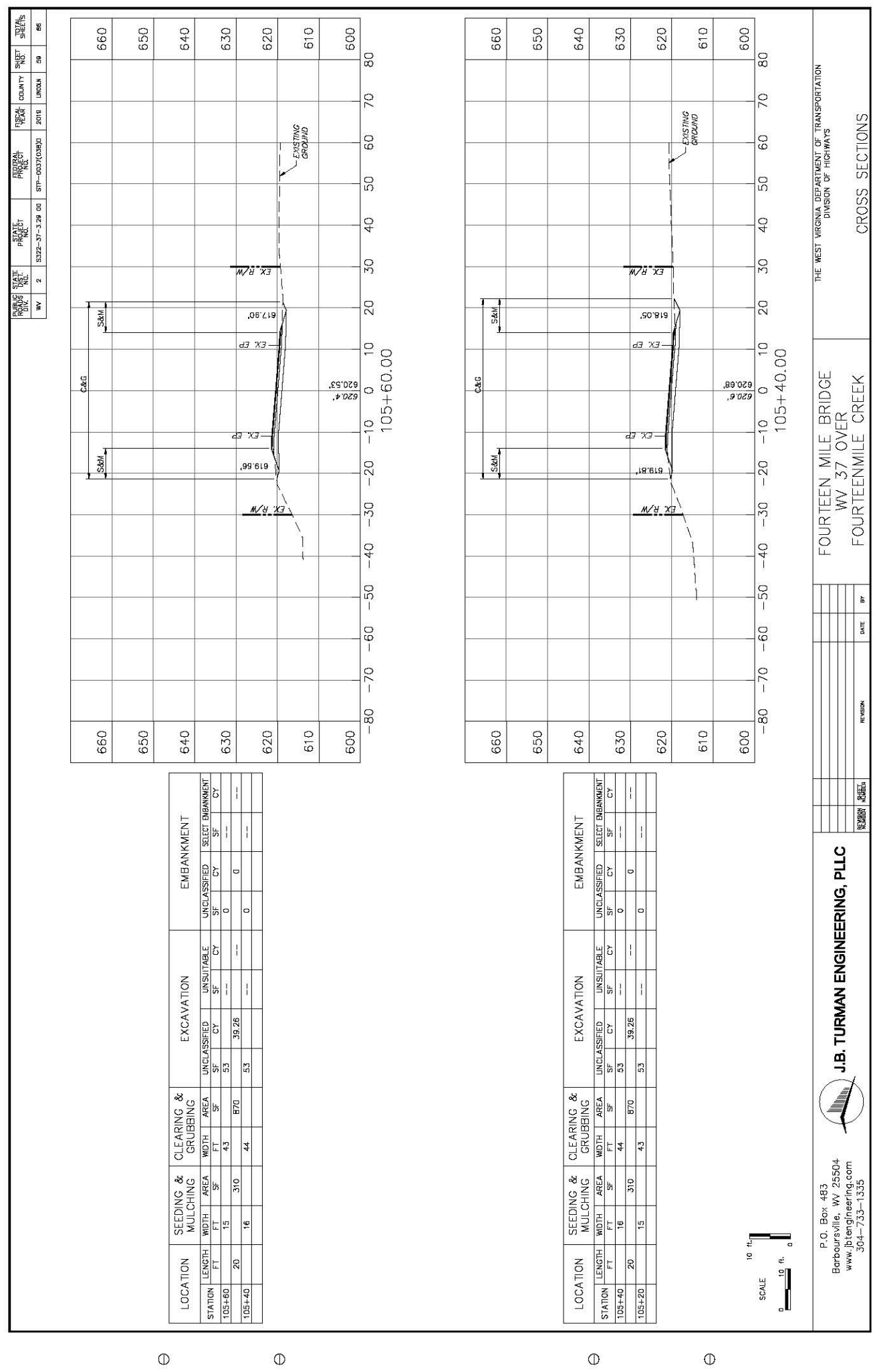




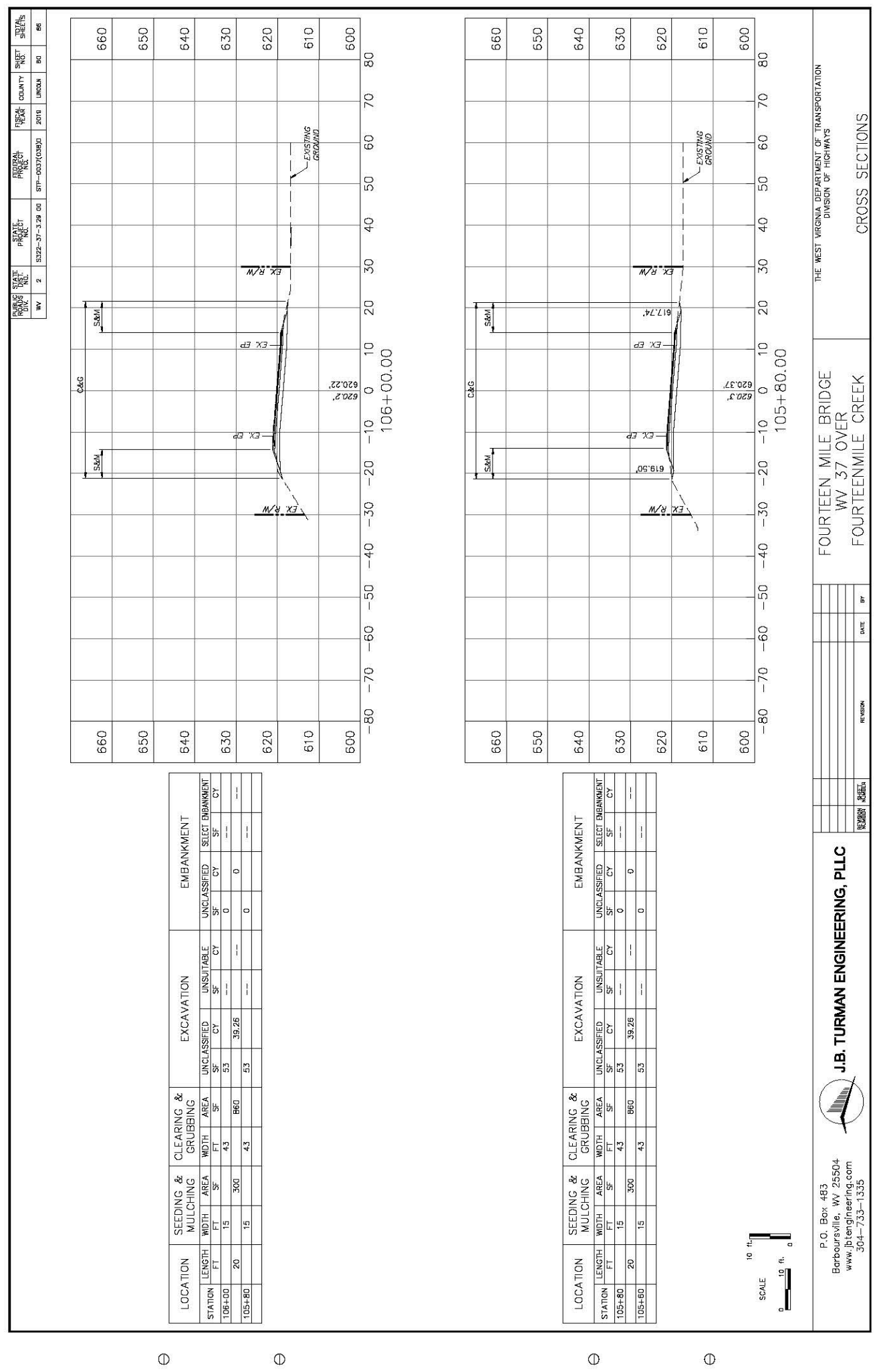




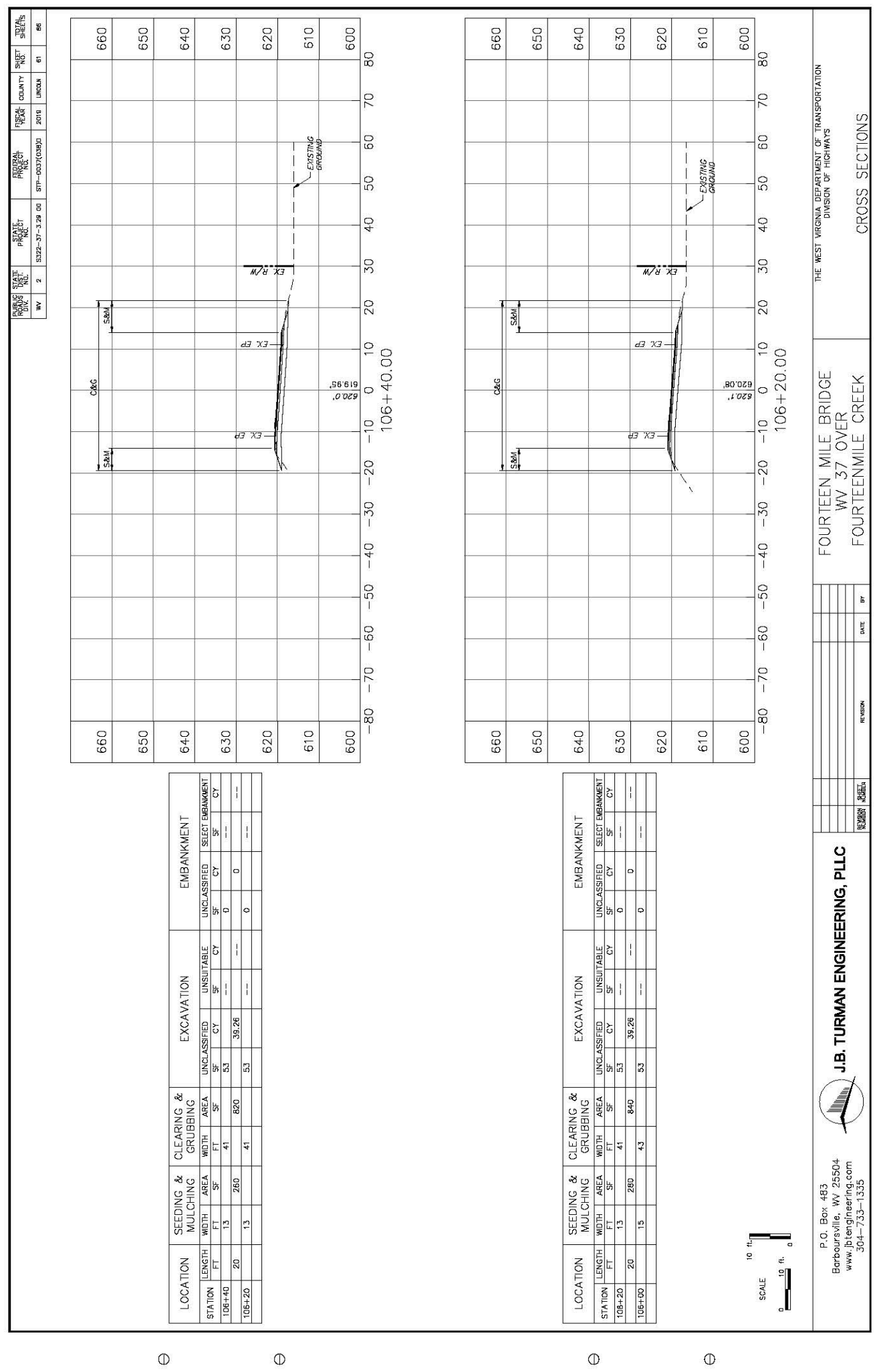




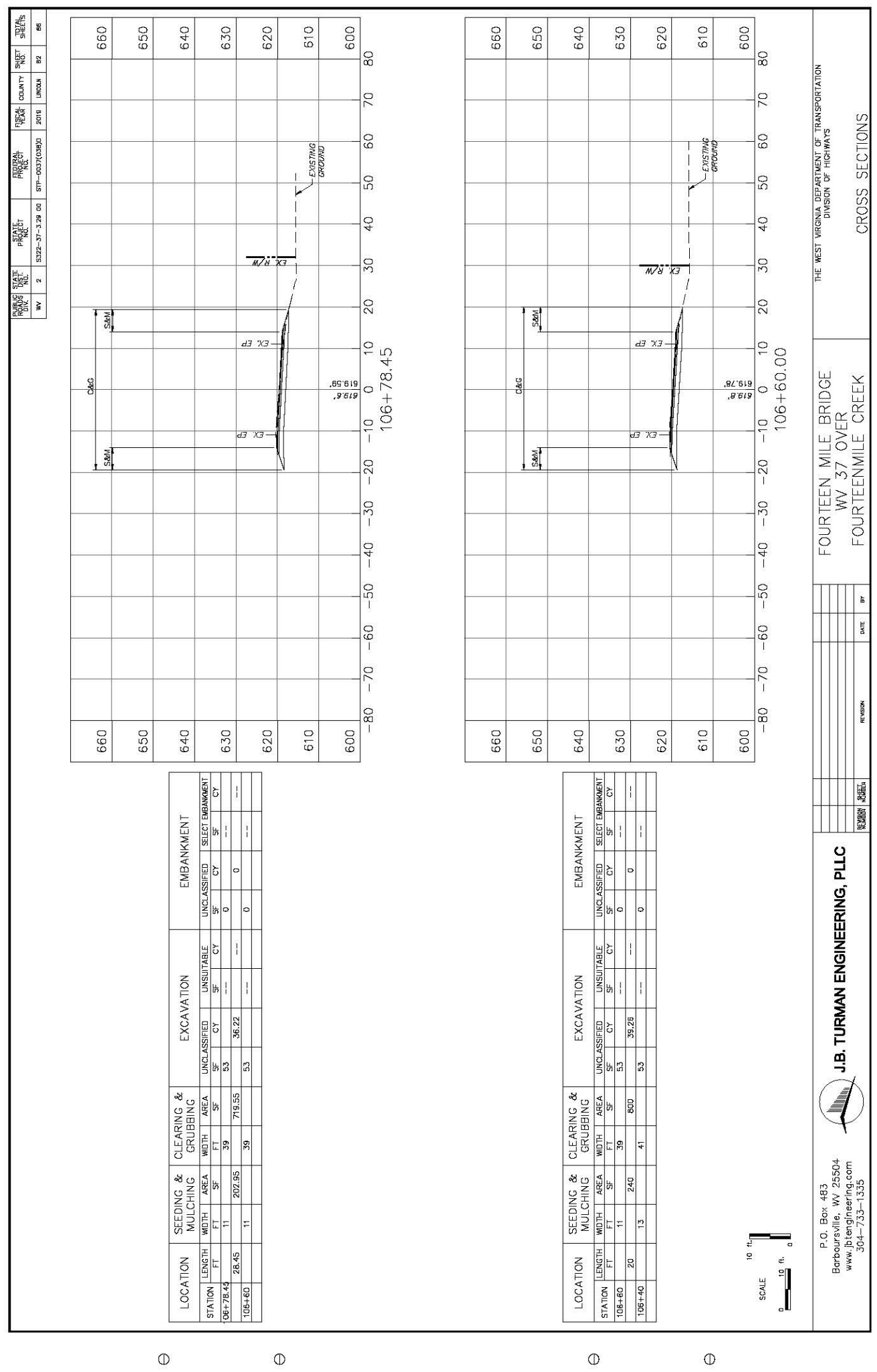




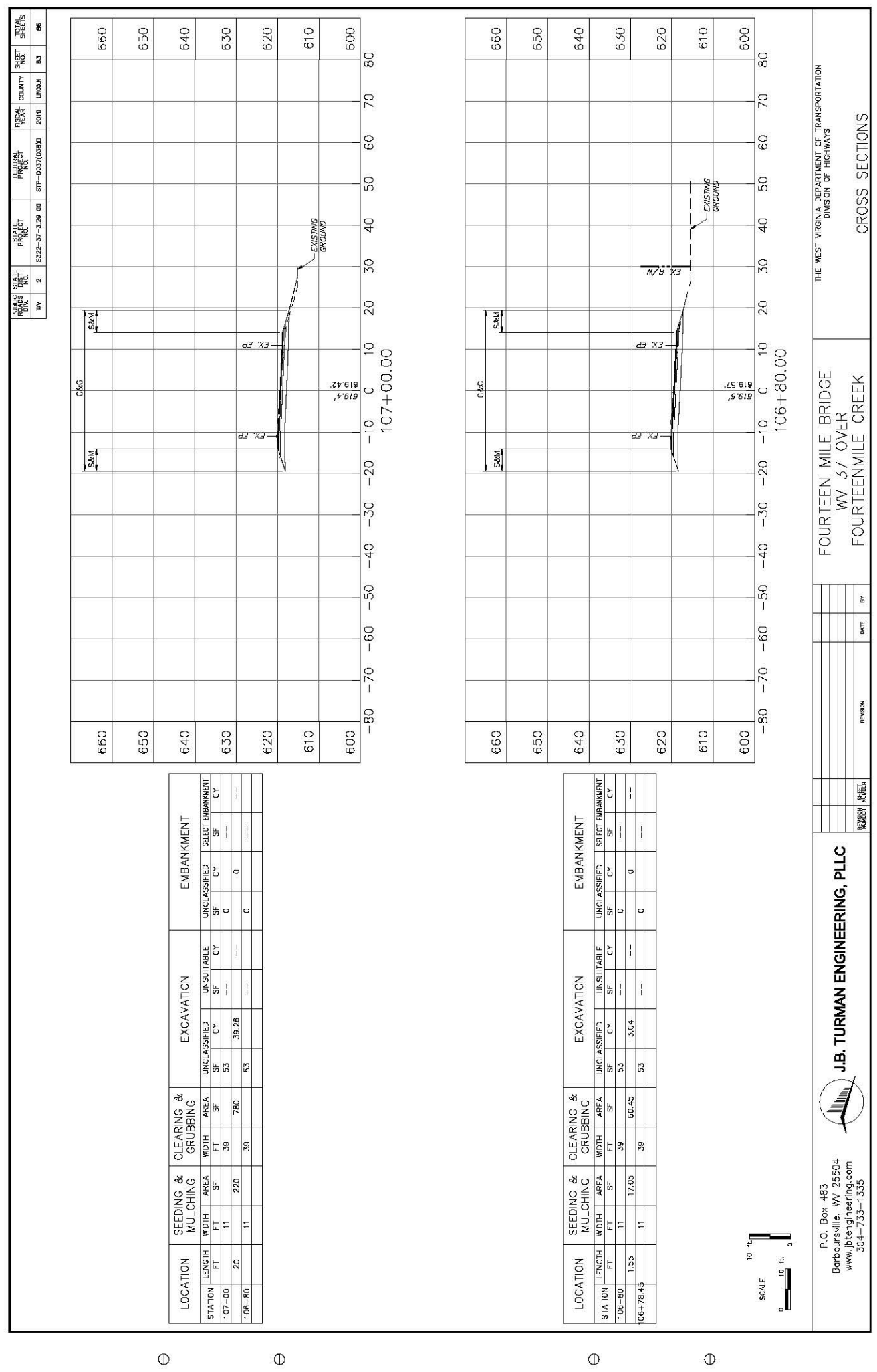




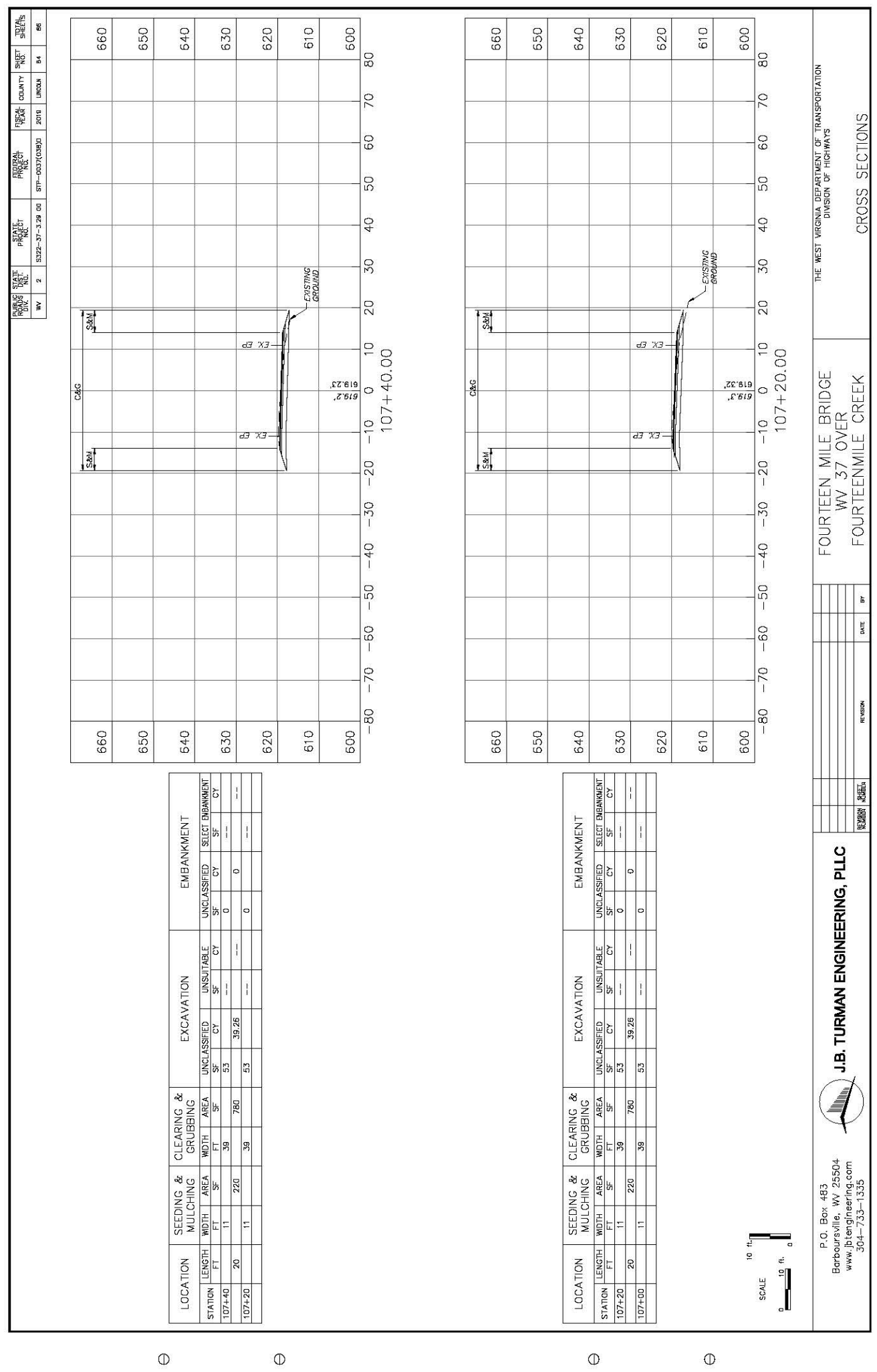




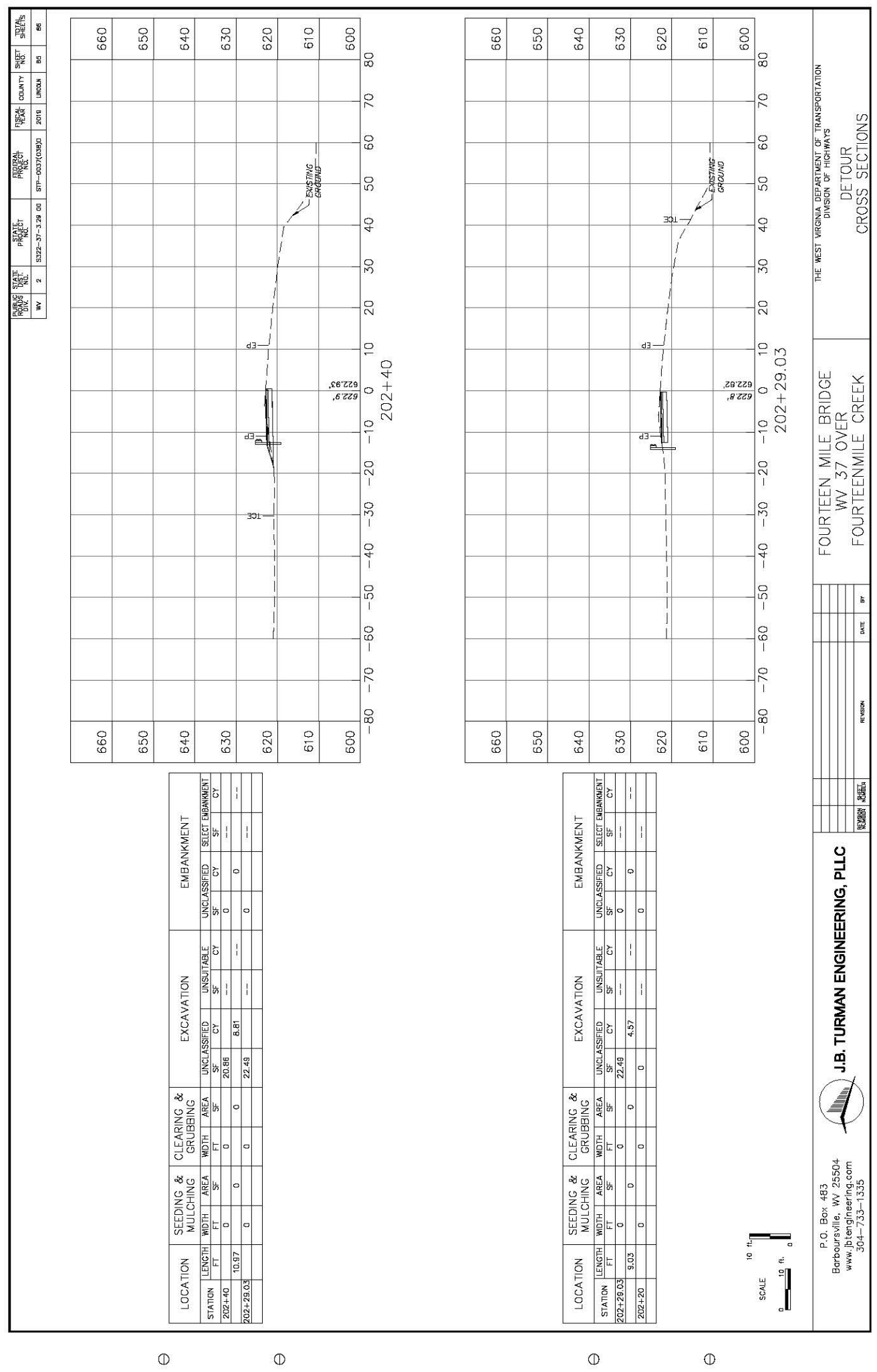




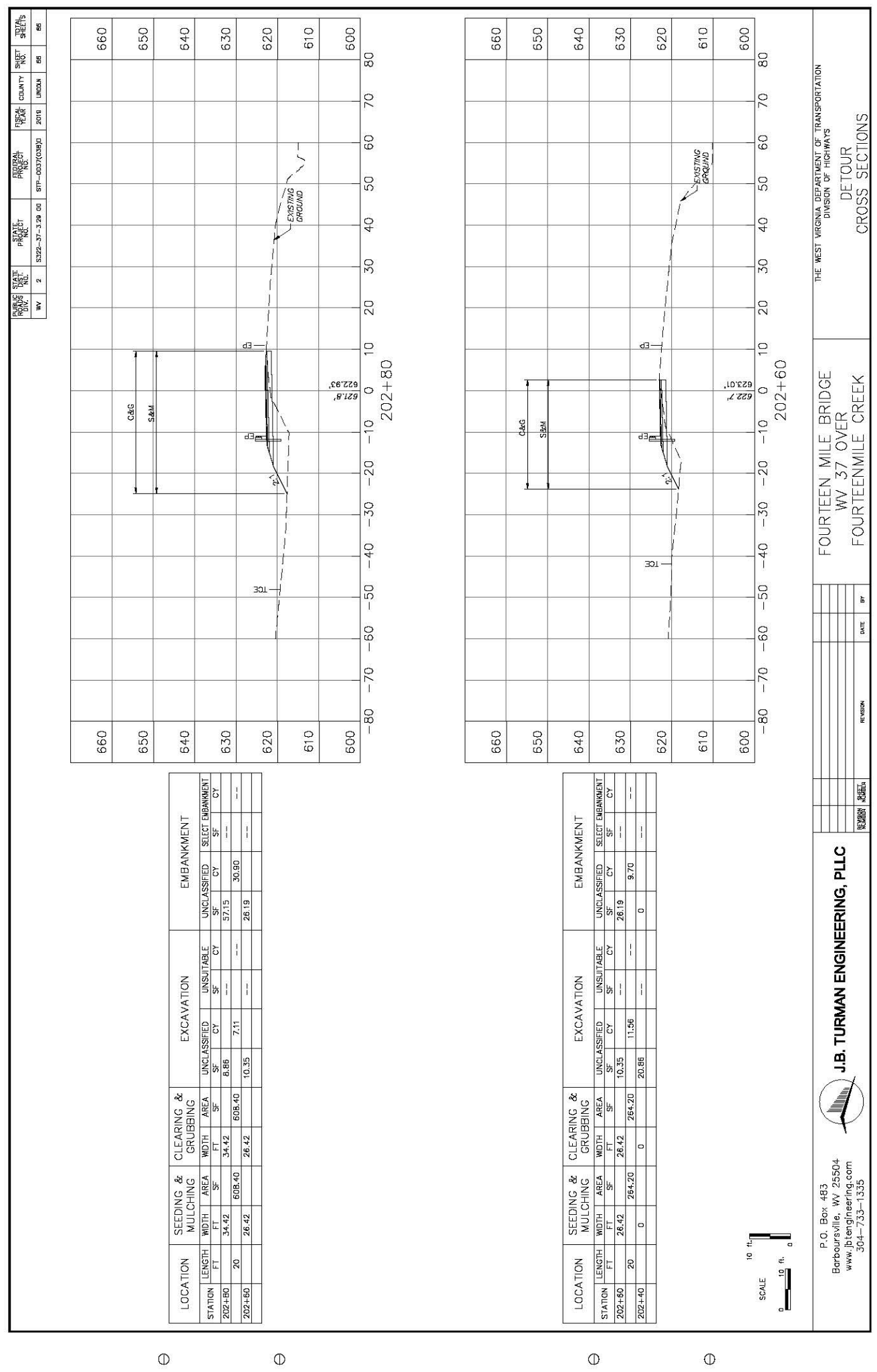




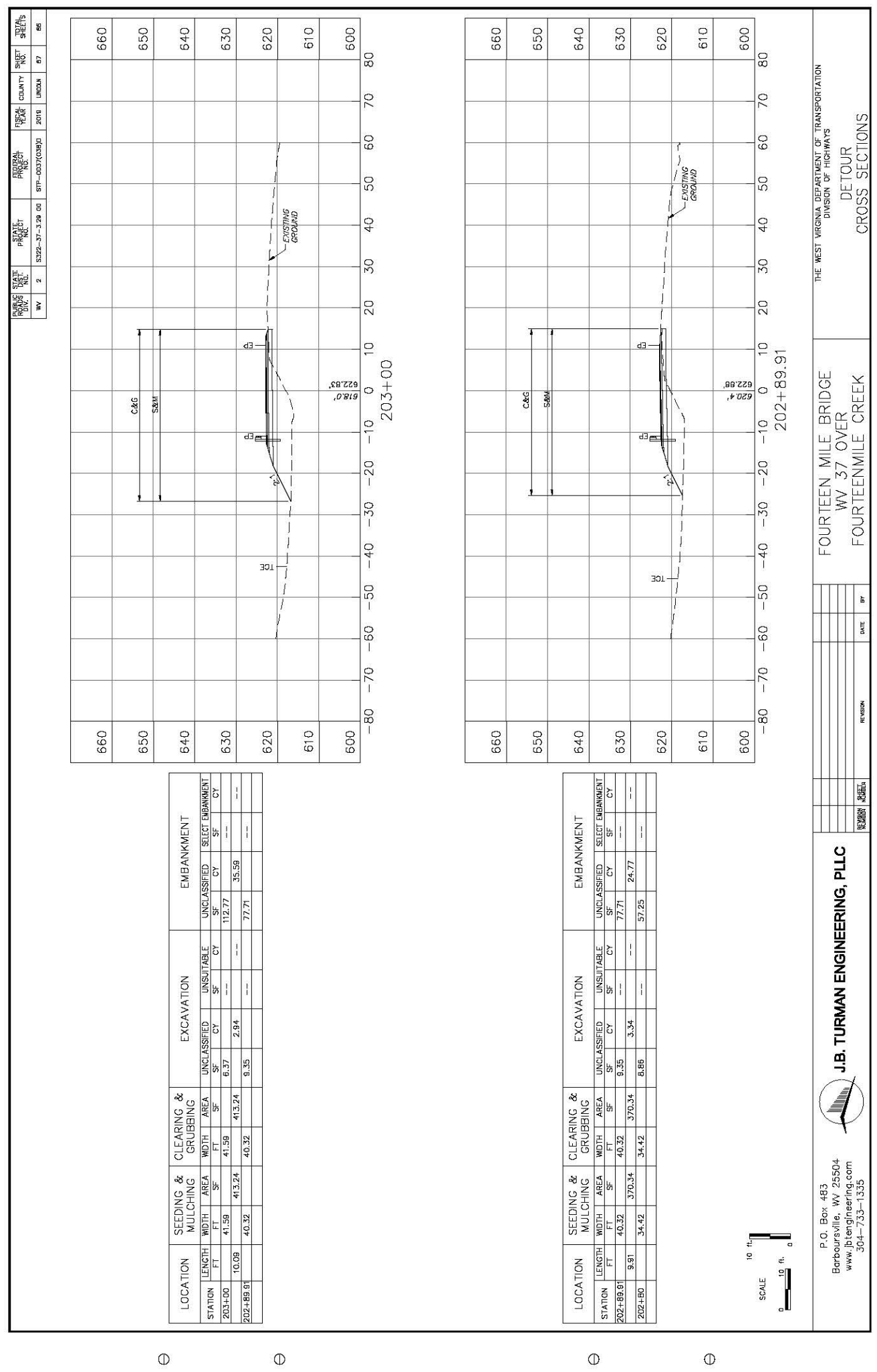




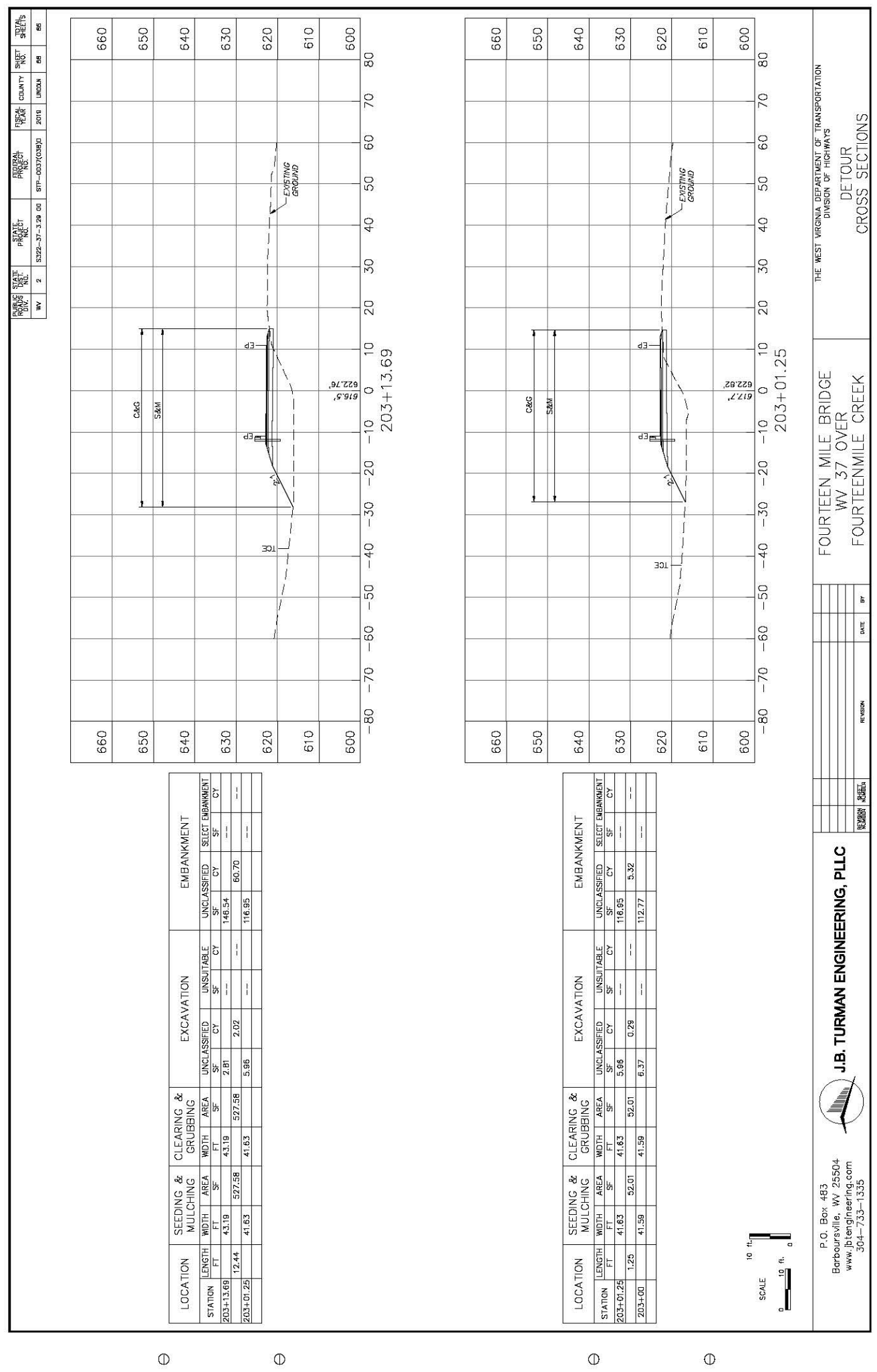




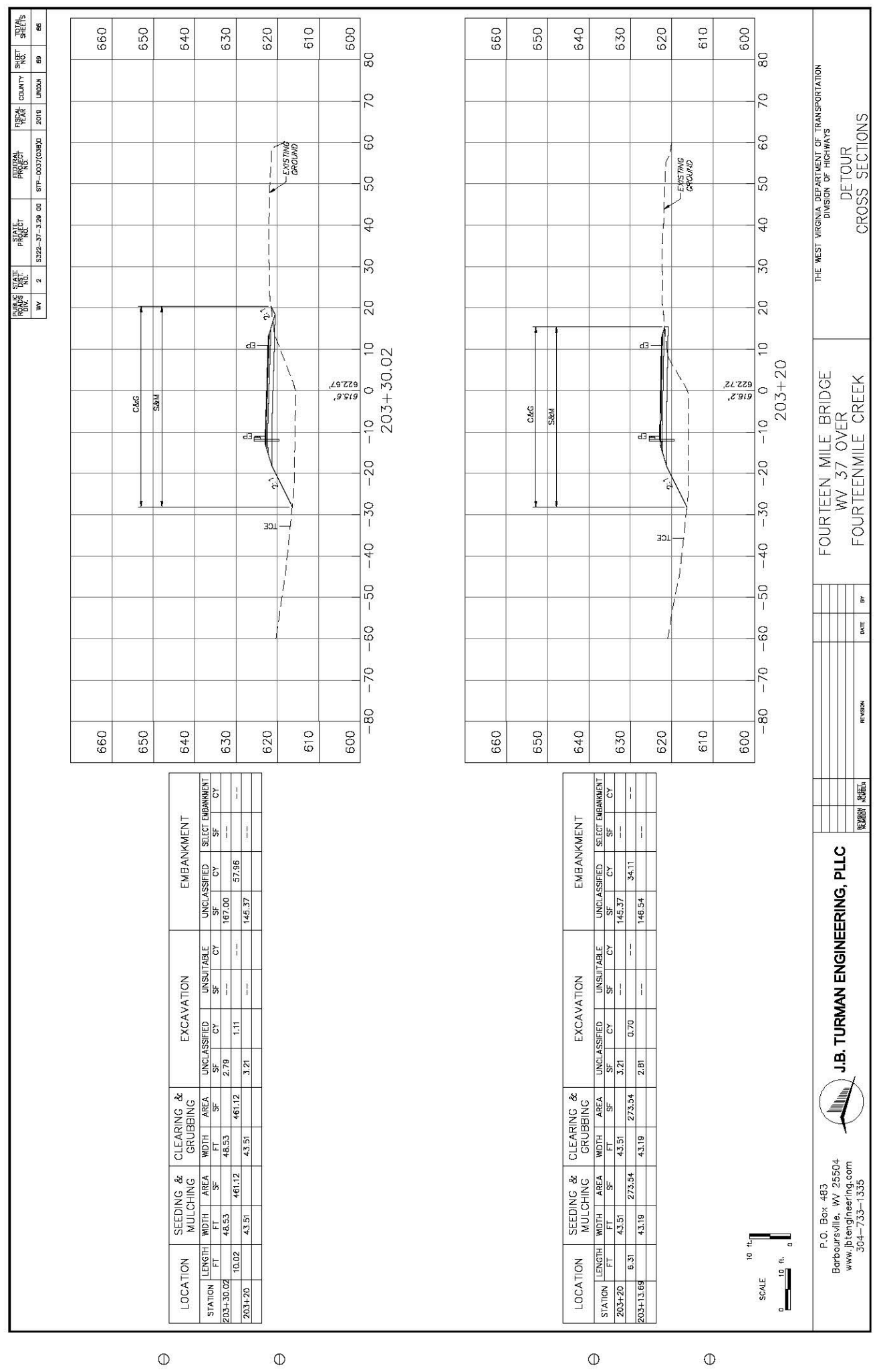




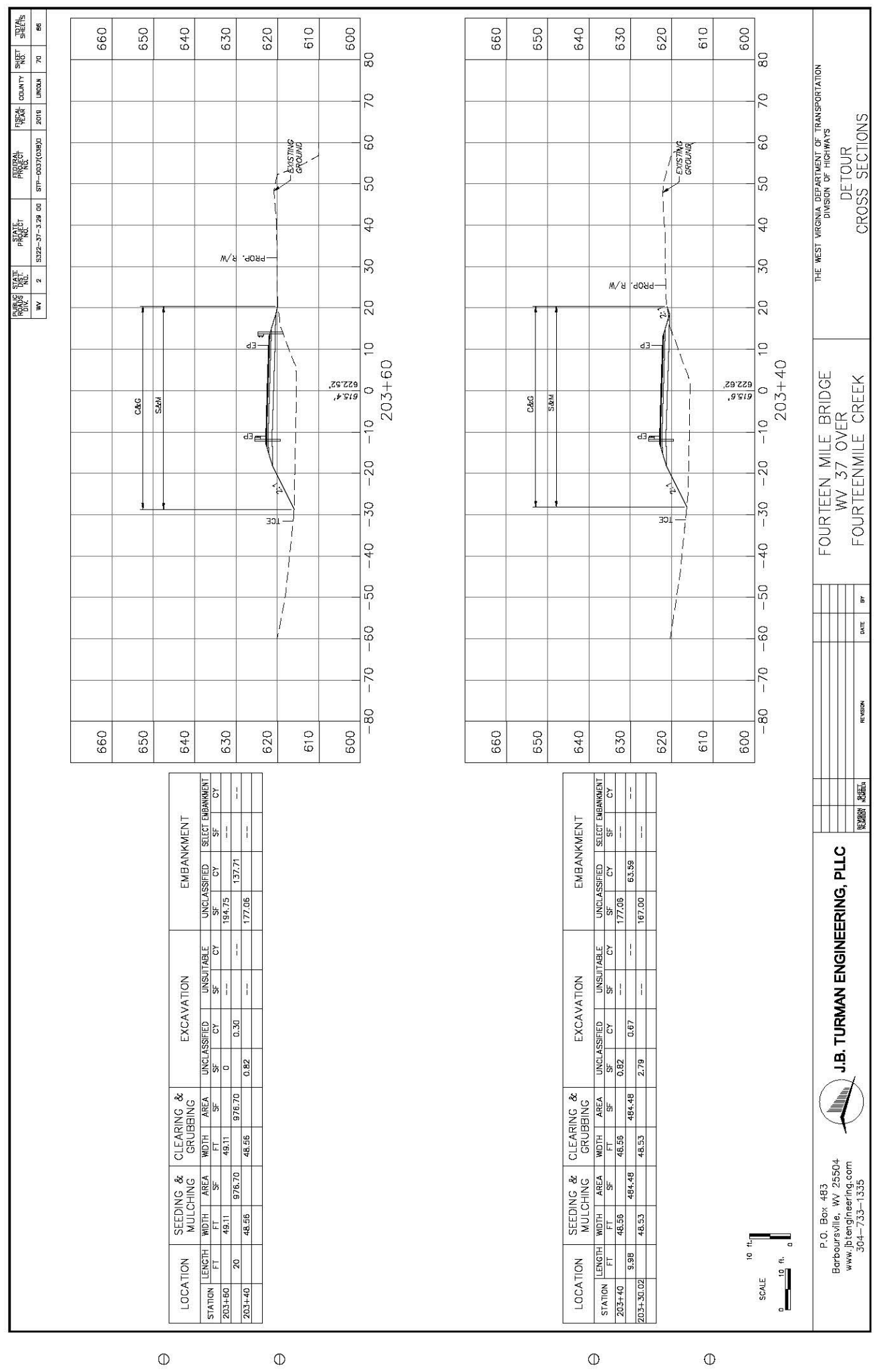




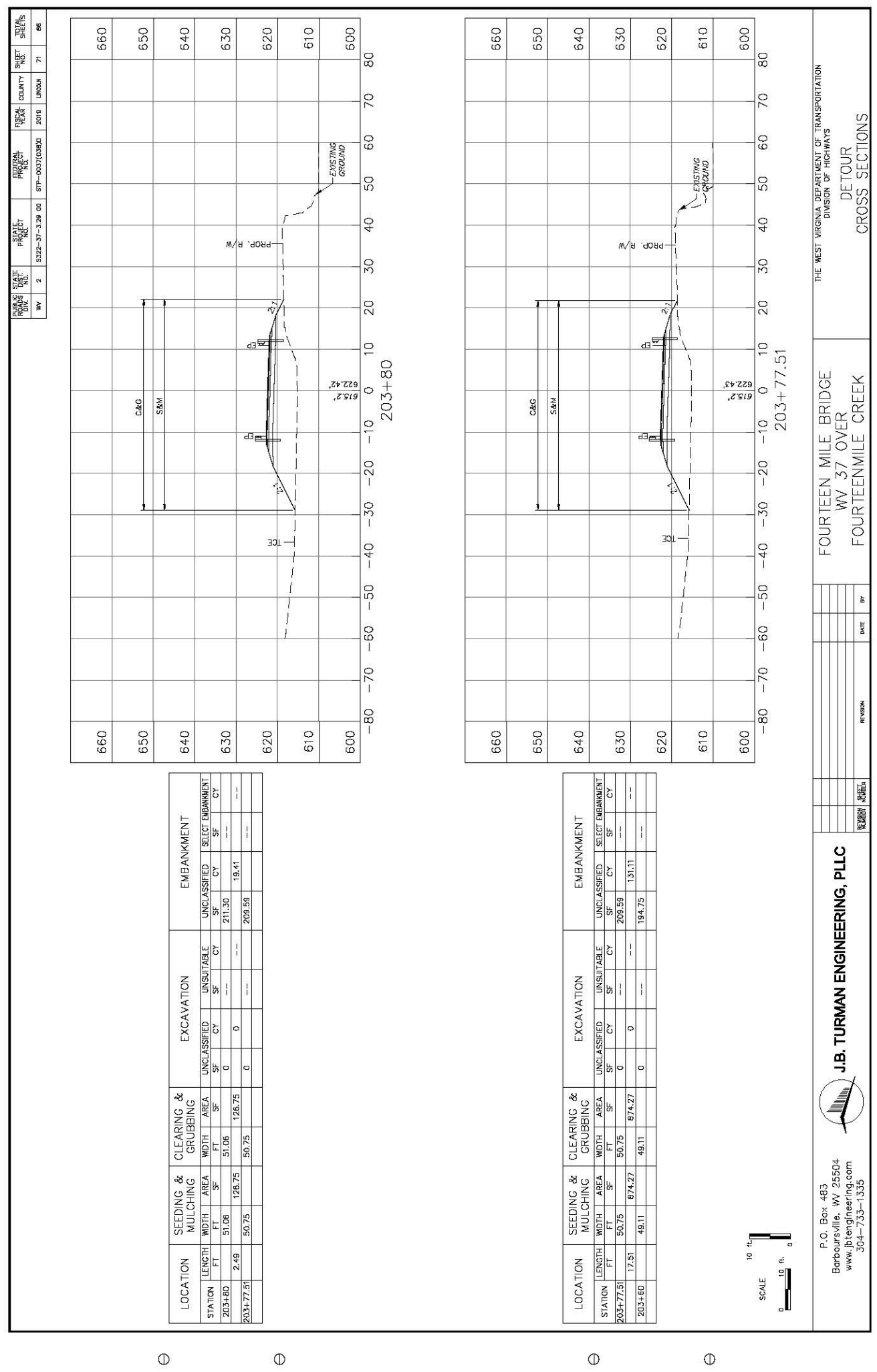




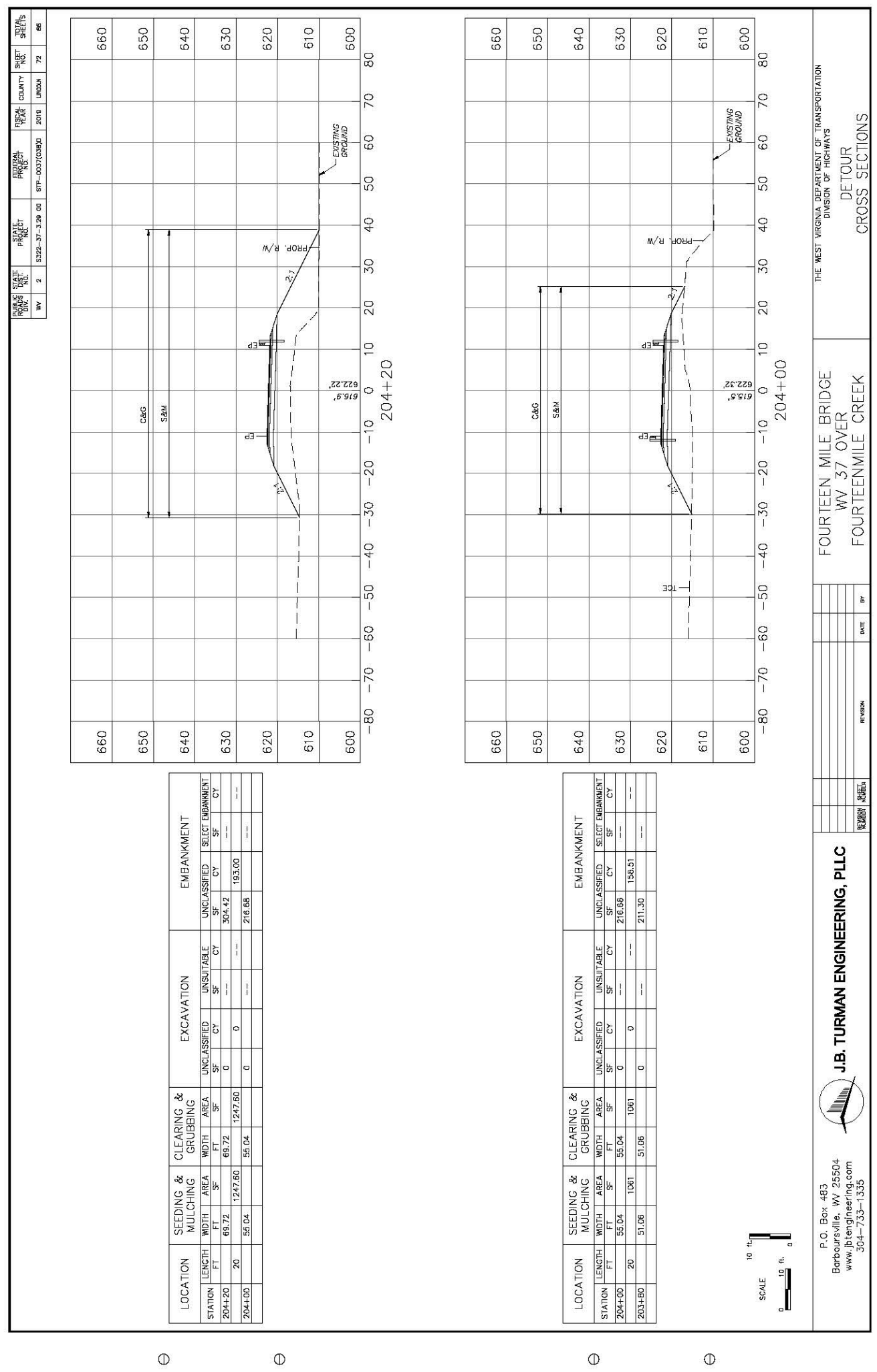




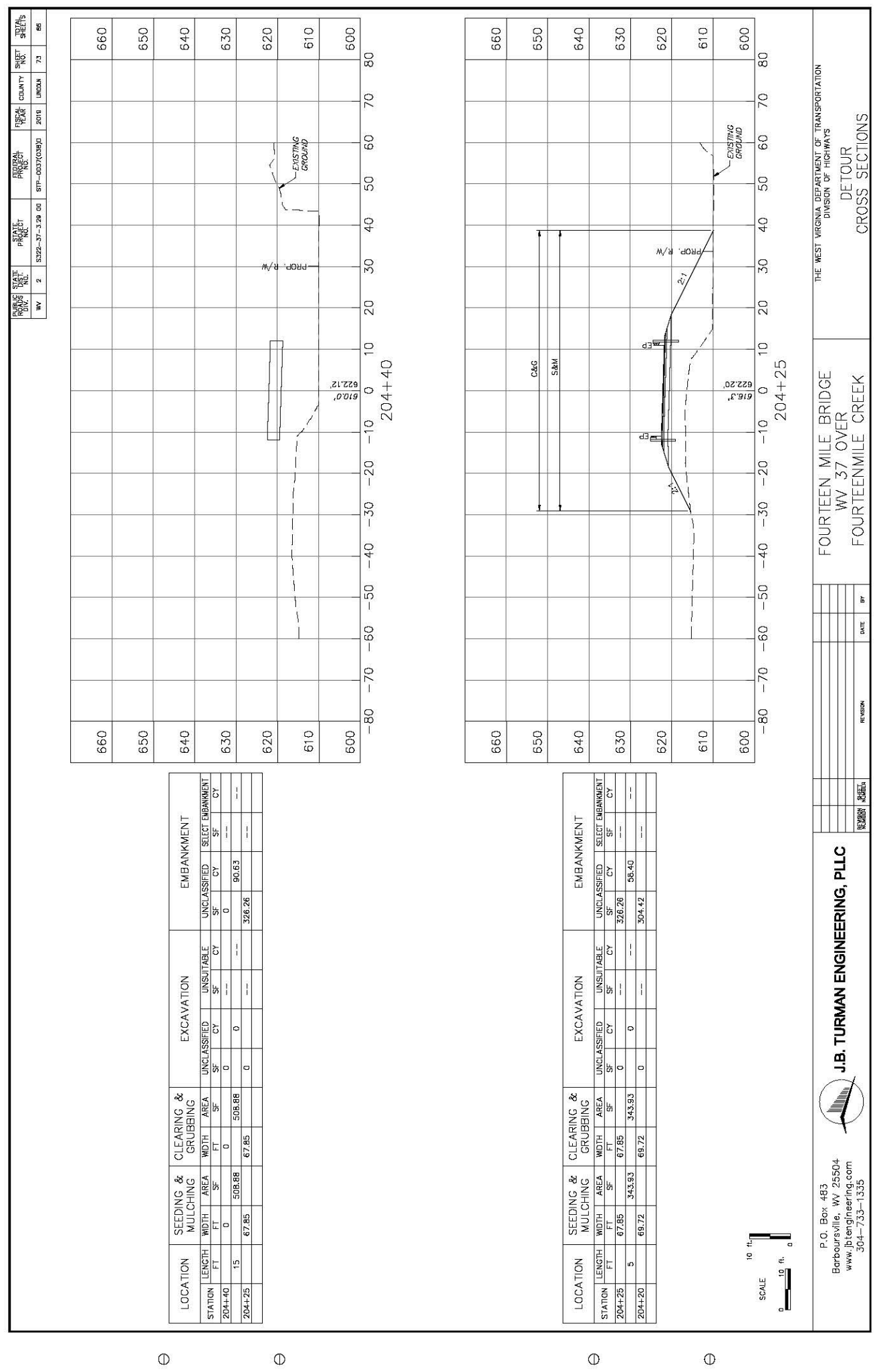




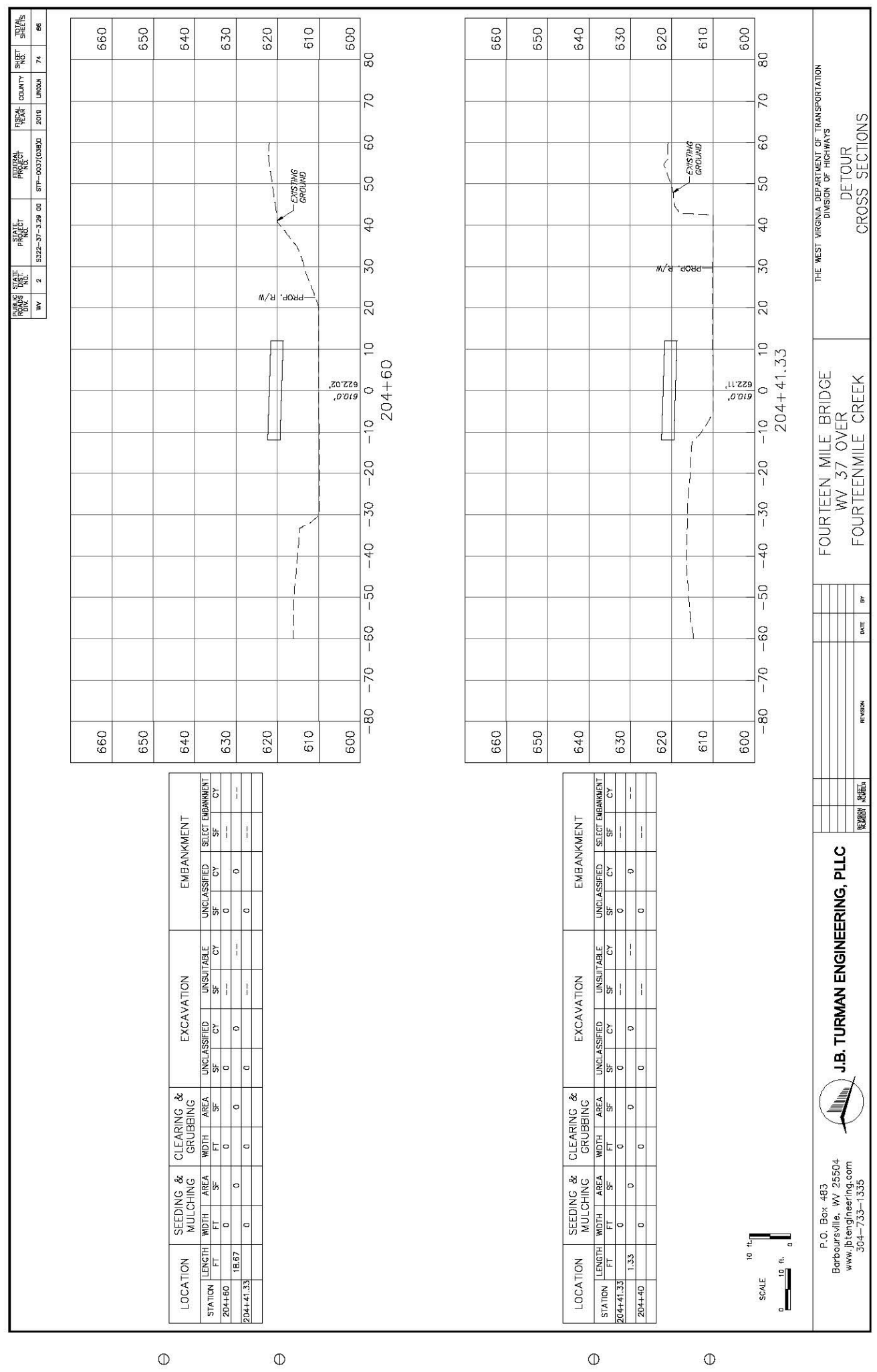




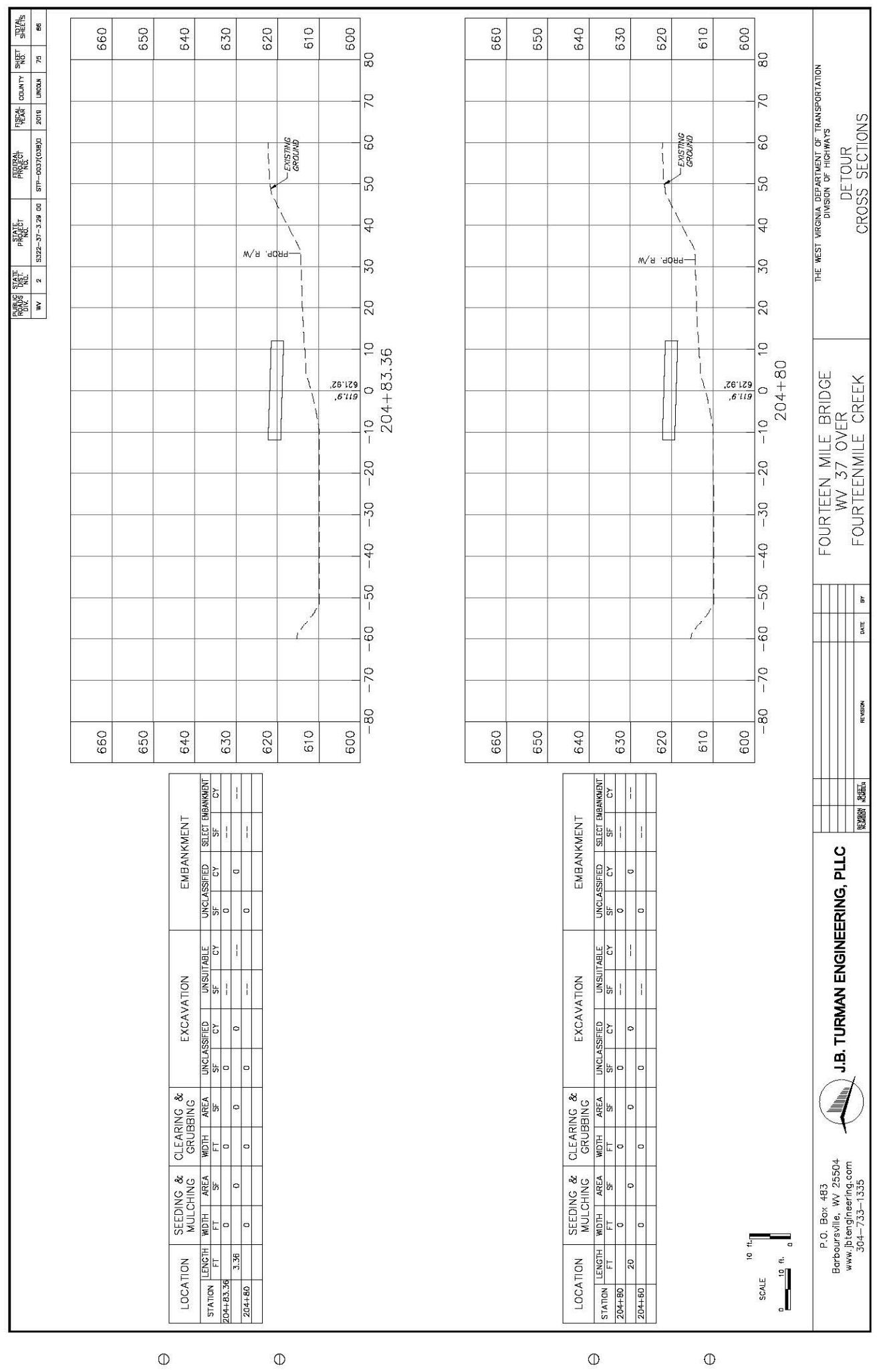




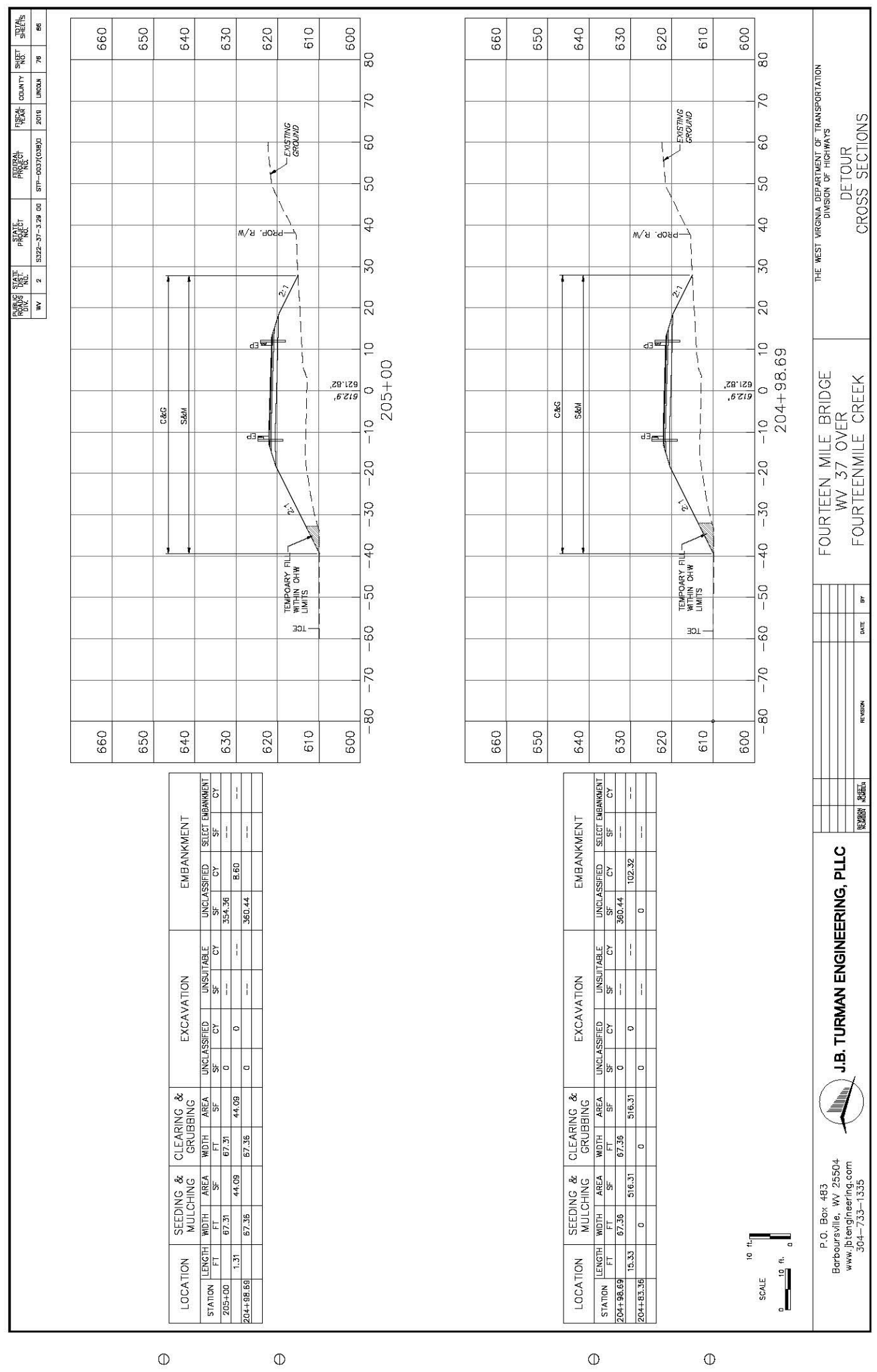




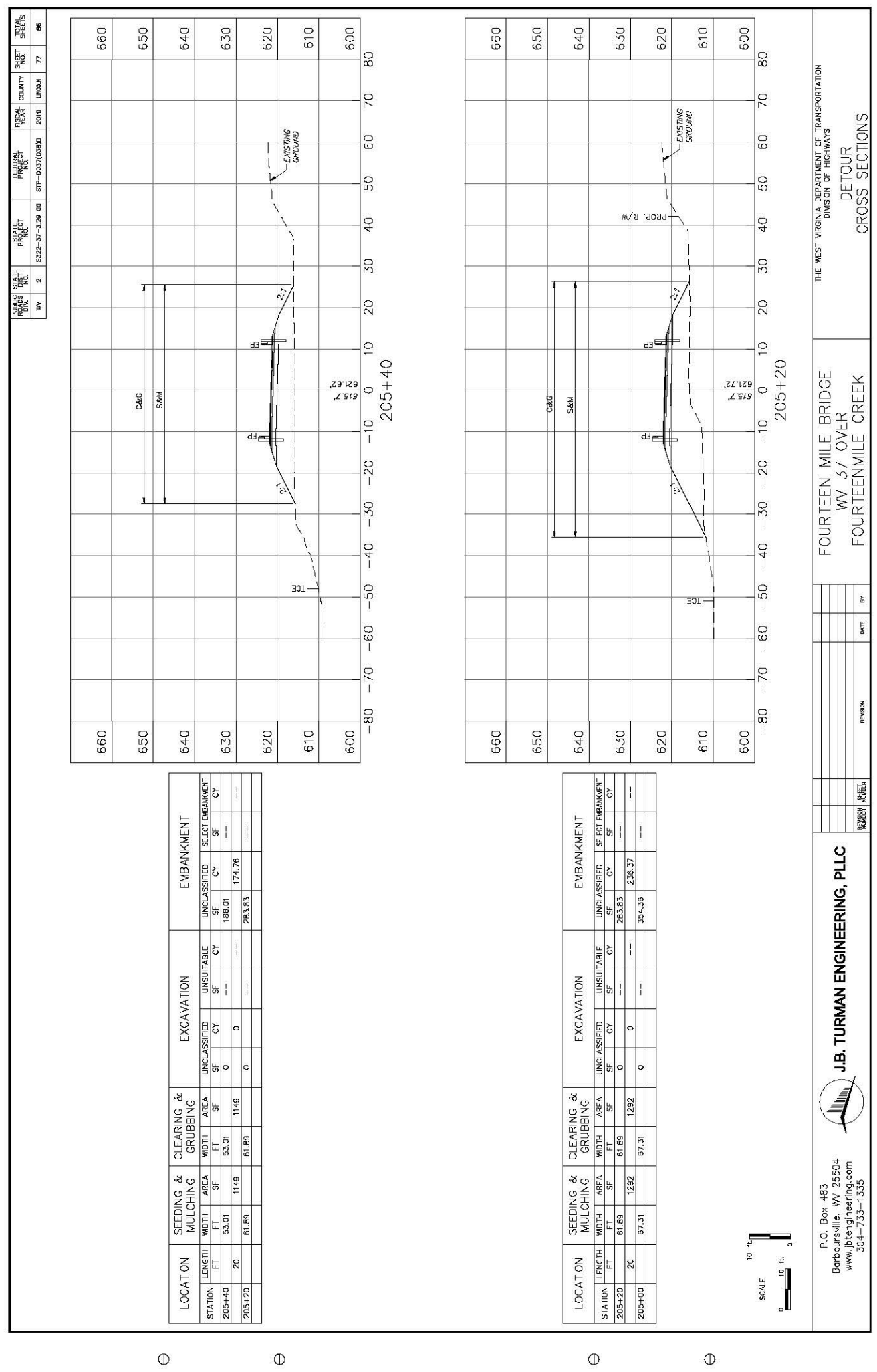




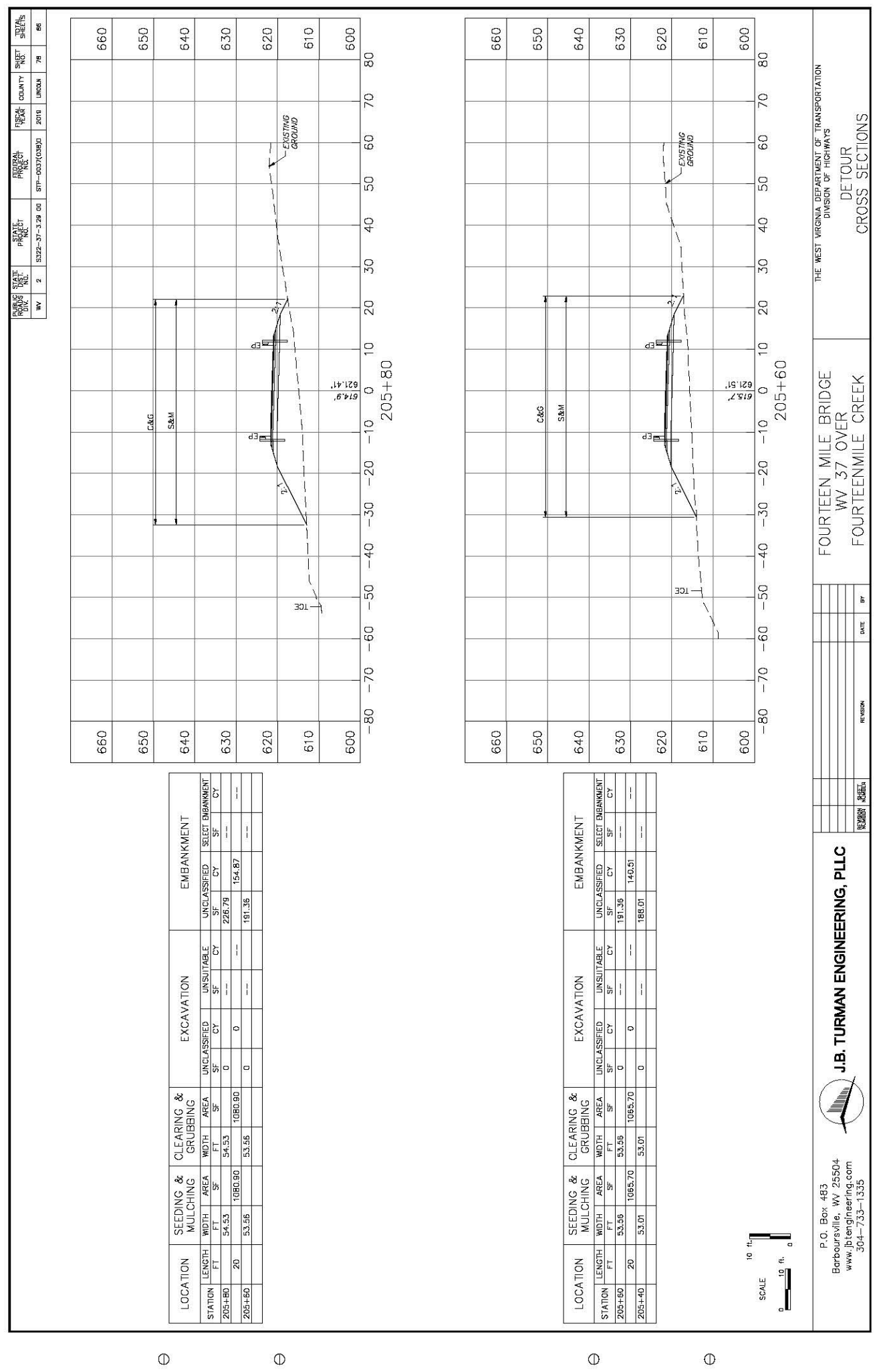




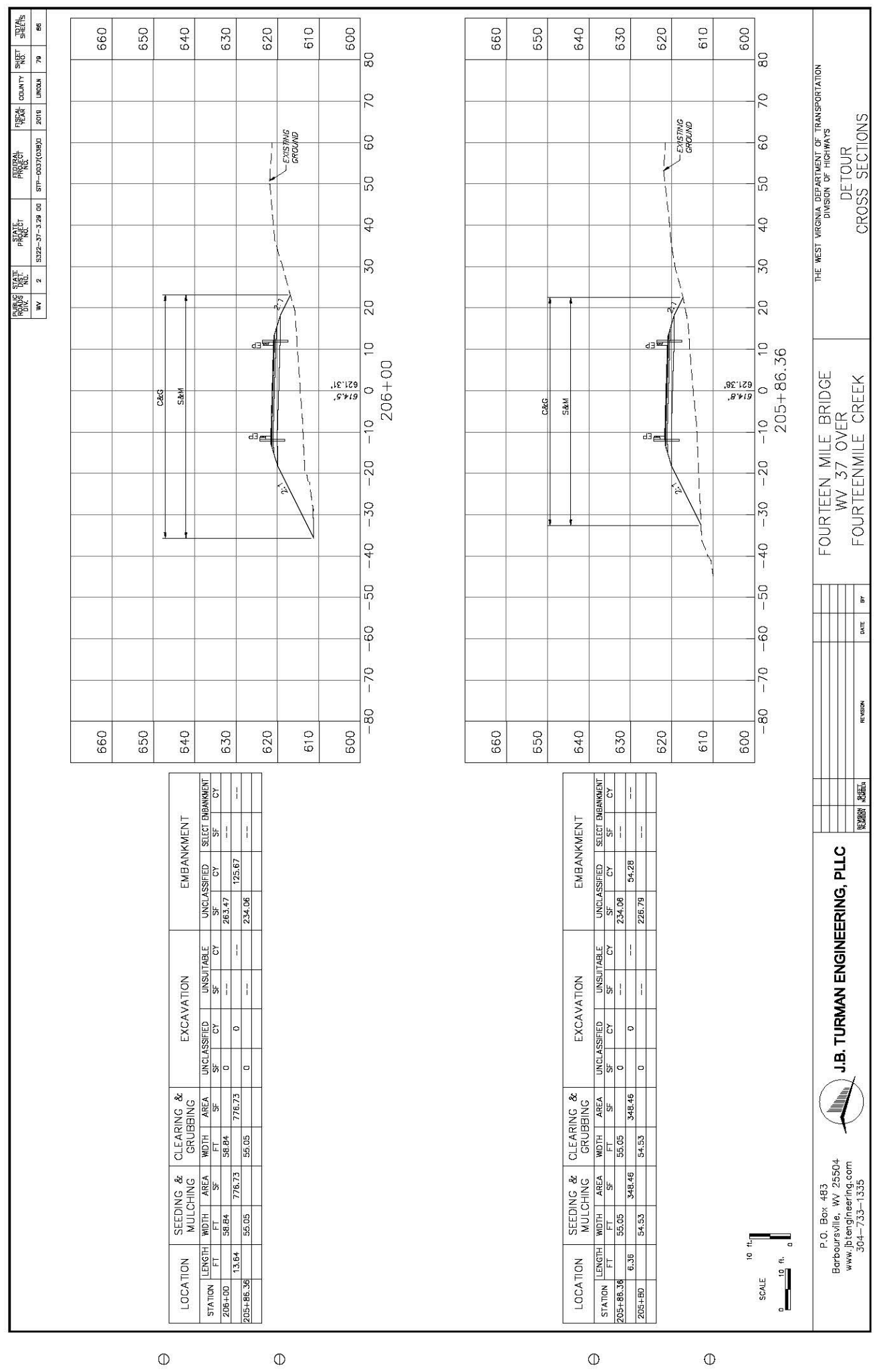




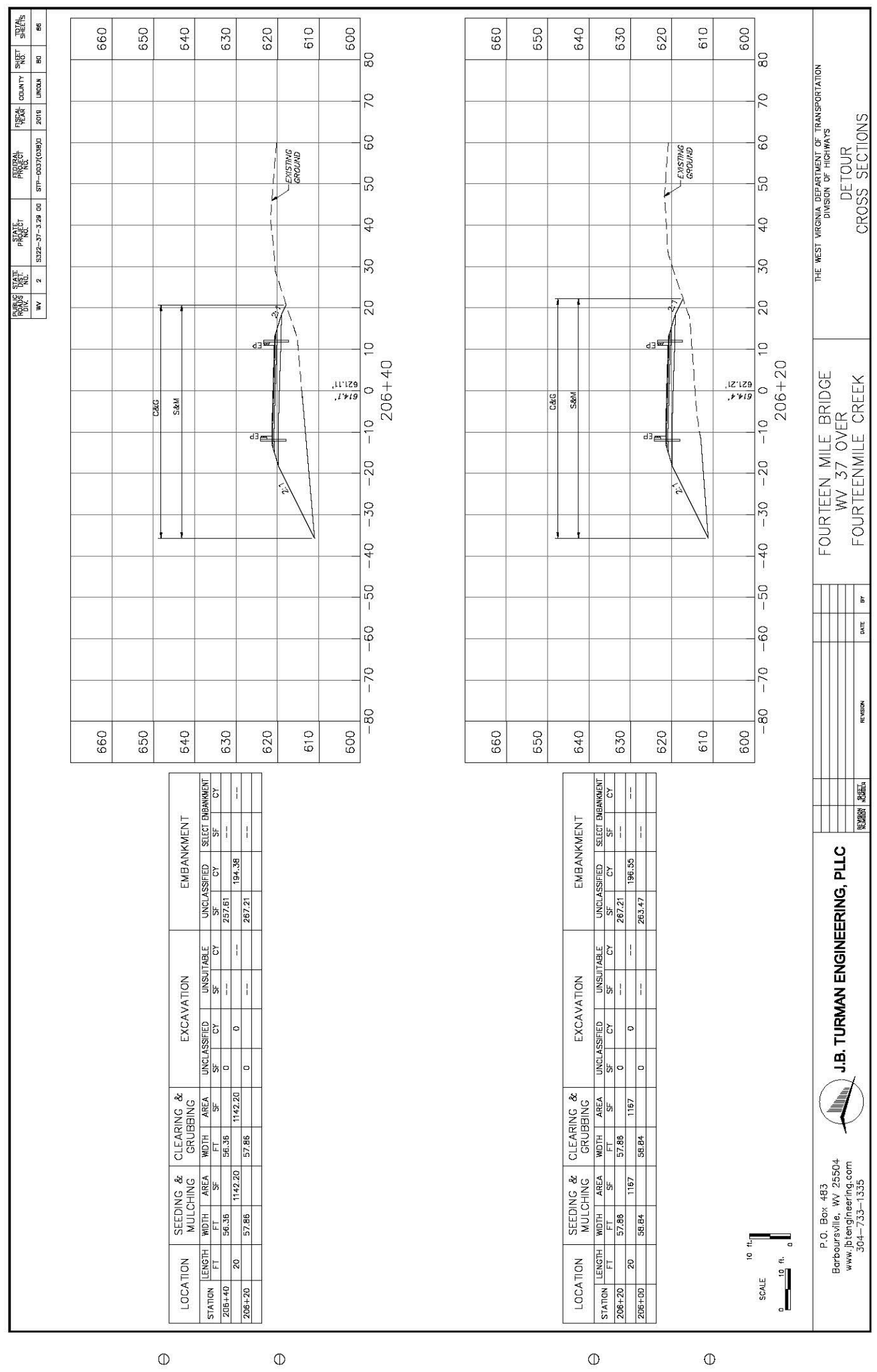




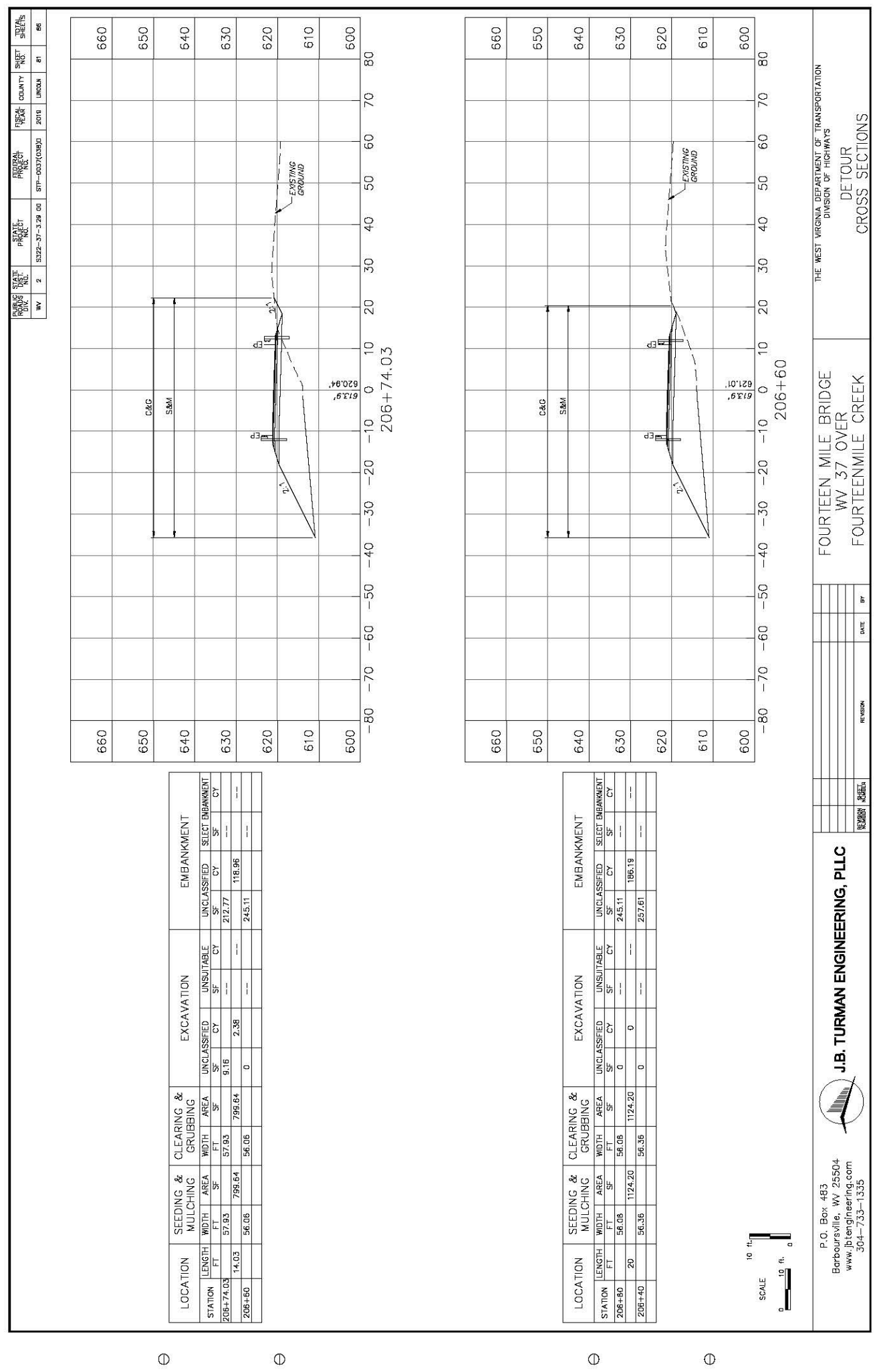




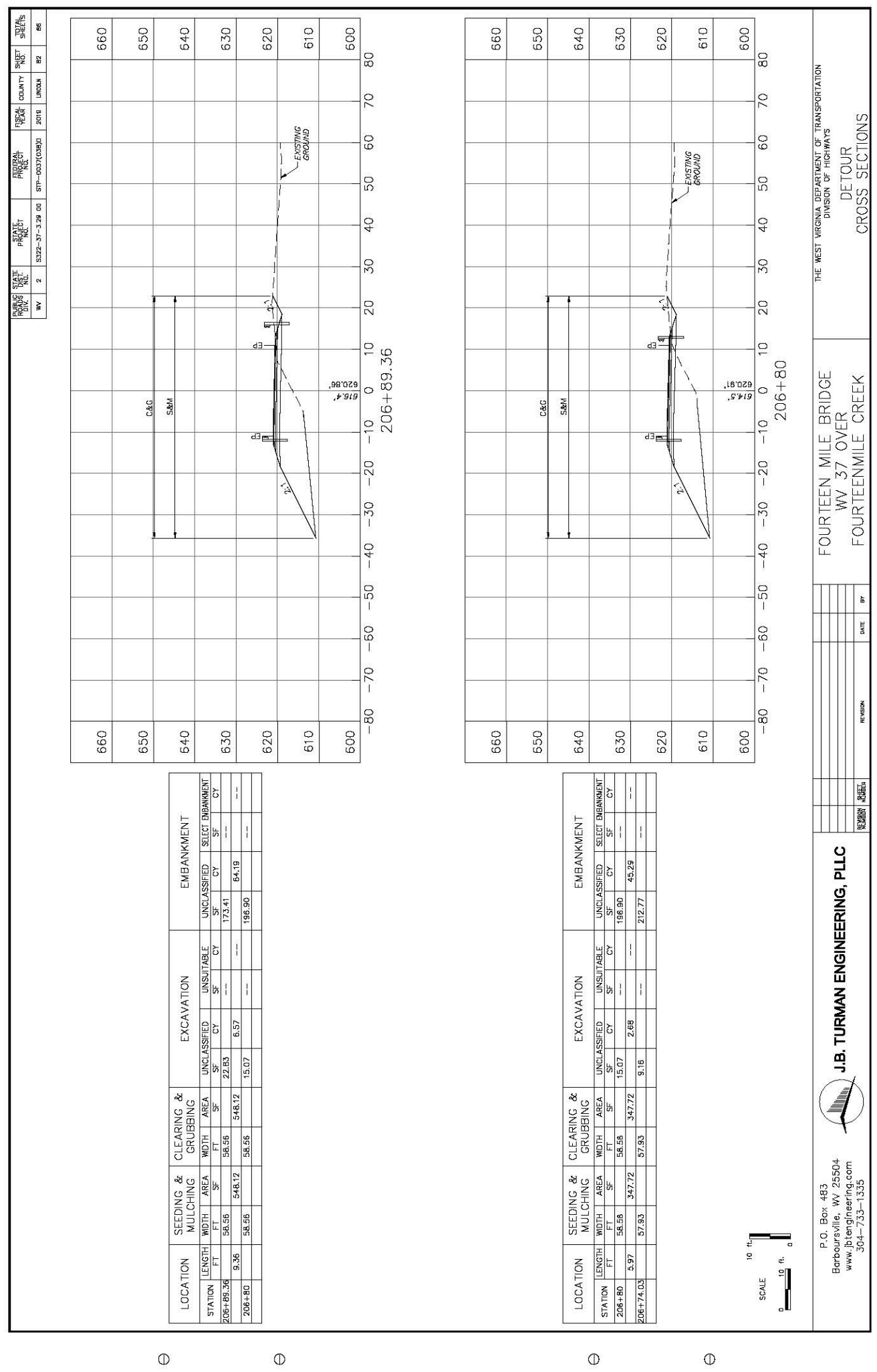




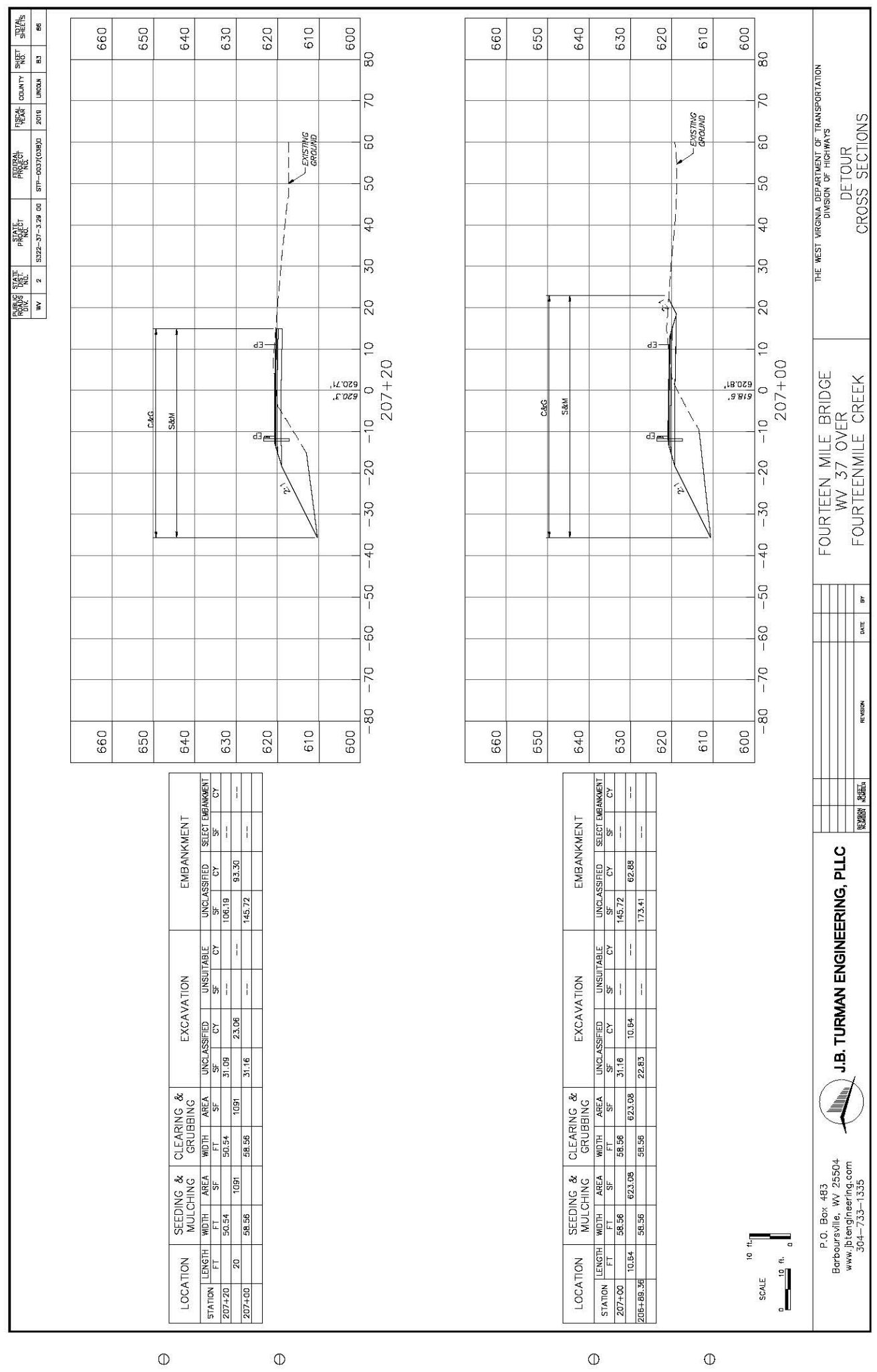




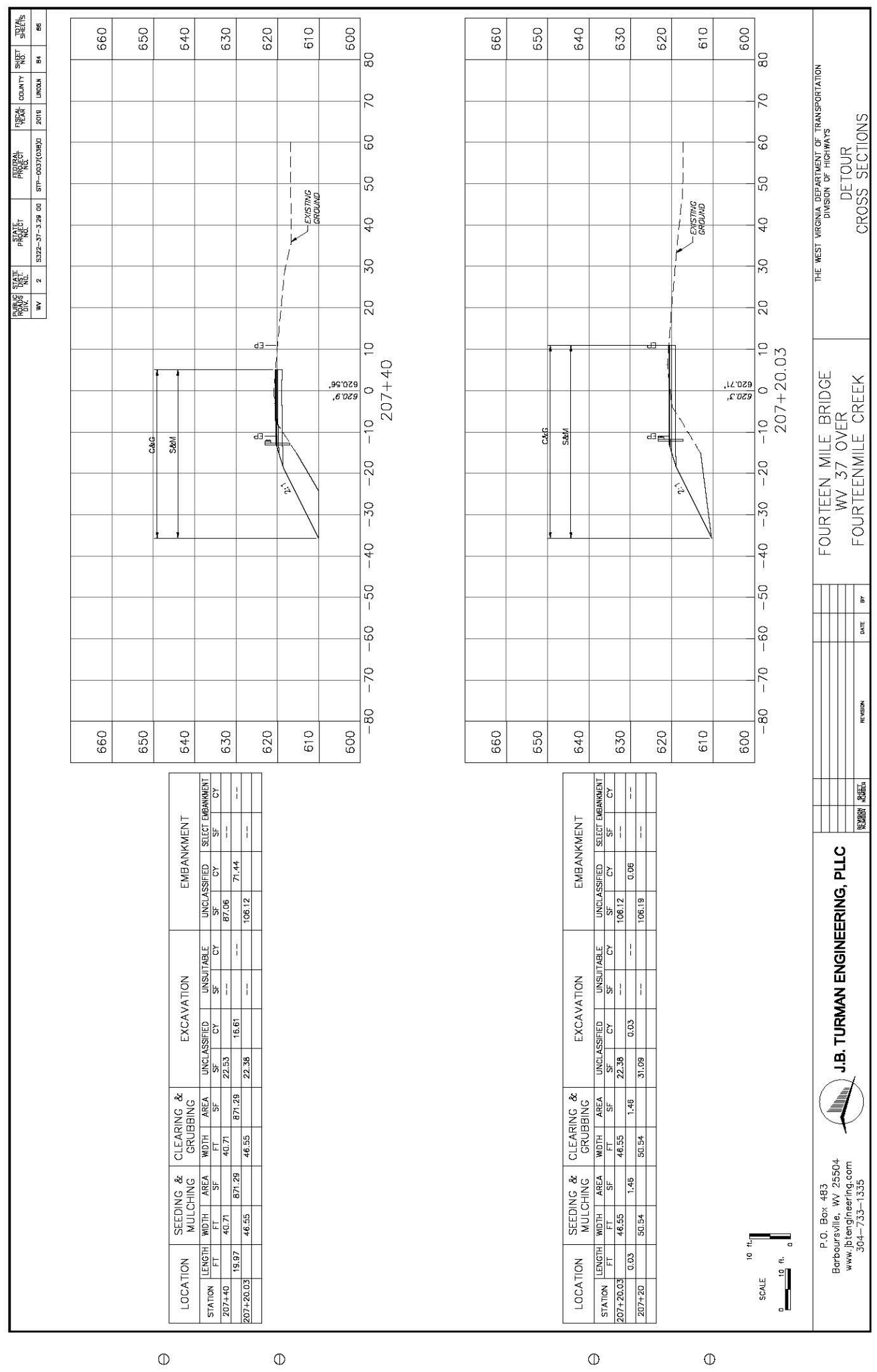




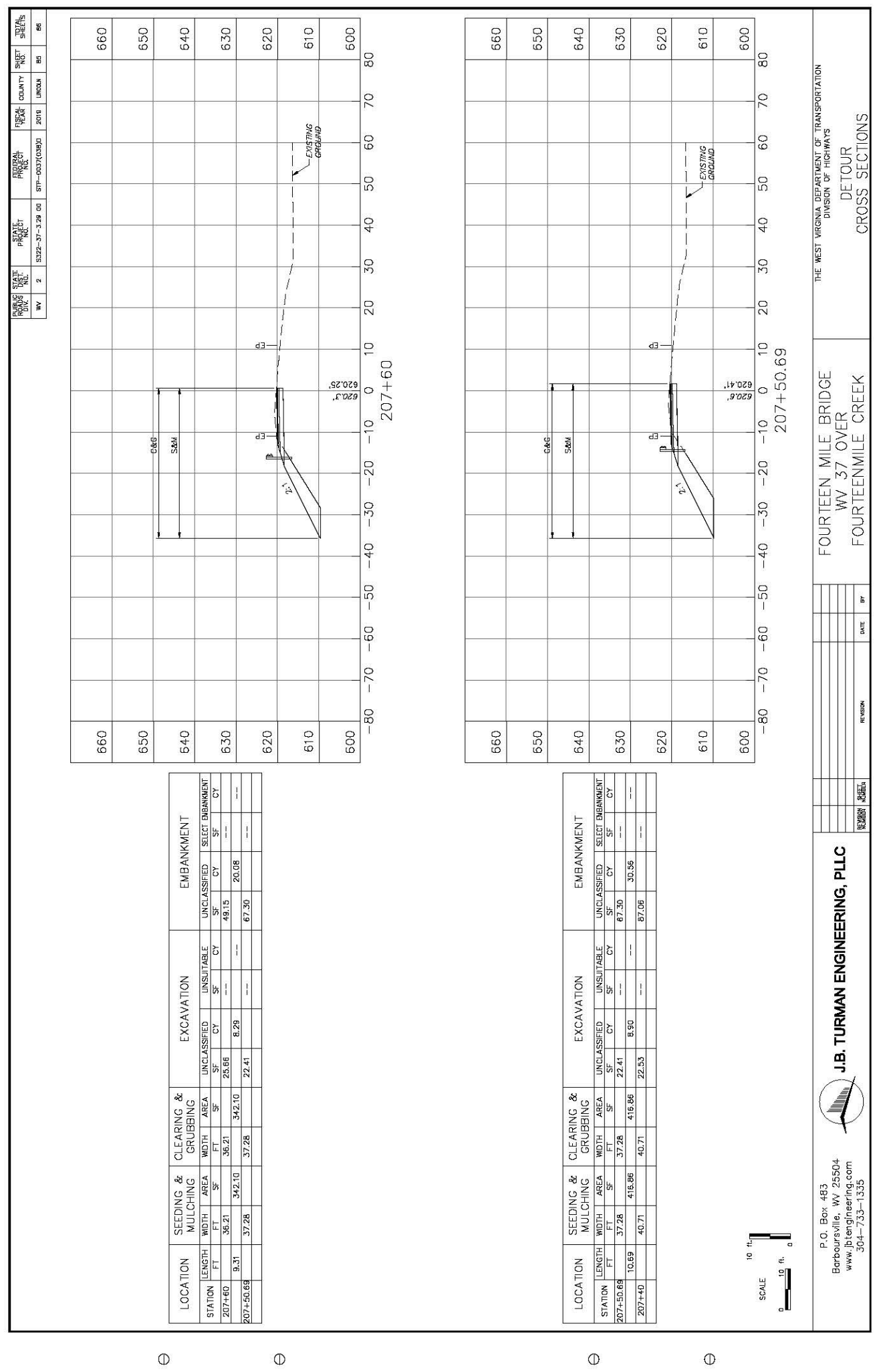




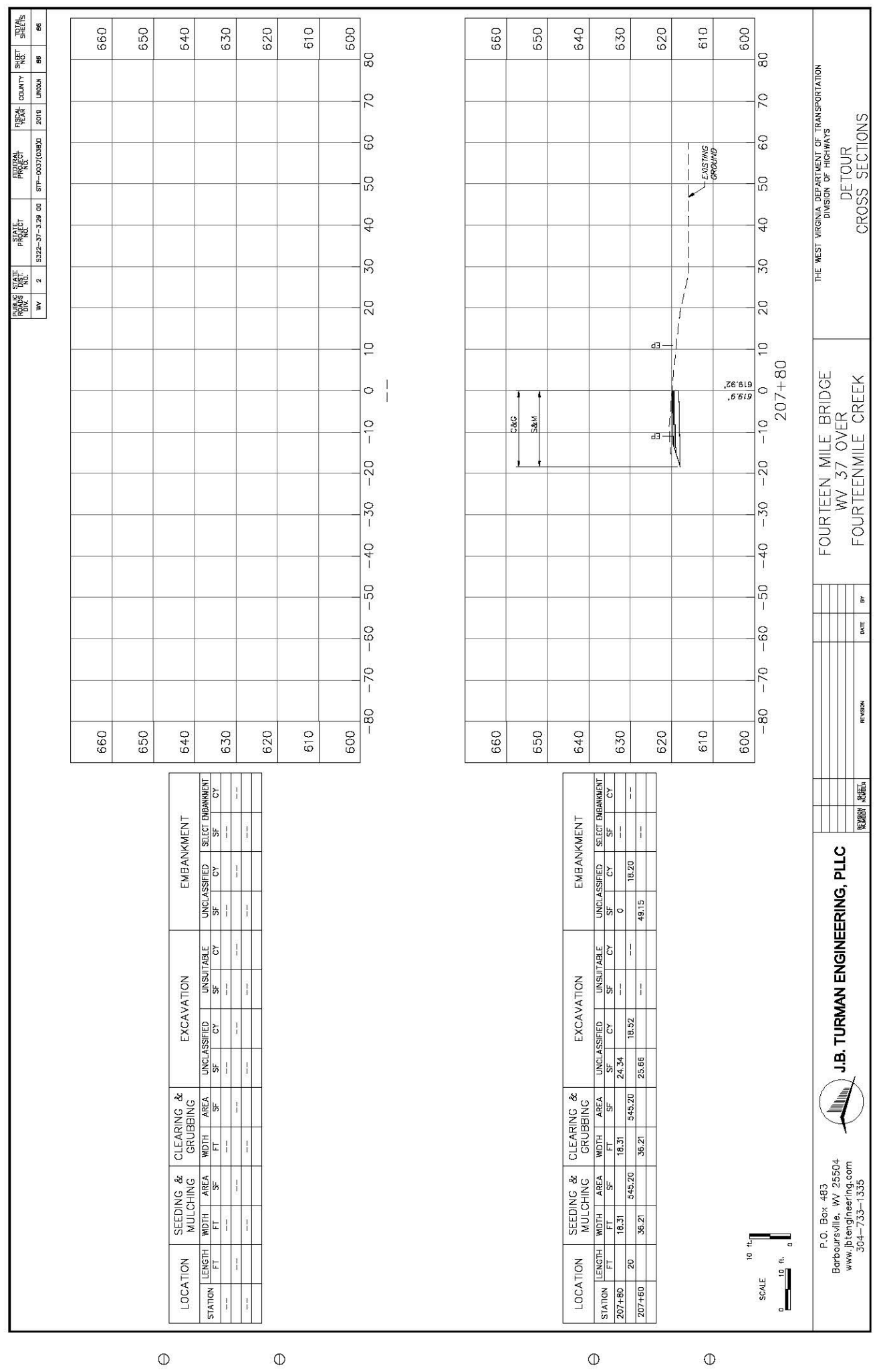

